\title{
THE ROLE OF PLANT DIVERSITY, \\ PLANT FUNCTIONAL GROUPS, AND MINERAL NITROGEN \\ FOR SOIL MICROBIAL FUNCTIONING \\ AND SOIL MESOFAUNA IN TEMPERATE GRASSLAND
}

\author{
Dissertation \\ zur Erlangung des mathematisch-naturwissenschaftlichen Doktorgrades \\ „Doctor rerum naturalium“ \\ der Georg-August-Universität Göttingen \\ im Promotionsstudiengang Biologie \\ der Georg August University School of Science (GAUSS)
}

vorgelegt von

Dipl.-Biol.Tanja Strecker

aus Lindenfels im Odenwald

Göttingen, im Mai 2020 


\section{Betreuungsausschuss}

Prof. Dr. Stefan Scheu und

Prof. Dr. Mark Maraun

Tierökologie, Georg-August-Universität Göttingen

Prof. Dr. Nico Eisenhauer

Experimentelle Interaktionsökologie, Universität Leipzig

\section{Mitglieder der Prüfungskommission}

Referent/in: Prof. Dr. Stefan Scheu, Abt. Tierökologie, J.-F.-Blumenbach-Institut für Zoologie und Anthropologie, Georg-August-Universität Göttingen

Korreferent/in: Prof. Dr. Marko Rohlfs, Populations- und Evolutionsökologie, Universität Bremen

\section{Weitere Mitglieder der Prüfungskommission:}

Prof. Dr. Michaela Dippold, Biogeochemie der Agrarökosysteme, Universität Göttingen

Prof. Dr. Klaus Hövemeyer, Tierökologie, Universität Göttingen

Prof. Dr. Andreas Schuldt, Waldnaturschutz, Universität Göttingen

Prof. Dr. Catrin Westphal, Funktionelle Agrobiodiversität, Universität Göttingen

Tag der mündlichen Prüfung: Mo., 22.06.2020 
Gewidmet meiner Familie.

Wir sind alle Schicksalsgefährten, vom gleichen Stern durch den Raum getragen. Antoine de Saint-Exupéry (1900 - 1944) 


\section{Table of Contents}

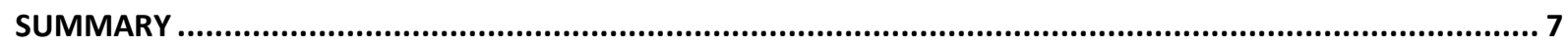

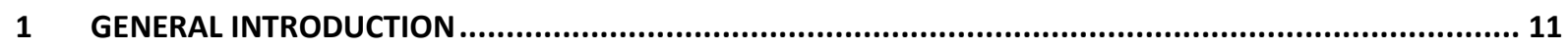

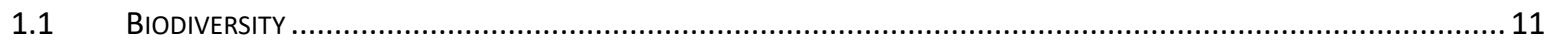

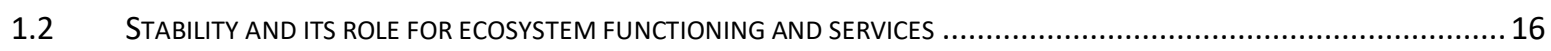

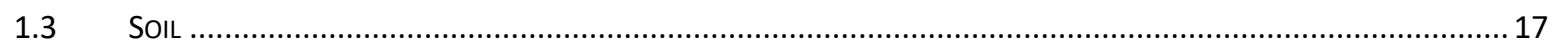

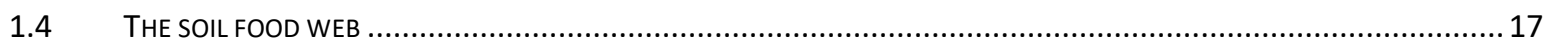

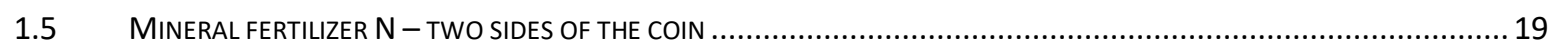

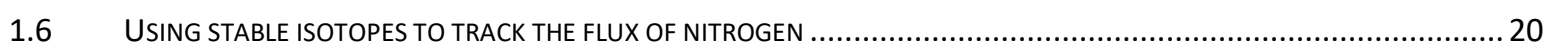

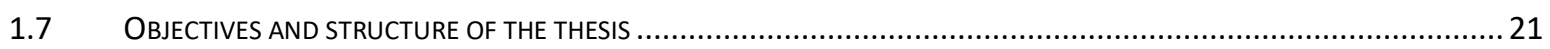

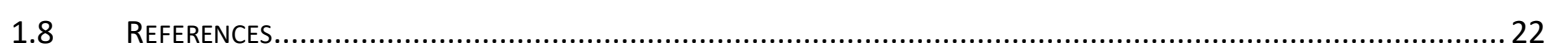

2 FUNCTIONAL COMPOSITION OF PLANT COMMUNITIES DETERMINES THE SPATIAL AND TEMPORAL STABILITY OF SOIL MICROBIAL PROPERTIES IN A LONG-TERM PLANT DIVERSITY EXPERIMENT ...................... 27

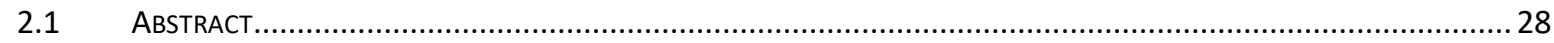

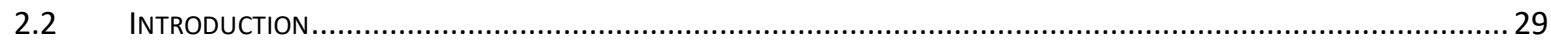

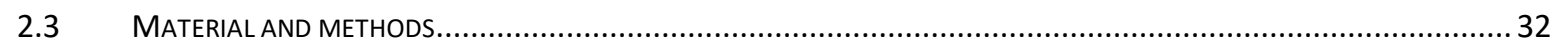

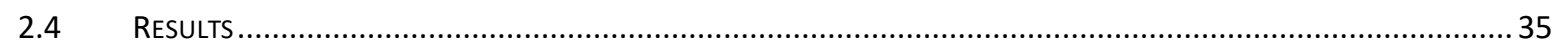

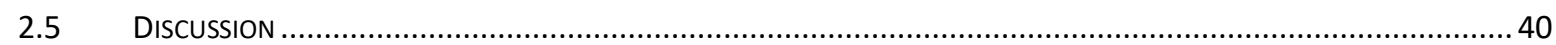

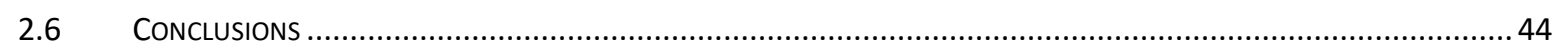

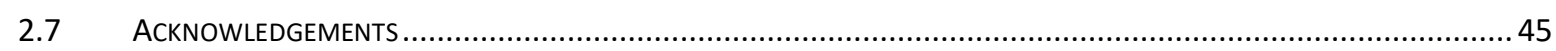

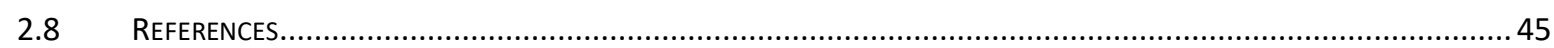

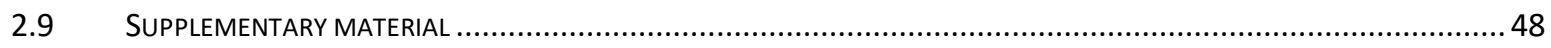

3 EFFECTS OF PLANT DIVERSITY, FUNCTIONAL GROUP COMPOSITION, AND FERTILIZATION ON SOIL

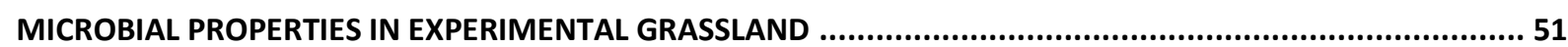

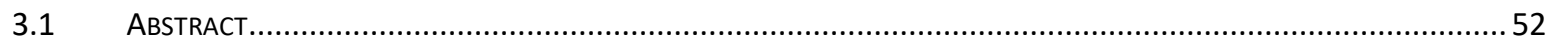

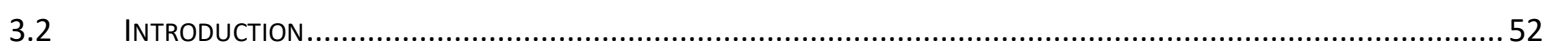

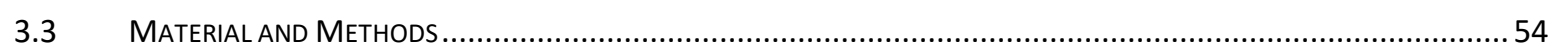

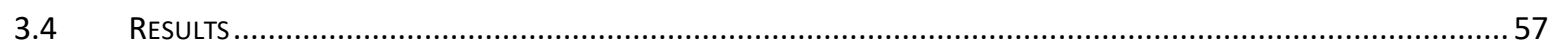

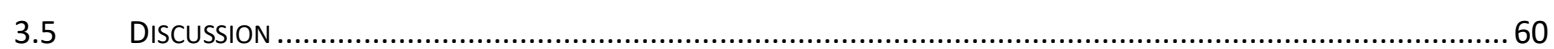

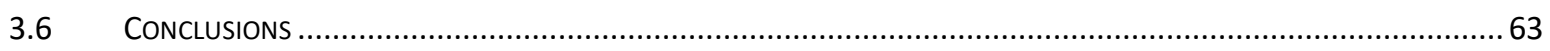

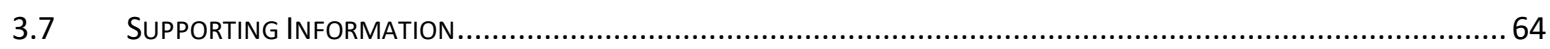

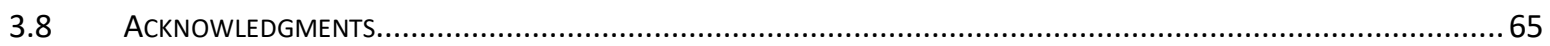

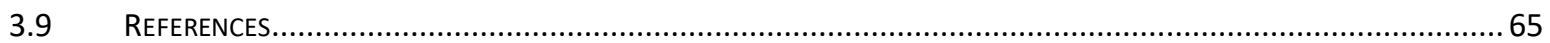

4 INCORPORATION OF MINERAL NITROGEN INTO THE SOIL FOOD WEB AS AFFECTED BY PLANT

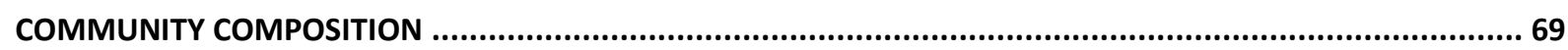

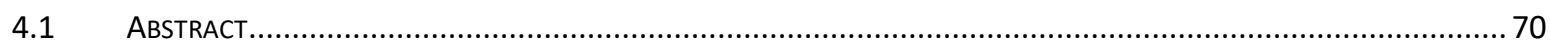

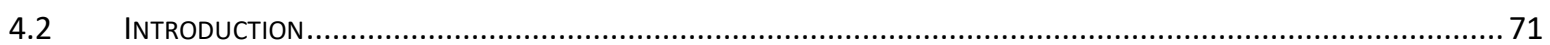

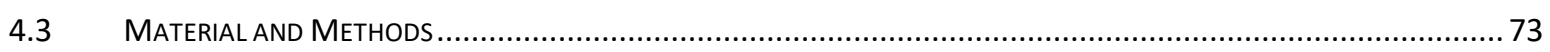

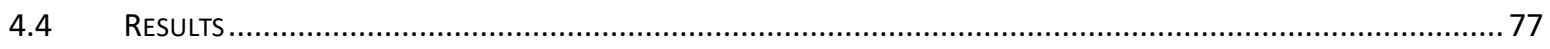

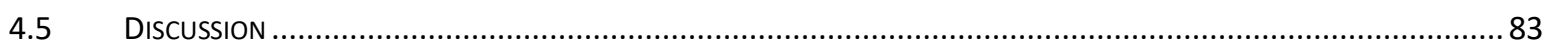

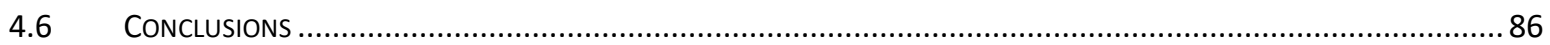

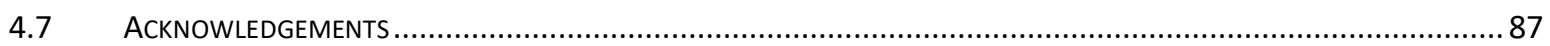

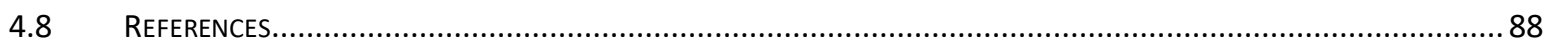

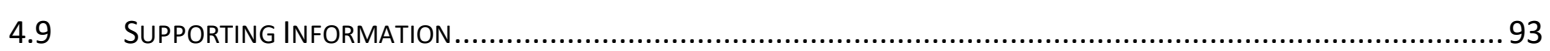

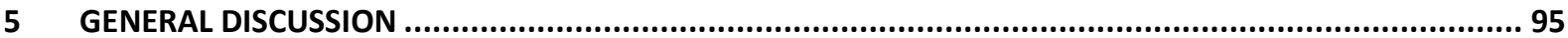


5.1 CHANGES IN SOIL MICROBIAL PROPERTIES WITH TIME AND PLANT COMMUNITY COMPOSITION ...............................95

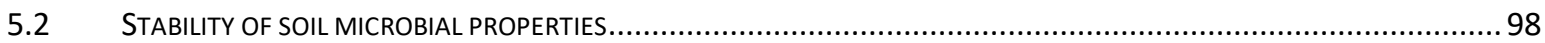

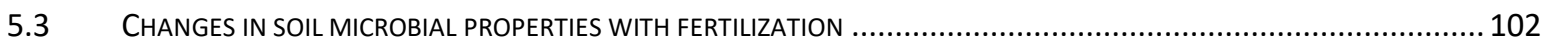

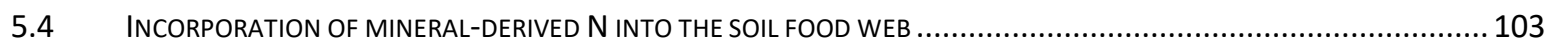

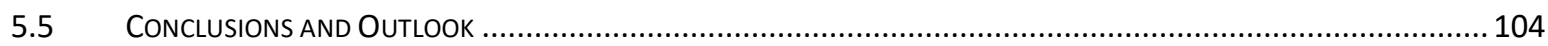

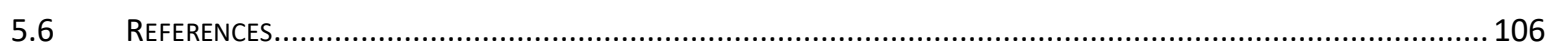

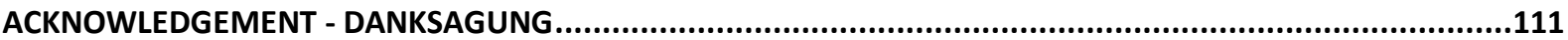

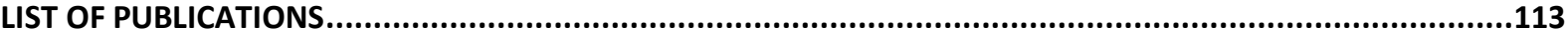

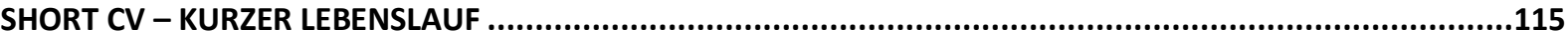

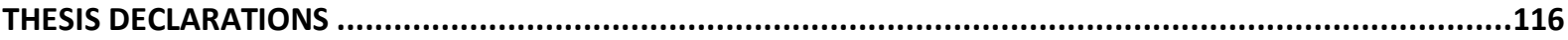




\section{Summary}

Soil-derived ecosystem functions such as decomposition and element cycling are crucial for ecosystem services such as production of food, fodder and biofuels; in short, they are essential prerequisites for human and animal life. They dependent on biodiversity, soil microbial functioning and the soil-inhabiting fauna. Since about 30 years, ecological research focuses on biodiversityecosystem function (BEF) relationships, and by now it is general consensus among ecologists that biodiversity is essential for maintaining ecosystem functioning. Although many studies on BEF relationships have been done, further knowledge on the mechanisms underlying the positive BEF relationships is still needed. Especially the role of (plant) biodiversity for belowground processes and soil organisms has been neglected in earlier studies on BEF relationships. Also, studies investigating the stability of soil microbial functioning and its relation to plant diversity are scarce, although stability of ecosystem functions is essential for the sustainable provisioning of ecosystem services. Additionally, the influence of mineral $\mathrm{N}$ fertilization on soil organisms and its interaction with plant community properties is of major importance for ecosystem functioning and needs further investigation, as the application of $\mathrm{N}$ fertilizer increases worldwide, but is known to has controversial effects on ecosystem functions, such as increasing crop productivity, but decreasing plant diversity. Within the framework of the present thesis I conducted three studies investigating the impact of plant diversity and plant community composition (identity of plant functional groups) on soil microbial properties and their stability in bulk-soil, combined with the investigation of mineral $\mathrm{N}$ incorporation into soil microorganisms and its channelling from microorganisms into soil fauna (mesofauna). The studies were conducted on the field site of the Jena Experiment, comprising plant communities with up to 60 plant species and 1-4 plant functional groups (legumes, grasses, small herbs, tall herbs; all species belong to Molinio-Arrhenateretea meadows typical for hay meadows in Central Europe).

In study 1 (Chapter 2, Stability Experiment), we tracked soil microbial properties (basal respiration and biomass $\mathrm{C}$ ) over a time period of 12 years. We found that plant species richness consistently increased both soil microbial basal respiration and biomass after a time-lag of four years after the establishment of the experiment, and that the positive relationship between plant species richness and soil microbial properties lasted until the end of the study. The delayed response of the soil microbial community to changes in land-use (from former arable field monocultures to semi-natural experimental grassland) points to the long time, plant effects need to materialize in the belowground system. After the time-lag, increasing amounts and variety of plant-derived inputs into the soil with increasing plant diversity presumably fostered soil microbial respiration and biomass. 
We expected plant diversity to show specific dynamic effects over the three time phases of our longterm study (each phase spanning four years) on the temporal stability of soil microbial properties. Due to the disturbance (=land-use change) at the beginning of the experiment and the following maturation of the plant communities, we expected plant diversity to exert destabilizing effects during phase 1 , neutral effects in phase 2 , and positive effects in phase 3 on the temporal stability of soil microbial properties. Indeed, we found the effect of plant diversity on the temporal stability of soil microbial properties to turn from being negative to neutral, but this neutral relationship lasted until the end of the study, suggesting that the recovery of soil microbial communities from former arable land-use takes more than a decade. For the spatial stability of soil microbial properties, the presence of plant functional groups was of major importance, with legumes and tall herbs reducing the spatial stability of microbial respiration, and grasses increasing the spatial stability of the latter. Presumably, plant-trait-based mechanisms such as rhizodeposition of $\mathrm{N}$-rich compounds by legumes, patchy $\mathrm{C}$ provisioning to the soil by tap-roots of tall herbs, and evenly distributed $\mathrm{C}$ provisioning by grass roots provoked the observed effects of plant functional groups on soil microorganisms. The results of study 2 (Chapter 3, Fertilization Experiment) revealed that mineral $\mathrm{N}$ fertilizer and plant diversity acted independent of each other on soil microorganisms. Unexpectedly, fertilization did not increase soil microbial biomass. As the soil system has been shown to react with a time-lag of several years to environmental changes such as management practice or plant diversity (see above), we assume that the duration of our Fertilization Experiment (two years) may have been too short to unravel the full response of soil microorganisms to fertilization. Instead, fertilization superimposed the negative legume effect on soil microbial respiration, although the underlying mechanisms are likely to be different. Legumes are known to fuel the soil system with organic $\mathrm{N}$, thereby increasing soil microbial $\mathrm{C}$ use efficiency. In contrast, mineral $\mathrm{N}$ fertilizer probably decreases rhizosphere priming effects by delivering inorganic $\mathrm{N}$, and probably also increased microbial $\mathrm{C}$ use efficiency in the present study, as suggested by decreased microbial C-to-N-ratios in fertilized experimental plots. Although mineral $\mathrm{N}$ fertilizer neither affected soil microbial biomass nor interacted with plant diversity on soil microbial properties within the investigated time frame of two years, the interactive effect between fertilization and legumes on the soil microbial C-to- $\mathrm{N}$-ratio indicates that mineral $\mathrm{N}$ was incorporated into the soil microbial biomass.

To investigate the role of plant community properties for the microbial uptake of mineral $\mathrm{N}$, and whether mineral-derived $\mathrm{N}$ is channelled from microorganisms to higher trophic levels, we labelled soil with mineral ${ }^{15} \mathrm{~N}$ and analysed its incorporation into soil microbial biomass and most abundant mesofauna taxa over three months (Chapter 4, Tracer Experiment). Mineral-derived ${ }^{15} \mathrm{~N}$ incorporation decreased over time in all investigated organisms (except in the primary decomposer Tectocepheus velatus sarekensis), reflecting the fast incorporation of mineral ${ }^{15} \mathrm{~N}$ into 
microorganisms and its dominant channeling into mesofauna species. Plant species richness reduced the uptake of mineral ${ }^{15} \mathrm{~N}$ in microorganisms, presumably because competition for $\mathrm{N}$ in soil is aggravated in more diverse plant communities. The effects of plant diversity on the incorporation of mineral-derived ${ }^{15} \mathrm{~N}$ into mesofauna species were species-specific, and reflected different nutritional strategies among animal species. For example, plant species richness decreased ${ }^{15} \mathrm{~N}$ incorporation into the secondary decomposer Ceratophysella sp., likely because Ceratophysella sp. fed on microorganisms that were also reduced in ${ }^{15} \mathrm{~N}$ due to limited $\mathrm{N}$ supply in plant communities of high diversity. Interestingly, plant species richness exerted time-dependent effects in other mesofauna species, e.g. in the primary decomposer Tectocepheus velatus sarekensis. Potentially, the increase in ${ }^{15} \mathrm{~N}$ in $T$. velatus sarekensis with plant species richness later in the experiment was due to increased availability of dead plant roots containing ${ }^{15} \mathrm{~N}$ from the mineral ${ }^{15} \mathrm{~N}$ added. Also plant community composition (plant functional group identity) played a major role for the ${ }^{15} \mathrm{~N}$ incorporation into soil organisms. For example, presence of legumes decreased ${ }^{15} \mathrm{~N}$ in soil microorganisms, presumably due the release of unlabelled organic $\mathrm{N}$ via rhizodeposition. Grasses increased the incorporation of ${ }^{15} \mathrm{~N}$ in Ceratophysella sp., suggesting that the diet of Ceratophysella sp. is not restricted to microorganisms but also includes plant roots highly labelled with ${ }^{15} \mathrm{~N}$. The results of study 3 highlight that mineral $\mathrm{N}$ is quickly channeled into soil animal food webs via microorganisms. Our results highlight that plant diversity and community composition alter the competition for $\mathrm{N}$ in soil and change the nutrient transfer across trophic levels in soil food webs, potentially leading to changes in soil animal population dynamics and community composition.

In short, the present thesis indicates that

1| plant diversity and community composition drive soil microbial properties (respiration, biomass), as well as the temporal and spatial stability of these properties.

2 | the soil system reacts with a time-lag of several years to land-use change, and soil microbial communities need more than a decade to recover from former agricultural land-use.

$3 \mid$ plant functional groups exert trait-specific effects on soil microbial properties, and these effects complement each other.

4| mineral $\mathrm{N}$ fertilization acts independent of plant diversity on soil microbial properties, but exerts interacting effects with certain plant functional groups (legumes),

5 | soil microorganisms largely and quickly incorporate mineral $\mathrm{N}$, and channel this $\mathrm{N}$ to higher trophic levels of the soil food web.

6| plant diversity and community composition shape the incorporation of mineral $\mathrm{N}$ into soil microorganisms and soil fauna.

Taken together, the present thesis reinforces and complements the findings of earlier BEF studies, and emphasizes the importance of maintaining grasslands with high plant diversity including all 
investigated plant functional groups (legumes, grasses, small and tall herbs) with their trait-specific effects for essential soil ecosystem functions and services. Especially in a changing world with increasing anthropogenic impacts such as increasing mineral $\mathrm{N}$ fertilizer application, plant diversity may also buffer detrimental effects of mineral $\mathrm{N}$ on ecosystems. 


\section{General Introduction}

\subsection{Biodiversity}

Biodiversity is essential for the functioning of the earth's ecosystems and thus for humankind (Cardinale et al., 2012; Chapin et al., 2000; Hooper et al., 2005; Wilson, 1988). Virtually all ecosystem functions rely directly or indirectly on biodiversity (Chapin et al., 2000), including primary productivity, decomposition and nutrient cycling, production of oxygen, water cycling and purification, pollination, disease regulation, and climate regulation. Thereby, biodiversity ensures ecosystem services such as the provision of food, fibre and fuel, fresh water, biochemicals, and medicine. Also, biodiversity is an important source of recreation and spiritual anchorage (Millenium Ecosystem Assesment, 2005). In brief, biodiversity touches everything we rely on.

Currently, about 1.2 million eukaryotic species are systematically catalogued in a central database (Mora et al., 2011), about 0.55-0.8 million species more are described but not catalogued (Streit, 2006). No one knows how many life forms actually live on this planet as conducting representative samplings of organisms in all types of ecosystems is very difficult and experts who can identify the organisms are scarce. Estimations on how many species live in the Earth's ecosystems assume 6.5 million eukaryotic species on land and 2.2 million species in oceans, meaning that $86 \%$ of existing species on land and 91\% marine species are still unknown (Mora et al., 2011).

In soil, there exist about 52,000 known species of soil animals, including ants, termites, earthworms, mites, collembolans, protozoans, and nematodes (Wall et al. 2001; Table 1). Additionally, there are about 26,500 species (or lineages) of microorganisms such as bacteria and fungi. It is striking, that the majority of the existing soil fauna is still unknown. Especially the biodiversity of soil microorganisms (and their functioning), but also that of soil meso- and macrofauna still is viewed as an "enigma" (Anderson, 1975; Nielsen et al., 2010).

Table 1. Estimated number of species of vascular plants and soil organisms ordered according to body size (Barrios 2007, modified from Wall et al. 2001).

\begin{tabular}{|c|c|c|c|c|}
\hline Size & Group & Known species & Estimated total species & \% Known \\
\hline \multirow[t]{13}{*}{ 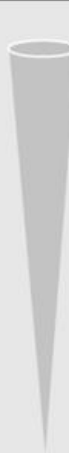 } & $\begin{array}{l}\text { Vascular plants } \\
\text { Macrofauna }\end{array}$ & 270000 & 300000 & 90 \\
\hline & Ants & 8800 & 15000 & 58.7 \\
\hline & Termites & 1600 & 3000 & 53.3 \\
\hline & Earthworms & 3600 & No estimate & No estimate \\
\hline & Mesofauna & & & \\
\hline & Mites & $20.000-30.000$ & 900,000 & $2.2-3.3$ \\
\hline & Collembola & 6500 & 24,000 & 27.1 \\
\hline & Microfauna & & & \\
\hline & Protozoa & 1500 & 200,000 & $7.5 \%$ \\
\hline & Nematodes & 5000 & 400,000 & 1.3 \\
\hline & Microflora & & & \\
\hline & Bacteria & 13,000 & 1.000 .000 & $1 \%$ \\
\hline & Fungi & $18000-35000$ & 1.500 .000 & $1-2 \%$ \\
\hline
\end{tabular}


Since humans began to colonize the world, hundreds of species got extinct. Extinction rates still increase due to the accelerated technical development and exploitation of ecosystems (Millenium Ecosystem Assesment, 2005). The current extinction rates of species are estimated to be 100-1000 times higher than the expected natural extinction rate (Pimm et al., 1995) and to be higher than the former "Big Five" extinctions in geological time (Barnosky et al., 2011). Scientists presume that this is the beginning of the $6^{\text {th }}$ mass extinction since 540 million years (Barnosky et al., 2011; Ceballos et al., 2015; Ripple et al., 2017). Already in 1992, the Union of Concerned Scientists published the first "World Scientists' Warning to Humanity" pointing to the threatening of biodiversity and whole ecosystems due to human activities (Ripple et al., 2017; World Scientists' Warning to Humanity, 1992). Worldwide, the marine catch has been going down since the mid-1990ies, while at the same time fishing effort has been going up, demonstrating the over-exploitation of oceans (Fig. 1). Dead zones increased from about 40 to over 650 since the 1960ies. Between 1970 and 2012, vertebrates abundance declined by $58 \%$, with fresh water, marine and terrestrial populations declined by 81,36 , and $35 \%$, respectively.
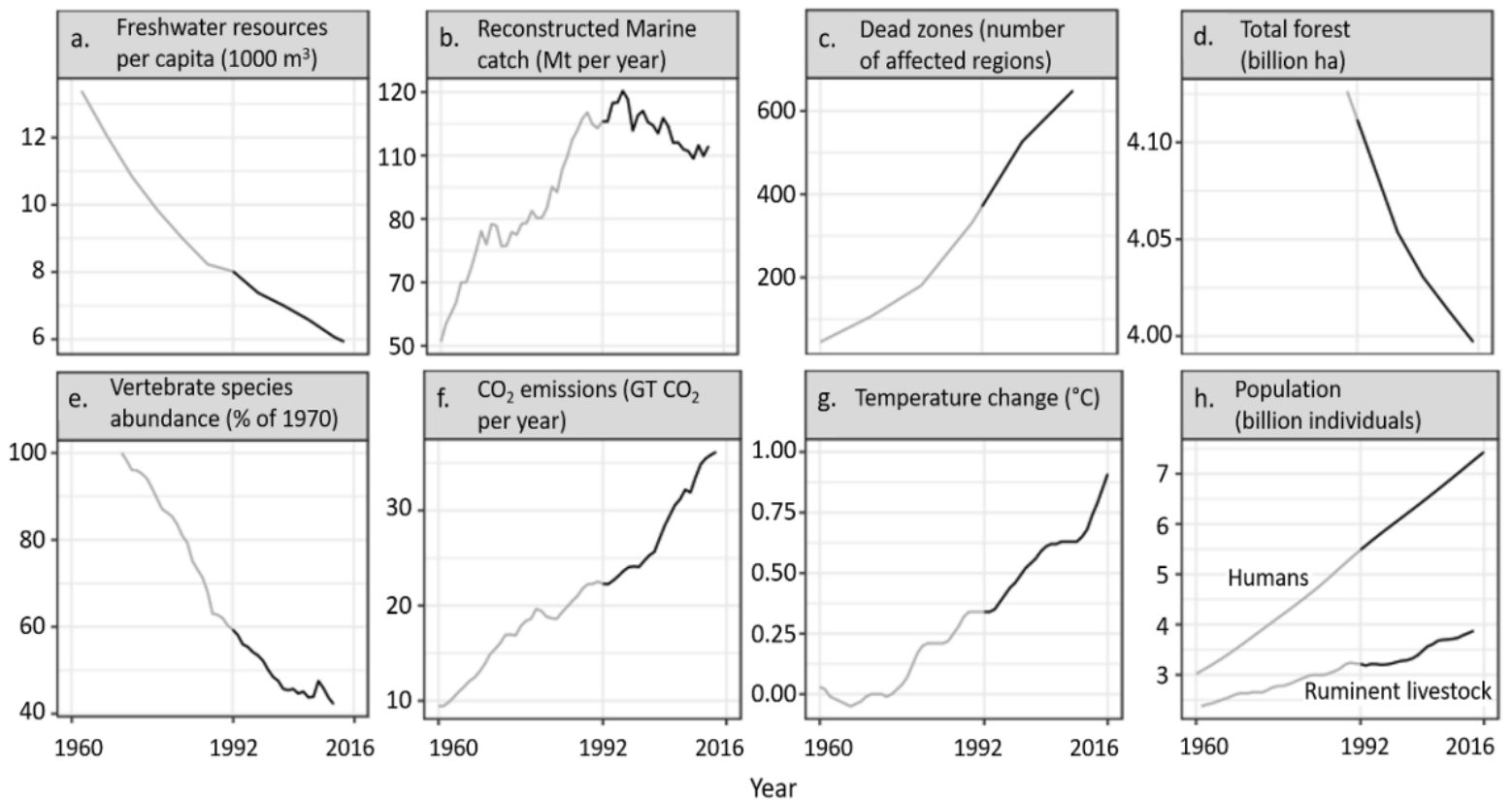

Figure 1. Trends over time for environmental issues identified in the 1992 scientists' warning to humanity. The years before and after the 1992 scientists' warning are shown as grey and black lines, respectively; (a) fresh water resources (b) marine catch, (c) dead zones, (d) total forest, (e), the vertebrate species abundance index, (f) $\mathrm{CO}_{2}$ emissions, (g) five- year means of global temperature, (h) population development of humans and ruminant livestock (domestic cattle, sheep, goats, and buffaloes). Note that $y$-axes do not start at zero. Percentage change, since 1992, for the variables in each panel are as follows: (a) - 26.1\%; (b) -6.4\%; (c) +75.3\%; (d) -2.8\%; (e) -28.9\%; (f) +62.1\%; (g) 167.6\%; (h) humans: +35.5\%, ruminant livestock: $+20.5 \%$. (Modified after Ripple et al. 2017). 
In Germany, about $48 \%$ percent of the organisms, including animals, plants, and fungi, are either endangered or extinct (Fig. 2); the status of about $5 \%$ of the organisms is unknown and only $37 \%$ of the organisms are at low risk to go extinct. Reasons for the rapid decline in biodiversity are worldwide expansion of industrialization and human settlement areas, over-exploitation of resources, high

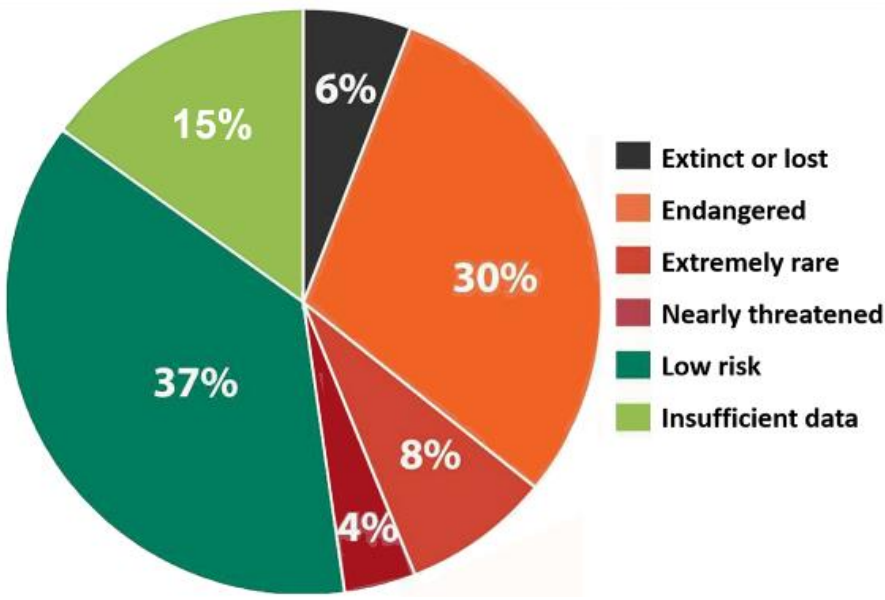

Figure 2. Risk situation for animals, plants, and fungi in Germany (FONA, Federal Agency for Nature Conservation, 2015).

emissions of greenhouse gases, and high depositions of nitrogen and pollutants. These factors lead to habitat destruction, climate changes such as warming, shifts of climate zones, desertification, flooding events, over-fertilization, as well as acidification of terrestrial and marine ecosystems (Wilson, 1988). Further, freshwater resources decline and dead zones increase.

As a consequence, ecologists focused on investigating the role of biodiversity for ecosystem functioning and on how biodiversity acts on different ecosystem functions (Bengtsson 1998, Loreau 2000, Scherber et al. 2010, Lefcheck et al. 2015). In particular, the interactions between plant diversity (plant species richness) and human-induced environmental changes have been investigated. A number of large biodiversity experiments have been established and are still running worldwide, most located in Europe and Northern America. These large-scale experiments include

- the Cedar Creek Ecosystem Science Reserve existing since the 1940ies in Minnesota,

- the BioCON Experiment within Cedar Creek, investigating the role of elevated $\mathrm{CO}_{2}$ and nitrogen deposition on ecosystem functioning, since 1997 (Reich et al. 2006),

- the Ecotron Experiment at Silwood Park in the UK (Naeem et al., 1994),

- the BIODEPTH Experiment across different biomes in Europe (Hector et al., 1999),

- the Biodiversity Exploratories ranging across different land-use types in Germany (Fischer et al., 2010), and

- the Jena Experiment in semi-natural temperate grassland in Germany (Roscher et al., 2004). Although the idea of a positive relationship between biodiversity and ecosystem properties already originated in the late 1950ies (Elton, 1958), it was put aside by other ideas until the 1980ies. First studies that reconfirmed Elton's observations were conducted in the early 1990ies (Tilman et al., 2014). These studies investigated effects of biodiversity in different ecosystems and found increasing biodiversity to increase primary productivity and resistance against drought in grasslands (Naeem et 
al., 1994; Tilman and Downing, 1994) as well as resistance against biological invasions in marine ecosystems (Stachowicz et al., 1999). By now, the positive relationship between biodiversity and ecosystem functioning is proven by hundreds of experimental and theoretical studies (Tilman et al., 2014). Therefore, today research focuses on the mechanisms how biodiversity contributes to ecosystem functioning (Eisenhauer et al., 2017; Weisser et al., 2017) and what happens in detail to ecosystems if biodiversity declines.

The fact that biodiversity is vital for ecosystems and the persistence of humankind by now also dropped into the awareness of international and national politics. The United Nations General Assembly declared the year 2010 to the "International Year of Biodiversity" with the aim to make the protection of biodiversity more popular. In 2018, a consortium of about 20 scientists published the "Frankfurt Declaration for the conservation of biodiversity" in which they recommended how to protect biodiversity in Germany in the long-term

(http://www.senckenberg.de/root/index.php?page id=5206\&year=2018\&kid=2\&id=4879). If these efforts will lead to success is questionable as human short-term technical progress and consumption of resources seem to override the long-term needs for sustainability (Leggewie and Welzer, 2009).

\section{What is biodiversity?}

The term biodiversity comprises a wide spectrum of biotic scales, from genetic variation within species, genetic variation between species, over species richness within a habitat or ecosystem, to habitat number and diversity within an ecosystem, and distribution of ecosystems and biomes across the planet. Biodiversity can be described as entities (how many genotypes, species, ecosystems), as the evenness of their distribution, differences in their functional traits, and interactions. Different components of biodiversity (e.g., numbers, relative abundance, presence/ absence of key species) can have different effects on ecosystem properties and processes (Hooper et al., 2005).

\section{What are functional traits?}

To mechanistically understand the interrelationships between the different components of ecosystems, i.e. how ecosystem processes function, we need to know functional traits of organisms. Functional traits are those that either affect ecosystem properties (functional effect traits) or species' responses to environmental conditions (functional response traits) (Hooper et al., 2005). Like most of the recent studies, in the present doctoral work I refer to functional effect traits. According to the spectrum of different functional traits present in a community, i.e. with higher functional trait diversity, ecosystem properties such as decomposition, nutrient cycling or primary productivity increase (Heemsbergen et al., 2004; Roscher et al., 2013). Species can be assigned to functional groups according to the functional traits they are sharing. For example, plants from temperate 
grasslands can be grouped into legumes, grasses and herbs according to their morphological and phenological traits, e.g. flowering time, ability to fix molecular nitrogen, as well as plant height and rooting depth (Roscher et al., 2004). Often, functional groups are equivalent to taxonomic groups as these have similar ecological properties.

\section{Why investigating effects of plant diversity?}

Plants are the primary producers in ecosystems, providing the nutritional basis for the whole consumer food web. Plant diversity enhances plant biomass production (Weigelt et al., 2009) as well as soil microbial biomass carbon (Eisenhauer et al., 2010) and, to a certain degree, can buffer against disturbances such as drought (Tilman and Downing, 1994).

Plants form the bridge between the aboveground and belowground system as they fix atmospheric carbon and translocate resources into their roots. Roots release carbon and nutrients in the form of sugars and amino acids into the soil, thereby delivering resources for soil animals and heterotrophic microorganisms. In addition, dead plant material enters the soil system and serves as resource for decomposers. As described above, plants with different functional traits occupy different ecological niches and deliver resources of different qualities, at different locations (e.g., via different rooting depths and densities) or at different times over the year (seasonality). By this means, plant species also foster soil microbial communities (Eisenhauer et al., 2010; Sechi et al., 2014). As a result of these plant functional trait effects, plant diversity promotes small-scale heterogeneity in soil and facilitates soil animals to occupy distinct trophic niches (Ferlian et al., 2015; Schneider et al., 2004). Of course, plants not only deliver resources, but they also demand resources such as water, nutrients and space. Thus, they simultaneously act as competitors with soil animals, soil microorganisms and other plants (Kuzyakov and Xu, 2013). The kind and strength of interactions between plants and other organisms depend on their specific functional traits. High diversity plant communities contain a wider spectrum of functional traits than communities with low plant diversity. The outcome of the interactions between functional traits of these plant communities is difficult to predict as long as the underlying mechanisms are unknown. By performing plant diversity experiments employing a gradient of plant and functional diversity, we intended to uncover how plant diversity influences particular ecosystem properties and processes. In particular, we investigated effects of plant diversity on soil microbial biomass and soil microbial respiration, two important indicators for intact soils (Anderson and Domsch, 1985; Bardgett and Shine, 1999). We also investigated effects of plant diversity on soil animals (mesofauna, in combination with fertilizer $\mathrm{N}$ ) as plant species shape the microhabitats of soil animals and interact intimately with them (Bonkowski et al., 2009; Eisenhauer et al., 2013; Sechi et al., 2014). 


\subsection{Stability and its role for ecosystem functioning and services}

Provisioning of ecosystem goods and services are only guaranteed if ecosystem processes are stable in the long-term (McCann, 2000; Tilman et al., 2014). Already in 1958, C. S. Elton observed insect calamities in forest and agricultural monocultures and concluded that in natural ecosystems plant diversity stabilizes animal population dynamics (Elton, 1958). MacArthur (1955) argued that multiple energy pathways stabilize consumer populations, as the loss of any one pathway would be less severe. During the 1970ies, other ideas occurred based on computational models that used randomly constructed communities with randomly constructed interactions strengths between organisms (McCann, 2000; Pimm, 1984). These models suggested that biodiversity destabilizes community dynamics (May, 1973) and this questioned the diversity begets stability hypothesis. It lasted about ten years, until Yodzis (1981) used real world population data in his model and showed that indeed biodiversity (i.e., species richness with species responding differentially to environmental changes) are needed to stabilize ecosystem properties.

Table 2. Definitions of different types of stability (McCann 2000).

\begin{tabular}{|c|c|}
\hline \multicolumn{2}{|c|}{ Definitions of stability. } \\
\hline Term & Definition \\
\hline \multicolumn{2}{|c|}{ Definitions of dynamic stability } \\
\hline Equilibrium stability & $\begin{array}{l}\text { A discrete measure that considers a system stable if it returns to } \\
\text { its equilibrium after a small perturbation away from the } \\
\text { equilibrium. A stable system, therefore, has no variability in the } \\
\text { absence of perturbations. }\end{array}$ \\
\hline General stability & $\begin{array}{l}\text { A measure which assumes that stability increases as the lower } \\
\text { limit of population density moves further away from zero. Under } \\
\text { non-equilibrium dynamics, such limits to population dynamics } \\
\text { generally imply a decrease in population variance (see variability } \\
\text { definition below). }\end{array}$ \\
\hline Variability & $\begin{array}{l}\text { The variance in population densities over time, usually measured } \\
\text { as the coefficient in variation. Common in experimental tests of } \\
\text { stability. }\end{array}$ \\
\hline \multicolumn{2}{|c|}{ Definitions of resilience and resistance stability } \\
\hline Equilibrium resilience & $\begin{array}{l}\text { A measure of stability that assumes system stability increases as } \\
\text { time required to return to equilibrium decreases after a } \\
\text { perturbation. A rapid response means that a system recoils } \\
\text { rapidly back to its equilibrium state. }\end{array}$ \\
\hline General resilience & $\begin{array}{l}\text { A measure of stability that assumes system stability increases as } \\
\text { return time to the equilibrium/non-equilibrium solution decreases } \\
\text { after a perturbation. A rapid response means that a system } \\
\text { recoils rapidly back to its equilibrium/non-equilibrium state. }\end{array}$ \\
\hline Resistance & $\begin{array}{l}\text { A measure of the degree to which a variable changes after a } \\
\text { perturbation. Frequently used as a discrete measure that } \\
\text { assesses a community's ability to resist invasion (that is, if an } \\
\text { invader fails, the community resists invasion). }\end{array}$ \\
\hline
\end{tabular}

Although few studies found contrasting results (McCann, 2000), recent ecological experiments reconfirmed Elton's diversity begets stability hypothesis (Haddad et al., 2011; Ives and Carpenter, 2007; McCann, 2000; Weigelt et al., 2008). In fact, ecologists increasingly focus on the role of biodiversity for the stability of ecosystem functioning as humans affect both (see above).

Depending on the scientific question, different types of stability are addressed. Generally, two categories of stability types exist based either upon the system's dynamic stability or on the system's ability to defy change (McCann 2000; Table 2). Community stability is not equal to population stability, because densities of distinct species can fluctuate in response to environmental factors, while the summed densities of individuals (or the biomass) within the whole community may remain stable. General stability increases if population densities move further away from extremely low or high densities, and implies decreased variability (McCann, 2000). This measure is appropriate as stability indicator in experimental studies and was used in the present dissertation (Chapter 3, Stability study). 


\subsection{Soil}

Soil is one of the most complex biomaterial on earth (Adhikari and Hartemink, 2016) and comprises a dynamic system where pedosphere, lithosphere, hydrosphere, atmosphere and biosphere are close together. Soil develops when parent rock material is weathering due to UV radiation or chemical influences. Its development lasts thousands of years, and acquires the interrelated activities of soilinhabiting organisms (Blume et al., 2016; Buscot and Varma, 2005). Soils are irreplaceable for the provision of many ecosystem functions and services. These include provisioning services (substrates for plant growth, food for humans, fresh water, wood, fibre, fuel), regulating services (gas and water storage and purification, climate, floods, erosion, biological processes such as pollination and diseases), cultural services and supporting services (nutrient cycling, production, habitat, biodiversity) (Adhikari and Hartemink, 2016; Millenium Ecosystem Assesment, 2005). In terrestrial ecosystems, soil is the most species-rich habitat at local scales. Life in soils is temperature- and $\mathrm{pH}$-dependent; thus, organisms in soils are adapted to different chemical properties as well as to different climates and seasonal changes in temperature. Soils in temperate grasslands typically are exposed to temperature cycles with frost in winter, high temperatures in summer, and drought in late summer. At the end of the growing season, grasses become dormant and most of the aboveground (and partly belowground) plant biomass dies off, thereby adding dead organic matter into the soil and building up the humus-rich A-horizon.

Soil is stratified into different layers, with mineral soil in deeper layers and organic soil in the upper layers. Life concentrates in the upper soil layers, as these are rich in organic matter serving as diet for soil biota. Soil is not only structured in horizontal layers, but also contains vertical structures in the form of soil pores of different sizes (Blume et al., 2016), typically from micrometres to centimetres. These pores enable gases, water (and solutions) as well as animals to move through the soil system.

\subsection{The soil food web}

Soil animals interact in different ways with their environment. Feeding interactions are among the most important interactions between organisms as diet is one of the most essential resources and its quality and distribution shapes the structure of soil food webs. Feeding relationships include those between predator and prey, between competitors using the same resource, or between mutualists where two organisms benefit from each other, e.g. between plants and associated mycorrhizal fungi. According to what they feed on, animals are assigned to trophic groups either mainly feeding on plants (herbivores), on other animals (predators) or dead organic matter (decomposers). Most soil animals form part of the decomposer food web (Bardgett, 2005). According to their trophic group, soil organisms function as primary decomposers feeding predominantly on dead organic matter 
(detritus), secondary decomposers feeding on microorganisms such as bacteria and fungi, or predators feeding on animals (Scheu, 2002).

This classification implies that several animal species feed on equal or similar resources, thereby being functionally equivalent, i.e. they exert similar top-down forces on their prey (Scheu, 2002). The concept of trophic groups simplifies the structure of food webs and enables identifying main relationships within a food web. In soil ecology, using the concept of trophic groups is helpful because of the high diversity of soil animal species. The fact that soil animals of the same taxonomic group often feed on similar resources facilitates the investigation of soil food webs (Scheu, 2002). Nevertheless, feeding relationships between soil animals and their resources are highly flexible. Many species cannot be assigned explicitly to one trophic group, because they switch their diet depending on food availability (Endlweber et al., 2009; Lemanski and Scheu, 2014; Scheu and Folger, 2004). Additionally, species within animal groups such as Collembola often form a continuum from primary to secondary decomposers (Scheu and Falca, 2000). Another important criterion for classifying soil animals is body size. Several studies demonstrated that body size is a master trait in structuring food webs (Brose et al., 2006; Schneider et al., 2012). Global environmental change may affect body-sizes of animals in ecosystems, and hence, alter top-down and bottom-up control in food webs (Brose et al., 2012). In soil typically three size classes are differentiated, microfauna $(<100 \mu \mathrm{m}$, e.g., nematodes and protists), mesofauna (100 $\mu \mathrm{m}-2 \mathrm{~mm}$, e.g., Collembola and Oribatida) and macrofauna (> 2mm, e.g., earthworms, spiders and many insects) (Fig. 3).

In terrestrial ecosystems most of the primary production ultimately enters the decomposer food web relying on dead organic matter (DOM), only a minor part typically is processed by the grazer food web relying on living plants (Moore et al., 2004; Odum and Biever, 1984). This points to the essential role of decomposers for the functioning of ecosystems. 


\subsection{Mineral fertilizer $\mathbf{N}$ - two sides of the coin}

All living creatures rely on nitrogen $(\mathrm{N})$ because it is an essential element of proteins and nucleic acids. Since the Haber-Bosch process was implemented industrially for the first time in 1913, the production of mineral fertilizer $\mathrm{N}$ began to flourish. Subsequently, the production of food and fodder grew exponentially and with them human global population (Fig. 4). The agricultural use of mineral fertilizer $\mathrm{N}$ was a revolution of farming techniques, enabled higher crop yields worldwide and released millions of people from hunger. Nevertheless, $\mathrm{N}$ plays a very controversial role for the functioning of ecosystems and human well-being. This originates from the fact that biota on the one hand rely on $\mathrm{N}$, but also suffer from too high $\mathrm{N}$ dosage (Ruttan et al., 1975). $\mathrm{N}$ deposition increased strongly due to intense application of mineral fertilizer N in agro-ecosystems (Galloway et al., 2008), extension of cattle breeding and fossil fuel combustion that release large amounts of nitrous oxide into the atmosphere. Moreover, the production of mineral fertilizer $N$ itself is based on the use of fossil fuel and thereby contributes to global warming (Schröder, 2014). The difficulty of using mineral fertilizer $\mathrm{N}$ (and also organic fertilizer $\mathrm{N}$ ) in agro-ecosystems is that $\mathrm{N}$ is very reactive and mobile, thus not only plants take up fertilizer $\mathrm{N}$, but also a large amount of $\mathrm{N}$ is lost to the air or groundwater, e.g. by leaching. Due to the mobile nature of reactive $\mathrm{N}\left(\mathrm{NO}_{3}, \mathrm{NH}_{3}, \mathrm{~N}_{2} \mathrm{O}\right)$ and its worldwide emission, not only agro-ecosystems are affected, but also natural and semi-natural ecosystems (Stevens et al., 2010; Vitousek and Aber, 1997). Although $\mathrm{N}$ still is a limiting factor for plant growth (and partly also soil microbial growth) in most terrestrial ecosystems, many ecosystem processes and biodiversity suffer from too high N inputs (Butchart et al., 2010; Dickson and Foster, 2011; Isbell et al., 2013). Reactive N contributes to the formation of tropospheric ozone and smog, global warming effects, the depletion of stratospheric ozone, deteriorates the quality of groundwater and surface water (Erisman et al., 2011). Thus, too high amounts of $\mathrm{N}$ reduce the vitality of plants, animals and humans (Schröder, 2014). Therefore, the input of (mineral) $N$ into and its fate within terrestrial ecosystems has become

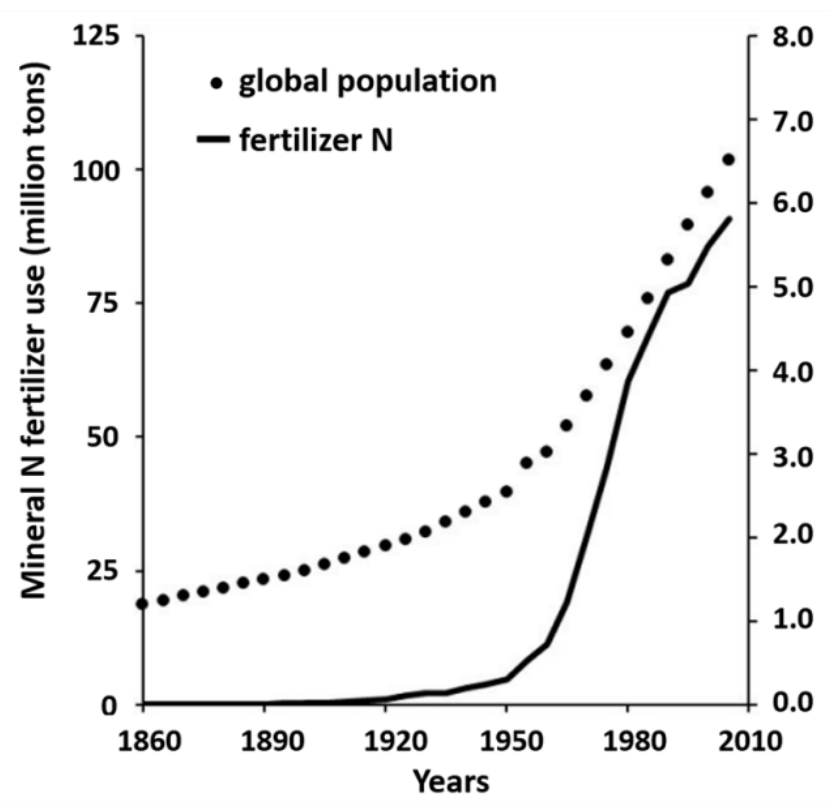
an important topic of current ecological research (Erisman et al., 2011; Galloway et al., 2008, 2004; Reich et al., 2001; Scheunemann et al., 2016; van Diepen et al., 2010). In the present thesis, we combined testing the effects of both, fertilizer $\mathrm{N}$ and loss of plant diversity, on soil microbial properties.

Figure 2. Historical development of mineral fertilizer $\mathrm{N}$ production and human population (sources: International Fertilizer Industry Association - IFA; FAOSTAT, 2014.). 


\subsection{Using stable isotopes to track the flux of nitrogen}

Observing feeding habits of soil animals directly is difficult, if not impossible, because of the opaqueness of soil. Therefore, soil ecologists use methods that allow investigating the nutrition and feeding relationships of soil animals indirectly. One of these methods is measuring the ratios of stable isotopes (Dawson and Siegwolf, 2007; Potapov et al., 2019; Scheu, 2002).

When animals consume and digest food they incorporate $\mathrm{N}$ into their tissues. $\mathrm{N}$ consists of two stable isotopes, ${ }^{14} \mathrm{~N}$ and ${ }^{15} \mathrm{~N}$, whereof ${ }^{15} \mathrm{~N}$ is the very minor component. Because enzymes discriminate molecules containing ${ }^{15} \mathrm{~N}$, animal excrements are depleted in ${ }^{15} \mathrm{~N}$, while animal tissue becomes enriched in ${ }^{15} \mathrm{~N}$. The natural isotope $\mathrm{N}$ signature (i.e., the ${ }^{15} \mathrm{~N}$-to- ${ }^{14} \mathrm{~N}$ ratio) of animals increases by about $3.4 \%$ \% (SD = \pm 1$)$ per trophic level, thus allowing to use stable nitrogen isotope ratios as a trophic level-indicator (Eggers and Hefin Jones, 2000; Post, 2002). Marine and freshwater food web ecologists heavily use stable isotopes for investigating food webs since about 30 years (Layman et al., 2012; Minagawa and Wada, 1984; Pasquaud et al., 2007). Not only trophic positions of species are investigated with the stable isotope method, but also changes in the trophic position of species with age (Haubert et al., 2005; Minagawa and Wada, 1984) and habitat (Abend and Smith, 1995; Ferlian and Scheu, 2013; Potapov et al., 2018). Soil ecologists only started to use stable isotope methods in the 1990ies because techniques allowing to measure small amounts of animal tissues were lacking before (Hyodo, 2015). By measuring natural stable isotope $\mathrm{N}$ signatures of forest soil macro-invertebrates, Ponsard and Arditi (2000) found the studied species to belong either to detritivores or predators. Scheu and Falca (2000) identified different trophic groups in forest soil macro- and mesofauna and found that many decomposer species rather form a continuum between primary and secondary decomposers than distinct trophic groups. As the concept of trophic groups can be questioned, Popatov et al. (2018) tested the trophic consistency of supra specific taxa across major lineages of temperate soil invertebrates, and reasoned that using this concept is appropriate provided that taxonomic resolution and research question are matching. Today, measuring natural stable $\mathrm{N}$ isotopes is widespread and proved to be a useful tool in soil food web ecology (Hobbie et al., 2001; Maraun et al., 2011; Popatov et al., 2018; Schmidt et al., 2004; Tiunov et al., 2015).

Furthermore, also labelling approaches using ${ }^{15} \mathrm{~N}$ compounds are employed to trace the flux of nitrogen through food webs (Maraun et al., 2011; Zieger et al., 2017). Continuous addition of stable isotopes into ecosystems allows measuring pool sizes in different compartments of the ecosystems, while pulse labeling enables tracing pathways of $\mathrm{N}$ through ecosystem compartments over time, i.e. along the food chain. (Coleman et al., 1983) distinguished between slow and fast nutrient pathways in soil which (Moore et al., 2005) identified as the fungal and bacterial food channels. In the review of Crotty et al. (2012) about using stable isotopes in soil food web ecology, they point to the importance of soil protists for trophic fluxes and the channelling of $\mathrm{C}$ and $\mathrm{N}$ to higher trophic levels. 
Zieger et al. (2017) identified root-derived $\mathrm{N}$ as $\mathrm{N}$ source for temperate forest soil animals. Crotty et al. (2011) investigated the flow of labelled C and $N$ through soil food webs in grassland and woodland and found bacteria being an important nutrient source for secondary decomposers. Jesch et al. (2018) used ${ }^{15} \mathrm{~N}$ pulse labeling to test for belowground-resource partitioning in plants, potentially explaining positive biodiversity effects on ecosystem functioning, and found that other mechanisms than previously assumed must drive the positive biodiversity-ecosystem function relationship. Hence, while the investigation of natural stable isotope signatures in soil animals provide a snapshot of food web structures, labeling experiments allow investigating element fluxes, mechanisms and dynamics within soil food webs.

\subsection{Objectives and structure of the thesis}

In this thesis, we investigated the effects of plant community diversity (species richness, functional group richness and functional community composition) and fertilizer nitrogen on soil microorganisms and mesofauna. The first study (Chapter 2, Stability Study) focused on long-term effects of plant diversity and community composition on the spatial and temporal stability of soil microbial properties. In the second study (Chapter 3, Fertilization Study) we investigated the combined effects of changing plant diversity and nitrogen fertilization on soil microbial properties such as microbial biomass $\mathrm{C}$, microbial respiration and the microbial respiratory quotient $\left(\mathrm{qO}_{2}\right)$, a measure of microbial $\mathrm{C}$ use efficiency. In the third study (Chapter $4,{ }^{15} \mathrm{~N}$ Tracer Study), we analyzed the incorporation of isotopically labelled ${ }^{15} \mathrm{NH}_{4}{ }^{15} \mathrm{NO}_{3}$ into soil microbial biomass and soil mesofauna species to investigate the role of microorganisms as $\mathrm{N}$ source for soil animals and how this $\mathrm{N}$ incorporation is influenced by plant diversity and plant functional groups. We tested the following main hypothesis:

(1) Plant diversity increases the stability of soil microbial properties over the long-term, but plant functional groups exert contrasting effects on soil microorganisms due to their specific plant functional traits (Chapter2, Stability study).

(2) Fertilization of grassland with $\mathrm{N}$ amplifies the positive effects of high plant diversity (species richness and functional group richness) on soil microbial properties, such as soil microbial biomass and respiration (Chapter 3, Fertilization study).

(3) Adding labelled mineral $\mathrm{N}$ to the soil allows tracing the incorporation of microbial $\mathrm{N}$ into soil animal consumers and thereby identifying which mesofauna species rely on soil microorganisms as diet (Chapter $4,{ }^{15} \mathrm{~N}$ Tracer study).

(4) Certain plant community properties decrease the incorporation of mineral $\mathrm{N}$ into mesofauna species due to higher competition at high plant diversity, additional provisioning of $\mathrm{N}$ in presence of legumes (dilution effect), and higher competition in presence of grasses (Chapter 4). 


\subsection{References}

Abend, A.G., Smith, T.D., 1995. Differences in ratios of stable isotopes of nitrogen in long-finned pilot whales (Globicephala melas) in the western and eastern North Atlantic. ICES Journal of Marine Science 52, 837841.

Adhikari, K., Hartemink, A.E., 2016. Linking soils to ecosystem services - A global review. Geoderma 262, 101111. doi:10.1016/j.geoderma.2015.08.009

Anderson, J.M., 1975. The enigma of soil animal species diversity, in: Vanek, J. (Ed.), Progress in Soil Ecology. Academia, Publishing House of the Czechoslovak Academy of Science, Prague, pp. 51-58.

Anderson, T.-H., Domsch, K.H., 1985. Determination of ecophysiological maintenance carbon requirements of soil microorganisms in a dormant state. Biology and Fertility of Soils 1, 81-89. doi:10.1007/BF00255134

Bardgett, R.D., 2005. The Biology of Soil - A Community and Ecosystem Approach, 1st ed. Oxford University Press, Oxford. DOI:10.1093/acprof:oso/9780198525035.001.0001

Bardgett, R.D., Shine, A., 1999. Linkages between plant litter diversity, soil microbial biomass and ecosystem function in temperate grasslands. Soil Biology and Biochemistry 31, 317-321. doi:10.1016/S00380717(98)00121-7

Barnosky, A.D., Matzke, N., Tomiya, S., Wogan, G.O.U., Swartz, B., Quental, T.B., Marshall, C., McGuire, J.L., Lindsey, E.L., Maguire, K.C., Mersey, B., Ferrer, E.A., 2011. Has the Earth's sixth mass extinction already arrived? Nature 471, 51-57. doi:10.1038/nature09678

Barrios, E., 2007. Soil biota, ecosystem services and land productivity. Ecological Economics 64, 269-285. doi:10.1016/j.ecolecon.2007.03.004

Bengtsson, J., 1998. Which species? What kind of diversity? Which ecosystem function? Some problems in studies of relations between biodiversity and ecosystem function. Applied Soil Ecology 10, 191-199. doi:10.1016/S0929-1393(98)00120-6

Blume, H.-P., Brümmer, G.W., Horn, R., Kandeler, E., Kögel-Knabner, I., Kretzschmar, R., Stahr, K., Wilke, B.-M., Thiele-Bruhn, S., Welp, G., 2016. Scheffer/Schachtschnabel: Lehrbuch der Bodenkunde, 15th ed. Spektrum Akademischer Verlag Heidelberg Berlin, Heidelberg Berlin. doi:10.1007/978-3-662-499603

Bonkowski, M., Villenave, C., Griffiths, B., 2009. Rhizosphere fauna: The functional and structural diversity of intimate interactions of soil fauna with plant roots. Plant and Soil 321, 213-233. doi:10.1007/s11104-0090013-2

Brose, U., Dunne, J.A., Montoya, J.M., Petchey, O.L., Schneider, F.D., Jacob, U., 2012. Climate change in sizestructured ecosystems. Philosophical Transactions of The Royal Society B 367, 2903-2912. doi:10.1098/rstb.2012.0232

Brose, U., Jonsson, T., Berlow, E.L., Warren, P., Banasek-Richter, C., Bersier, L.-F., Blanchard, J.L., Brey, T., Carpenter, S.R., Cattin Blandenier, M.-F., Cushing, L., Ali Dawah, H., Dell, T., Edwards, F., Harper-Smith, S., Jacob, U., Ledger, M.E., Martinez, N.D., Memmott, J., Mintenbeck, K., Pinnegar, J.K., Rall, B.C., Rayner, T.S., Reumann, D.C., Ruess, L., Ulrich, W., Williams, R.J., Woodward, G., Coehn, J.E., 2006. Consumer-Resource Body-Size Relationships in Natural Food Webs. Ecology 87, 2411-2417.

Buscot, F., Varma, A., 2005. Microorganisms in Soils - Roles in Genesis and Functions, 1st ed. Springer-Verlag Berlin Heidelberg New York, Berlin Heidelberg.

Butchart, S.H.M., Walpole, M., Collen, B., van Strien, A., Scharlemann, J.P.W., Almond, R.E. a, Baillie, J.E.M., Bomhard, B., Brown, C., Bruno, J., Carpenter, K.E., Carr, G.M., Chanson, J., Chenery, A.M., Csirke, J., Davidson, N.C., Dentener, F., Foster, M., Galli, A., Galloway, J.N., Genovesi, P., Gregory, R.D., Hockings, M., Kapos, V., Lamarque, J.-F., Leverington, F., Loh, J., McGeoch, M. a, McRae, L., Minasyan, A., Hernández Morcillo, M., Oldfield, T.E.E., Pauly, D., Quader, S., Revenga, C., Sauer, J.R., Skolnik, B., Spear, D., StanwellSmith, D., Stuart, S.N., Symes, A., Tierney, M., Tyrrell, T.D., Vié, J.-C., Watson, R., 2010. Global biodiversity: indicators of recent declines. Science (New York, N.Y.) 328, 1164-1168. doi:10.1126/science.1187512

Cardinale, B.J., Duffy, J.E., Gonzalez, A., Hooper, D.U., Perrings, C., Venail, P., Narwani, A., Mace, G.M., Tilman, D., Wardle, D. a, Kinzig, A.P., Daily, G.C., Loreau, M., Grace, J.B., Larigauderie, A., Srivastava, D.S., Naeem, S., 2012. Biodiversity loss and its impact on humanity. Nature 486, 59-67. doi:10.1038/nature11148

Ceballos, G., Ehrlich, P.R., Barnosky, A.D., Garcia, A., Pringle, R.M., Palmer, T.M., 2015. Accelerated Modern Human-Induced Species Losses: Entering the Sixth Mass Extinction. Science Advances 1, e1400253e1400253. doi:\|url\{10.1126/sciadv.1400253\}

Chapin, F.S., Zavaleta, E.S., Eviner, V.T., Naylor, R.L., Vitousek, P.M., Reynolds, H.L., Hooper, D.U., Lavorel, S., Sala, O.E., Hobbie, S.E., Mack, M.C., Díaz, S., 2000. Consequences of changing biodiversity. Nature 405, 23442. doi:10.1038/35012241

Coleman, D.C., Reid, C.P.P., Cole, C. V, 1983. Biological Strategies of Nutrient Cycling in Soil Systems. Advances in Ecological Research 13, 1-55. 
Crotty, F. V., Adl, S.M., Blackshaw, R.P., Murray, P.J., 2012. Using stable isotopes to differentiate trophic feeding channels within soil food webs. Journal of Eukaryotic Microbiology 59, 520-526. doi:10.1111/j.15507408.2011.00608.x.

Crotty, F. V, Blackshaw, R.P., Murray, P.J., 2011. Tracking the flow of bacterially derived $13 \mathrm{C}$ and $15 \mathrm{~N}$ through soil faunal feeding channels. Rapid Communications in Mass Spectrometry : RCM 25, 1503-13. doi:10.1002/rcm.4945

Dawson, T.E., Siegwolf, R.T.W. (Eds.), 2007. Stable Isotopes as Indicators of Ecological Change, 1st ed. Elsevier Science AP Academic Press.

Dickson, T.L., Foster, B.L., 2011. Fertilization decreases plant biodiversity even when light is not limiting. Ecology Letters 14, 380-8. doi:10.1111/j.1461-0248.2011.01599.x

Eggers, T., Hefin Jones, T., 2000. You are what you eat...or are you? Trends in Ecology \& Evolution 15, 265-266. doi:10.1016/S0169-5347(00)01877-2

Eisenhauer, N., Bessler, H., Engels, C., Gleixner, G., Habekost, M., Milcu, A., Partsch, S., Sabais, C.W., Scherber, C., Steinbeiss, S., Weigelt, A., Weisser, W.W., Scheu, S., 2010. Plant diversity effects on soil microorganisms support the singular hypothesis. Ecology 91, 485-96.

Eisenhauer, N., Dobies, T., Cesarz, S., Hobbie, S.E., Meyer, R.J., Worm, K., Reich, P.B., 2013. Plant diversity effects on soil food webs are stronger than those of elevated $\mathrm{CO} 2$ and $\mathrm{N}$ deposition in a long-term grassland experiment. Proceedings of the National Academy of Sciences of the United States of America 110, 688994. doi:10.1073/pnas.1217382110

Eisenhauer, N., Lanoue, A., Strecker, T., Scheu, S., Steinauer, K., Thakur, M.P., Mommer, L., 2017. Root biomass and exudates link plant diversity with soil bacterial and fungal biomass. Scientific Reports 7. doi:10.1038/srep44641

Elton, C.S., 1958. The Ecology of Invasions by Animals and Plants. doi:10.1007/978-1-4899-7214-9

Endlweber, K., Ruess, L., Scheu, S., 2009. Collembola switch diet in presence of plant roots thereby functioning as herbivores. Soil Biology and Biochemistry 41, 1151-1154. doi:10.1016/j.soilbio.2009.02.022

Erisman, J.W., van Grinsven, H., Grizzetti, B., Bouraoui, F., Powlson, D., Sutton, M.A., Bleeker, A., Reis, S., 2011. The European nitrogen problem in a global perspective, in: The European Nitrogen Assessment. pp. 9-31. doi:10.1017/CBO9780511976988.005

Ferlian, O., Klarner, B., Langeneckert, A.E., Scheu, S., 2015. Trophic niche differentiation and utilisation of food resources in collembolans based on complementary analyses of fatty acids and stable isotopes. Soil Biology and Biochemistry 82, 28-35. doi:10.1016/j.soilbio.2014.12.012

Ferlian, O., Scheu, S., 2013. Shifts in trophic interactions with forest type in soil generalist predators as indicated by complementary analyses of fatty acids and stable isotopes. Oikos 1-10. doi:10.1111/j.16000706.2013.00848.x.

Fischer, M., Bossdorf, O., Gockel, S., Hänsel, F., Hemp, A., Hessenmöller, D., Korte, G., Nieschulze, J., Pfeiffer, S., Prati, D., Renner, S., Schöning, I., Schumacher, U., Wells, K., Buscot, F., Kalko, E.K.V., Linsenmair, K.E., Schulze, E.D., Weisser, W.W., 2010. Implementing large-scale and long-term functional biodiversity research: The Biodiversity Exploratories. Basic and Applied Ecology 11, 473-485. doi:10.1016/j.baae.2010.07.009

Galloway, J.N., Dentener, F.J., Capone, D.G., Boyer, E.W., Howarth, R.W., Seitzinger, S.P., Asner, G.P., Cleveland, C.C., Green, P.A., Holland, E.A., Karl, D.M., Michaels, A.F., Porter, J.H., Townsend, A.R., Vo, C.J., 2004. Nitrogen cycles: past, present, and future. Biogeochemistry 70, 153-226.

Galloway, J.N., Townsend, A.R., Erisman, J.W., Bekunda, M., Cai, Z., Freney, J.R., Martinelli, L. a, Seitzinger, S.P., Sutton, M. a, 2008. Transformation of the nitrogen cycle: recent trends, questions, and potential solutions. Science (New York, N.Y.) 320, 889-92. doi:10.1126/science.1136674

Haddad, N.M., Crutsinger, G.M., Gross, K., Haarstad, J., Tilman, D., 2011. Plant diversity and the stability of foodwebs. Ecology Letters 14, 42-46. doi:10.1111/j.1461-0248.2010.01548.x

Haubert, D., Langel, R., Scheu, S., Ruess, L., 2005. Effects of food quality, starvation and life stage on stable isotope fractionation in Collembola. Pedobiologia 49, 229-237. doi:10.1016/j.pedobi.2004.11.001

Hector, A., Schmid, B., Beierkuhnlein, C., Caldeira, M.C., Diemer, M., Dimitrakopoulos, P.G., Finn, J.A., Freitas, H., Giller, P.S., Good, J., Harris, R., Högberg, P., Huss-Danell, K., Joshi, J., Jumpponen, A., Körner, C., Leadley, P.W., Loreau, M., Minns, A., Mulder, C.P.H., O`Donovan, G., Otway, S.J., Pereira, J.S., Prinz, A., Read, D.J., Scherer-Lorenzen, M., Schulze, E.-D., Siamantziouras, A.-S.D., Spehn, E.M., Terry, A.C., Troumbis, A.Y., Woodward, F.I., Yachi, S., Lawton, J.H., 1999. Plant Diversity and Productivity Experiments in European Grasslands. Science 286, 1123-1127. doi:10.1126/science.286.5442.1123

Heemsbergen, D. a, Berg, M.P., Loreau, M., van Hal, J.R., Faber, J.H., Verhoef, H. a, 2004. Biodiversity effects on soil processes explained by interspecific functional dissimilarity. Science (New York, N.Y.) 306, 1019-20. doi:10.1126/science.1101865 
Hobbie, E., Weber, N., Trappe, J., 2001. Mycorrhizal vs saprotrophic status of fungi: the isotopic evidence. New Phytologist 601-610.

Hooper, D.U., Chapin, F.S., Ewel, J.J., Hector, A., Inchausti, P., Lavorel, S., Lawton, J.H., Lodge, D.M., Loreau, M., Naeem, S., Schmid, B., Setälä, H., Symstad, A.J., Vandermeer, J., Wardle, D.A., 2005. Effects Of Biodiversity On Ecosystem Functioning: A Consensus Of Current Knowledge. Ecological Monographs 75, 3-35.

Hyodo, F., 2015. Use of stable carbon and nitrogen isotopes in insect trophic ecology. Entomological Science n/a-n/a. doi:10.1111/ens.12128

Isbell, F., Reich, P.B., Tilman, D., Hobbie, S.E., Polasky, S., Binder, S., 2013. Nutrient enrichment, biodiversity loss, and consequent declines in ecosystem productivity. Proceedings of the National Academy of Sciences of the United States of America 110, 11911-6. doi:10.1073/pnas.1310880110

Ives, A.R., Carpenter, S.R., 2007. Stability and diversity of ecosystems. Science (New York, N.Y.) 317, 58-62. doi:10.1126/science.1133258

Jesch, A., Barry, K.E., Ravenek, J.M., Bachmann, D., Strecker, T., Weigelt, A., Buchmann, N., de Kroon, H., Gessler, A., Mommer, L., Roscher, C., Scherer-Lorenzen, M., 2018. Below-ground resource partitioning alone cannot explain the biodiversity-ecosystem function relationship: A field test using multiple tracers. Journal of Ecology. doi:10.1111/1365-2745.12947

Kuzyakov, Y., Xu, X., 2013. Competition between roots and microorganisms for nitrogen: Mechanisms and ecological relevance. New Phytologist. doi:10.1111/nph.12235

Layman, C.A., Araujo, M.S., Boucek, R., Hammerschlag-peyer, C.M., Harrison, E., Jud, Z.R., Matich, P., Rosenblatt, A.E., Vaudo, J.J., Yeager, L.A., Post, D.M., Bearhop, S., 2012. Applying stable isotopes to examine food-web structure : an overview of analytical tools 87, 545-562. doi:10.1111/j.1469-185X.2011.00208.x

Lefcheck, J.S., Byrnes, J.E.K., Isbell, F., Gamfeldt, L., Griffin, J.N., Eisenhauer, N., Hensel, M.J.S., Hector, A., Cardinale, B.J., Duffy, J.E., 2015. Biodiversity enhances ecosystem multifunctionality across trophic levels and habitats. Nature Communications 6, 1-7. doi:10.1038/ncomms7936

Leggewie, C., Welzer, H., 2009. Das Ende der Welt, wie wir sie kannten: Klima, Zukunft und die Chancen der Demokratie. S. Fischer Verlag.

Lemanski, K., Scheu, S., 2014. Fertilizer addition lessens the flux of microbial carbon to higher trophic levels in soil food webs of grassland. Oecologia 176, 487-496. doi:10.1007/s00442-014-3037-0

Loreau, M., 2000. Biodiversity and ecosystem functioning: recent theoretical advances. Oikos 91, 3-17. doi:10.1034/j.1600-0706.2000.910101.x

MacArthur, R., 1955. Fluctuations of Animal Populations and a Measure of Community Stability. Ecology 36, 533. doi:10.2307/1929601

Maraun, M., Erdmann, G., Fischer, B.M., Pollierer, M.M., Norton, R. a., Schneider, K., Scheu, S., 2011. Stable isotopes revisited: Their use and limits for oribatid mite trophic ecology. Soil Biology and Biochemistry 43, 877-882. doi:10.1016/j.soilbio.2011.01.003

May, R.M., 1973. Stability and complexity in model ecosystems. Princeton University Press.

McCann, K.S., 2000. The diversity-stability debate. Nature 405, 228-33. doi:10.1038/35012234

Millenium Ecosystem Assesment, 2005. Ecosystems and human well-being: Synthesis. Island Press, Washington, DC.

Minagawa, M., Wada, E., 1984. Stepwise enrichment of $15 \mathrm{~N}$ along food chains Further evidence and the relation between $\delta 15 \mathrm{~N}$ and animal age. Geochimica et Cosmochimica Acta 48, 1135-1140.

Moore, J.C., Berlow, E.L., Coleman, D.C., Ruiter, P.C., Dong, Q., Hastings, A., Johnson, N.C., McCann, K.S., Melville, K., Morin, P.J., Nadelhoffer, K., Rosemond, A.D., Post, D.M., Sabo, J.L., Scow, K.M., Vanni, M.J., Wall, D.H., 2004. Detritus, trophic dynamics and biodiversity. Ecology Letters 7, 584-600. doi:10.1111/j.1461-0248.2004.00606.x

Moore, J.C., McCann, K., De Ruiter, P.C., 2005. Modeling trophic pathways, nutrient cycling, and dynamic stability in soils. Pedobiologia 49, 499-510. doi:10.1016/j.pedobi.2005.05.008

Mora, C., Tittensor, D.P., Adl, S., Simpson, A.G.B., Worm, B., 2011. How many species are there on earth and in the ocean? PLoS Biology 9, 1-8. doi:10.1371/journal.pbio.1001127

Naeem, S., Thompson, L.J., Lawler, S.P., Lawton, J.H., Woodflin, R.M., 1994. Declining biodiversity can alter the performance of ecosystems. Letters to Nature 368, 734-737.

Nielsen, U.N., Osler, G.H.R., Campbell, C.D., Neilson, R., Burslem, D.F.R.P., van der Wal, R., 2010. The Enigma of Soil Animal Species Diversity Revisited: The Role of Small-Scale Heterogeneity. PLoS ONE 5, e11567. doi:10.1371/journal.pone.0011567

Odum, E.P., Biever, L.J., 1984. The University of Chicago Resource Quality, Mutualism , and Energy Partitioning in Food Chains. The American Naturalist 124, 360-376. doi:10.1086/284279

Pasquaud, S., Lobry, J., Elie, P., 2007. Facing the necessity of describing estuarine ecosystems : a review of food web ecology study techniques. Hydrobiologia 588, 159-172. doi:10.1007/s10750-007-0660-3 
Pimm, S.L., 1984. The complexity and stability of ecosystems. Nature. doi:10.1038/315635c0

Pimm, S.L., Russell, G.J., Gittleman, J.L., Brooks, T.M., Pimm, S.L., Russell, G.J., Gittleman, J.L., Brooks, T.M., 1995. The Future of Biodiversity. Science 269, 347-350.

Ponsard, S., Arditi, R., 2000. WHAT CAN STABLE ISOTOPES (?15N AND ?13C) TELL ABOUT THE FOOD WEB OF SOIL MACRO-INVERTEBRATES? Ecology 81, 852-864. doi:DOI: 10.1890/00129658(2000)081[0852:WCSINA]2.0.CO;2

Post, D., 2002. Using stable isotopes to estimate trophic position: models, methods, and assumptions. Ecology 83, 703-718.

Potapov, A.M., Tiunov, A. V, Scheu, S., 2019. Uncovering trophic positions and food resources of soil animals using bulk natural stable isotope composition. Biological Reviews 94, 37-54.

Reich, P.B., Hobbie, S.E., Lee, T., Ellsworth, D.S., West, J.B., Tilman, D., Knops, J.M.H., Naeem, S., Trost, J., 2006. Nitrogen limitation constrains sustainability of ecosystem response to CO2. Nature 440, 922-5. doi:10.1038/nature04486

Reich, P.B., Knops, J., Tilman, D., Craine, J., Ellsworth, D., Tjoelker, M., Lee, T., Wedin, D., Naeem, S., Bahauddin, D., Hendrey, G., Jose, S., Wrage, K., Goth, J., Bengston, W., 2001. Plant diversity enhances ecosystem responses to elevated CO2 and nitrogen deposition. Nature 410, 809-812. doi:10.1038/35081122

Ripple, W.J., Wolf, C., Newsome, T.M., Galetti, M., Alamgir, M., Crist, E., Mahmoud, M.I., Laurance, W.F., 2017. World Scientists' Warning to Humanity: A Second Notice. BioScience 67, 1026-1028. doi:10.1093/biosci/bix125

Roscher, C., Schumacher, J., Baade, J., 2004. The role of biodiversity for element cycling and trophic interactions: an experimental approach in a grassland community. Basic and Applied Ecology 5, $107-121$.

Roscher, C., Schumacher, J., Lipowsky, A., Gubsch, M., Weigelt, A., Pompe, S., Kolle, O., Buchmann, N., Schmid, B., Schulze, E.D., 2013. A functional trait-based approach to understand community assembly and diversityproductivity relationships over 7 years in experimental grasslands. Perspectives in Plant Ecology, Evolution and Systematics 15, 139-149. doi:10.1016/j.ppees.2013.02.004

Ruttan, V.W., Pimentel, D., Url, S., 1975. Food Production and the Energy Crisis: A Comment. Science 187, 560561.

Scherber, C., Eisenhauer, N., Weisser, W.W., Schmid, B., Voigt, W., Fischer, M., Schulze, E.-D., Roscher, C., Weigelt, A., Allan, E., Bessler, H., Bonkowski, M., Buchmann, N., Buscot, F., Clement, L.W., Ebeling, A., Engels, C., Halle, S., Kertscher, I., Klein, A.-M., Koller, R., König, S., Kowalski, E., Kummer, V., Kuu, A., Lange, M., Lauterbach, D., Middelhoff, C., Migunova, V.D., Milcu, A., Müller, R., Partsch, S., Petermann, J.S., Renker, C., Rottstock, T., Sabais, A., Scheu, S., Schumacher, J., Temperton, V.M., Tscharntke, T., 2010. Bottom-up effects of plant diversity on multitrophic interactions in a biodiversity experiment. Nature 468, 553-6. doi:10.1038/nature09492

Scheu, S., 2002. The soil food web: Structure and perspectives. European Journal of Soil Biology 38, 11-20. doi:10.1016/S1164-5563(01)01117-7

Scheu, S., Falca, M., 2000. The soil food web of two beech forests ( Fagus sylvatica ) of contrasting humus type: stable isotope analysis of a macro- and a mesofauna-dominated community. Oecologia 123, 285-296. doi:10.1007/s004420051015

Scheu, S., Folger, M., 2004. Single and mixed diets in Collembola: Effects on reproduction and stable isotope fractionation. Functional Ecology 18, 94-102. doi:10.1046/j.0269-8463.2004.00807.x

Scheunemann, N., Pausch, J., Digel, C., Kramer, S., Scharroba, A., Kuzyakov, Y., Kandeler, E., Ruess, L., Butenschoen, O., Scheu, S., 2016. Incorporation of root $\mathrm{C}$ and fertilizer $\mathrm{N}$ into the food web of an arable field: Variations with functional group and energy channel. Food Webs 9, 39-45. doi:10.1016/j.fooweb.2016.02.006

Schmidt, O., Curry, J.P., Dyckmans, J., Rota, E., Scrimgeour, C.M., 2004. Dual stable isotope analysis ( $\delta 13 \mathrm{C}$ and $\delta 15 N)$ of soil invertebrates and their food sources. Pedobiologia 48, 171-180. doi:10.1016/j.pedobi.2003.12.003

Schneider, F.D., Scheu, S., Brose, U., 2012. Body mass constraints on feeding rates determine the consequences of predator loss. Ecology Letters 15, 436-443. doi:10.1111/j.1461-0248.2012.01750.x

Schneider, K., Migge, S., Norton, R. a., Scheu, S., Langel, R., Reineking, A., Maraun, M., 2004. Trophic niche differentiation in soil microarthropods (Oribatida, Acari): Evidence from stable isotope ratios (15N/14N). Soil Biology and Biochemistry 36, 1769-1774. doi:10.1016/j.soilbio.2004.04.033

Schröder, J.J., 2014. The Position of Mineral Nitrogen Fertilizer in Efficient Use of Nitrogen and Land : A Review. Natural Resources 5, 936-948. doi:10.4236/nr.2014.515080

Sechi, V., D’Annibale, A., Ambus, P., S??rossy, Z., Krogh, P.H., Eriksen, J., Holmstrup, M., 2014. Collembola feeding habits and niche specialization in agricultural grasslands of different composition. Soil Biology and Biochemistry 74, 31-38. doi:10.1016/j.soilbio.2014.02.019 
Stachowicz, J.J., Whitlatch, R.B., Osman, R.W., 1999. Species Diversity and Invasion Resistance in a Marine Ecosystem. Science 286, 1577-1579.

Stevens, C.J., Duprè, C., Dorland, E., Gaudnik, C., Gowing, D.J.G., Bleeker, A., Diekmann, M., Alard, D., Bobbink, R., Fowler, D., Corcket, E., Mountford, J.O., Vandvik, V., Aarrestad, P.A., Muller, S., Dise, N.B., 2010. Nitrogen deposition threatens species richness of grasslands across Europe. Environmental Pollution (Barking, Essex : 1987) 158, 2940-5. doi:10.1016/j.envpol.2010.06.006

Streit, B., 2006. Biozahl 2006 - 2 Millionen-Grenze erreicht. Natur Und Museum, Senckenbergische Naturforschende Gesellschaft 136, 131-134.

Tilman, D., Downing, J., 1994. Biodiversity and stability in grasslands. Nature 367, 363-365.

Tilman, D., Isbell, F., Cowles, J.M., 2014. Biodiversity and Ecosystem Functioning. The Annual Review of Ecology, Evolution, and Systematics 45, 471-493. doi:10.1126/science.1064088

Tiunov, A. V., Semenina, E.E., Aleksandrova, A. V., Tsurikov, S.M., Anichkin, A.E., Novozhilov, Y.K., 2015. Stable isotope composition ( $\delta 13 \mathrm{C}$ and $\delta 15 \mathrm{~N}$ values) of slime molds: placing bacterivorous soil protozoans in the food web context. Rapid Communications in Mass Spectrometry 29, 1465-1472. doi:10.1002/rcm.7238

van Diepen, L.T. a., Lilleskov, E. a., Pregitzer, K.S., Miller, R.M., 2010. Simulated Nitrogen Deposition Causes a Decline of Intra- and Extraradical Abundance of Arbuscular Mycorrhizal Fungi and Changes in Microbial Community Structure in Northern Hardwood Forests. Ecosystems 13, 683-695. doi:10.1007/s10021-0109347-0

Vitousek, P., Aber, J., 1997. Human alteration of the global nitrogen cycle: sources and consequences. Ecological Applications 7, 737-750.

Wall, D.H., Adams, G., Parsons, A.N., 2001. Soil Biodiversity, in: Chapin III, S.F., Sala, O.E., Huber-Sannwald, E. (Eds.), Biodiversity in a Changing Environment - Scenarios for the 21 Century. Springer-Verlag New York, New York, pp. 47-82.

Weigelt, A., Schumacher, J., Roscher, C., Schmid, B., 2008. Does biodiversity increase spatial stability in plant community biomass? Ecology Letters 11, 338-47. doi:10.1111/j.1461-0248.2007.01145.x

Weigelt, A., Weisser, W.W., Buchmann, N., Scherer-Lorenzen, M., 2009. Biodiversity for multifunctional grasslands: equal productivity in high-diversity low-input and low-diversity high-input systems. Biogeosciences 6, 1695-1706. doi:10.5194/bg-6-1695-2009

Weisser, W.W., Roscher, C., Meyer, S.T., Ebeling, A., Luo, G., Allan, E., Beßler, H., Barnard, R.L., Buchmann, N., Buscot, F., Engels, C., Fischer, C., Fischer, M., Gessler, A., Gleixner, G., Halle, S., Hildebrandt, A., Hillebrand, H., de Kroon, H., Lange, M., Leimer, S., Le Roux, X., Milcu, A., Mommer, L., Niklaus, P.A., Oelmann, Y., Proulx, R., Roy, J., Scherber, C., Scherer-Lorenzen, M., Scheu, S., Tscharntke, T., Wachendorf, M., Wagg, C., Weigelt, A., Wilcke, W., Wirth, C., Schulze, E.D., Schmid, B., Eisenhauer, N., 2017. Biodiversity effects on ecosystem functioning in a 15-year grassland experiment: Patterns, mechanisms, and open questions. Basic and Applied Ecology 23, 1-73. doi:10.1016/j.baae.2017.06.002

Wilson, E.O., 1988. Biodiversity. National Academy Press Washington D.C., Washington, D.C. doi:10.17226/989

World Scientists' Warning to Humanity, 1992. Union of Concerned Scientists, Cambridge, MA. www.ucsusa.org Yodzis, P., 1981. The stability of real ecosystems. Nature 289, 674-676.

Zieger, S.L., Holczinger, A., Sommer, J., Rath, M., Kuzyakov, Y., Polle, A., Maraun, M., Scheu, S., 2017. Beech trees fuel soil animal food webs via root-derived nitrogen. Basic and Applied Ecology 22, 28-35. doi:10.1016/j.baae.2017.06.006. 
2 Functional composition of plant communities determines the spatial and temporal stability of soil microbial properties in a longterm plant diversity experiment

Tanja Strecker, Odette González Macé, Stefan Scheu and Nico Eisenhauer

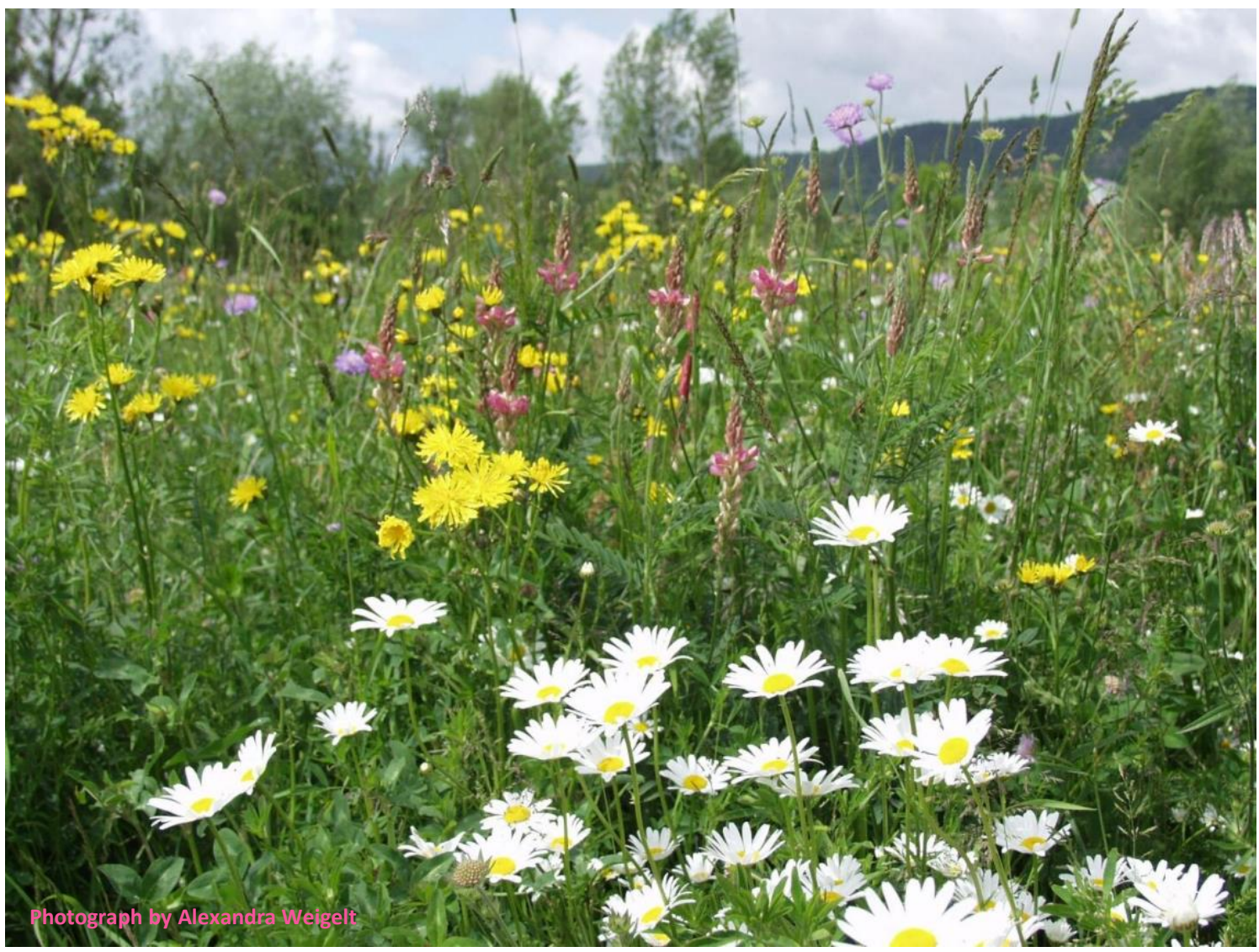

Published in:

Strecker T, Gonzalez Mace O, Scheu S, Eisenhauer E (2016) Functional composition of plant communities determine the spatial and temporal stability of soil microbial properties in a longterm plant diversity experiment, Oikos 125: 1743-1754, DOI: 10.1111/oik.03181. 


\subsection{Abstract}

Stable provisioning of ecosystem functions and services is crucial for human well-being in a changing world. Two essential ecological components driving vital ecosystem functions in terrestrial ecosystems are plant diversity and soil microorganisms. In this study, we tracked soil microbial basal respiration and biomass over a time period of 12 years in a grassland biodiversity experiment (the Jena Experiment) and examined the role of plant diversity and plant functional group composition for the spatial and temporal stability of soil microbial properties (basal respiration and biomass) in bulksoil. Spatial and temporal stability were calculated as the inverse coefficient of variation $\left(\mathrm{CV}^{-1}\right)$ of soil microbial respiration and biomass measured from soil samples taken over space and time, respectively. We found that 1) plant species richness consistently increased soil microbial properties after a time lag of four years since the establishment of the experimental plots, 2) plant species richness had minor effects on the spatial stability of soil microbial properties, whereas 3 ) the functional composition of plant communities significantly affected spatial stability of soil microbial properties, with legumes and tall herbs reducing both the spatial stability of microbial respiration and biomass, while grasses increased the latter, and 4) the effect of plant diversity on temporal stability of soil microbial properties turned from being negative to neutral, suggesting that the recovery of soil microbial communities from former arable land-use takes more than a decade. Our results highlight the importance of plant functional group composition for the spatial and temporal stability of soil microbial properties, and hence for microbially-driven ecosystem processes, such as decomposition and element cycling, in temperate semi-natural grassland. 


\subsection{Introduction}

The provisioning of ecosystem functions and services is a prerequisite for human well-being. In the face of unprecedented environmental changes caused by anthropogenic activities, debates among ecologists arose regarding the biotic and abiotic factors driving ecosystem functioning and stability (McCann 2000). Especially global changes in land-use and climate trigger complex shifts within ecosystems, resulting in declines of global biodiversity and threatening the provisioning of ecosystem services (Chapin et al. 2000). Biodiversity is a crucial determinant of ecosystem functioning (Chapin et al. 2000, Hooper et al. 2005) as it enhances ecosystem functions and services like primary productivity, element cycling and food production (Chapin et al. 2000, Isbell et al. 2011), and insures ecosystems against loss of functioning in case of species extinctions (Yachi and Loreau 1999). Spatial and temporal stability of ecosystem processes (Weigelt et al. 2008, Isbell et al. 2015) are essential ingredients for reliable ecosystem functioning (McCann 2000). Different types of stability have been investigated, including resistance, resilience (Pimm 1984), and reliability (Milcu et al. 2 010). Stability of community properties can be caused by multiple mechanisms: complementarity (Marquard et al. 2009), overyielding (Lehman and Tilman 2000), negative covariance (Roscher et al. 2011b), competitive interactions among species (Lehman and Tilman 2000), and statistical averaging (Roscher et al. 2011b). Thus, current theory and results of recent experiments suggest that biodiversity and stability of ecosystem functions and services are closely related (Tilman et al. 2014). Most studies on plant diversity and ecosystem stability focused on the stability of plant productivity. Here, we explore the effects of plant diversity and plant community composition on the stability of soil microbial properties, as plant (diversity) effects have been reported to cascade not only to higher trophic levels (Scherber et al. 2010) but also into the belowground system (Milcu et al. 2010). The majority of processes in soil are mediated by microorganisms, i.e. bacteria and fungi, pointing to the central role of these organisms for ecosystem functioning (van der Heijden et al. 2008). For example, microbial mineralization of organic materials and provisioning of nutrients to plants are essential ecosystem processes that provide the basis for other ecosystem functions, such as primary productivity. Recent studies found plant species richness and community composition to be important drivers of soil microbial properties, such as microbial biomass, activity, community structure (Eisenhauer et al. 2013, Lange et al. 2015), and also stability of soil microbial denitrification (McGill et al. 2010). Effects of plant species diversity on belowground processes have been assumed to be due to more constant and higher plant-derived resource inputs (Milcu et al. 2010), and more constant soil moisture levels (Wardle 1992), as well as higher probability of synergistic interactions among plant species at higher plant diversity (Massaccesi et al. 2015). Plant species richness as well as functional group richness have been shown to increase the spatial stability of plant biomass production due to several mechanisms, such as plant density (Eisenhauer et al. 2011c), resulting in 
more complete niche occupation (Milcu et al. 2010). These stabilizing effects of plant diversity on plant productivity may cascade to belowground detritivore food webs as they also benefit from more constant and more homogenous inputs of plant-derived resources (Milcu et al. 2010, Kuzyakov and Blagodatskaya 2015). Further, temporal stability of ecosystem properties, such as plant productivity and soil microbial activity, has been shown to change with plant species richness due to temporally increasing complementarity effects (Marquard et al. 2009, Eisenhauer et al. 2010, Reich et al. 2012). These studies also suggest that plant diversity effects strengthen over time, thus likely stabilizing processes driven by soil microorganisms and soil fauna (Eisenhauer et al. 2011a). In addition to species diversity, plant functional groups impact the spatial and temporal stability of primary productivity (Weigelt et al. 2008). In particular grasses have been shown to increase both spatial and temporal stability of plant productivity, probably due to their dense, evenly distributed root system, clonal growth (Weigelt et al. 2008), and long persistence of genets of some grass species (De Witte and Stöcklin 2010). Uniform root distribution and plant-derived inputs to the belowground system likely also increase temporal and spatial stability of microbial communities. Moreover, the ability of grasses to stimulate microbial activity through enhanced root exudation after mowing (Hamilton and Frank 2001) in combination with the management practice typical in European grasslands (mowing several times per year) likely fuel soil microorganisms resulting in increased spatial stability of microbial communities and microbially-driven soil processes. Small herbs may also increase the spatial and temporal stability of microbial communities due to even soil surface coverage and shallow roots. Moreover, temporal asynchrony (negative covariance) between small herb species (Roscher et al. 2011b) likely increases the stability of microbial communities. In contrast to grasses and small herbs, the presence of legumes was reported to decrease the spatial and temporal stability of plant productivity (Eisenhauer et al. 2011c) due to the improvement of soil $\mathrm{N}$ availability within the legume rhizosphere, leading to patchy N provisioning (Spehn et al. 2002, Weigelt et al. 2008). As processes in the rhizosphere are highly dynamic in time due to continuous root growth and root exudation (Kuzyakov and Blagodatskaya 2015), variations in legume-derived $\mathrm{N}$ resources are likely to result in spatially and temporally more variable microbial communities and processes. Similarly, tall herbs are associated with patchy nutrient distribution, e.g. due to the formation of tap-roots and high local resource input (Sydes and Grime 1984). Also, in herbs fine root turnover is higher than in grasses, enhancing the dynamics of $C$ and $N$ inputs in the soil (Fornara et al. 2009).

In this study, we measured the spatial and temporal stability of soil microbial biomass and respiration in a long-term plant diversity experiment in temperate semi-natural grassland (Jena Experiment; Roscher et al. 2004). We used a unique long-term dataset on annually measured soil microbial properties from 2003 to 2014. To account for the establishment phase of the experiment (Eisenhauer et al. 2012), we grouped the time series into three phases, each spanning four years. We expected 
temporal stability of soil microbial biomass and respiration to decrease with increasing plant diversity in phase 1 of the experiment due to the consolidation of the establishment of a semi-natural grassland (Habekost et al. 2008, Eisenhauer et al. 2010) (phase 1: short-term; Fig. 1). As effects of plant diversity strengthen over time (Eisenhauer et al. 2011b, 2012, Reich et al. 2012), we expected temporal stability of soil microorganisms to vary little with plant diversity after five to eight years (phase 2: intermediate-term). After fading of history effects of former land use, we expected the relationship between plant diversity and soil microbial biomass and activity to turn positive (Reich et al. 2012, Tilman et al. 2014; phase 3: long-term). We tested the hypotheses that:

1) the relationships between soil microbial properties (respiration and biomass $\mathrm{C}$ ) and plant diversity are positive and strengthen over time;

2) plant diversity increases the spatial stability of soil microbial properties;

3) plant diversity decreases the temporal stability of soil microbial properties during phase 1 , does not significantly affect it in phase 2 , and increases it in phase 3 of the experiment;

4) plant functional groups differentially affect the stability of soil microbial properties with legumes and tall herbs decreasing spatial and temporal stability of microbial biomass and respiration, and grasses and small herbs increasing them.

These hypotheses were tested by analysing soil microbial properties over time as well as the (change of) spatial and temporal stability of soil microbial biomass and respiration in grassland plots of different levels of plant species richness, plant functional group richness, and in the presence/absence of the four above-mentioned plant functional groups.

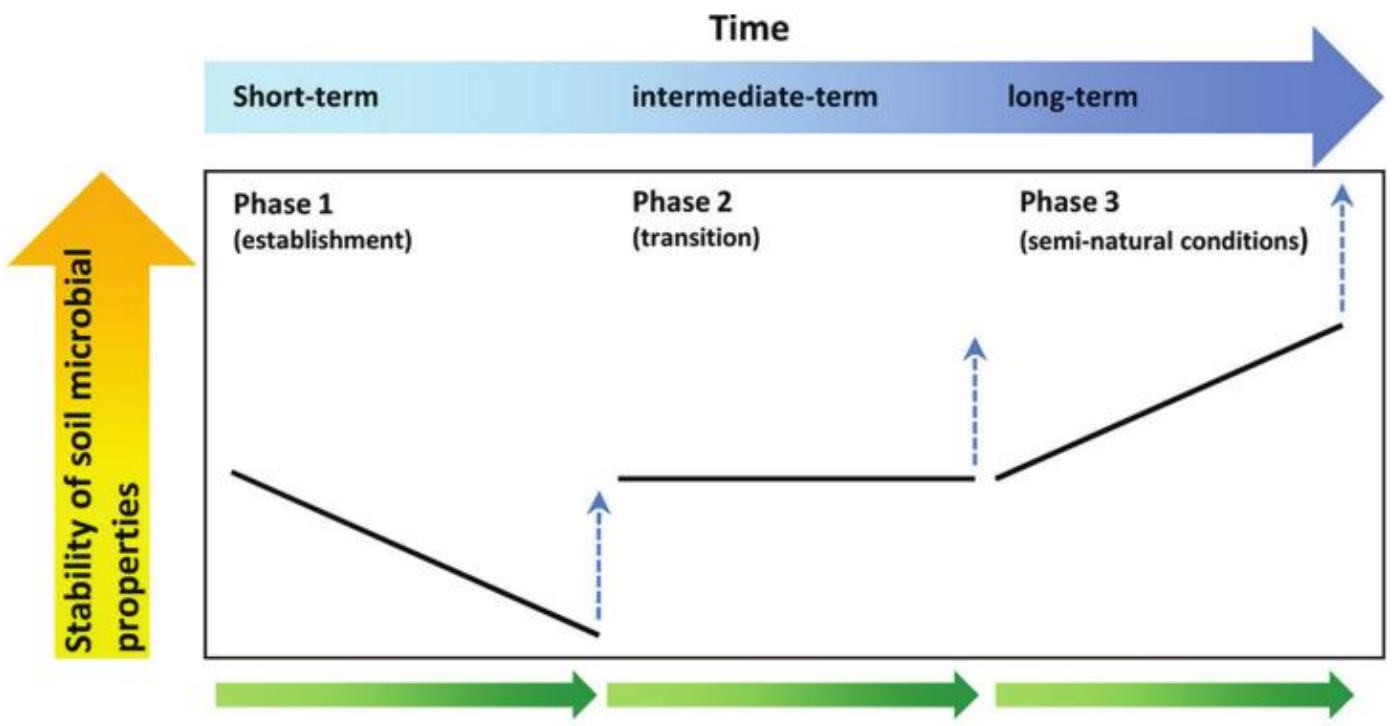

Plant species diversity

Figure 1. Conceptual depiction of the hypothesized relationships between plant species diversity and stability of soil microbial properties (i.e. microbial biomass and respiration in the present study) and time. 


\subsection{Material and methods}

\section{Study site}

The experiment was performed on the field site of the Jena Experiment, a long-term biodiversity experiment focusing on the role of plant diversity for ecosystem functioning in semi-natural grassland (Roscher et al. 2004). The study site is situated in the floodplain of the Saale River near the city of Jena (Thuringia, Germany, $50^{\circ} 55^{\prime} \mathrm{N}, 11^{\circ} 35^{\prime} \mathrm{E}, 130 \mathrm{~m}$ a.s.l.). The soil is an Eutric Fluvisol (FAOUnesco 1997) developed from fluvial sediments. Mean annual temperature is $9.3^{\circ} \mathrm{C}$, and mean annual precipitation is $587 \mathrm{~mm}$ (Supplementay material Appendix 1). Prior to the establishment of the Jena Experiment in May 2002, the site had been used as arable field for about 40 years. The plant communities established in the Jena Experiment were assembled from local plant species (belonging to Molinio-enateretea meadows, Arrhenaterion community, Ellenberg 1996) typical for hay meadows in central Europe (for complete species list see Roscher et al. 2004).

\section{Experimental design}

A plant species richness gradient comprising communities with 1, 2, 4, 8, 16 and 60 plant species and a plant functional group richness gradient with 1, 2, 3 and 4 different plant functional groups were established from a pool of 60 plant species (for details see Roscher et al. 2004). Plant species were ascribed to functional groups using cluster analysis based on above- and belowground morphological traits, phenological traits, and $\mathrm{N}_{2}$ fixation (Roscher et al. 2004). The 60 species were grouped into grasses (16 species), small herbs (12 species), tall herbs (20 species), and legumes (12 species).The experiment consisted of 82 plots of $20 \times 20 \mathrm{~m}$. Plots were mown twice a year in June and September and weeded in April, July and September to maintain the target plant species composition. Plots were grouped into four blocks accounting for soil heterogeneity at the field site (Fig. 2). Each block contained an equal number of plots of plant species and plant functional group richness levels (Roscher et al. 2004).

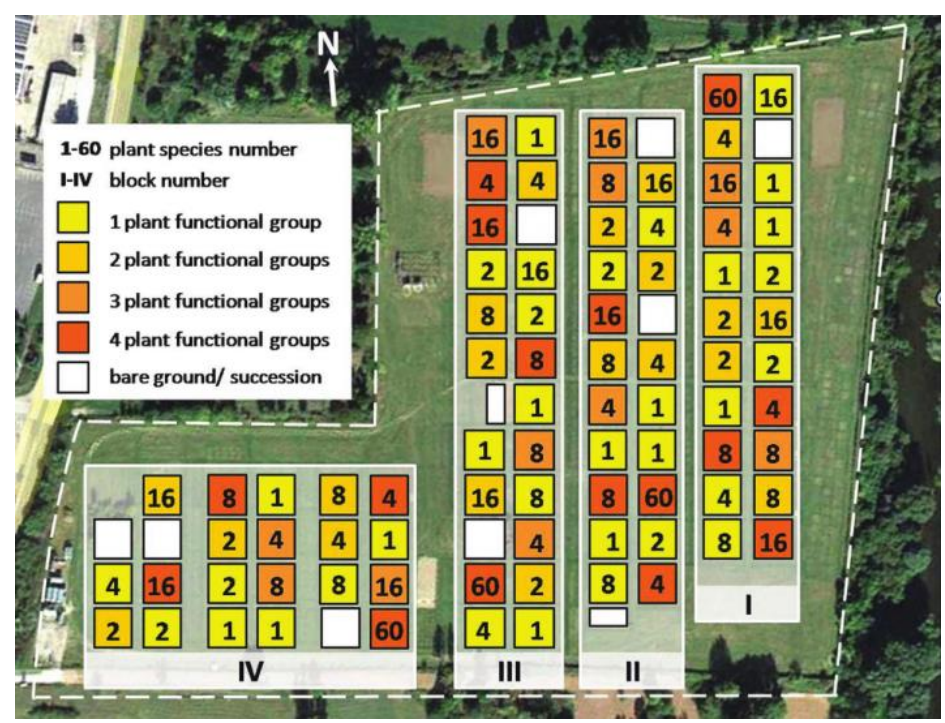

Figure 2. Schematic design of the experimental field site of the Jena Experiment. Each square represents one plot $(20 \times 20 \mathrm{~m})$ with different number of plant species (number in the plots) and functional groups (colour of the plot). The dotted line indicates the border of the experimental field. Bare ground and succession plots were not included in the present study. 


\section{Soil sampling}

Two different samplings were carried out. For measuring spatial stability, five soil cores were taken on each plot with a soil corer ( $1.5 \mathrm{~cm}$ diameter, $10 \mathrm{~cm}$ deep) in September 2010, i.e. eight years after establishment of the experiment (resulting in 82 plots $\times 5$ samples $=410$ samples). The samples were taken using a fixed spatial pattern with distances of 1-2 m among samples. For temporal stability, eleven sampling campaigns were carried out in May or early June from 2003 to 2014, with five subsamples per plot that were pooled plot-wise, resulting in one soil sample per plot (except for 2005; resulting in 82 plots $\times 11$ years $=902$ samples). In each year, five randomly located soil samples were taken per plot with a soil corer ( $5 \mathrm{~cm}$ diameter, $5 \mathrm{~cm}$ deep) and pooled plot-wise. Before measuring, all samples were homogenized, sieved $(2 \mathrm{~mm})$, larger roots and soil animals were picked by hand, and samples were stored in plastic bags at $5^{\circ} \mathrm{C}$. In June 2013, the Jena Experiment experienced a summer flood (Wagner et al. 2015, Wright et al. 2015), which occurred before the soil sampling in 2013 and did not affect soil microbial properties in May 2014, which is why we do not consider flood effects in the present study.

\section{Soil microbial basal respiration and biomass $\mathrm{C}$}

Microbial respiration was measured using an electrolytic $\mathrm{O}_{2}$-microcompensation apparatus (Scheu 1992). $\mathrm{O}_{2}$-consumption of soil microorganisms in $\sim 5 \mathrm{~g}$ of fresh soil (equivalent to ca $3.5 \mathrm{~g}$ soil dry weight) was measured at $22^{\circ} \mathrm{C}$ over a period of $24 \mathrm{~h}$. Basal respiration $\left[\mu \mathrm{O}_{2} \mathrm{~g}^{-1} \mathrm{dry}_{\text {soil h}}{ }^{-1}\right]$ was calculated as mean of the $\mathrm{O}_{2}$-consumption rates of hours 14 to 24 after the start of the measurements. Substrate-induced respiration (SIR) was determined by adding D-glucose to saturate catabolic enzymes of the microorganisms according to preliminary studies (4 mg D-glucose $\mathrm{g}^{-1} \mathrm{dry}$ soil solved in $400 \mu$ l deionized water; Anderson and Domsch 1978). The maximum initial respiratory response (MIRR; $\left[\mu \mathrm{O} \mathrm{O} 2 \mathrm{~g}^{-1}\right.$ dry soil $\left.\mathrm{h}^{-1}\right]$ ) was calculated as mean of the lowest three $\mathrm{O}^{2}$-consumption values within the first $10 \mathrm{~h}$ after glucose addition. Microbial biomass carbon [ $\mu \mathrm{g} \mathrm{C} \mathrm{g}^{-1} \mathrm{dry}$ soil] was calculated as $38 \times$ MIRR (Beck al. 1997). Beck et al. (1997) found that, except for acidic soils, the SIR method is comparable to other methods estimating soil microbial biomass $\mathrm{C}$ like the fumigation extraction method introduced by Vance et al. (1987).

\section{Calculations}

Stability of microbial parameters was calculated as the inverse coefficient of variation $\left(\mathrm{CV}^{-1}=\right.$ mean/standard deviation), i.e. the ratio of mean biomass or respiration to its standard deviation (Haddad et al. 2011). Hence, the spatial stability was calculated by dividing the mean value of the five measurements of each plot taken in 2010 by the standard deviation of these five measurements (Eisenhauer et al. 2011c). For temporal stability, we grouped the measurements of three or four 
consecutive years and calculated the temporal stability for every phase (phase 1: 2003-2006; phase 2: 2007-2010; phase 3: 2011-2014).

\section{Statistical analyses}

Data were tested for normality (Shapiro-Wilk-test) and homoscedasticity (Levene's test) and logtransformed if necessary to achieve requirements for general linear models (GLM) and repeated measures GLM. For testing the effects of plant community properties on spatial stability of microbial parameters, we used sequential GLMs (type I sum of squares). For effects on temporal stability of microbial parameters, we used repeated measures GLMs. Plant species richness was log-transformed to linearize the saturating relationship between plant diversity and microbial properties (Hooper et al. 2005). Block and presence of grasses (GR), tall herbs (TH), small herbs (SH) and legumes (LEG) were used as categorical predictor variables, while log-transformed plant species richness (SR) and plant functional group richness (FGR) were tested as linear variables. Stability of microbial basal respiration and stability of microbial biomass carbon served as response variables for temporal and spatial stability. F-values given in the results refer to those where the respective factor was fitted first in the sequential model (Schmid et al. 2002). Calculation of temporal stability was based on the three phases. As measures from year 2005 were lacking, phase 1 (2003-2006) consisted of three years, while phase 2 (2007-2010) and phase 3 (2011-2014) consisted of four years each. To test whether the different numbers of years within the three phases affected the results of the temporal stability analysis, we systemically excluded step-by-step one year after the other from phases 2 and 3 , and tested our model with different combinations of years within the respective phases. Reducing the numbers of years from four to three measurements in phases 2 and 3 , and altering the combination of year identity within these phases did not change the main conclusions of our work. Therefore, we included the results of the full dataset in the main text and give the results of the additional models in the supplementary material (SM A2). We additionally tested the effects of plant species richness on microbial respiration and biomass from 2003 to 2014 (time series) with repeated measures GLM to trace the change of the plant species richness effect over time (Eisenhauer et al. 2010).

\section{Data deposition}

Data are available from the open access library PANGAEA

(http://doi.pangaea.de/10.1594/PANGAEA.854694). 


\subsection{Results}

\section{Soil microbial respiration and biomass C over time}

Soil microbial respiration and biomass increased significantly with plant species richness four years after establishment of the experiment (Fig. 3A-B), and this positive relationship persisted until the last measurement of the present time series in 2014. Furthermore, the slope of the relationship between microbial respiration and plant species richness was highest seven years after the establishment of the experiment, while the slope of the relationship between microbial biomass $C$ and plant species richness peaked only after 11 years (Fig. 4).
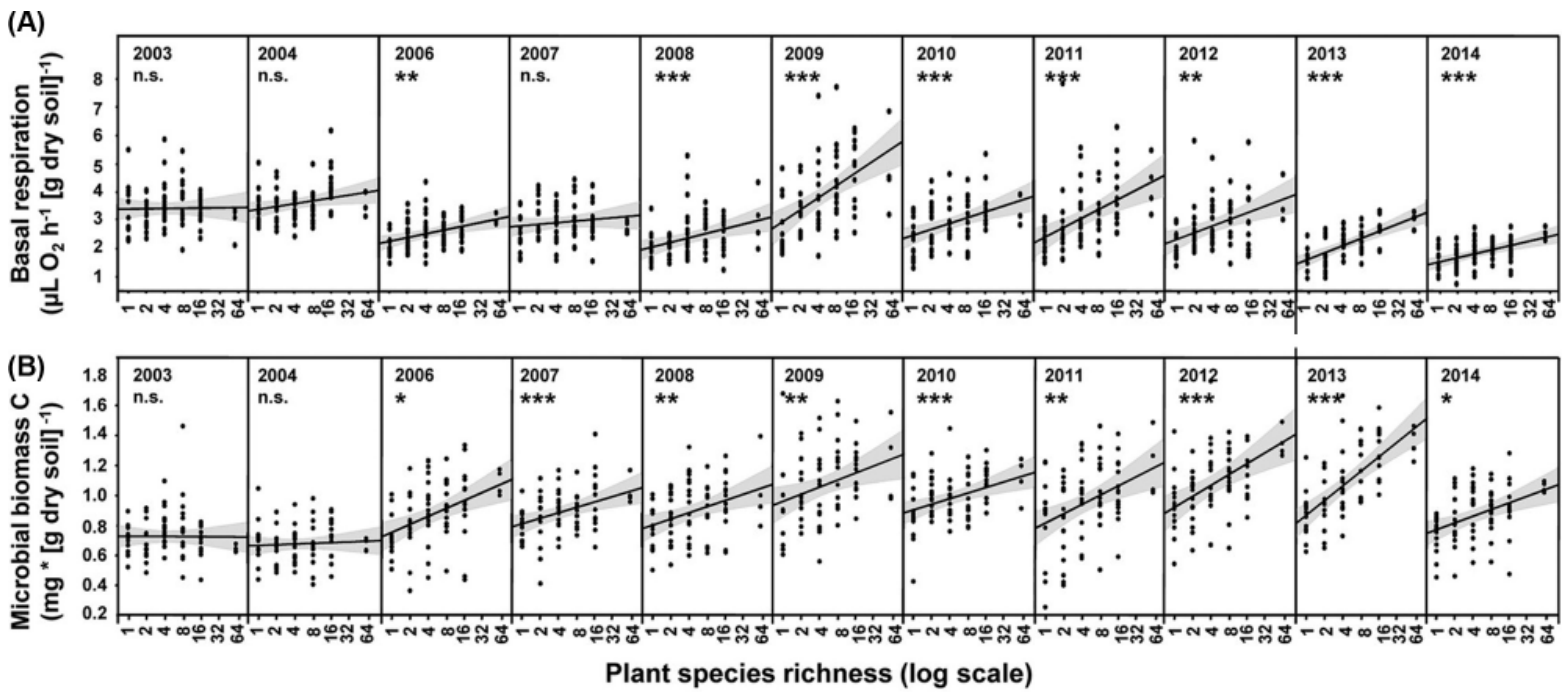

Figure 3. Soil microbial respiration (A) and biomass C (B) as affected by plant species richness from 2003 to 2014 (except 2005). Regression lines (black) with 95\% confidence intervals (grey). Asterisks indicate significant effects of plant species richness within years $\left(*, p \leq 0.05 ; *, p \leq 0.01 ;{ }^{* * *}, p \leq 0.001 ;\right.$ n.s., not significant).

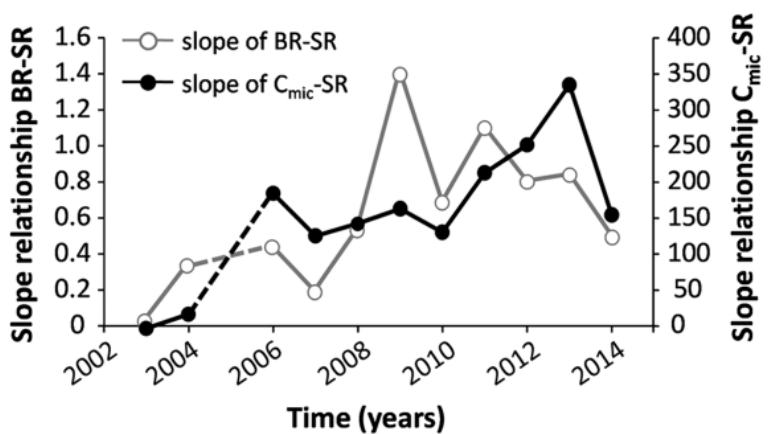

Figure 4. Slopes of the relationships between microbial basal respiration (BR) and plant species richness (SR), and between microbial biomass C (Cmic) and plant species richness from 2003 to 2014. Dotted lines are used where measurements (in 2005) were missing.

\section{Spatial stability of soil microbial properties}

Plant species richness and functional group richness did not significantly affect spatial stability of soil microbial parameters, but increased the means of both soil microbial respiration and biomass (Table 1). In contrast, plant functional group richness significantly increased the standard deviation of soil 
microbial biomass. Among plant functional groups, legumes significantly reduced the spatial stability of both microbial respiration and biomass (Fig. 5A, G). Legumes significantly increased the mean of microbial biomass, but even more they increased the standard deviations of both microbial respiration and biomass, indicating destabilization of microbial communities in space (Fig. 5H, C, I). In addition, tall herbs significantly reduced the spatial stability of microbial respiration (Fig. 5D) and in trend microbial biomass. Further, tall herbs significantly increased the mean of soil microbial biomass. In the presence of grasses, the spatial stability of soil microbial biomass increased significantly but mean microbial biomass remained unaffected (Fig. 5K, L). Spatial stability of microbial respiration did not significantly respond to the presence of grasses, while the mean increased significantly. The presence of small herbs did not significantly affect the spatial stability of microbial properties, but significantly increased the means of both microbial respiration and biomass.
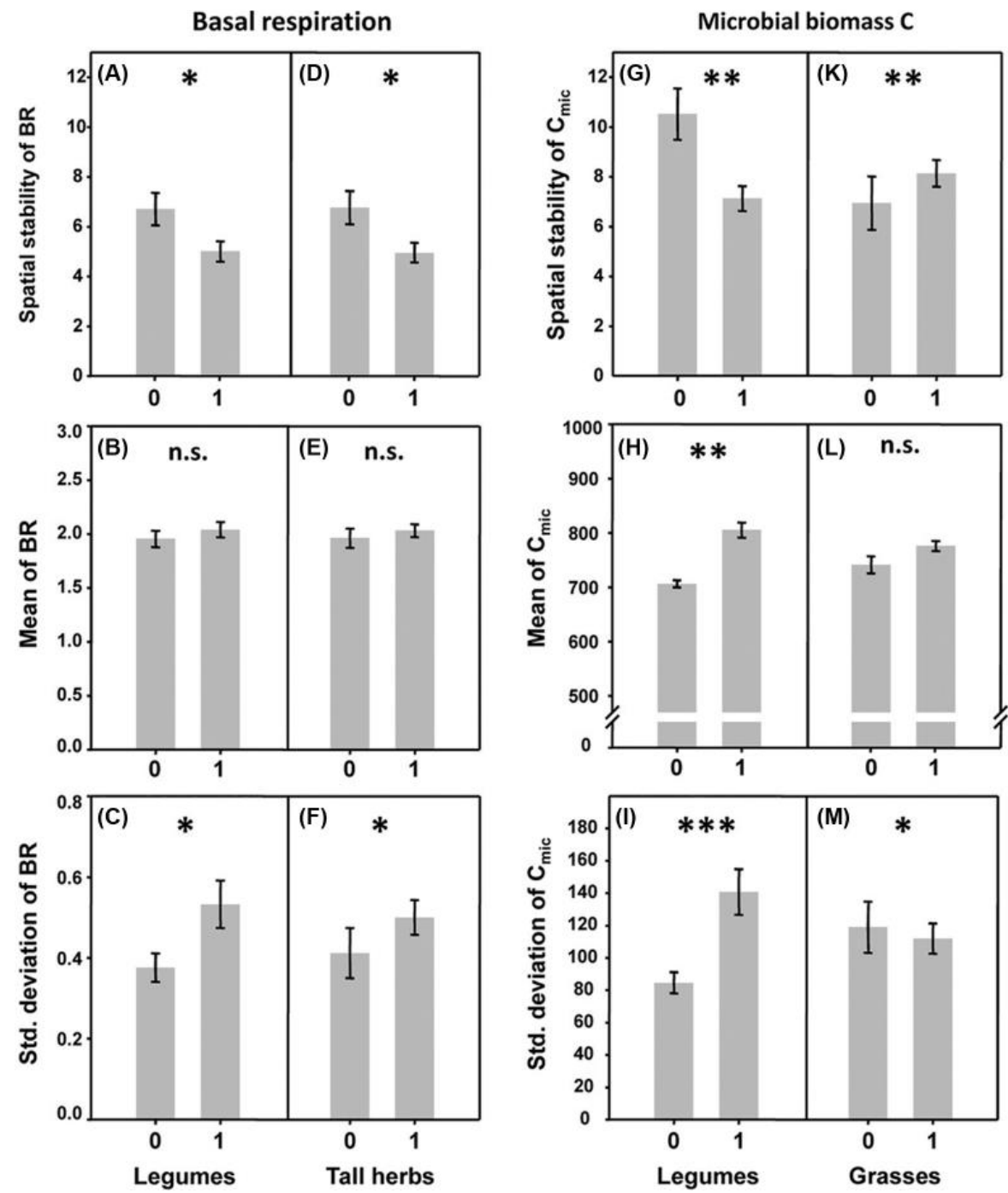

Figure 5. Spatial stability (A), mean value (B), and standard deviation (C) of microbial respiration (BR) in the absence $(0)$ and in the presence (1) of legumes. (D-F) Same parameters in the absence and presence of tall herbs. (G-I) Spatial stability, mean value, and standard deviation of microbial biomass $C$ ( $\left.C_{\text {mic }}\right)$ in absence and presence of legumes, and $(\mathrm{K}-\mathrm{M})$ same parameters in the absence and presence of grasses. Means with \pm standard error bars. Asterisks indicate significant differences $\left({ }^{*}, \mathrm{p} \leq 0.05 ;{ }^{* *}, \mathrm{p} \leq 0.01 ;{ }^{* * *}, \mathrm{p} \leq 0.001 ; \mathrm{n}\right.$.s. , not significant). 
Table 1. GLM (type I sum of squares) table of F-values for effects of block, log-transformed plant species richness (SR), plant functional group richness (FGR), presence of legumes (LEG), grasses (GR), small herbs (SH), and tall herbs $(\mathrm{TH})$ on the spatial stability, mean and standard deviation of soil microbial basal respiration (BR, log-transformed) and microbial biomass $\mathrm{C}\left(\mathrm{C}_{\text {mic }}\right)$.

\begin{tabular}{|c|c|c|c|c|c|c|}
\hline & \multicolumn{3}{|c|}{ BR stability } & \multicolumn{3}{|c|}{$\mathrm{C}_{\text {mic }}$ stability } \\
\hline & DF & $\mathrm{F}$ & $p$ & DF & $\mathrm{F}$ & $p$ \\
\hline Block & 3 & 2.51 & 0.0662 & 3 & 0.18 & 0.9101 \\
\hline SR & 1 & 0.02 & 0.8754 & 1 & 0.27 & 0.6043 \\
\hline FGR & 1 & 0.92 & 0.3398 & 1 & 0.88 & 0.3506 \\
\hline LEG & 1 & 5.75 & $0.0192 \downarrow$ & 1 & 8.65 & $0.0044 \downarrow$ \\
\hline GR & 1 & 1.93 & 0.1688 & 1 & 7.54 & $0.0077 \uparrow$ \\
\hline $\mathrm{SH}$ & 1 & 0.23 & 0.6346 & 1 & 0.04 & 0.8353 \\
\hline $\mathrm{TH}$ & 1 & 5.17 & $0.0259 \downarrow$ & 1 & 3.41 & $0.0691 \downarrow$ \\
\hline DF error & 69 & & & 69 & & \\
\hline DF model & 9 & & & 9 & & \\
\hline \multirow[t]{3}{*}{ F-statistic } & 2.27 & & & 2.42 & & \\
\hline & \multicolumn{3}{|c|}{ BR mean } & \multicolumn{3}{|c|}{$\mathrm{C}_{\text {mic }}$ mean } \\
\hline & DF & $\mathrm{F}$ & $\mathrm{p}$ & DF & $\mathrm{F}$ & $p$ \\
\hline Block & 3 & 6.59 & 0.0006 & 3 & 3.02 & 0.0357 \\
\hline SR & 1 & 20.78 & $<.0001 \uparrow$ & 1 & 24.09 & $<.0001 \uparrow$ \\
\hline FGR & 1 & 7.48 & $0.0079 \uparrow$ & 1 & 21.69 & $<.0001 \uparrow$ \\
\hline LEG & 1 & 0.24 & 0.6222 & 1 & 7.52 & $0.0078 \uparrow$ \\
\hline GR & 1 & 5.99 & $0.0169 \uparrow$ & 1 & 2.17 & 0.1451 \\
\hline $\mathrm{SH}$ & 1 & 4.65 & $0.0344 \uparrow$ & 1 & 14.65 & $0.0003 \uparrow$ \\
\hline $\mathrm{TH}$ & 1 & 2.51 & 0.1177 & 1 & 6.06 & $0.0163 \uparrow$ \\
\hline DF error & 69 & & & 69 & & \\
\hline DF model & 9 & & & 9 & & \\
\hline \multirow[t]{3}{*}{ F-statistic } & 4.7 & & & 4.54 & & \\
\hline & \multicolumn{3}{|c|}{ BR standard deviation } & \multicolumn{3}{|c|}{$\mathrm{C}_{\text {mic }}$ standard deviation } \\
\hline & DF & $\mathrm{F}$ & $\mathrm{p}$ & DF & $\mathrm{F}$ & $\mathrm{p}$ \\
\hline Block & 3 & 3.26 & 0.0266 & 3 & 1.26 & 0.2959 \\
\hline SR & 1 & 0.84 & 0.3623 & 1 & 0.44 & 0.509 \\
\hline FGR & 1 & 1.54 & 0.2182 & 1 & 4.14 & $0.0456 \uparrow$ \\
\hline LEG & 1 & 5.49 & $0.022 \uparrow$ & 1 & 14.75 & $0.0003 \uparrow$ \\
\hline GR & 1 & 0.41 & 0.5238 & 1 & 5.59 & $0.0208 \downarrow$ \\
\hline $\mathrm{SH}$ & 1 & 0.14 & 0.7081 & 1 & 0.48 & 0.4912 \\
\hline $\mathrm{TH}$ & 1 & 4.76 & $0.0324 \uparrow$ & 1 & 5.25 & $\mathbf{0 . 0 2 5 0} \uparrow$ \\
\hline DF error & 69 & & & 69 & & \\
\hline DF model & 9 & & & 9 & & \\
\hline F-statistic & 2.22 & & & 3.25 & & \\
\hline
\end{tabular}

F-values refer to those where the respective factor was fitted first. DF = degrees of freedom; $F=F$-value; $p=p$ value. $\downarrow / \uparrow=$ increase/decrease with increasing diversity level or in the presence of the respective plant functional group. Significant effects $(p \leq 0.05)$ and marginally significant effects $(p \leq 0.1)$ are given in bold.

\section{Temporal stability of soil microbial properties}

Plant diversity (plant species richness and functional group richness) did not significantly affect the temporal stability of microbial respiration in any of the three time phases (Table 2, Fig. 6A for plant species richness), while the means and the standard deviations of microbial respiration significantly increased with plant species richness in most phases (Fig. 6B-C).

During phase 1 , plant functional group richness tended to enhance the temporal stability of microbial respiration. Simultaneously, plant functional group richness significantly increased mean microbial respiration. The presence of grasses significantly enhanced the temporal stability of microbial respiration. Additionally, the mean microbial respiration tended to increase in the presence of 
Table 2. GLM (type I sum of squares) table of F-values for effects of block, log-transformed plant species richness (SR), plant functional group richness (FGR), presence of legumes (LEG), grasses (GR), small herbs (SH), and tall herbs $(\mathrm{TH})$ on the temporal stability, mean, and standard deviation of soil microbial basal respiration $(B R)$ and microbial biomass $C\left(C_{\text {mic }}\right)$ for three subsequent time phases.

\begin{tabular}{|c|c|c|c|c|c|c|c|c|c|}
\hline & \multicolumn{3}{|c|}{ Phase 1 (2003-2006) } & \multicolumn{3}{|c|}{ Phase 2 (2007-2010) } & \multicolumn{3}{|c|}{ Phase 3 (2011-2014) } \\
\hline & DF & $\mathrm{F}$ & $\mathrm{p}$ & DF & $\mathrm{F}$ & $\mathrm{p}$ & DF & $\mathrm{F}$ & $\mathrm{p}$ \\
\hline \multicolumn{10}{|l|}{ BR stability } \\
\hline Block & 3 & 1.46 & 0.2332 & 3 & 3.96 & 0.0117 & 3 & 2.24 & 0.0915 \\
\hline SR & 1 & 1.55 & 0.2173 & 1 & 1.27 & 0.2638 & 1 & 0.01 & 0.9672 \\
\hline FGR & 1 & 2.84 & $0.0964 \uparrow$ & 1 & 2.63 & 0.1094 & 1 & 0.09 & 0.7698 \\
\hline LEG & 1 & 0.02 & 0.8907 & 1 & 2.69 & 0.1057 & 1 & 1.56 & 0.2162 \\
\hline GR & 1 & 7.59 & $0.0075 \uparrow$ & 1 & 0.06 & 0.8044 & 1 & 0.18 & 0.6758 \\
\hline $\mathrm{SH}$ & 1 & 0.91 & 0.3448 & 1 & 0.81 & 0.3712 & 1 & 0.08 & 0.7828 \\
\hline $\mathrm{TH}$ & 1 & 0.01 & 0.9397 & 1 & 1.22 & 0.2743 & 1 & 1.84 & 0.18 \\
\hline DF model & 9 & & & 9 & & & 9 & & \\
\hline DF error & 67 & & & 67 & & & 67 & & \\
\hline F-statistic & 1.45 & & & 1.84 & & & 1.33 & & \\
\hline \multicolumn{10}{|l|}{ BR mean } \\
\hline Block & 3 & 1.18 & 0.3251 & 3 & 5.43 & 0.0021 & 3 & 2.34 & 0.0818 \\
\hline SR & 1 & 7.97 & $0.0063 \uparrow$ & 1 & 56.15 & $<.0001 \uparrow$ & 1 & 81.45 & $<.0001 \uparrow$ \\
\hline FGR & 1 & 4.48 & $\mathbf{0 . 0 3 8 1} \uparrow$ & 1 & 30.36 & $<.0001 \uparrow$ & 1 & 33.92 & $<.0001 \uparrow$ \\
\hline LEG & 1 & 1.85 & 0.1790 & 1 & 1.69 & 0.1983 & 1 & 5.65 & $0.0204 \uparrow$ \\
\hline GR & 1 & 3.72 & $0.0581 \uparrow$ & 1 & 40.55 & $<.0001 \uparrow$ & 1 & 29.93 & $<.0001 \uparrow$ \\
\hline $\mathrm{SH}$ & 1 & 1.97 & 0.1647 & 1 & 9.83 & $0.0026 \uparrow$ & 1 & 11.69 & $0.0011 \uparrow$ \\
\hline $\mathrm{TH}$ & 1 & 2.48 & 0.1205 & 1 & 7.62 & $0.0075 \uparrow$ & 1 & 13.63 & $0.0005 \uparrow$ \\
\hline DF model & 9 & & & 9 & & & 9 & & \\
\hline DF error & 65 & & & 65 & & & 65 & & \\
\hline F-statistic & 1.65 & & & 9.51 & & & 10.37 & & \\
\hline \multicolumn{10}{|c|}{ BR standard deviation } \\
\hline Block & 3 & 0.37 & 0.773 & 3 & 2.69 & 0.0536 & 3 & 2.77 & 0.0484 \\
\hline $\mathrm{SR}$ & 1 & 1.83 & 0.1803 & 1 & 11.78 & $0.0010 \uparrow$ & 1 & 8.76 & $0.0043 \uparrow$ \\
\hline FGR & 1 & 4.22 & $0.0441 \downarrow$ & 1 & 16.71 & $0.0001 \uparrow$ & 1 & 2.82 & $0.0978 \uparrow$ \\
\hline LEG & 1 & 0.76 & 0.3876 & 1 & 6.13 & $0.0159 \uparrow$ & 1 & 2.25 & 0.1387 \\
\hline GR & 1 & 9.10 & $0.0036 \downarrow$ & 1 & 3.62 & $0.0614 \uparrow$ & 1 & 1.64 & 0.2048 \\
\hline $\mathrm{SH}$ & 1 & 1.40 & 0.2418 & 1 & 3.91 & $0.0522 \uparrow$ & 1 & 0.45 & 0.5027 \\
\hline $\mathrm{TH}$ & 1 & 0.07 & 0.797 & 1 & 8.04 & $0.0061 \uparrow$ & 1 & 0.05 & 0.8227 \\
\hline DF model & 9 & & & 9 & & & 9 & & \\
\hline DF error & 65 & & & 65 & & & 65 & & \\
\hline F-statistic & 1.86 & & & 2.96 & & & 2.16 & & \\
\hline \multicolumn{10}{|l|}{$C_{\text {mic }}$ stability } \\
\hline Block & 3 & 0.56 & 0.6421 & 3 & 3.55 & 0.0194 & 3 & 0.2 & 0.8961 \\
\hline $\mathrm{SR}$ & 1 & 10.18 & $0.0022 \downarrow$ & 1 & 5.35 & $0.0241 \downarrow$ & 1 & 0.03 & 0.8596 \\
\hline FGR & 1 & 6.62 & $0.0125 \downarrow$ & 1 & 1.06 & 0.3084 & 1 & 0.33 & 0.5672 \\
\hline LEG & 1 & 6.51 & $0.0133 \downarrow$ & 1 & 0.48 & 0.4906 & 1 & 0.86 & 0.3585 \\
\hline GR & 1 & 1.13 & 0.2917 & 1 & 0.59 & 0.4469 & 1 & 0.14 & 0.7067 \\
\hline $\mathrm{SH}$ & 1 & 5.91 & $0.0180 \downarrow$ & 1 & 2.39 & 0.1270 & 1 & 0.01 & 0.9861 \\
\hline $\mathrm{TH}$ & 1 & 0.18 & 0.6707 & 1 & 0.06 & 0.8004 & 1 & 0.25 & 0.6213 \\
\hline DF model & 9 & & & 9 & & & 9 & & \\
\hline DF error & 61 & & & 61 & & & 61 & & \\
\hline F-statistic & 1.83 & & & 2.01 & & & 0.25 & & \\
\hline \multicolumn{10}{|l|}{$\mathrm{C}_{\text {mic }}$ mean } \\
\hline Block & 3 & 6.58 & 0.0006 & 3 & 16.63 & $<.0001$ & 3 & 15.78 & $<.0001$ \\
\hline SR & 1 & 5.3 & $0.0244 \uparrow$ & 1 & 32.3 & $<.0001 \uparrow$ & 1 & 56.02 & $<.0001 \uparrow$ \\
\hline FGR & 1 & 7.31 & $\mathbf{0 . 0 0 8 7} \uparrow$ & 1 & 25.37 & $<.0001 \uparrow$ & 1 & 44.68 & $<.0001 \uparrow$ \\
\hline LEG & 1 & 3.55 & $0.0640 \uparrow$ & 1 & 14.63 & $0.0003 \uparrow$ & 1 & 12.72 & $\mathbf{0 . 0 0 0 7} \uparrow$ \\
\hline GR & 1 & 0.67 & 0.4158 & 1 & 3.46 & $0.0673 \uparrow$ & 1 & 16.17 & $0.0001 \uparrow$ \\
\hline $\mathrm{SH}$ & 1 & 5.57 & $0.0212 \uparrow$ & 1 & 14.31 & $0.0003 \uparrow$ & 1 & 24.76 & $<.0001 \uparrow$ \\
\hline $\mathrm{TH}$ & 1 & 1.95 & 0.1667 & 1 & 4.67 & $0.0343 \uparrow$ & 1 & 11.74 & $0.0010 \uparrow$ \\
\hline DF model & 9 & & & 9 & & & 9 & & \\
\hline DF error & 67 & & & 67 & & & 67 & & \\
\hline F-statistic & 3.28 & & & 10 & & & 12.48 & & \\
\hline \multicolumn{10}{|c|}{$\mathrm{C}_{\text {mic }}$ standard deviation } \\
\hline Block & 3 & 0.11 & 0.9542 & 3 & 4.71 & 0.0048 & 3 & 1.41 & 0.2481 \\
\hline SR & 1 & 17.34 & $<.0001 \uparrow$ & 1 & $<0.01$ & 0.9973 & 1 & 4.23 & $0.0436 \uparrow$ \\
\hline FGR & 1 & 15.47 & $0.0002 \uparrow$ & 1 & 0.55 & 0.4605 & 1 & 7.39 & $0.0083 \uparrow$ \\
\hline LEG & 1 & 9.69 & $0.0027 \uparrow$ & 1 & 0.91 & 0.3428 & 1 & 1.76 & 0.1891 \\
\hline GR & 1 & 3.46 & $0.0674 \uparrow$ & 1 & 0.1 & 0.7521 & 1 & 1.26 & 0.2648 \\
\hline $\mathrm{SH}$ & 1 & 8.73 & $0.0043 \uparrow$ & 1 & 0.09 & 0.7608 & 1 & 1.75 & 0.1909 \\
\hline $\mathrm{TH}$ & 1 & 3.23 & $0.0770 \uparrow$ & 1 & 0.72 & 0.3989 & 1 & 4.9 & $0.0303 \uparrow$ \\
\hline DF model & 9 & & & 9 & & & 9 & & \\
\hline DF error & 67 & & & 67 & & & 67 & & \\
\hline F-statistic & 2.57 & & & 1.85 & & & 1.43 & & \\
\hline
\end{tabular}

F-values refer to those where the respective factor was fitted first. $D F=$ degrees of freedom; $F=F$-value; $p=p$ value. $\uparrow / \downarrow=$ increase/decrease with increasing diversity level or in the presence of the respective plant functional group. Significant effects $(p \leq 0.05)$ and marginally significant effects $(p \leq 0.1)$ are given in bold. 
grasses. None of the other plant functional groups significantly influenced the stability of soil microbial respiration.

In general, the temporal stability of microbial biomass responded more strongly to plant community properties than that of microbial respiration. During phase 1 , the temporal stability of microbial biomass significantly decreased with increasing plant species richness (Fig. 6D) and functional group richness. Although the mean of soil microbial biomass significantly increased with increasing plant diversity (Fig. 6E), the concurrent increase in standard deviation with increasing plant diversity (Fig. 6F) was much more pronounced and caused the destabilizing effect of plant diversity during the phase 1. Also, the presence of legumes and small herbs reduced the temporal stability of microbial biomass during the phase 1 .

During phase 2, plant community properties did not significantly influence the temporal stability of microbial respiration, while associated means significantly increased with plant diversity as well as in the presence of grasses, small herbs, and tall herbs. In contrast, the temporal stability of microbial biomass significantly decreased with increasing plant species richness during phase 2 , while plant functional groups did not significantly affect the temporal stability of microbial biomass. The means of microbial biomass increased in response to the presence of all plant functional groups (only by trend for grasses).

During phase 3, plant community properties did not significantly affect the temporal stability of microbial respiration, but means of microbial respiration significantly increased with plant species richness and functional group richness. Also, the means of microbial respiration increased in presence of each of the four plant functional groups, with plant functional group effects getting stronger in later phases. As for mean soil microbial biomass in phases 2 and 3 , these results have to be treated with caution as testing the presence of plant functional groups before plant diversity may have captured some of the plant diversity effects.

Temporal stability of microbial biomass did not significantly vary with plant community properties during phase 3 , i.e. the initial destabilizing effect of plant diversity vanished with time. The mean of microbial biomass significantly increased in response to increasing plant diversity and in the presence of the different plant functional groups. The effects of plant community properties on the mean microbial biomass got stronger from phase to phase and were strongest for plant diversity. Importantly, the temporal stability of microbial biomass increased with time (as the number of plant community properties that reduced stability decreased with time).

Testing for potential relationships between spatial and temporal stability (Eisenhauer et al. 2011c) of microbial basal respiration and biomass revealed no significant correlations (all $p>0.1$ ). 

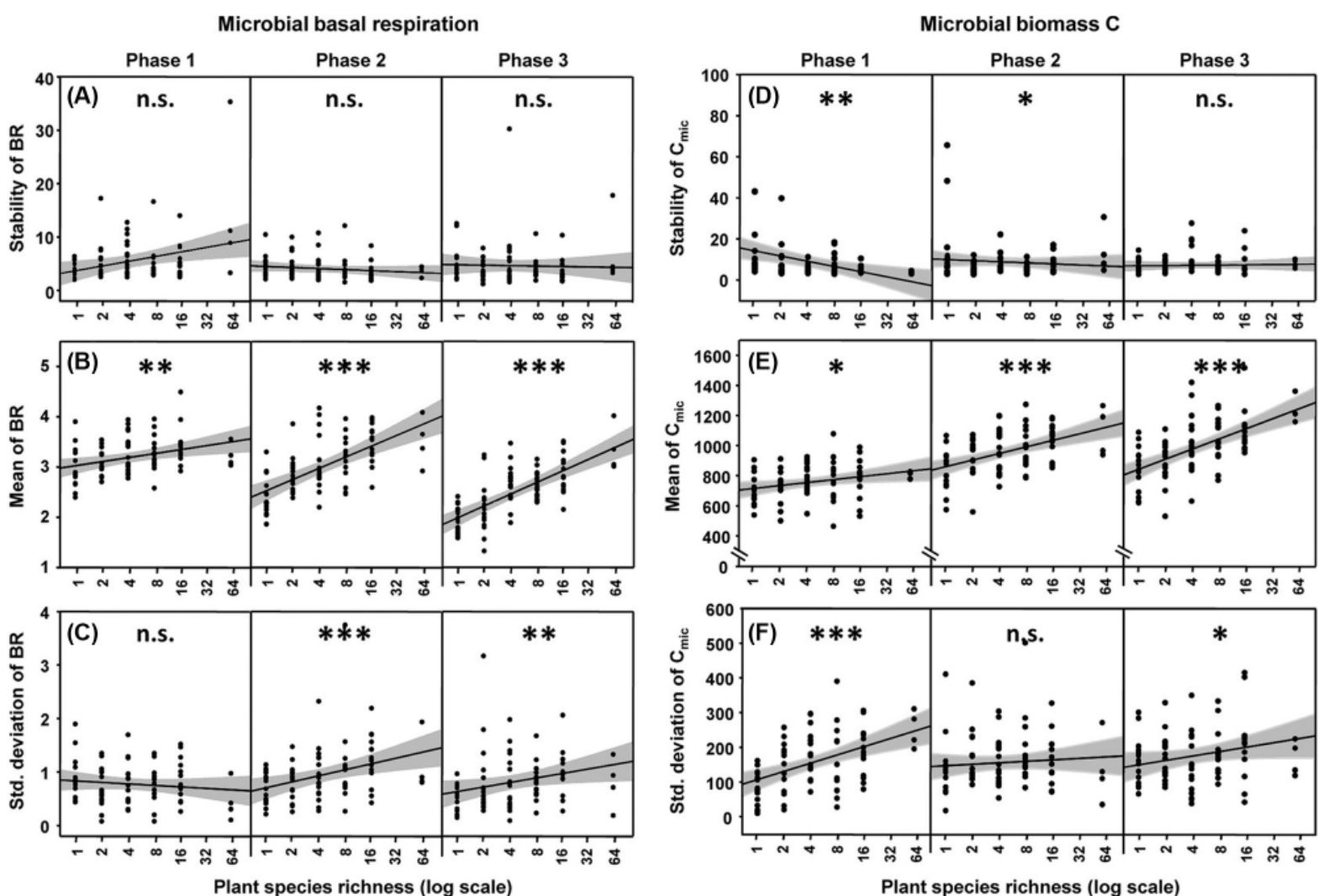

Figure 6. Temporal stability, mean value, and standard deviation of $(A-C)$ microbial respiration (BR) and (D-F) microbial biomass $C$ (Cmic) as affected by plant species richness in phases 1, 2 and 3 . Regression lines (black) with $95 \%$ confidence intervals (grey). Asterisks indicate significant differences $(*, p \leq 0.05 ; * *, p \leq 0.01 ; * * *, p \leq$ $0.001 ;$ n.s. $=$ not significant).

\subsection{Discussion}

If biodiversity stabilizes ecosystem properties has attracted increasing scientific attention in the last decades and still is debated (Isbell et al. 2015, Wright et al. 2015). We investigated the roles of plant diversity and plant functional group composition for the spatial and temporal stability of microbial properties in bulk soil in a long-term grassland biodiversity experiment. The relationship between plant species richness and soil microbial properties (respiration and biomass $\mathrm{C}$ ) became more significant over time and positive relationships persisted until the last measurement of the time series in 2014 . In contrast to our hypotheses, plant diversity had minor effects on the spatial and temporal stability of soil microbial properties. As predicted, plant diversity reduced temporal stability shortly after the establishment of the experiment though due to plant community-specific shifts in soil communities. The functional composition of plant communities was a significant determinant of the spatial stability of soil microbial properties: the presence of legumes and tall herbs reduced the spatial stability of both soil microbial respiration and biomass, while grasses increased the spatial stability of the latter. 


\section{Plant diversity effects on soil microbial properties over time}

In line with our hypothesis 1 , soil microbial respiration and biomass increased significantly with plant species richness four years after establishment of the experiment. Although the positive relationships persisted until the last measurement of the time series in 2014, the relationships did not strengthen homogeneously over time, thus confirming hypothesis 1 in part.

We found the relationship between microbial respiration and plant species richness to be strongest seven years after establishment of the experiment, while that between microbial biomass $C$ and plant species richness was strongest only four years later, i.e. after 11 years. We suggest that the microbial respiration strengthened over the first seven years of the experiment with increasing plant species richness due to increasing plant inputs (Marquard et al. 2009, Reich et al. 2012, Ravenek et al. 2014). This mechanism was most probably dampened in the following years because the soil microbial community adapted to the soil conditions in maturing semi-natural grassland. Adaptation can include a shift in physiological properties as well as in microbial com- munity structure, both leading to more efficient resource use by microbial communities (Wardle and Ghani 1995). We furthermore suggest that adaptation to semi-natural grassland is a prerequisite for increasing microbial bio- mass $C$ that took place with a time lag after the microbial community had been adapted. Reinforcing the findings of Eisenhauer et al. (2010), who found plant species richness to increase soil microbial respiration and biomass four years after the establishment of the experimental grassland, we for the first time show that the positive effects of plant species richness on soil microbial properties remain significant within a time frame of more than 10 years. Future long-term studies should explore the abiotic and biotic drivers of inter- annual variability in the slope of plant diversity-ecosystem function relationships.

\section{Plant diversity effects on the spatial stability of soil microbial properties}

Contrary to hypothesis 2 , the spatial stability of soil microbial respiration and biomass did not significantly correlate with plant diversity (plant species richness and functional group richness). In contrast to our results, Wardle and Bonner (1999) found that spatial variability of soil microbial respiration decreased with plant diversity (i.e. spatial stability of microbial respiration increased). We expected to find a positive plant diversity-spatial stability relationship due to higher spatial stability of plant productivity (Eisenhauer et al. 2011c), higher root biomass (Ravenek et al. 2014), and more uniform organic inputs into the soil (Milcu et al. 2010). In our study, counteracting processes might have determined soil microbial communities and prevented a clear trend in spatial stability with increasing plant diversity. For example, in the rhizosphere where labile $\mathrm{C}$ substrates are secreted by plant roots, microbial r-strategists with low $\mathrm{C}$ use efficiency may dominate over highly efficient Kstrategists, which dominate in bulk soil. Thus, we might have sampled rhizosphere-patches with high respiration rates and high microbial biomass, and bulk soil-patches where microbial respiration and 
biomass are lower (Kuzyakov and Blagodatskaya 2015) at high plant diversity. As highlighted by Weigelt et al. (2008), the spatial scale of plant diversity-spatial stability relationship needs further attention.

\section{Plant diversity effects on the temporal stability of soil microbial properties}

We hypothesized effects of plant diversity on the temporal stability of microbial properties to change over time with destabilizing effects during phase 1 (Habekost et al. 2008, Eisenhauer et al. 2010), neutral effects during phase 2 (consolidation of soil microbial communities), and stabilizing effects in phase 3 (higher stability and amount of plant inputs to soil; Milcu et al. 2010). In line with our hypothesis 3 , temporal stability of soil microbial biomass decreased significantly with plant diversity in phase 1. During this phase (four years after the establishment of the Jena Experiment), the soil microbial community experienced a major land-use change from arable field monocultures to newly established semi-natural grassland with up to 60 plant species. As a consequence, soil microbial communities (Habekost et al. 2008) and properties (respiration and biomass; Eisenhauer et al. 2010) changed according to the newly established plant communities. These changes likely were most pronounced in plots most different to the former land-use. Supporting this assumption, Eisenhauer et al. (2010) found microbial respiration and biomass to increase most at high plant diversity. During phases 2 and 3 , none of the plant community properties significantly influenced the temporal stability of microbial respiration. Contrary to these findings, McGill et al. (2010) found temporal stability of microbial processes, such as denitrification, to increase with plant diversity and suggested this to be due to complementarity between functional traits of different plant species buffering microbial denitrification against variability in environmental factors.

In our study, we found the variability (standard deviation) of microbial respiration to decrease with increasing functional group richness during phase 1, while it increased with functional group richness during phase 2 . This suggests that during phase 2 plant inputs into the soil (and as a consequence soil conditions) were more different in high-diversity plots than in low-diversity plots. These changes in soil conditions from phase 1 to 2 probably occurred due to declining evenness of the plant functional groups within and /or between high-diversity plots, while the evenness of plant functional groups in low-diversity plots remained more similar. Indeed, Roscher et al. (2013) found the proportion of plant functional groups to shift over time with increasing abundance of grasses and decreasing abundance of legumes, and reduced plant species evenness most pronounced in high-diversity plant communities during phase 2 of our experiment (C. Roscher pers. comm.).

Confirming hypothesis 3 , the temporal stability of soil microbial biomass decreased with plant species richness and plant functional group richness during phase 1. However, the negative relationship between stability of microbial biomass and plant diversity decreased during phases 2 and 3 , while means of soil microbial biomass progressively increased with plant diversity with time. 
We suggest that during phase 1 , low-diversity plant communities changed little in comparison to the former land-use, and, as a consequence, soil microbial biomass and functioning stayed constant at low plant diversity (Fig. 4e; Eisenhauer et al. 2010). By contrast, soil microbial biomass increased in high-diversity plant communities in the initial years of the experiment, and soil microbial communities changed from a disturbed (zymogenous) to a more established (autochthonous) microbial community (Eisenhauer et al. 2010). This successional shift of soil microbial communities and properties at high plant diversity caused the observed negative plant diversity-stability relationship. Presumably, high-diversity plant communities provided a higher quantity and quality of plant-derived organic inputs to the soil (Lange et al. 2015) compared to agricultural and plant monoculture soils.

On the basis of the constant increase of the microbial biomass and respiration with plant diversity since the establishment of the Jena Experiment (Fig. 3; Eisenhauer et al. 2010), we assume that these changes are likely to continue in the future. This suggests that the time required by the microbial community to adapt to diverse plant communities in semi-natural grassland and to achieve stable community properties is taking longer than the duration of our experiment. This is supported by Buckley and Schmidt (2001) who found soil microbial communities in abandoned arable fields to be more similar to those of active arable fields than to those of uncultivated fields even seven years after abandonment. They concluded that current plant effects on the microbial community were superimposed by the influence of past agricultural use.

\section{Effects of plant functional groups on spatial and temporal stability of soil microbial properties}

Conform to hypothesis 4 , legumes decreased the spatial stability of microbial respiration and biomass. Further, temporal stability of microbial biomass was also decreased by legumes, but only during phase 1 of the experiment. Presumably, the destabilizing effects of legumes on the soil microbial community in space and time resulted from increased $\mathrm{N}$ availability in the rhizosphere of legumes (Spehn et al. 2002), leading to hotspots of microbial biomass and activity compared to the bulk soil (Kuzyakov and Blagodatskaya 2015). Due to the patchiness of hotspots, the spatial and temporal stability of microbial communities on the experimental plot-level was reduced. This is supported by results of the study of Chen et al. (2008) who found higher soil microbial biomass in the presence of legumes compared to that of grasses in a greenhouse experiment and concluded this to be due to higher root exudation by legumes. Further supporting our assumption of patchy hotspots of $\mathrm{N}$ provision and microbial biomass and activity in the presence of legumes, Ravenek et al. (2014) found reduced root biomass in the presence of legumes at our experimental field site. Unexpectedly, how- ever, the effect of legumes on the temporal stability of microbial biomass disappeared after phase 1. Especially in more mature grasslands, legumes are inferior to grasses regarding light 
acquisition as well as uptake of water and nutrients from the soil (Haynes 1980). Thus, their relative abundance and performance decreased during the experiment (Roscher et al. 2011a), and their effects on microbial communities (i.e. negative effects on the stability) may have faded away. In the present study, grasses increased the spatial stability of microbial biomass as well as the temporal stability of microbial respiration during phase 1. Presumably this was due to dense root mats persisting over long periods of time (De Witte and Stöcklin 2010). Again, however, we did not expect these effects to disappear after phase 1 of the experiment, especially as the coverage of grasses is known to be very stable because grasses are strong competitors for soil nutrients compared to other plant functional groups (Kiær et al. 2013) and have been reported to be temporally stable on the field site of the Jena Experiment (Roscher et al. 2011b). Therefore, in future studies rhizodeposition, including measurements of root exudation, on the scale of individual plants should be added to the analyses of soil microbial communities.

Small herbs did not influence the spatial stability of soil microbial communities, but in contrast to hypothesis 4, their presence decreased the temporal stability of microbial biomass. Roscher et al. (2011b) reported lower plant species synchrony on the same field site in communities with small herbs. This suggests that the soil microbial biomass was destabilized over time because of spatiotemporal changes in the rhizosphere (changing distribution of roots and rhizodeposition) of small herb species. Supporting this assumption, Bezemer et al. (2010) found the soil decomposer community to vary at the scale of individual plants and with plant species identity.

Tall herbs decreased the spatial stability of microbial respiration, confirming hypothesis 4 . Tall herbs are characterized by deep rooting systems that allocate $C$ to deep soil layers (Roscher et al. 2004). Thereby tall herbs may increase patchy provisioning of resources to soil microorganisms. In addition, tall herbs were shown to increase small-scale heterogeneity of aboveground plant biomass production (Weigelt et al. 2008), and this may also have contributed to heterogeneous spatial distribution of tap roots and resource inputs to the soil.

\subsection{Conclusions}

Our results emphasize the essential role of plant species rich- ness for high abundance and activity of soil microorganisms in the long-term. Only such long-term studies will allow to explore the abiotic and biotic drivers of varying slopes of relationships between plant diversity and soil microbial properties as found in the present study. Further, our results highlight the importance of functional group composition of plant communities for the spatial stability of soil micro- bial properties, whereby legumes and tall herbs reduced the spatial stability (increased the spatial heterogeneity) of both microbial respiration and biomass, while the presence of grasses increased the latter. Furthermore, the temporal stabil- ity of soil microbial properties was reduced by plant diversity as 
well as by legumes and tall herbs during the first years of the experiment (phase 1). As the relationship between sta- bility of soil microbial properties and plant diversity turned from being negative to neutral for the rest of this long-term study, we suggest that recovery of the soil microbial com- munity from former arable land-use in highly diverse plant communities can take decades. To understand the mechanisms governing spatial and temporal stability of soil microbial communities and to dis- entangle differences in the stability of microbial communi- ties between the rhizosphere and bulk soil, information on root species identity and root functional traits, such as mor- phology, turnover, and exudates is needed. Further, future studies should address if increased spatial heterogeneity (i.e. decreased spatial stability) of soil microbial properties contributes to plant community effects on the diversity of animal species of higher trophic levels below but also above the ground.

\subsection{Acknowledgements}

We thank W.W. Weisser, C. Roscher and A. Weigelt for the project coordination; C. Roscher also for helpful comments on the manuscript. We are grateful to Anne Ebeling for coordinating the field work, and to the gardeners for maintaining the field site. For the help on the field site, we thank Roeland Cortois, Gerlinde de Deyn, Britta Jensen, Melissa Jüds and Alice Böll. Further, we thank Andrea Gräbe-Treger and Ingrid Kleinhans for the help in the lab at the Göttingen University. Funding - This work was funded by the Deutsche Forschungsge- meinschaft (FOR 456 and FOR 1451; the Jena Experiment). NE acknowledges funding by the Deutsche Forschungsgemeinschaft (German Research Foundation; Ei 862/1, Ei 862/2). Further sup- port came from the German Centre for Integrative Biodiversity Research (iDiv) Halle-Jena-Leipzig, funded by the German Research Foundation (FZT 118).

\subsection{References}

Anderson, J. and Domsch, K. 1978. A physiological method for the quantitative measurement of microbial biomass in soils. - Soil Biol. Biochem. 10: 215-221.

Beck,T.etal.1997. An inter-laboratory comparison of ten different ways of measuring soil microbial biomass C. Soil Biol. Biochem. 29: 1023-1032.

Bezemer, T. M. et al. 2010. Divergent composition but similar function of soil food webs of individual plants: plant species and community effects. - Ecology 91: 3027-3036.

Buckley, D. H. and Schmidt, T. M. 2001. The structure of microbial communities in soil and the impact of lasting cultivation. - Microb. Ecol. 42: 11-21.

Chapin, F. S. et al. 2000. Consequences of changing biodiversity. - Nature 405: 234-42.

Chen, M. et al. 2008. Plant growth and soil microbial community structure of legumes and grasses grown in monoculture or mixture. - J. Environ. Sci. 20: 1231-1237.

De Witte, L. C. and Stöcklin, J. 2010. Longevity of clonal plants: why it matters and how to measure it. - Ann. Bot. 106: 859-870.

Eisenhauer, N. et al. 2010. Plant diversity effects on soil microorganisms support the singular hypothesis. Ecology 91: 485-96. 
Eisenhauer, N. et al. 2011a. Plant diversity surpasses plant functional groups and plant productivity as driver of soil biota in the long term. - PLoS ONE 6: e16055.

Eisenhauer, N. et al. 2011b. Changes in plant species richness induce functional shifts in soil nematode communities in experimental grassland. - PLOS ONE 6: e24087.

Eisenhauer, N. et al. 2011c. Impact of above- and below-ground invertebrates on temporal and spatial stability of grassland of different diversity. - J. Ecol. 99: 572-582.

Eisenhauer, N. et al. 2012. Increasing plant diversity effects on productivity with time due to delayed soil biota effects on plants. - Basic Appl. Ecol. 13: 571-578.

Eisenhauer, N. et al. 2013. Plant diversity effects on soil food webs are stronger than those of elevated CO2 and $\mathrm{N}$ deposition in a long-term grassland experiment. - Proc. Natl. Acad. Sci. USA 110: 6889-6894.

Ellenberg, H. 1996. Vegetation Mitteleuropas mit den Alpen in ökologischer, dynamischer und historischer Sicht. - Ulmer.

FAO-Unesco 1997. Soil map of the world. Revised legend with corrections and update. (FAO-Unesco, Ed.). ISRIC.

Fornara, D. A. et al. 2009. Linkages between plant functional composition, fine root processes and potential soil $\mathrm{N}$ mineralization rates. - J. Ecol. 97: 48-56.

Habekost, M. et al. 2008. Seasonal changes in the soil microbial community in a grassland plant diversity gradient four years after establishment. - Soil Biol. Biochem. 40: 2588-2595.

Haddad, N. M. et al. 2011. Plant diversity and the stability of foodwebs. - Ecol. Lett. 14: 42-46.

Hamilton, E. W. and Frank, D. A. 2001. Can plants stimulate soil microbes and their own nutrient supply? Evidence from a grazing tolerant grass. - Ecology 82: 2397-2402.

Haynes, R. J. 1980. Competitive aspects of the grass-legume association. - In: Advances in agronomy, 33rd edn. Academic Press, pp. 227-261.

Hooper, D. U. et al. 2005. Effects of biodiversity on ecosystem functioning: a consensus of current knowledge. Ecol. Monogr. 75: 3-35.

Isbell, F. et al. 2011. High plant diversity is needed to maintain ecosystem services. - Nature 477: $199-202$.

Isbell, F. et al. 2015. Biodiversity increases the resistance of ecosystem productivity to climate extremes. Nature 526: 574-577.

Kiær, L. P. et al. 2013. Root and shoot competition: a meta-analysis. - J. Ecol. 101: 1298-1312.

Kuzyakov, Y. and Blagodatskaya, E. 2015. Microbial hotspots and hot moments in soil: concept and review. Soil Biol. Biochem. 83: 184-199.

Lange, M. et al. 2015. Plant diversity increases soil microbial activity and soil carbon storage. - Nat. Commun. 6 : 6707.

Lehman, C. L. and Tilman, D. 2000. Biodiversity, stability and productivity in competitive communities. - Am. Nat. 156: 534-552.

Marquard, E. et al. 2009. Plant species richness and functional composition drive overyielding in a six-year grassland experiment. - Ecology 90: 3290-3302.

Massaccesi, L. et al. 2015. Impact of plant species evenness, dominant species identity and spatial arrangement on the structure and functioning of soil microbial communities in a model grassland. - Oecologia 177: 74759.

McCann, K. S. 2000. The diversity-stability debate. - Nature 405: 228-233.

McGill, B. M. et al. 2010. Plant trait diversity buffers variability in denitrification potential over changes in season and soil conditions. - PLoS ONE 5: e11618.

Milcu, A. et al. 2010. Plant diversity enhances the reliability of belowground processes. - Soil Biol. Biochem. 42: 2102-2110.

Pimm, S. L. 1984. The complexity and stability of ecosystems. - Nature 307: 321-326.

Ravenek, J. M. et al. 2014. Long-term study of root biomass in a biodiversity experiment reveals shifts in diversity effects over time. - Oikos 123: 1528-1436.

Reich, P. B. et al. 2012. Impacts of biodiversity loss escalate through time as redundancy fades. - Science 336 :

589-92.

Roscher, C. et al. 2004. The role of biodiversity for element cycling and trophic interactions: an experimental approach in a grassland community. - Basic Appl. Ecol. 5: 107-121.

Roscher, C. et al. 2011a. N2 fixation and performance of 12 legume species in a 6-year grassland biodiversity experiment. - Plant Soil 341: 333-348.

Roscher, C. et al. 2011b. Identifying population- and community-level mechanisms of diversity-stability relationships in experimental grasslands. - J. Ecol. 99: 1460-1469. 
Roscher, C. et al. 2013. A functional trait-based approach to understand community assembly and diversityproductivity relationships over seven years in experimental grasslands. - Persp. Plant Ecol. Evol. Syst. 15: 139-149.

Scherber, C. et al. 2010. Bottom-up effects of plant diversity on multitrophic interactions in a biodiversity experiment. - Nature 468: 553-556.

Scheu, S. 1992. Automated measurement of the respiratory response of soil microcompartments: active microbial biomass in earthworm faeces. - Soil Biol. Biochem. 24: 1113-1118.

Schmid, B. et al. 2002. The design and analysis of biodiversity experiments. - In: Loreau, M. et al. (eds), Biodiversity and ecosystem functioning. Oxford Univ. Press, pp. 61-75.

Spehn, E. M. et al. 2002. The role of legumes as a component of biodiversity in a cross-European study of grassland biomass nitrogen. - Oikos 98: 205-218.

Sydes, C. L. and Grime, J. P. 1984. A comparative study of root development using a simulated rock crevice. - J. Ecol. 72: 937-946.

Tilman, D. et al. 2014. Biodiversity and ecosystem functioning. - Annu. Rev. Ecol. Evol. Syst. 45: 471-493.

van der Heijden, M. G. A. et al. 2008. The unseen majority: soil microbes as drivers of plant diversity and productivity in terrestrial ecosystems. - Ecol. Lett. 11: 296-310.

Vance, E. D. et al. 1987. An extraction method for measuring soil microbial biomass C. - Soil Biol. Biochem. 19: 703-707.

Wagner, D. et al. 2015. Plant species richness does not attenuate responses of soil microbial and nematode communities to a flood event. - Soil Biol. Biochem. 89: 135-149.

Wardle, D. 1992. A comparative assessment of factors which influence microbial biomass carbon and nitrogen levels in soil. - Biol. Rev. 67: 321-358.

Wardle, D. A. and Ghani, A. 1995. A critique of the microbial metabolic quotient (qCO2) as a bioindicator of disturbance and ecosystem development. - Soil Biol. Biochem. 27: 1601-1610.

Wardle, D. and Bonner, K. 1999. Plant removals in perennial grassland: vegetation dynamics, decomposers, soil biodiversity, and ecosystem properties. - Ecol. Monogr. 69: 535-568.

Weigelt, A. et al. 2008. Does biodiversity increase spatial stability in plant community biomass? - Ecol. Lett. 11: 338-347.

Wright, A. J. et al. 2015. Flooding disturbances increase resource availability and productivity but reduce stability in diverse plant communities. - Nat. Commun. 6: 6092.

Yachi, S. and Loreau, M. 1999. Biodiversity and ecosystem productivity in a fluctuating environment: the insurance hypothesis. - Proc. Natl Acad. Sci. USA 96: 1463-1468. 


\subsection{Supplementary material}

\section{Appendix 1}

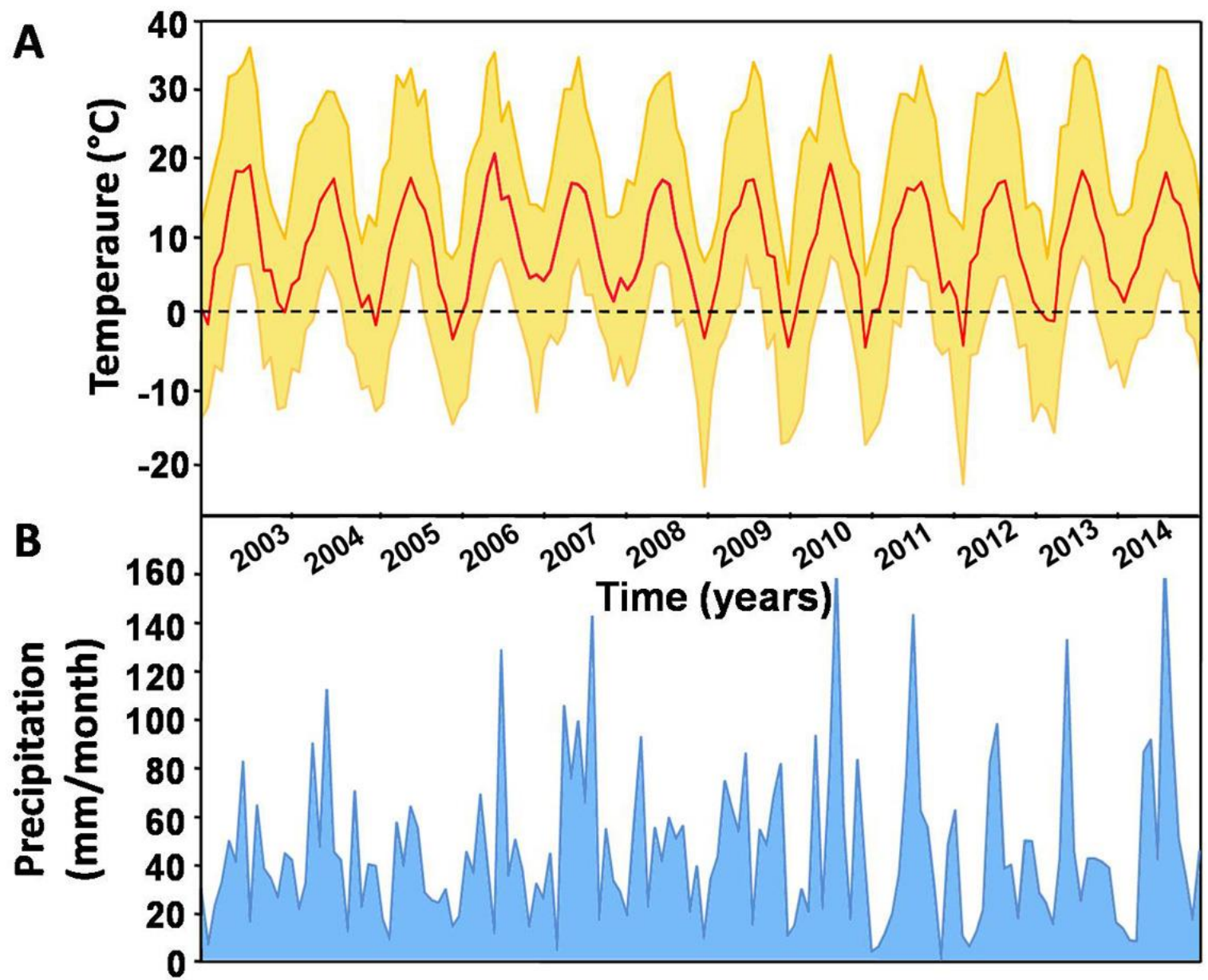

Figure A1. Temperature (A) and precipitation (B) at the field site of the Jena Experiment from 2003 to 2014 (measured by the weather station at the field site).

\section{Appendix 2}

\section{Test of the effect of different combinations of years on the outcome of the temporal stability} analyses in phases $\mathbf{2}$ and 3.

In detail, the original dataset comprises microbial measurements of all years, with phase 1 containing measures from 2003, 2004 and 2006, phase 2 containing measurements from 2007-2010 and phase 3 from 2011-2014. Dataset 'A' comprises measurements with phase 1 with measurements from 2003, 2004 and 2006 (data are shown in the main text of the research article), phase 2 with measurements from 2007-2009, and phase 3 with measurements from 2010-2012, i.e. we discarded measurements of the last year from phase 2 and 3, respectively, thus obtaining three phases with three measurements each; for dataset ' $A$ ' we additionally shifted the beginning of phase 3 from 2011 to 2010 to test whether results significantly change, if the years of phase 2 and 3 would follow each other directly; but this was not the case. Datasets ' $B$ ' $-{ }^{\prime} E$ ' also contained only three years 
per phase by systemically discarding one specific year from each original combination in phases 2 and 3. Altogether, we tested five additional combinations of the three phases, with each phase spanning over four years, but containing only measurements from three years. As a result, reducing the numbers of years from four to three measurements in phases 2 and 3 , and altering the combination of year identity within these phases, only slightly changed the effects of plant species richness and plant community composition on the stability of microbial properties and did not change the main conclusions of our work.

Table A2. GLM (type I sum of squares) table of F-values for effects of block, log-transformed plant species richness (SR), plant functional group richness (FGR), presence of legumes (LEG), grasses (GR), sma*Il herbs (SH), and tall herbs $(\mathrm{TH})$ on the temporal stability of soil microbial basal respiration (BR) and microbial biomass $C$ (Cmic) for time phases 2 and 3, according to different combinations of years within the time phases (datasets A-E).

\begin{tabular}{lllllll}
\hline Original dataset & \multicolumn{2}{l}{ Phase $2(2007-2010)$} & \multicolumn{3}{l}{ Phase 3 (2011-2014) } \\
\hline BR stability & DF & F-value & p-value & DF & F-value & p-value \\
\hline BLOCK & 3 & 3.96 & $\mathbf{0 . 0 1 1 7}$ & 3 & 2.24 & $\mathbf{0 . 0 9 1 5}$ \\
SR & 1 & 1.27 & 0.2638 & 1 & 0 & 0.9672 \\
FG & 1 & 2.63 & 0.1094 & 1 & 0.09 & 0.7698 \\
LEG & 1 & 2.69 & 0.1057 & 1 & 1.56 & 0.2162 \\
GR & 1 & 0.06 & 0.8044 & 1 & 0.18 & 0.6758 \\
SH & 1 & 0.81 & 0.3712 & 1 & 0.08 & 0.7828 \\
TH & 1 & 1.22 & 0.2743 & 1 & 1.84 & 0.18 \\
DF model & 9 & 1.84 & 0.0767 & 9 & 1.33 & 0.2366 \\
DF error & 67 & & & 67 & & $\mathrm{p}$-value \\
\hline Cmic stability & DF & F-value & p-value & DF & F-value & 0.8961 \\
BLOCK & 3 & 3.55 & $\mathbf{0 . 0 1 9 4}$ & 3 & 0.2 & 0.8596 \\
SR & 1 & 5.35 & $\mathbf{0 . 0 2 4 1}$ & 1 & 0.03 & 0.5672 \\
FG & 1 & 1.06 & 0.3084 & 1 & 0.33 & 0.3585 \\
LEG & 1 & 0.48 & 0.4906 & 1 & 0.86 & 0.7067 \\
GR & 1 & 0.59 & 0.4469 & 1 & 0.14 & 0.9861 \\
SH & 1 & 2.39 & 0.127 & 1 & 0 & 0.6213 \\
TH & 1 & 0.06 & 0.8004 & 1 & 0.25 & 0.9841 \\
DF model & 9 & 2.01 & 0.0538 & 9 & 0.25 &
\end{tabular}

\begin{tabular}{lllllll}
\hline Dataset "A" & Phase 2 (2007-2009) & & \multicolumn{3}{l}{ Phase 3 (2010-2012) } \\
\hline BR stability & DF & F-value & p-value & DF & F-value & p-value \\
\hline BLOCK & 3 & 1.1 & 0.3558 & 3 & 0.45 & 0.716 \\
SR & 1 & 1.06 & 0.3072 & 1 & 0.61 & 0.4365 \\
FG & 1 & 0.03 & 0.8663 & 1 & 0.22 & 0.6408 \\
LEG & 1 & 0.84 & 0.363 & 1 & 2.37 & 0.1288 \\
GR & 1 & 0.84 & 0.3626 & 1 & 1.47 & 0.2294 \\
SH & 1 & 0.55 & 0.4629 & 1 & 0.47 & 0.4944 \\
TH & 1 & 0.11 & 0.7397 & 1 & 1.63 & 0.2064 \\
DF model & 9 & 0.83 & 0.5923 & 9 & 0.82 & 0.601 \\
DF error & 66 & & & 66 & & p-value \\
\hline Cmic stability & DF & F-value & p-value & DF & F-value & 0.2718 \\
\hline BLOCK & 3 & 2.82 & 0.0453 & 3 & 1.33 & 0.6999 \\
SR & 1 & 0.38 & 0.539 & 1 & 0.15 & 0.0725 \\
FG & 1 & 0.06 & 0.8005 & 1 & 3.33 & 0.2581 \\
LEG & 1 & 0.06 & 0.8045 & 1 & 1.3 & 0.3388 \\
GR & 1 & 0.72 & 0.3992 & 1 & 0.93 & 0.5796 \\
SH & 1 & 2.25 & 0.1386 & 1 & 0.31 & 0.1633 \\
TH & 1 & 1.42 & 0.238 & 1 & 1.99 & 0.4802 \\
Modell & 9 & 1.64 & 0.1207 & 9 & 0.96 & \\
Error & 67 & & & 67 & & \\
& & & & & &
\end{tabular}




\begin{tabular}{|c|c|c|c|c|c|c|}
\hline \multirow{2}{*}{$\begin{array}{l}\text { Dataset "B" } \\
\text { BR stability }\end{array}$} & \multicolumn{3}{|c|}{ Phase 2 (2007-2009) } & \multicolumn{3}{|c|}{ Phase 3 (2011-2013) } \\
\hline & DF & F-value & $p$-value & DF & F-value & $p$-value \\
\hline BLOCK & 3 & 1.12 & 0.3464 & 3 & 1.37 & 0.2597 \\
\hline SR & 1 & 1.16 & 0.2859 & 1 & 0.45 & 0.5067 \\
\hline$F G$ & 1 & 0.03 & 0.8675 & 1 & 0 & 0.9825 \\
\hline LEG & 1 & 0.91 & 0.3447 & 1 & 0.8 & 0.3744 \\
\hline GR & 1 & 0.95 & 0.3336 & 1 & 2.29 & 0.1347 \\
\hline $\mathrm{SH}$ & 1 & 0.61 & 0.4392 & 1 & 0.73 & 0.3971 \\
\hline $\mathrm{TH}$ & 1 & 0.13 & 0.7205 & 1 & 2.01 & 0.1615 \\
\hline DF model & 9 & 0.94 & 0.4998 & 9 & 1.19 & 0.3189 \\
\hline DF error & 65 & & & 65 & & \\
\hline Cmic stability & DF & F-value & $p$-value & DF & F-value & $p$-value \\
\hline BLOCK & 3 & 3.62 & 0.0175 & 3 & 1.27 & 0.2927 \\
\hline SR & 1 & 0 & 0.9868 & 1 & 3.03 & 0.0866 \\
\hline FG & 1 & 0.06 & 0.8096 & 1 & 3.04 & 0.086 \\
\hline LEG & 1 & 0.83 & 0.3662 & 1 & 3.19 & 0.0787 \\
\hline GR & 1 & 0 & 0.9731 & 1 & 0.48 & 0.4889 \\
\hline $\mathrm{SH}$ & 1 & 1.2 & 0.2776 & 1 & 0.1 & 0.7516 \\
\hline $\mathrm{TH}$ & 1 & 0.84 & 0.3621 & 1 & 1.73 & 0.193 \\
\hline DF model & 9 & 1.56 & 0.1454 & 9 & 0.99 & 0.4574 \\
\hline DF error & 66 & & & 66 & & \\
\hline Dataset "C" & \multicolumn{3}{|c|}{ Phase $2(2007,2008,2010)$} & \multicolumn{3}{|c|}{ Phase $3(2011,2012,2014)$} \\
\hline BR stability & DF & F-value & $\mathrm{p}$-value & DF & F-value & $p$-value \\
\hline BLOCK & 3 & 0.47 & 0.701 & 3 & 2.9 & 0.0415 \\
\hline SR & 1 & 0.93 & 0.3378 & 1 & 0.3 & 0.5875 \\
\hline$F G$ & 1 & 0.63 & 0.4304 & 1 & 0.01 & 0.9136 \\
\hline LEG & 1 & 1.84 & 0.1794 & 1 & 0.26 & 0.6133 \\
\hline GR & 1 & 0.01 & 0.9238 & 1 & 0.12 & 0.7289 \\
\hline $\mathrm{SH}$ & 1 & 0.23 & 0.6309 & 1 & 0.14 & 0.7082 \\
\hline $\mathrm{TH}$ & 1 & 0.03 & 0.8628 & 1 & 0.72 & 0.3978 \\
\hline DF model & 9 & 0.46 & 0.8979 & 9 & 1.29 & 0.258 \\
\hline DF error & 67 & & & 67 & & \\
\hline Cmic stability & DF & F-value & $p$-value & DF & F-value & $p$-value \\
\hline BLOCK & 3 & 1.91 & 0.137 & 3 & 0.6 & 0.6178 \\
\hline $\mathrm{SR}$ & 1 & 0.05 & 0.8266 & 1 & 0.16 & 0.6882 \\
\hline$F G$ & 1 & 0.56 & 0.4562 & 1 & 0.29 & 0.5939 \\
\hline LEG & 1 & 2.52 & 0.1173 & 1 & 1.31 & 0.2559 \\
\hline GR & 1 & 0.22 & 0.6425 & 1 & 0.01 & 0.9222 \\
\hline $\mathrm{SH}$ & 1 & 0.39 & 0.537 & 1 & 0 & 0.9571 \\
\hline $\mathrm{TH}$ & 1 & 0.81 & 0.3702 & 1 & 0.01 & 0.9156 \\
\hline DF model & 9 & 1.19 & 0.3137 & 9 & 0.45 & 0.904 \\
\hline DF error & 66 & & & 66 & & \\
\hline Dataset "D" & \multicolumn{3}{|c|}{ Phase $2(2007,2009,2010)$} & \multicolumn{3}{|c|}{ Phase $3(2011,2013,2014)$} \\
\hline BR stability & DF & F-value & $p$-value & DF & F-value & $p$-value \\
\hline BLOCK & 3 & 0.72 & 0.543 & 3 & 4.93 & 0.0038 \\
\hline SR & 1 & 3.02 & 0.0868 & 1 & 0.62 & 0.4322 \\
\hline$F G$ & 1 & 1.9 & 0.1731 & 1 & 0.05 & 0.8193 \\
\hline LEG & 1 & 2.24 & 0.1391 & 1 & 1.89 & 0.1741 \\
\hline GR & 1 & 1.56 & 0.2168 & 1 & 1.31 & 0.2568 \\
\hline $\mathrm{SH}$ & 1 & 1.43 & 0.2362 & 1 & 0.15 & 0.7044 \\
\hline $\mathrm{TH}$ & 1 & 0.29 & 0.59 & 1 & 0.34 & 0.5639 \\
\hline DF model & 9 & 1 & 0.4462 & 9 & 2.11 & 0.0411 \\
\hline DF error & 64 & & & 64 & & \\
\hline Cmic stability & DF & F-value & $p$-value & DF & F-value & $p$-value \\
\hline BLOCK & 3 & 1.88 & 0.1411 & 3 & 0.71 & 0.55 \\
\hline SR & 1 & 0.91 & 0.3448 & 1 & 0.02 & 0.9008 \\
\hline $\mathrm{FG}$ & 1 & 0.05 & 0.8192 & 1 & 0.01 & 0.9224 \\
\hline LEG & 1 & 0.1 & 0.7483 & 1 & 1.13 & 0.2926 \\
\hline GR & 1 & 0.43 & 0.5125 & 1 & 0.68 & 0.4133 \\
\hline $\mathrm{SH}$ & 1 & 0 & 0.988 & 1 & 0.9 & 0.3458 \\
\hline $\mathrm{TH}$ & 1 & 0.17 & 0.6847 & 1 & 0.59 & 0.4452 \\
\hline DF model & 9 & 0.95 & 0.4878 & 9 & 0.59 & 0.8044 \\
\hline DF error & 64 & & & 64 & & \\
\hline
\end{tabular}


3 Effects of plant diversity, functional group composition, and fertilization on soil microbial properties in experimental grassland

Tanja Strecker, Romain L. Barnard, Pascal A. Niklaus, Michael Scherer-Lorenzen, Alexandra Weigelt, Stefan Scheu and Nico Eisenhauer

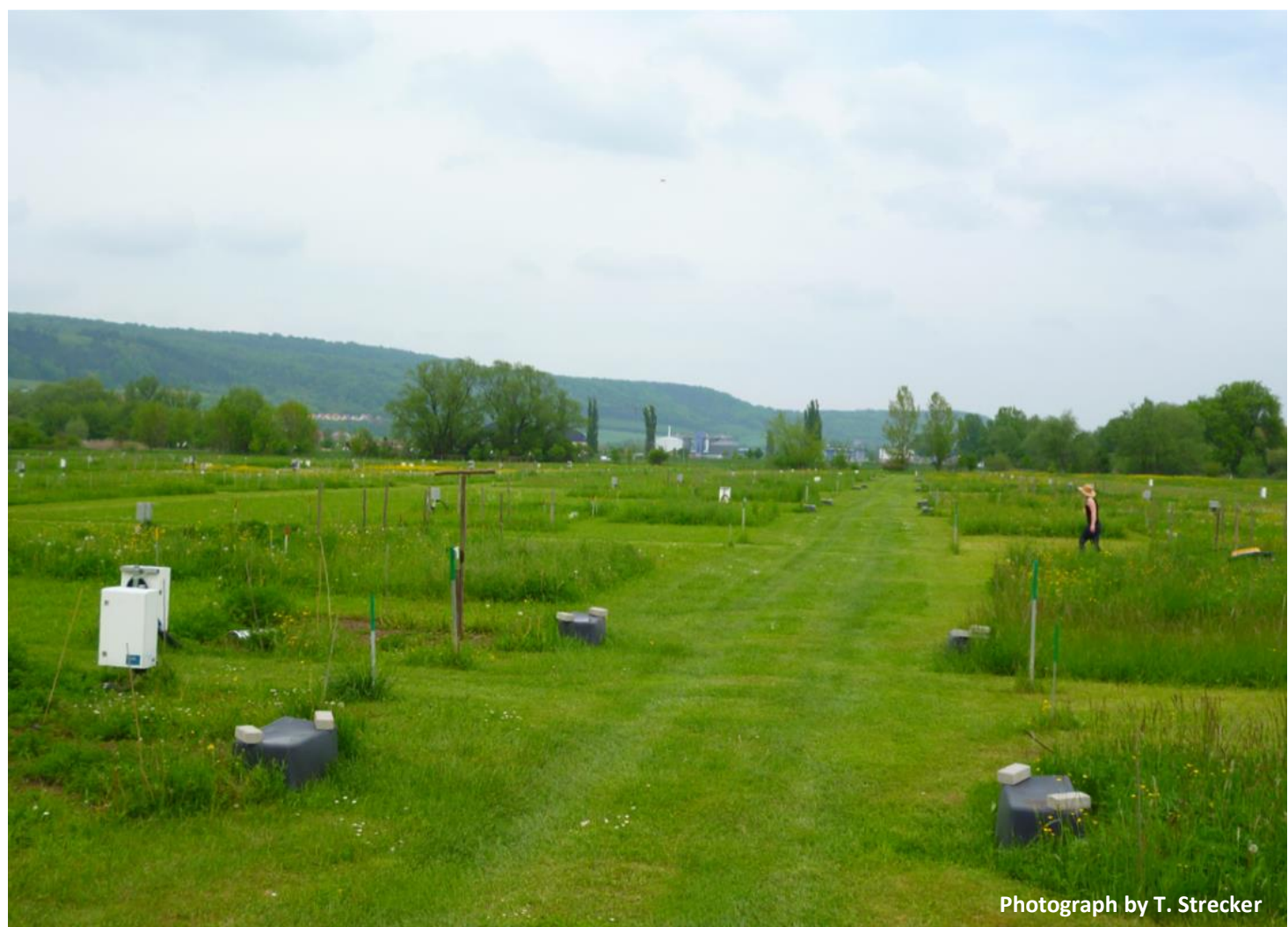

Published in:

Strecker T, Barnard RL, Niklaus PA, Scherer-Lorenzen M, Weigelt A, Scheu S, et al. (2015) Effects of Plant Diversity, Functional Group Composition, and Fertilization on Soil Microbial Properties in Experimental Grassland. PLoS ONE 10(5): e0125678. doi:10.1371/journal.pone.0125678 


\subsection{Abstract}

Background: Loss of biodiversity and increased nutrient inputs are two of the most crucial anthropogenic factors driving ecosystem change. Although both received considerable attention in previous studies, information on their interactive effects on ecosystem functioning is scarce. In particular, little is known on how soil biota and their functions are affected by combined changes in plant diversity and fertilization.

Methodology/Principal Findings: We investigated the effects of plant diversity, functional community composition, and fertilization on the biomass and respiration of soil microbial communities in a long-term biodiversity experiment in semi-natural grassland (Jena Experiment). Plant species richness enhanced microbial basal respiration and microbial biomass, but did not significantly affect microbial specific respiration. In contrast, the presence of legumes and fertilization significantly decreased microbial specific respiration, without altering microbial biomass. The effect of legumes was superimposed by fertilization as indicated by a significant interaction between the presence of legumes and fertilization. Further, changes in microbial stoichiometry (C-to$\mathrm{N}$ ratio) and specific respiration suggest the presence of legumes to reduce $\mathrm{N}$ limitation of soil microorganisms and to modify microbial $\mathrm{C}$ use efficiency.

Conclusions/Significance: Our study highlights the role of plant species and functional group diversity as well as interactions between plant community composition and fertilizer application for soil microbial functions. Our results suggest soil microbial stoichiometry to be a powerful indicator of microbial functioning under $\mathrm{N}$ limited conditions. Although our results support the notion that plant diversity and fertilizer application independently affect microbial functioning, legume effects on microbial $\mathrm{N}$ limitation were superimposed by fertilization, indicating significant interactions between the functional composition of plant communities and nutrient inputs for soil processes.

\subsection{Introduction}

Loss of biodiversity and increased nutrient inputs are two of the most crucial anthropogenic impacts on Earth's biosphere (Galloway et al. 2008, Butchart et al. 2010). Many studies have investigated the effects of species loss and eutrophication on ecosystem functioning; however, usually these factors have been considered in isolation. Knowledge of how these factors interactively influence ecosystem functions, such as decomposition and element cycling, is incomplete (but see e.g. (Chung et al. 2007, Isbell et al. 2013)).

Plant diversity plays an important role for ecosystem functions, such as primary productivity (Roscher et al. 2005, Cardinale et al. 2011) and its temporal and spatial stability (Tilman and Downing 1994, McCann 2000, Eisenhauer et al. 2011). Diverse grassland plant communities are more productive 
than plant communities with low diversity (Cardinale et al. 2011, Reich et al. 2012). Positive effects of species diversity on plant productivity in turn increase the input of organic carbon (C) to the soil, e.g., by producing more root exudates and shoot and root litter, thereby enhancing resource supply to decomposers (Zak et al. 2003, Leggewie and Welzer 2009). In particular, grasses may lead to high rates of soil microbial respiration and biomass due to their dense root system and high root exudation rates compared to other plant functional groups (Eisenhauer et al. 2010, Roscher et al. 2012).

Microbial communities are known to respond to the identity and diversity of $C$ substrates secreted by plant roots (Grayston et al. 1996, Johnson et al. 2008, Leggewie and Welzer 2009). As different plant species provide different biochemical compounds (Grayston et al. 1998), higher plant diversity is likely to improve the nutrition of microorganisms. Thus, microorganisms may not only profit from higher quantity, but also from higher variety of plant-derived resources in species-rich plant communities (Leggewie and Welzer 2009) and from lower temporal variability of C supply (Milcu et al. 2010). Consequently, microbially-driven processes, such as decomposition and element cycling, are affected by plant diversity (Hooper et al. 2005). Previous studies found microbial biomass to increase with increasing plant diversity (Zak et al. 2003, Eisenhauer et al. 2010, De Deyn et al. 2010), thereby also modifying biogeochemical cycles (Zak et al. 2003, Chung et al. 2007). However, previous studies also stressed the importance of certain plant functional groups for the composition and functioning of soil organisms (Spehn et al. 2000, Milcu et al. 2008). For instance, $\mathrm{N}$ fixation by rhizobia associated with legumes and high root biomass of grasses have been identified as major drivers of soil communities (Spehn et al. 2000, Eisenhauer et al. 2009b).

Given the significant role of $\mathrm{N}$ in shaping the composition of terrestrial ecosystems (Vitousek and Aber 1997), anthropogenic $\mathrm{N}$ inputs may alter the relationship between plant diversity and ecosystem functioning (Reich et al. 2001) as well as interactions between plants and soil organisms (Chung et al. 2007, Eisenhauer et al. 2012). Soil microorganisms are generally C-limited (Wardle 1992, Hobbie and Hobbie 2013, Farrell et al. 2014) and drive soil N transformations that, for a large part, require easily accessible $\mathrm{C}$ [28]. On the other hand, plants are typically $\mathrm{N}$ - and/or P limited (LeBauer and Treseder 2008). $\mathrm{N}$ addition therefore generally increases primary productivity and organic matter input to the soil (Gough et al. 2000, Dijkstra et al. 2005), and can directly contribute to microbial growth and activity (Treseder 2008), thereby leading to enhanced competition between plants and microorganisms for $\mathrm{N}$ (Kaye and Hart 1997). However, $\mathrm{N}$ addition can also adversely affect soil microbial biomass and activity (Treseder 2008). A number of mechanisms have been proposed to explain effects of increased $\mathrm{N}$ input on soil microbial growth, including soil acidification (Johnson et al. 1991, Fenn et al. 2006) as well as leaching of nutrients such as magnesium and calcium (Vitousek 
and Aber 1997, Treseder 2008). This leads to uncertainty on the overall outcome for soil microbial properties, especially when considering $\mathrm{N}$ addition in interaction with other environmental changes. We investigated effects of plant diversity and community composition, fertilizer addition, and their interactions on the activity (respiration) and biomass of soil microorganisms in temperate grassland. At the Jena Experiment field site, where we conducted this study, the positive effect of fertilizer on primary productivity was slightly strengthened by plant species richness (Weigelt et al. 2009). However, effects of fertilization mainly occurred in plots without legumes (Weigelt et al. 2009),suggesting significant interactive effects of plant community composition and fertilization on soil microorganisms. Specifically, we tested the following hypotheses:

(1) Plant species and functional group richness increase soil microbial respiration and biomass due to increased resource supply by plants.

(2) Plant functional groups (grasses, small herbs, tall herbs, legumes) differently affect soil microorganisms due to group-specific functional traits.

(3) Fertilization increases soil microbial biomass and respiration by enhancing plant productivity.

(4) Effects of plant diversity and community composition on soil microbial respiration and biomass are strengthened by fertilization.

\subsection{Material and Methods}

\section{Ethic statement}

Soil and plant biomass sampling were conducted with the permission of the city council of Jena, Germany.

\section{Study site}

The experiment was performed on the field site of the Jena Experiment, a long-term biodiversity study focusing on the role of biodiversity for ecosystem functioning in semi-natural temperate grassland (Roscher et al. 2004). The study site is situated in the floodplain of the Saale River near the city of Jena (Thuringia, Germany, $50^{\circ} 55^{`} \mathrm{~N}, 11^{\circ} 35^{`} \mathrm{E}, 130 \mathrm{~m}$ a. s. I.). Mean annual temperature is $9.3^{\circ} \mathrm{C}$ and mean annual precipitation is $587 \mathrm{~mm}$. Prior to establishment of the Jena Experiment in May 2002 the site had been used as arable field for about 40 years. The plant communities established in the Jena Experiment were assembled from plant species typical for hay meadows in Central Europe.

\section{Experimental design}

We established model grassland communities from a pool of 60 plant species differing in two aspects of plant diversity. The experiment included a gradient of plant species richness of 1, 2, 4, 8, 16 and 60 
plant species and a gradient of plant functional group richness of 1, 2, 3 and 4 different plant functional groups (for details see (Roscher et al. 2004)).Plant species were ascribed to functional groups using cluster analysis based on above- and belowground morphological traits, phenological traits, and $\mathrm{N}_{2}$ fixation (Roscher et al. 2004). The 60 species were grouped into grasses (16 species), small herbs (12 species), tall herbs (20 species), and legumes (12 species).

The experiment consists of 82 plots of $20 \times 20 \mathrm{~m}$. Plots are mown twice a year in June and September and weeded in April and July to maintain the target plant species composition. Plots were grouped into four blocks with two blocks sampled in the present study. Each block contains an equal number of plots of plant species and plant functional group richness levels. For more detailed information on the experimental design see (Roscher et al. 2004).

\section{Fertilizer treatment and aboveground plant biomass sampling}

Within each plot of $20 \times 20 \mathrm{~m}$, two subplots of $1.6 \times 4.0 \mathrm{~m}$ each were established; fertilizer was added to one of the subplots as mineral NPK pellets $\left(100 \mathrm{~kg} \mathrm{~N} \mathrm{ha}^{-1}, 44 \mathrm{~kg} \mathrm{P} \mathrm{ha}^{-1}, 83 \mathrm{~kg} \mathrm{~K} \mathrm{ha}^{-1}\right)$ in early spring (April 2006 and March 2007) and after the first mowing (June 2006 and June 2007); control subplots were kept unfertilized. Plots were mown twice a year during the growing season (June and September) at approximately $3 \mathrm{~cm}$ above soil surface. The cut material was removed from the plots. Mowing, fertilizing, and weeding were carried out block-wise, and the block effect was included in the statistical model. For more details see (Weigelt et al. 2009).

\section{Soil and aboveground plant biomass sampling}

Soil samples were taken in June 2008 in control and fertilized subplots in each of the plots of blocks 1 and 2. Eight samples were taken per subplot with a soil corer $(1.5 \mathrm{~cm}$ diameter, $15 \mathrm{~cm}$ deep), pooled and transferred to the laboratory. Roots and soil animals were picked by hand and the samples sieved through $2 \mathrm{~mm}$ mesh. Aboveground plant biomass was harvested subplot-wise in one randomly placed $0.2 \times 0.5 \mathrm{~m}$ area, dried $\left(70^{\circ} \mathrm{C}, 48 \mathrm{~h}\right)$ and weighed (Weigelt et al. 2009).

\section{Soil microbial biomass, C-to-N ratio, and respiration}

Microbial biomass C (MBC) was measured by substrate-induced respiration (SIR; see below) and chloroform fumigation extraction (CFE); soil microbial biomass determined by the two methods correlated significantly $\left(R^{2}=0.55, P<0.001\right)$. Combined with measurements of microbial biomass $N$ (MBN), the latter was used for calculating microbial C-to-N ratio, whereas the former was used to calculate microbial specific respiration as both basal respiration and substrate-induced respiration were measured from the same soil sample (see below). 
For measurement of microbial biomass by chloroform fumigation extraction ( $\mathrm{MBC}_{\mathrm{CFE}}$ ) two subsamples of $7 \mathrm{~g}$ were taken from each soil sample, one was fumigated with chloroform vapour for $24 \mathrm{~h}$, while the other remained unfumigated. Fumigated and unfumigated samples were extracted with $40 \mathrm{ml} 0.5 \mathrm{M} \mathrm{K}_{2} \mathrm{SO}_{4}$ with agitation for $30 \mathrm{~min}$, the extracts were filtered and frozen. Total $\mathrm{C}$ and $\mathrm{N}$ in the extracts was measured by dry combustion in a DIMA-TOC 100 Analyzer (Dimatec, Essen, Germany). $\mathrm{MBC}_{\mathrm{CFE}}$ was calculated as [(total $\mathrm{C}$ in fumigated soil) - (total $\mathrm{C}$ in non-fumigated soil)] / 0.45 (Wu et al. 1990). MBN was calculated as [(total $\mathrm{N}$ in fumigated soil) - (total $\mathrm{N}$ in non-fumigated soil)]/0.54 (Brookes et al. 1985).Gravimetric soil water content was measured by drying subsamples at $105^{\circ} \mathrm{C}$ for $48 \mathrm{~h}$. Microbial biomass $\mathrm{C}$-to-N ratio was determined from data on soil microbial biomass C and N (Jenkinson and Powlson 1976, Brookes et al. 1985, Joergensen and Mueller 1996). Microbial basal respiration was measured using an $\mathrm{O}_{2}$ microcompensation apparatus (Scheu 1992). $\mathrm{O}_{2}$ consumption of soil microorganisms in fresh soil equivalent to $3.5 \mathrm{~g}$ dry weight was measured at $22^{\circ} \mathrm{C}$ over a period of $24 \mathrm{~h}$. Basal respiration $\left[\mu \mathrm{L} \mathrm{O}_{2} \mathrm{~g}^{-1}\right.$ dry soil h$\left.{ }^{-1}\right]$ was calculated as mean of the $\mathrm{O}_{2}$ consumption rates of hours 14 to 24 after the start of measurements. Substrate-induced respiration (Anderson and Domsch 1978) was determined by adding D-glucose to saturate catabolic enzymes of microorganisms according to preliminary studies ( $4 \mathrm{mg} \mathrm{g}^{-1}$ dry soil solved in $400 \mu \mathrm{L}$ deionized water). Maximum initial respiratory response (MIRR; $\left[\mu \mathrm{L} \mathrm{O}_{2} \mathrm{~g}^{-1} \mathrm{dry}\right.$ soil $\left.\mathrm{h}^{-1}\right]$ ) was calculated as mean of the lowest three $\mathrm{O}_{2}$ consumption values within the first $10 \mathrm{~h}$ after glucose addition. $\mathrm{MBC}_{\mathrm{SIR}}\left[\mu \mathrm{g} \mathrm{Cg}^{-1} \mathrm{dry}\right.$ soil] was calculated as $38 \times$ MIRR (Beck et al. 1997). Data on microbial basal respiration and $\mathrm{MBC}_{\text {SIR }}$ were used to calculate microbial specific respiration (metabolic oxygen quotient; $\left[\mu \mathrm{L} \mathrm{O}_{2} \mathrm{mg}^{-1} \mathrm{MBC} \mathrm{h}\right.$ ${ }^{1}$ ]) as a measure of microbial $C$ use efficiency by dividing basal respiration by $\mathrm{MBC}_{\mathrm{SIR}}$ (Anderson and Domsch 1985). $\mathrm{MBC}_{S I R}$ was used to analyze the response of microbial biomass $C$ to experimental treatments, as done in previous studies of the Jena Experiment (Eisenhauer et al. 2010).

\section{Statistical analyses}

Data (except microbial C-to-N ratio) were log-transformed to meet the requirements of parametric statistical tests. Plant species richness was log-transformed to linearize the saturating relationship between plant diversity and soil microbial properties (Hooper et al. 2005). Effects of block, plot, (logtransformed) plant species richness, plant functional group richness, fertilization, and presence of grasses, tall herbs, small herbs, and legumes as well as interactions between plant community factors and fertilization were analyzed by sequential split-plot general linear models (GLM, type I sum of squares). The effects of block and plant community factors were tested against plot in order to avoid pseudo-replication, whereas fertilization and interactions were tested against the total error. Multiple comparisons of means were conducted using Tukey's honest significant difference test. Statistical analyses were performed using SAS 9.3 (SAS Institute, Cary, USA). Regressions between 
microbial C-to-N ratio as well as aboveground plant biomass and microbial properties were carried out using Sigmaplot 10.0 (Systat Software Inc., San Jose, USA).

\subsection{Results}

Soil water content and aboveground plant biomass were significantly increased by plant species richness ( $F=13.12, P<0.001, R^{2}=0.16$, and $F=58.45, P<0.001, R^{2}=0.43$, respectively). Moreover, plant species richness significantly increased basal respiration and $\mathrm{MBC}_{\mathrm{SIR}}$ (Fig. 1a, b; Table1). Aboveground plant biomass and soil water content correlated positively with MBN (plant biomass: $F=8.31, P<0.01$, $\mathrm{R}^{2}=0.09$,Fig. 1 ; ; soil water: $F=89.35, P<0.001, R^{2}=0.53$ ) and $M B C_{S I R}$ (plant biomass: $F=10.88, P<0.01$, $\mathrm{R}^{2}=0.12$, Fig. $1 \mathrm{~d}$; soil water: $\left.\mathrm{F}=47.18, \mathrm{P}<0.001, \mathrm{R}^{2}=0.37\right)$. Nevertheless, plant diversity effects on soil microbial respiration and $\mathrm{MBC}_{S \mathrm{SIR}}$ remained (marginally) significant even if accounting for the effect of aboveground plant biomass (respiration: $\mathrm{F}=17.77, \mathrm{P}<0.001$; microbial biomass: $\mathrm{F}=7.40, \mathrm{P}<0.01$ ) or soil water content (respiration: $F=5.53, P<0.05$; microbial biomass: $F=3.23, P<0.1$ ), indicating that plant diversity effects on soil microbial properties cannot be fully explained by aboveground plant biomass production and soil water content. Plant functional group richness significantly enhanced basal respiration, but only when fitted before plant species richness (Fig. 1e).

Table 1. Fertilization and plant community effects on soil microbial properties.

\begin{tabular}{|c|c|c|c|c|c|c|c|c|c|c|c|c|c|c|c|}
\hline & \multicolumn{3}{|c|}{$\log B R$} & \multicolumn{3}{|c|}{$\log M B C_{S I R}$} & \multicolumn{3}{|c|}{$\log q O_{2}$} & \multicolumn{3}{|c|}{$\log M B N$} & \multicolumn{3}{|c|}{ C-to-N ratio } \\
\hline & d.f. & $\mathbf{F}$ & $\mathbf{P}$ & d.f. & $\mathbf{F}$ & $\mathbf{P}$ & d.f. & $\mathbf{F}$ & $\mathbf{P}$ & d.f. & $\mathbf{F}$ & $\mathbf{P}$ & d.f. & $\mathbf{F}$ & $\mathbf{P}$ \\
\hline Block & 1,33 & 4.8 & 0.0366 & 1,33 & 16.1 & 0.0003 & 1,33 & 3.7 & 0.0621 & 1,32 & 18 & 0.0002 & 1,32 & 7.9 & 0.0083 \\
\hline $\log S R$ & 1,32 & 12 & $0.0015 \uparrow$ & 1,32 & 8.21 & $0.0073 \uparrow$ & 1,32 & 1.1 & 0.2988 & 1,32 & 2.5 & 0.122 & 1,32 & 0 & 0.8984 \\
\hline FR & 1,32 & 6.9 & $0.0132 \uparrow$ & 1,32 & 3.04 & 0.0906 & 1,32 & 1.7 & 0.2088 & 1,32 & 0.6 & 0.458 & 1,32 & 0.2 & 0.689 \\
\hline GR & 1,32 & 0.5 & 0.4994 & 1,32 & 0.44 & 0.5133 & 1,32 & 2.7 & 0.1116 & 1,32 & 3.1 & 0.087 & 1,32 & 5 & 0.0327 \\
\hline LEG & 1,32 & 7.4 & $0.0103 \downarrow$ & 1,32 & 1.56 & 0.2203 & 1,32 & 4 & $0.0552 \downarrow$ & 1,32 & 0.3 & 0.601 & 1,32 & 6.5 & 0.0156 \\
\hline TH & 1,32 & 0.3 & 0.5856 & 1,32 & $<0.01$ & 0.9706 & 1,32 & 0.4 & 0.5182 & 1,32 & 1.5 & 0.238 & 1,32 & 0.2 & 0.6669 \\
\hline SH & 1,32 & 9 & $0.0051 \uparrow$ & 1,32 & 7.43 & $0.0103 \uparrow$ & 1, 32 & 0.4 & 0.5416 & 1,32 & 1.9 & 0.179 & 1,32 & 0.2 & 0.643 \\
\hline Plot & 32,33 & 1 & 0.4781 & 32,33 & 2.36 & 0.0083 & 32,33 & 1 & 0.4507 & 32,32 & 5.8 & $<.0001$ & 32,32 & 6.1 & $<.0001$ \\
\hline FERT & 1,32 & 25 & $<.0001 \downarrow$ & 1,32 & 0.22 & 0.6418 & 1,32 & 45 & $<.0001 \downarrow$ & 1,32 & 0 & 0.943 & 1,32 & 0.4 & 0.5202 \\
\hline SR * FERT & 1,32 & 2.7 & 0.1073 & 1,32 & 2.62 & 0.1152 & 1,32 & 0.7 & 0.3947 & 1,32 & 2.2 & 0.144 & 1,32 & 0 & 0.9049 \\
\hline FR * FERT & 1,32 & 2.8 & 0.1068 & 1,32 & 0.53 & 0.4738 & 1,32 & 2.4 & 0.1283 & 1,32 & 1.5 & 0.237 & 1,32 & 0.1 & 0.8107 \\
\hline GR * FERT & 1,32 & 2.1 & 0.1545 & 1,32 & $<0.01$ & 0.9568 & 1,32 & 3.3 & 0.0773 & 1,32 & 0 & 0.892 & 1,32 & 2.1 & 0.1619 \\
\hline LEG * FERT & 1,32 & 5 & 0.0322 & 1,32 & 0.01 & 0.9343 & 1,32 & 7.8 & 0.0085 & 1,32 & 0.8 & 0.394 & 1,32 & 0.1 & 0.7176 \\
\hline TH * FERT & 1,32 & 0.1 & 0.7453 & 1,32 & 0.07 & 0.7912 & 1,32 & 0 & 0.8335 & 1,32 & 0.2 & 0.656 & 1,32 & 0.3 & 0.5655 \\
\hline SH * FERT & 1,32 & 0.3 & 0.5753 & 1,32 & 0.1 & 0.7579 & 1,32 & 0.2 & 0.6323 & 1,32 & 0.1 & 0.727 & 1,32 & 0.4 & 0.5201 \\
\hline d.f. error & 33 & & & 33 & & & 33 & & & 32 & & & 32 & & \\
\hline d.f. model & 46 & & & 46 & & & 46 & & & 46 & & & 46 & & \\
\hline F-statistic & 2.24 & & & 3.49 & & & 2.22 & & & 7.48 & & & 6.43 & & \\
\hline
\end{tabular}

GLM table of F-values for effects of block, plot, fertilization (FERT), log-transformed plant species richness(logSR), plant functional group richness (FR), presence of grasses (GR), legumes (LEG), small herbs (SH) or tall herbs (TH) and the respective interactions between fertilization and plant community properties on log-transformed data of microbial basal respiration $(\log B R)$, microbial biomass $C\left(\log M B C_{S I R}\right)$, microbial specific respiration $\left(\operatorname{logq} \mathrm{O}_{2}\right)$, and microbial biomass $\mathrm{N}$ ( $\log \mathrm{MBN}$ ) and un-transformed microbial C-to-N-ratio. d.f. = degrees of freedom; $\mathrm{F}=\mathrm{F}$ value; $P=p$-value. $\uparrow / \downarrow=$ increase/decrease with increasing diversity level or in presence of the respective plant functional group or treatment. Significant effects $(P \leq 0.05)$ are given in bold. 

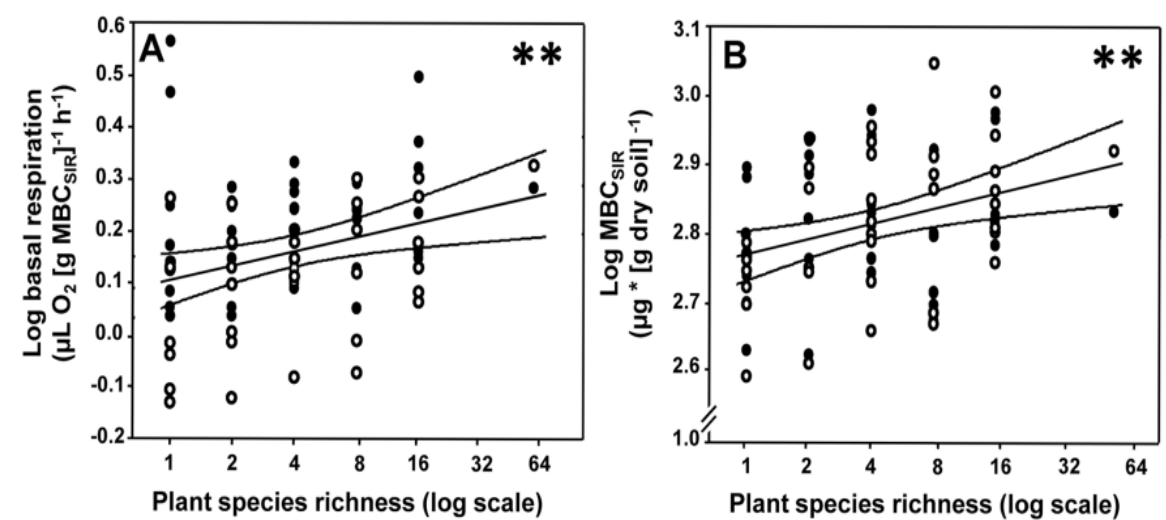

Figure 1. Effects of plant diversity and shoot biomass on microbial basal respiration and soil microbial biomass $\mathrm{C}$ and $\mathbf{N}$. Effects of plant species richness on $(A)$ basal respiration and (B) soil microbial biomass C. (C)
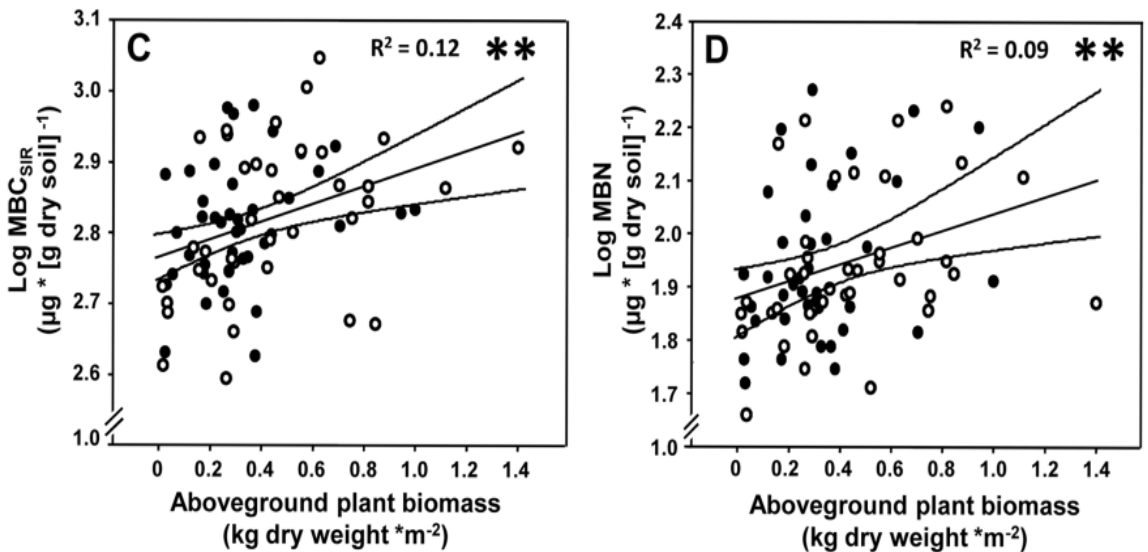

Relationships between aboveground plant biomass (dry weight) and soil microbial biomass $C$, and (D) between aboveground plant biomass and soil microbial biomass $N$. (E) Effects of plant functional group richness on basal

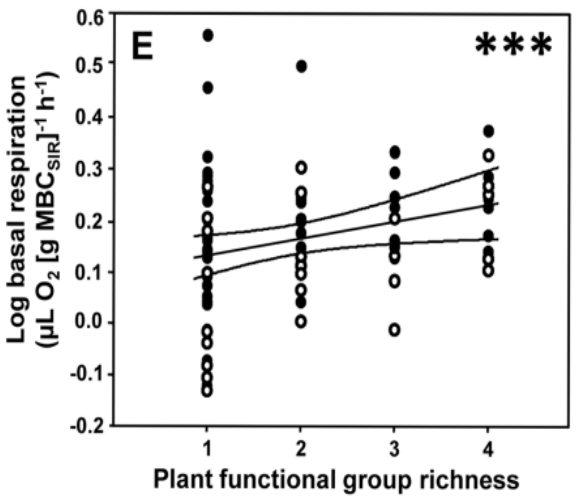
respiration. Note log scale of y-axes. Black dots are measures from unfertilized plots, white dots from fertilized plots. Regression lines with $95 \%$ confidence bands. Asterisks indicate significant differences $\left({ }^{*} \mathrm{p} \leq 0.01\right.$, $* * * p \leq 0.001)$.

The interaction between the presence of legumes and fertilization significantly affected basal respiration and specific respiration: legumes reduced basal and specific respiration in non-fertilized plots, but increased both of these variables in fertilized plots (Fig. 2a, b). As indicated by regression analyses specific respiration increased significantly with increasing microbial C-to- $\mathrm{N}$ ratio in nonfertilized but not in fertilized plots (Fig. 2c). The presence of legumes significantly decreased microbial C-to-N ratio (-12\%; Fig. 3a), while the presence of grasses significantly enhanced it (+9\%; Fig.

3b).Further, the presence of small herbs significantly increased basal respiration (+18\%; Fig. 3c) and soil $\mathrm{MBC}_{\mathrm{SIR}}$ (+18\%; Fig. 3d). Neither MBN nor microbial C-to-N ratio were significantly affected by plant diversity measures or by fertilization. 

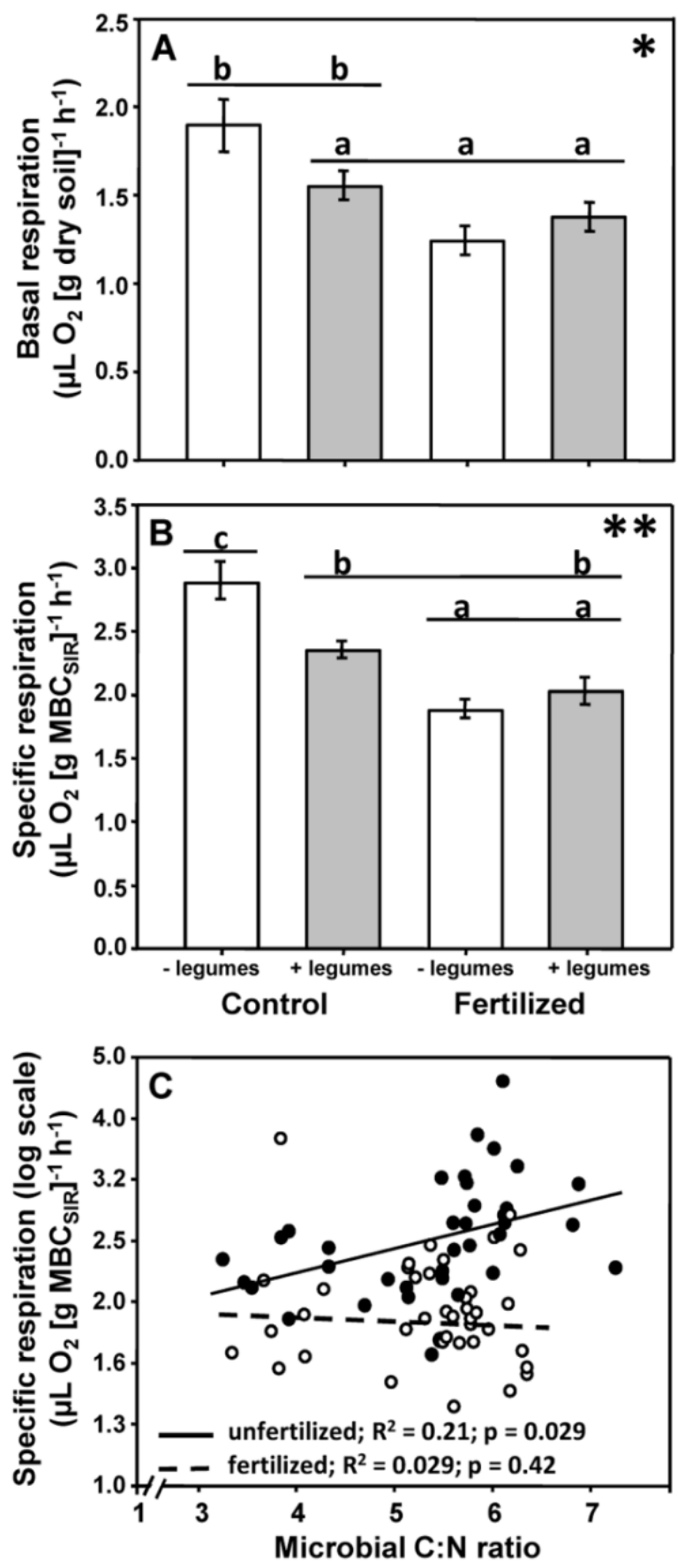

Figure 2. Interactive effects of the presence of legumes and fertilization on microbial basal respiration and specific respiration, and correlation between microbial C-to- $\mathbf{N}$ ratio and microbial specific respiration in fertilized and unfertilized plots. $(A)$ Interactive effects of the presence of legumes and fertilization on soil microbial basal respiration and (B) specific respiration. Means with standard error bars. Different letters indicate significant differences $\left({ }^{*} p \leq 0.05 ;{ }^{*} p \leq 0.01\right)$. (C) Regressions between soil microbial C-to-N (C:N) ratio and specific respiration in unfertilized plots (black line, black dots) and fertilized plots (dashed line, white dots) with coefficients of determination and $p$-values of slopes. 

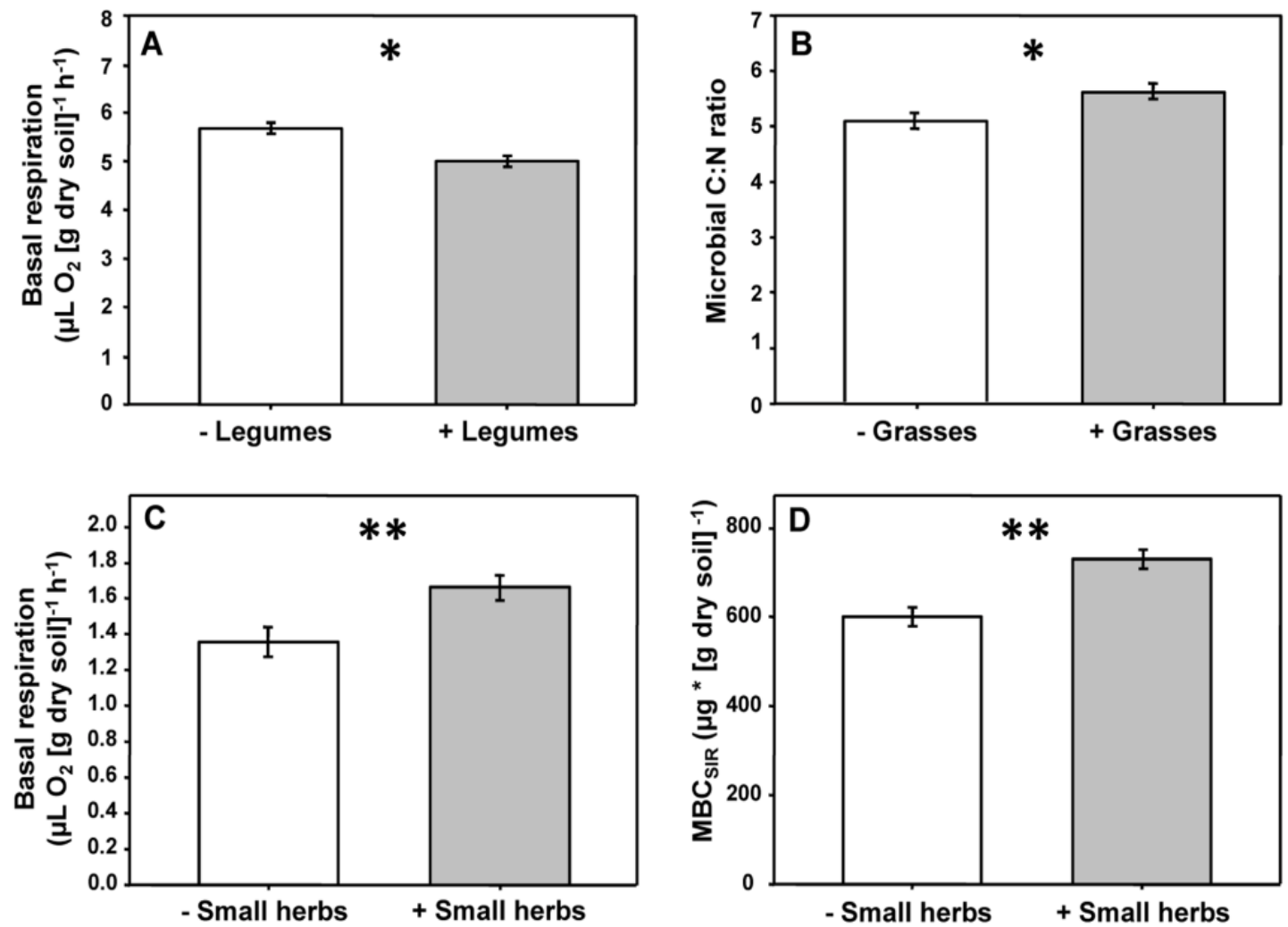

Figure 3. Effects of plant functional groups on microbial properties. Effects of (A) legumes and (B) grasses on microbial C-to-N (C:N) ratio. Effects of small herbs on (C) basal respiration and (D) soil microbial biomass $C$. Asterisks indicate significant differences $\left({ }^{*} p \leq 0.05,{ }^{* *} p \leq 0.01\right)$. Means with standard error bars.

\subsection{Discussion}

We investigated effects of plant community properties and fertilization on soil microbial biomass, respiration and $\mathrm{C}$ use efficiency. Plant community properties significantly affected soil microbial activity (respiration) and biomass, while fertilization affected microbial activity and C use efficiency (specific respiration). In contrast to our hypothesis, effects of plant diversity (species and functional group richness) were independent of fertilization. Our results highlight the importance of plant diversity for increased basal respiration and soil microbial biomass and are in line with previous studies (Spehn et al. 2000, Zak et al. 2003, Chung et al. 2007). Plant functional groups, legumes, grasses, and small herbs contrastingly affected soil microbial properties. The significant correlation between soil water content and plant species richness as well as the weaker plant species richness effect when fitted after soil water content suggests that effects of plant diversity on soil microbial respiration and biomass are mediated, at least in part, by changes in soil water content (Joffre et al. 2003, Lange et al. 2014). Our microbial stoichiometry results (C-to-N ratio) suggest that legumes reduced $\mathrm{N}$ limitation of soil microorganisms, and that under $\mathrm{N}$ limitation microbial stoichiometry determines the functioning of soil microbial communities (as indicated by changes in microbial specific respiration). Additionally, the ratio between fungal and bacterial biomass may have shifted 
towards bacteria in the presence of legumes as fungal biomass is known to decrease in presence of legumes and with increased $\mathrm{N}$ input (de Vries et al. 2006).

In accordance with our hypothesis 1, plant species richness significantly increased soil microbial biomass and basal respiration. Plant diversity effects on soil microbial properties remained significant even after accounting for the effect of aboveground plant biomass. This suggests that plant diversity impacted soil microbial functioning via mechanisms not directly related to aboveground plant productivity. Plant functional group richness increased microbial basal respiration, but did not significantly affect the other soil microbial parameters measured. The lack of effects of plant diversity on microbial specific respiration was unexpected, as Wardle and Ghani (Wardle and Ghani 1995) showed microbial specific respiration to decrease in more stable ecosystems such as those with high plant diversity (Eisenhauer et al. 2013). High diversity plant communities are likely to provide high amounts of resources to decomposer communities (Tilman and Downing 1994). Aboveground plant biomass correlated positively with $\mathrm{MBC}_{\mathrm{SIR}}$ and $\mathrm{MBN}$ despite plants were cut and residues were removed from the plots after mowing, suggesting that enhanced $\mathrm{C}$ and $\mathrm{N}$ availability to soil microorganisms in high diversity communities was due to increased amounts of root-derived resources (Ravenek et al. 2014). Microbial communities in the rhizosphere are known to heavily rely on root exudates (Baudoin et al. 2003) and other rhizodeposits (Dennis et al. 2010). Further, more constant $\mathrm{C}$ and $\mathrm{N}$ inputs into the soil and high plant coverage in high diverse plant communities (Tilman et al. 1997, Eisenhauer et al. 2009a) as well as more constant and favourable soil moisture (Wardle 1992) may have contributed to higher soil microbial respiration and biomass at high plant diversity (Eisenhauer et al. 2010).

Hypothesis 2 suggested plant functional groups to differently affect soil microbial properties, due to group-specific plant functional traits (Díaz and Cabido 2001, Roscher et al. 2004, Eisenhauer et al. 2010). Supporting this hypothesis, the presence of legumes significantly reduced basal respiration, specific respiration, and microbial C-to-N ratio, while small herbs significantly enhanced soil microbial basal respiration and biomass. The fact that legumes did not alter soil microbial biomass is in line with findings of Zak et al. (Zak et al. 2003), but contrasts with other plant diversity studies in experimental grasslands (e.g., (Biederbeck et al. 2005, Milcu et al. 2008)). Eisenhauer et al. (Eisenhauer et al. 2010) found increased soil microbial biomass in the presence of legumes at the same field site four years before the present study, but this effect disappeared two years later, indicating a change in the effects of certain plant functional groups on microbial properties over time. $\mathrm{N}_{2}$ fixation by legumes requires high amounts of phosphorus (Chaudhary et al. 2008), potentially leading to stronger $\mathrm{P}$ limitation of soil microorganisms as compared to plant communities without legumes. Indeed, Oelmann et al. (Oelmann et al. 2007) found legumes to reduce labile inorganic $\mathrm{P}$ compounds at our study site. Thus, competition for $\mathrm{P}$ between soil microorganisms and 
legumes may explain the missing legume effect on soil microbial biomass in this study (Kuzyakov and Xu 2013). Lower microbial C-to-N ratio in the presence of legumes indicates improved nitrogen supply of soil microorganisms due to $\mathrm{N}_{2}$ fixation by legumes. Therefore, the reduced microbial specific respiration in the presence of legumes likely was due to improved $C$ use efficiency induced by increased $\mathrm{N}$ supply.

In contrast to legumes, the presence of grasses increased microbial C-to-N ratio and specific respiration, indicating reduced microbial $C$ use efficiency. Grasses are characterized by higher tissue C-to-N ratios than other plant functional groups and by building dense fibrous root systems with high specific root length (Jackson et al. 1997, Weigelt et al. 2008). Thus, grasses likely enhance microbial activity and biomass by providing large amounts of rhizodeposits (Krift et al. 2001). However, we suggest grasses to force soil microorganisms to invest more energy into metabolic activity to alleviate $\mathrm{N}$ limitation, resulting in competition for $\mathrm{N}$ between soil microorganisms and plants (Kaye and Hart 1997). Reduced soil water content in the presence of grasses likely aggravated the competition between plants and microorganisms for capturing N (Kaye and Hart 1997, Schimel et al. 1997). Small herbs are generally shallow-rooting, with most roots in the soil layer sampled in the present study. Presumably, increased soil microbial activity and biomass in the presence of small herbs in our study were due to increased rhizodeposition in the topsoil (Martens 1990, Paterson 2003, Paterson et al. 2006).

In contrast to hypothesis 3 , fertilization did not affect soil microbial biomass. In earlier studies effects of fertilization on soil microbial biomass have been found to be positive (Zhong and Cai 2007, Chu et al. 2007), negative (Treseder 2008, Ramirez et al. 2012) or neutral (Donnison et al. 2000), suggesting that higher plant productivity due to fertilization does not uniformly translate into increased soil microbial biomass. A number of mechanisms may explain the lack of fertilizer effects on soil microbial biomass. First, the removal of the aboveground biomass after mowing prevented aboveground litter from entering the soil. Second, fertilization generally reduces plant resource allocation to belowground structures, resulting in reduced root biomass (Bardgett et al. 1999, Phillips and Fahey 2007, Wang et al. 2012), and hence, reduced root deposits serving as resources for microorganisms. Third, as the response of soil microbial communities to changes in plant community composition has been shown to lag behind by several years (Eisenhauer et al. 2010), our two-year study may have been too short to uncover the full effects of fertilization on soil microorganisms (Treseder 2008). Soil microbial activity may have responded earlier to fertilization than microbial biomass, due to fertilizer-mediated changes in rhizodeposition (Chung et al. 2007) or reduced root exudation (Dijkstra et al. 2005).

Fertilization superimposed the negative legume effect on basal and specific respiration. Legumes are known to negatively respond to $\mathrm{N}$ fertilization as they may be outcompeted by grasses starting to 
grow earlier in the season and having a more efficient root system for nutrient uptake (Wilman and Fisher 1996, Brum et al. 2009). Notably, both legumes and fertilizer addition decreased microbial respiration, but the underlying mechanisms are likely to be different: legumes decreased microbial activity probably by improving organic $\mathrm{N}$ supply, while fertilization presumably acted through decreasing rhizosphere priming effects (Kuzyakov 2002) and simultaneously through provision of inorganic $\mathrm{N}$ used by microorganisms (Harrison et al. 2008). Indeed, earlier studies in forest soils also found $\mathrm{N}$ amendment to decrease soil microbial activity (Bowden et al. 2004, Phillips and Fahey 2007). Although it remains elusive whether decreased specific respiration was induced by inhibition of microbial metabolism [33] or by increased microbial C use efficiency (Wardle and Ghani 1995), we assume the latter to be more likely as fertilization alleviates $\mathrm{N}$ limitation of microorganisms with high C-to-N ratio. In non-fertilized plots, microbial C-to-N ratio was positively correlated with specific respiration, while this was not the case in fertilized plots, indicating that soil microorganisms at the field site of the Jena Experiment are $\mathrm{N}$ limited as indicated in earlier studies (Eisenhauer et al. 2010). Hence, our results demonstrate microbial stoichiometry to be a powerful indicator of soil microbial functioning in $\mathrm{N}$ limited systems (Hartman and Richardson 2013). In addition, microbial C-to-N ratios at our study site are close to that of bacteria (i.e., 5:1 (Cleveland and Liptzin 2007)), suggesting that bacteria rather than fungi were responsible for the observed responses (Lange et al. 2014). Contrary to hypothesis 4 , fertilization did not strengthen the effects of plant diversity (species richness and functional group richness) on soil microbial respiration or biomass. Except for the interaction between legumes and fertilizer addition discussed above, fertilization and plant diversity did not in an interactive way affect any soil microbial parameters measured. This contrasts earlier studies reporting the addition of $\mathrm{N}$ to increase effects of plant diversity on ecosystem functioning (Reich et al. 2001, 2004), or to induce positive biodiversity-ecosystem functioning relationships (He et al. 2002). At the Jena Experiment field site Weigelt et al. (Weigelt et al. 2009) found $N$ fertilization to slightly increase effects of plant diversity on primary production. Overall, this suggests that plant diversity and fertilization act through decoupled mechanisms on microbial properties with the effects being independent of $\mathrm{N}$ fertilizer-induced increase in plant productivity in more diverse plant communities. Alternatively, the weak interactive effect of plant diversity and fertilization on plant biomass production may not be strong enough to cascade to changes in soil microbial respiration and biomass.

\subsection{Conclusions}

Overall, plant diversity beneficially affected soil microorganisms, likely due to changes in rhizodeposition, plant productivity, and soil moisture. Our results underline the importance of plant functional groups, in particular legumes, for soil microbial functioning and stoichiometry. Thus, promoting high plant diversity in managed grasslands, by including certain plant functional groups, is 
likely to beneficially affect microbially-driven ecosystem functions such as decomposition and element cycling. Generally, effects of plant diversity and fertilization were independent, while the effect of legumes on microbial $C$ use efficiency was modified by fertilization. Both legumes and fertilization alleviated $\mathrm{N}$ limitation of soil microorganisms, but this likely was due to different mechanisms with legumes acting via provisioning of organic $\mathrm{N}$, and fertilization acting via provisioning of inorganic $\mathrm{N}$ and decreasing rhizosphere priming effects. Our results suggest that both fertilizer application and the presence of legumes reduce soil microbial $\mathrm{N}$ limitation, and thereby modulate soil microbial stoichiometry and functioning. To mechanistically understand the observed response of microorganisms root-derived resources need closer investigation.

\subsection{Supporting Information}
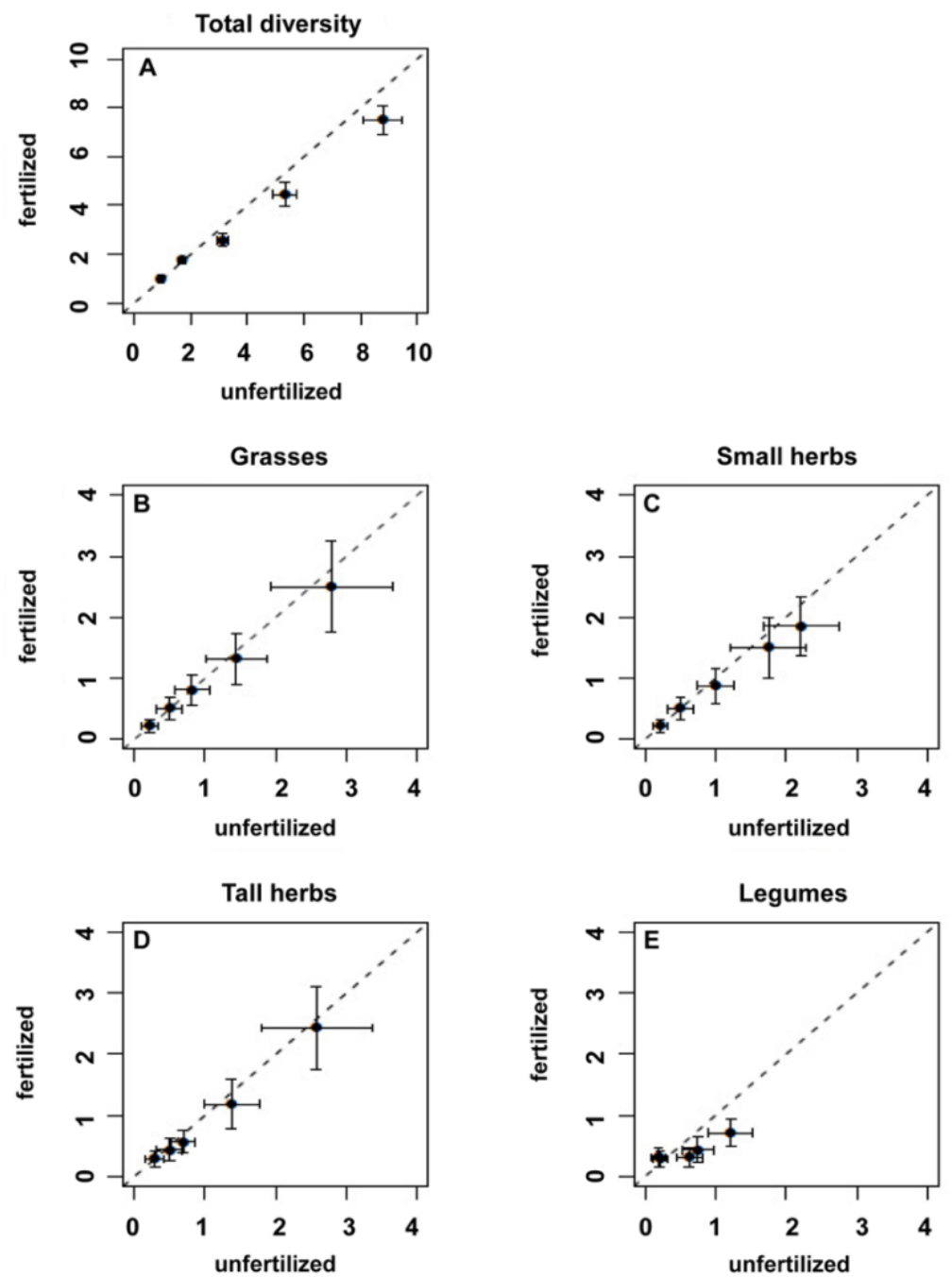

S1 Fig. Realized species richness in fertilized and unfertilized subplots. Number of realized species in unfertilized vs. fertilized subplots for (A) all species, (B) grasses, (C) small herbs, (D) tall herbs and (E) legumes. Given are means (+/-standard error) recorded in 2008 on plots with sown diversity levels of 1, 2, 4, 8 and 16 plant species. Species richness was derived from species specific frequency measurements in 30 quadrats of 10 $x 10 \mathrm{~cm}$ in size within the core area of $1 \mathrm{~m}^{2}$ of treated subplots. 


\subsection{Acknowledgments}

We thank Theodora Volovei for technical assistance.

\subsection{References}

Anderson J, Domsch K. A physiological method for the quantitative measurement of microbial biomass in soils. Soil Biol Biochem. 1978; 10:215-21.

Anderson T-H, Domsch KH. Determination of ecophysiological maintenance carbon requirements of soil microorganisms in a dormant state. Biol Fertil Soils. 1985 Sep; 1(2):81-9.

Bardgett RD, Mawdsley JL, Edwards S, Hobbs PJ, Rodwell JS, Davies WJ. Plant species and nitrogen effects on soil biological properties of temperate upland grasslands. Funct Ecol. 1999 Oct; 13- (5):650-60.

Baudoin E, Benizri E, Guckert A. Impact of artificial root exudates on the bacterial community structure in bulk soil and maize rhizosphere. Soil Biol Biochem. 2003 Sep; 35(9):1183-92.

Beck T, Joergensen R. An inter-laboratory comparison of ten different ways of measuring soil microbial biomass C. Soil Biol Biochem. 1997; 29(7):1023-32.

Biederbeck VO, Zentner RP, Campbell C a. Soil microbial populations and activities as influenced by le-gume green fallow in a semiarid climate. Soil Biol Biochem. 2005 Oct; 37(10):1775-84.

Bowden RD, Davidson E, Savage K, Arabia C, Steudler P. Chronic nitrogen additions reduce total soil respiration and microbial respiration in temperate forest soils at the Harvard Forest. For Ecol Manage. $2004 \mathrm{Jul}$; 196(1):43-56.

Brookes $\mathrm{P}$, Landman A. Chloroform fumigation and the release of soil nitrogen: a rapid direct extraction method to measure microbial biomass nitrogen in soil. Soil Biol Biochem. 1985; 17(6):837-42.

Brum OB, López S, García R, Andrés S, Calleja A. Influence of harvest season, cutting frequency and nitrogen fertilization of mountain meadows on yield, floristic composition and protein content of herb- age. Rev Bras Zootec. 2009; 38:596-604.

Butchart SHM, Walpole M, Collen B, van Strien A, Scharlemann JPW, Almond REA, et al. Global biodi- versity: indicators of recent declines. Science. 2010 May 28; 328(5982):1164-8. doi: 10.1126/science. 1187512 PMID: 20430971

Cardinale BJ, Matulich KL, Hooper DU, Byrnes JE, Duffy E, Gamfeldt L, et al. The functional role of pro- ducer diversity in ecosystems. Am J Bot. 2011 Mar; 98(3):572-92. doi: 10.3732/ajb.1000364 PMID: 21613148

Chaudhary MI, Adu-Gyamfi JJ, Saneoka H, Nguyen NT, Suwa R, Kanai S, et al. The effect of phospho- rus deficiency on nutrient uptake, nitrogen fixation and photosynthetic rate in mashbean, mungbean and soybean. Acta Physiol Plant. 2008 Feb 28; 30(4):537-44.

Chu H, Lin X, Fujii T, Morimoto S, Yagi K, Hu J, et al. Soil microbial biomass, dehydrogenase activity, bacterial community structure in response to long-term fertilizer management. Soil Biol Biochem. 2007 Nov; 39(11):2971-6.

Chung H, Zak DR, Reich PB, Ellsworth DS. Plant species richness, elevated CO2, and atmospheric ni- trogen deposition alter soil microbial community composition and function. Glob Chang Biol. 2007 May; 13(5):9809.

Cleveland CC, Liptzin D. C:N:P stoichiometry in soil: is there a "Redfield ratio" for the microbial bio- mass? Biogeochemistry. 2007 Jul 31; 85(3):235-52.

De Deyn GB, Quirk H, Bardgett RD. Plant species richness, identity and productivity differentially influ- ence key groups of microbes in grassland soils of contrasting fertility. Biol Lett. 2010 Feb 23; 7(1):75-8. doi: 10.1098/rsbl.2010.0575 PMID: 20685699

De Vries FT, Hoffland E, van Eekeren N, Brussaard L, Bloem J. Fungal/bacterial ratios in grasslands with contrasting nitrogen management. Soil Biol Biochem. 2006 Aug; 38(8):2092-103.

Dennis PG, Miller AJ, Hirsch PR. Are root exudates more important than other sources of rhizodeposits in structuring rhizosphere bacterial communities? FEMS Microbiol Ecol. 2010 Jun; 72(3):313-27. doi: 10.1111/j.1574-6941.2010.00860.x PMID: 20370828

Díaz S, Cabido M. Vive la difference: plant functional diversity matters to ecosystem processes. Trends Ecol Evol. 2001; 16(11):646-55.

Dickson TL, Foster BL. Fertilization decreases plant biodiversity even when light is not limiting. Ecol Lett. 2011 Apr; 14(4):380-8. doi: 10.1111/j.1461-0248.2011.01599.x PMID: 21332902

Dijkstra FA, Hobbie SE, Reich PB, Knops JMH. Divergent effects of elevated CO2, N fertilization, and plant diversity on soil $\mathrm{C}$ and $\mathrm{N}$ dynamics in a grassland field experiment. Plant Soil. 2005 May; 272- (12):41-52. 
Donnison LM, Gri GS, Hedger J, Hobbs PJ, Bardgett D. Management influences on soil microbial com- munities and their function in botanically diverse haymeadows of northern England and Wales. Soil Biol Biochem. 2000; 32:253-63.

Eisenhauer N, Bessler H, Engels C, Gleixner G, Habekost M, Milcu a, et al. Plant diversity effects on soil microorganisms support the singular hypothesis. Ecology. 2010 Feb; 91(2):485-96. PMID: 20392013

Eisenhauer N, Cesarz S, Koller R, Worm K, Reich PB. Global change belowground: impacts of elevat- ed CO2, nitrogen, and summer drought on soil food webs and biodiversity. Glob Chang Biol. 2012 Feb 27; 18(2):43547.

Eisenhauer N, Dobies T, Cesarz S, Hobbie SE, Meyer RJ, Worm K, et al. Plant diversity effects on soil food webs are stronger than those of elevated $\mathrm{CO} 2$ and $\mathrm{N}$ deposition in a long-term grassland experi- ment. Proc Natl Acad Sci U S A. 2013 Apr 23; 110(17):6889-94. doi: 10.1073/pnas.1217382110 PMID: 23576722

Eisenhauer N, Milcu A, Allan E, Nitschke N, Scherber C, Temperton V, et al. Impact of above- and below-ground invertebrates on temporal and spatial stability of grassland of different diversity. J Ecol. 2011 Jan 19; 99:572-82.

Eisenhauer N, Milcu A, Sabais ACW, Bessler H, Weigelt A, Engels C, et al. Plant community impacts on the structure of earthworm communities depend on season and change with time. Soil Biol Biochem. Elsevier Ltd; 2009 Dec; 41(12):2430-43.

Eisenhauer N, Milcu A, Sabais ACW, Scheu S. Earthworms enhance plant regrowth in a grassland plant diversity gradient. Eur J Soil Biol. Elsevier Masson SAS; 2009 Sep; 45(5-6):455-8.

Farrell M, Prendergast-Miller M, Jones DL, Hill PW, Condron LM. Soil microbial organic nitrogen uptake is regulated by carbon availability. Soil Biol Biochem. Elsevier Ltd; 2014 Oct; 77:261-7.

Fenn ME, Huntington TG, McLaughlin SB, Eagar C, Gomez A, Cook RB. Status of soil acidification in North America. J For Sci. 2006; 52:3-13.

Galloway JN, Townsend AR, Erisman JW, Bekunda M, Cai Z, Freney JR, et al. Transformation of the ni- trogen cycle: recent trends, questions, and potential solutions. Science. 2008 May 16; 320(5878):889-92. doi: 10.1126/science.1136674 PMID: 18487183

Gough L, Osenberg CW, Gross KL, Collins SL. Fertilization effects on species density and primary pro- ductivity in herbaceous plant communities. Oikos. 2000 Jun; 89(3):428-39.

Grayston S, Vaughan D, Jones D. Rhizosphere carbon flow in trees, in comparison with annual plants: the importance of root exudation and its impact on microbial activity and nutrient availability. Appl Soil Ecol. 1996; 5:29-56.

Grayston SJ, Wang S, Campbell CD, Edwards AC. Selective influence of plant species on microbial di- versity in the rhizosphere. Soil Biol Biochem. 1998 Mar; 30(3):369-78.

Harrison KA, Bol R, Bardgett RD. Do plant species with different growth strategies vary in their ability to compete with soil microbes for chemical forms of nitrogen? Soil Biol Biochem. 2008 Jan; 40(1):228-37.

Hartman WH, Richardson CJ. Differential nutrient limitation of soil microbial biomass and metabolic quotients (qCO2): is there a biological stoichiometry of soil microbes? PLoS One. 2013 Jan; 8(3): e57127. doi: 10.1371/journal.pone.0057127 PMID: 23526933

He J-S, Bazzaz FA, Schmid B. Interactive effects of diversity, nutrients and elevated CO2 on experi- mental plant communities. Oikos. 2002 Jun; 97(3):337-48.

Hobbie JE, Hobbie E a. Microbes in nature are limited by carbon and energy: the starving-survival life- style in soil and consequences for estimating microbial rates. Front Microbiol. 2013 Jan; 4 (November):324.

Hooper DU, Bignell DE, Brown VK, Brussaard L, Dangerfield JM, Wall DH, et al. Aboveground and Be- lowground Biodiversity in Terrestrial Ecosystems: Patterns, Mechanisms, and Feedbacks. Bioscience. 2000; 50(12):1049-61.

Hooper DU, Chapin FS, Ewel JJ, Hector A, Inchausti P, Lavorel S, et al. Effects Of Biodiversity On Eco- system Functioning: A Consensus Of Current Knowledge. Ecol Monogr. 2005; 75(July 2004):3-35.

Isbell F, Reich PB, Tilman D, Hobbie SE, Polasky S, Binder S. Nutrient enrichment, biodiversity loss, and consequent declines in ecosystem productivity. Proc Natl Acad Sci U S A. 2013 Jul 16; 110- (29):11911-6. doi: 10.1073/pnas.1310880110 PMID: 23818582

Jackson RB, Mooney HA, Schulze E-D. A global budget for fine root biomass, surface area and nutrient contents. Ecology. 1997; 94(July):7362-6.

Jenkinson D, Powlson D. The effects of biocidal treatments on metabolism in soil-I. Fumigation with chloroform. Soil Biol Biochem. 1976; 8:167-77.

Joergensen RG, Mueller T. The fumigation-extraction-method to estimate soil microbial biomass: cali- bration of the ken value. Soil Biol Biochem. 1996; 28(1):33-7.

Joffre R, Ourcival J-M, Rambal S, Rocheteau A. The key-role of topsoil moisture on CO2 efflux from a Mediterranean Quercus ilex forest. Ann For Sci. 2003; 60:519-26. 
Johnson D, Cresser M, Nilsson S, Turner J, Ulrich B, Binkley D, et al. Soil changes in forest ecosys- tems: evidence for and probable causes. Proc R Soc Edinburgh. 1991; 97B:81-116.

Johnson D, Phoenix GK, Grime JP. Plant community composition, not diversity, regulates soil respira- tion in grasslands. Biol Lett. 2008 Aug 23; 4(4):345-8. doi: 10.1098/rsbl.2008.0121 PMID: 18426747

Kaye J, Hart S. Competition for nitrogen between plants and soil microorganisms. Trends Ecol Evol. 1997; 12(97):139-42.

Krift T Van der, Kuikman P, Möller F, Berendse F. Plant species and nutritional-mediated control over rhizodeposition and root decomposition. Plant Soil. 2001;191-200.

Kuzyakov Y, Xu X. Competition between roots and microorganisms for nitrogen: mechanisms and eco- logical relevance. New Phytol. 2013; 198:656-69. doi: 10.1111/nph.12235 PMID: 23521345

Kuzyakov Y. Review: Factors affecting rhizosphere priming effects. J Plant Nutr Soil Sci. 2002 Aug; 165(4):38296.

Lange M, Habekost M, Eisenhauer N, Roscher C, Bessler H, Engels C, et al. Biotic and abiotic proper- ties mediating plant diversity effects on soil microbial communities in an experimental grassland. PLoS One. 2014 Jan; 9(5):e96182. doi: 10.1371/journal.pone.0096182 PMID: 24816860

LeBauer D, Treseder K. Nitrogen limitation of net primary productivity in terrestrial ecosystems is glob- ally distributed. Ecology. 2008; 89(2):371-9. PMID: 18409427

Martens R. Contribution of rhizodeposits to the maintenance and growth of soil microbial biomass. Soil Biol Biochem. 1990; 22(2):141-7.

McCann KS. The diversity-stability debate. Nature. 2000 May 11; 405(6783):228-33. PMID: 10821283

Milcu A, Partsch S, Scherber C, Weisser WW, Scheu S. Earthworms and legumes control litter decom- position in a plant diversity gradient. Ecology. 2008 Jul; 89(7):1872-82. PMID: 18705374

Milcu A, Thebault E, Scheu S, Eisenhauer N. Plant diversity enhances the reliability of belowground processes. Soil Biol Biochem. Elsevier Ltd; 2010 Dec; 42(12):2102-10.

Moran M. Arguments for rejecting the sequential Bonferroni in ecological studies. Oikos. 2003; 2:403-5.

Oelmann Y, Kreutziger Y, Temperton VM, Buchmann N, Roscher C, Schumacher J, et al. Nitrogen and phosphorus budgets in experimental grasslands of variable diversity. J Environ Qual. 2007; 36- (2):396-407. PMID: 17255627

Paterson E, Gebbing T, Abel C, Sim A, Telfer G. Rhizodeposition shapes rhizosphere microbial com- munity structure in organic soil. New Phytol. 2006 Nov 17; 173(3):600-10.

Paterson E. Importance of rhizodeposition in the coupling of plant and microbial productivity. Eur J Soil Sci. 2003; 54(December):741-50.

Phillips RP, Fahey TJ. Fertilization effects on fineroot biomass, rhizosphere microbes and respiratory fluxes in hardwood forest soils. New Phytol. 2007 Jan; 176(3):655-64. PMID: 17822400

Ramirez KS, Craine JM, Fierer N. Consistent effects of nitrogen amendments on soil microbial commu- nities and processes across biomes. Glob Chang Biol. 2012 Jun 6; 18(6):1918-27.

Ravenek JM, Bessler H, Engels C, Scherer-Lorenzen M, Gessler A, Gockele A, et al. Long-term study of root biomass in a biodiversity experiment reveals shifts in diversity effects over time. Oikos. 2014 May 4;(April):no-no. PMID: 25294947

Reich PB, Knops J, Tilman D, Craine J, Ellsworth D, Tjoelker M, et al. Plant diversity enhances ecosys- tem responses to elevated CO2 and nitrogen deposition. Nature. 2001 Jun 14; 410:809-12. PMID: 11298447

Reich PB, Tilman D, Isbell F, Mueller K, Hobbie SE, Flynn DFB, et al. Impacts of biodiversity loss esca- late through time as redundancy fades. Science. 2012 May 4; 336(6081):589-92. doi: 10.1126/ science.1217909 PMID: 22556253

Reich PB, Tilman D, Naeem S, Ellsworth DS, Knops J, Craine J, et al. Species and functional group di- versity independently influence biomass accumulation and its response to $\mathrm{CO} 2$ and N. Proc Natl Acad Sci U S A. 2004 Jul 6; 101(27):10101-6. PMID: 15220472

Roscher C, Schumacher J, Baade J. The role of biodiversity for element cycling and trophic interac- tions: an experimental approach in a grassland community. Basic Appl Ecol. 2004; 5:107-21.

Roscher C, Schumacher J, Gubsch M. Using plant functional traits to explain diversity-productivity relationships. PLoS One. 2012 Jan; 7(5):e36760. doi: 10.1371/journal.pone.0036760 PMID: 22623961

Roscher C, Temperton VM, Scherer-Lorenzen M, Schmitz M, Schumacher J, Schmid B, et al. Over- yielding in experimental grassland communities -irrespective of species pool or spatial scale. Ecol Lett. 2005 Apr; 8(4):419-29.

Scheu S. Automated measurement of the respiratory response of soil microcompartments: active mi-crobial biomass in earthworm faeces. Soil Biol Biochem. 1992; 24(11):1113-8.

Schimel DS, Braswell BH, Parton WJ. Equilibration of the terrestrial water, nitrogen, and carbon cycles. Proc Natl Acad Sci U S A. 1997 Aug 5; 94(16):8280-3. PMID: 11607734 
Schmid B, Hector A, Huston MA, Inchausti P, Nijs I, Leadley PW, et al. The design and analysis of biodi- versity experiments. In: Loreau M, Naeem S, Inchausti $P$, editors. Biodiversity and ecosystem function- ing. Oxford: Oxford University Press; 2002. p. 61-75.

Spehn E, Joshi J, Schmid B, Alphei J, Körner C. Plant diversity effects on soil heterotrophic activity in experimental grassland ecosystems. Plant Soil. 2000; 224:217-30.

Tilman D, Downing J. Biodiversity and stability in grasslands. Nature. 1994; 367:363-5.

Tilman D, Lehman CL, Thomson KT. Plant diversity and ecosystem productivity: Theoretical consider- ations. Ecology. 1997; 94(March):1857-61.

Treseder KK. Nitrogen additions and microbial biomass: a meta-analysis of ecosystem studies. Ecol Lett. 2008 Oct; 11(10):1111-20. doi: 10.1111/j.1461-0248.2008.01230.x PMID: 18673384

Vitousek P, Aber J. Human alteration of the global nitrogen cycle: sources and consequences. Ecol Appl. 1997; 7(November 1996):737-50.

Wang C, Han S, Zhou Y, Yan C, Cheng X, Zheng X, et al. Responses of fine roots and soil N availability to shortterm nitrogen fertilization in a broad-leaved Korean pine mixed forest in northeastern China. PLoS One. 2012 Jan; 7(3):e31042. doi: 10.1371/journal.pone.0031042 PMID: 22412833

Wardle D. A comparative assessment of factors which influence microbial biomass carbon and nitrogen levels in soil. Biol Rev. 1992; PMID: 1463811

Wardle DA, Ghani A. A critique of the microbial metabolic quotient (qCO2) as a bioindicator of distur-bance and ecosystem development. Soil Biol Biochem. 1995; 27(12):1601-10.

Weigelt A, Schumacher J, Roscher C, Schmid B. Does biodiversity increase spatial stability in plant community biomass? Ecol Lett. 2008 Apr; 11(4):338-47. doi: 10.1111/j.1461-0248.2007.01145.x PMID: 18190524

Weigelt A, Weisser WW, Buchmann N, Scherer-Lorenzen M. Biodiversity for multifunctional grass- lands: equal productivity in high-diversity low-input and low-diversity high-input systems. Biogeos- ciences. 2009 Aug 21; 6(8):1695-706.

Wilman D, Fisher a. Effects of interval between harvests and application of fertilizer $\mathrm{N}$ in spring on the growth of perennial ryegrass in a grass/white clover sward. Grass Forage Sci. 1996 Mar; 51(1):52-7.

Wu J, Joergensen RG, Pommerening B, Chaussod R, Brookes PC. Measurement of soil microbial bio- mass by fumigation-extraction-an automated procedure. Soil Biol Biochem. 1990; 22(8):1167-9.

Zak D, Holmes W, White D, Peacock A, Tilman D. Plant diversity, soil microbial communities, and eco- system function: are there any links? Ecology. 2003; 84(8):2042-50.

Zhong WH, Cai ZC. Long-term effects of inorganic fertilizers on microbial biomass and community functional diversity in a paddy soil derived from quaternary red clay. Appl Soil Ecol. 2007 Jun; 36(2-3):84-91. 
4 Incorporation of mineral nitrogen into the soil food web as affected by plant community composition

Tanja Strecker, Annette Jesch, Dörte Bachmann, Melissa Jüds, Kevin Karbstein, Janneke Ravenek, Christiane Roscher, Alexandra Weigelt, Nico Eisenhauer, and Stefan Scheu

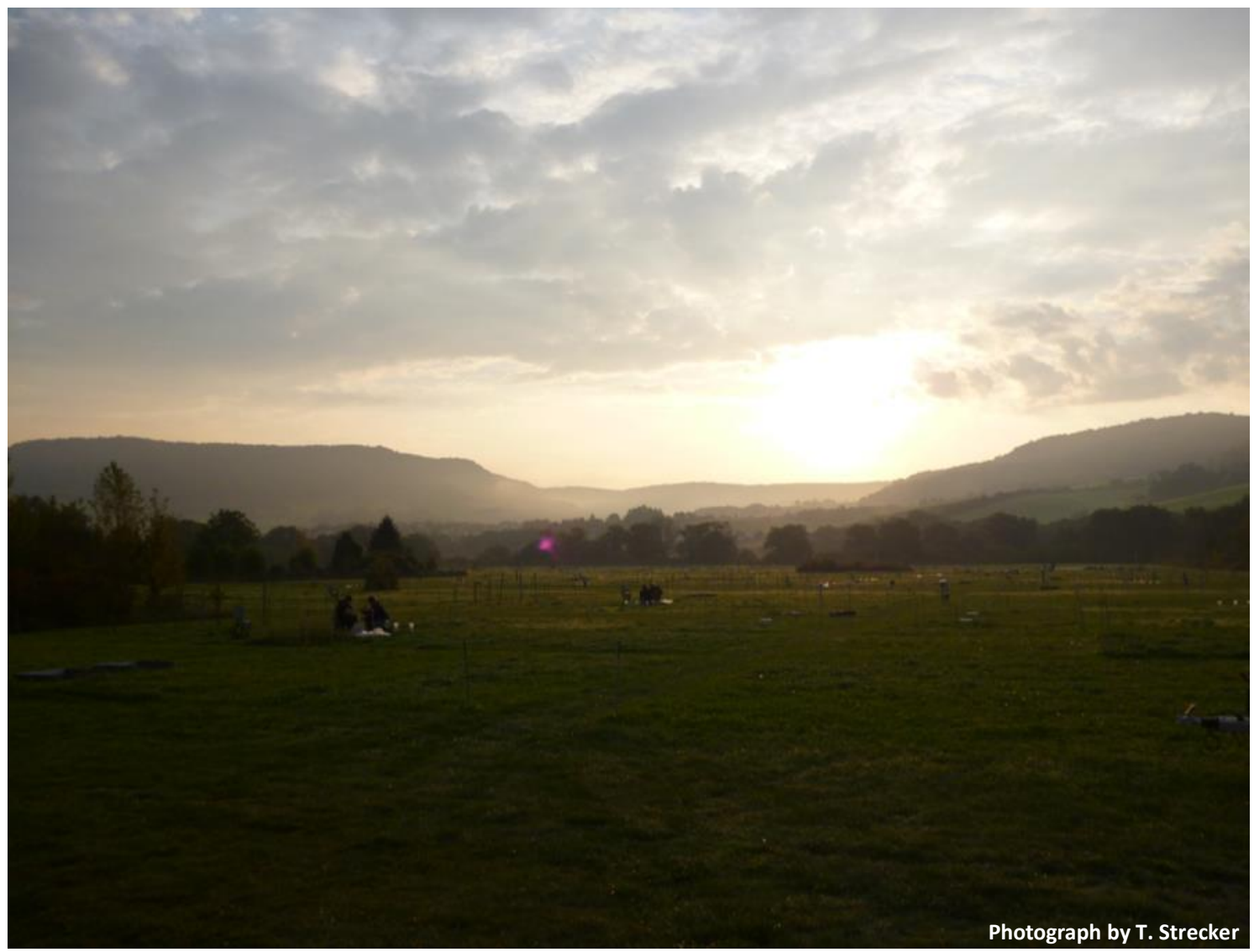

Submitted to: Ecology and Evolution (April 2020) 


\subsection{Abstract}

Background: Although nitrogen $(\mathrm{N})$ deposition is increasing globally, $\mathrm{N}$ availability is still a limiting nutrient for many organisms, such as microorganisms (bacteria and fungi) and mesofauna. Nevertheless, little is known to which extent soil organisms rely on mineral-derived nitrogen and whether plant community diversity and composition modifies the uptake of this $\mathrm{N}$ source.

Methodology/Principal Findings: We set up a field experiment in experimental grasslands with different levels of plant species richness $(2,4,8$, and 16 plant species), and plant functional group richness (1, 2, 3, and 4 plant functional groups; legumes, grasses, small herbs, tall herbs). We labelled soil with ${ }^{15} \mathrm{NH}_{4}{ }^{15} \mathrm{NO}_{3}$ and analyzed the incorporation of mineral-derived ${ }^{15} \mathrm{~N}$ into soil microorganisms and most abundant mesofauna taxa (Tectocepheus velatus sarekensis - oribatid mite, primary decomposer; Lepidocyrtus cyaneus, Isotoma viridis, Parisotoma notabilis, Ceratophysella sp. and Stenaphorura denisi - all springtails, secondary decomposers; as well as Lasioseius berlesei - gamasid mite, predator) over three months $(5,15,30,60$, and 120 days after labeling). Incorporation of mineral-derived $\mathrm{N}$ peaked at the first sampling date into all studied soil organisms (i.e., two days after labelling in microorganisms, 5 days after labelling in mesofauna). The incorporation of mineralderived $\mathrm{N}$ into the predatory gamasid mite L. berlesei was only affected by time. Increasing plant species richness and presence of legumes decreased the incorporation of mineral $\mathrm{N}$ into soil microorganisms. Increasing plant species richness also decreased the incorporation of mineralderived $\mathrm{N}$ into the secondary decomposer springtail Ceratophysella sp. Effects of both, plant species richness and functional group richness on other studied mesofauna species varied with time. Presence of grasses increased the incorporation of mineral-derived N into Ceratophysella sp., however decreased it in the primary decomposer oribatid mite $T$. velatus sarekensis.

Conclusions/Significance: The results highlight that soil microorganisms heavily incorporate mineral $\mathrm{N}$, and that this $\mathrm{N}$ is quickly channelled into higher trophic levels of the soil food web. The amount of mineral-derived $\mathrm{N}$ incorporated into soil animals, as well as the plant community properties affecting this incorporation, differed markedly between soil animal taxa, reflecting species-specific nutritional strategies. Our results further emphasize that plant diversity and community composition alter the competition for $\mathrm{N}$ in soil and change the nutrient transfer across trophic levels in soil food webs, potentially leading to changes in soil animal population dynamics and community composition. In the face of elevated $\mathrm{N}$ deposition worldwide, sustaining high plant diversity in semi-natural grassland may buffer detrimental effects of elevated $\mathrm{N}$ deposition on soil biota. 


\subsection{Introduction}

Soil microorganisms and soil fauna are key players for ecosystem functions such as decomposition and element cycling. The nitrogen $(\mathrm{N})$ cycle is an almost entirely microbially-driven process (Veresoglou et al., 2012), but soil animals also contribute directly or indirectly to $\mathrm{N}$ cycling (Carrillo et al., 2011; Seastedt, 1984; Verhoef and Brussaard, 1990). Soil animal species can be classified into primary decomposers, secondary decomposers and predators (Scheu, 2002). Primary decomposers contribute to decomposition and mineralization of nutrients by feeding on dead plant material, while secondary decomposers mainly feed on microorganisms living in soil or being associated with plant roots. Both, primary and secondary decomposers, such as Oribatida and Collembola, significantly contribute to carbon (C) and N cycling (Filser, 2002; Lemanski and Scheu, 2015; Osler and Sommerkorn, 2007; Pollierer et al., 2012; Verhoef and Brussaard, 1990). The beneficial effects of these animal groups on $\mathrm{C}$ and $\mathrm{N}$ cycling are mostly indirect either via modifying microbial activity (Buscot and Varma, 2005) or via distributing microbial propagules (Filser, 2002; Renker et al., 2005). However, the sources from which soil animals acquire $\mathrm{N}$ for their own nutrition and the factors affecting $\mathrm{N}$ acquisition by soil animals are little understood.

Nitrogen is an essential, but limiting resource for plants and soil animals (Vitousek and Howarth, 1991; Wilder and Eubanks, 2010). Despite the central role of $\mathrm{N}$ for soil animal nutrition, most of the studies that investigated element fluxes in soil food webs focused on the flux of C (Albers et al., 2006; Müller et al., 2016; Pollierer et al., 2007), and little is known about the resources soil animals use to meet their $\mathrm{N}$ requirements. Generally, soil animals, such as primary and secondary decomposers, meet their demand for $\mathrm{N}$ based either on microbial $\mathrm{N}$ or on plant litter $\mathrm{N}$. However, the relative contribution of these sources for soil animal $\mathrm{N}$ nutrition is little understood. Soil animals may acquire both $\mathrm{C}$ and $\mathrm{N}$ from the same or from different sources, with recent studies pointing rather to the former (Farrell et al., 2014; Zieger et al., 2017b). Pollierer et al. (2012) demonstrated that soil animals in beech forest use both the microbial energy channel (bacteria and fungi) as well as plants as $C$ sources. Thus, soil animals may satisfy their demand for $\mathrm{N}$ also by both channels. Zieger et al. (2017a) and Scheunemann et al. (2016) showed that decomposer mesofauna species in beech forests and arable fields gain $\mathrm{C}$ as well as $\mathrm{N}$ by feeding on microorganisms, especially fungi.

The acquisition of $\mathrm{N}$ by soil animals for building up their body tissue likely also varies with environmental factors influencing soil animal nutrition. In particular, plants may modify the incorporation of $\mathrm{N}$ by soil animals as they compete with microorganisms for $\mathrm{N}$ in soil and thereby alter the availability of microbial N for soil animals (Kuzyakov and Xu, 2013; Strecker et al., 2015). Simultaneously, plants may provide soil microorganisms and animals with $\mathrm{C}$ and $\mathrm{N}$ via rhizodeposition (Schenck zu Schweinsberg-Mickan et al., 2012; Zieger et al., 2017b). Recent studies showed that plant diversity increases soil $\mathrm{N}$ storage (Oelmann et al., 2011), soil microbial activity and 
C storage (Lange et al., 2015) as well as soil microbial biomass (Eisenhauer et al., 2017, 2010; Strecker et al., 2015). Scherber et al. (2010) demonstrated cascading effects of plant diversity on the whole animal food web in temperate experimental grasslands which might be due to plant-mediated changes in animal $\mathrm{N}$ nutrition. Plant diversity and the ecosystem functions related to it are increasingly threatened by human activities worldwide (Cardinale et al., 2012; Chapin et al., 2000; Isbell et al., 2011). For understanding the impact of plant diversity loss on the soil animal food web, the role of plants for the nutrition of soil animals needs closer consideration (Chahartaghi et al., 2005; Crotty et al., 2011; Sechi et al., 2014).

Plants compete with soil microorganisms for mineral $\mathrm{N}$ as both typically are limited by $\mathrm{N}$ (Hodge et al., 2000; Kuzyakov and Xu, 2013), and this likely is more severe in species-rich plant communities as plants take up nutrients more efficiently in more diverse communities (Bessler et al., 2012; Jesch et al., 2018; Roscher et al., 2008). This holds especially in the long term as soil microorganisms can take up nutrients quickly but have shorter live cycles than plants. Scheunemann et al. (2016) studied the incorporation of mineral $\mathrm{N}$ into soil microorganisms and mesofauna of an arable field, but did not consider plants and plant diversity as potential driving factor for the incorporation of $\mathrm{N}$ into soil animals. Eisenhauer et al. (2013) investigated the effects of plant diversity and $\mathrm{N}$ deposition on the abundance and diversity of soil fauna, but did not consider the incorporation of $\mathrm{N}$ into soil animals. With the present study, we addressed these gaps by investigating the incorporation of mineral $\mathrm{N}$ into soil microorganisms and subsequently into soil mesofauna species as modified by plant diversity. Besides plant diversity, plant functional groups, such as grasses and legumes, may affect nutrient incorporation into soil mesofauna as they have different root C-to-N-ratios (Chen et al., 2008), and differ in their annual $\mathrm{N}$ uptake (Bessler et al., 2012). Grasses are highly competitive for soil $\mathrm{N}$ due to their dense root system and clonal growth (de Witte and Stöcklin, 2010). Accordingly, they strongly exploit $\mathrm{N}$ resources in soil and reduce $\mathrm{N}$ availability (Bessler et al., 2012; Hodge et al., 1999; Roscher et al., 2008; Wedin and Tilman, 1990). Strecker et al. (2015) observed that the microbial C-to-N ratio to increase in presence of grasses at the field site of the present study, indicating competition for $\mathrm{N}$ between microorganisms and grasses. This finding is supported by results of Oelmann et al. (2007a) who found reduced soil mineral $\mathrm{N}$ concentration in the presence of grasses at the same field site. Consequently, soil animal species relying on microbial $\mathrm{N}$ likely also experience increased $\mathrm{N}$ limitation in the presence of grasses. Legumes can fix molecular $\mathrm{N}$ via rhizobia and fuel the soil system with organic nitrogen via rhizodeposition and input of litter material. Thereby, legumes mitigate competition for $\mathrm{N}$ and influence the $\mathrm{N}$ nutrition of soil organisms (Marschner et al., 2011; Oelmann et al., 2007a; Spehn et al., 2002).

Ayres et al. (2007) observed that legumes substantially increase the release of $\mathrm{N}$ into the soil after defoliation with subsequent increase in soil microbial biomass. Milcu et al. (2006) demonstrated that 
tissue $\mathrm{N}$ concentration in earthworms decreased in presence of Collembola, and that legumes diminished the competition for $\mathrm{N}$ between these decomposer animals. The positive effect of legumes on the $\mathrm{N}$ availability for these animals likely also holds for other decomposer species.

In the present study, we aimed at tracking the incorporation of labeled mineral $\mathrm{N}$ into soil microorganisms and the channeling of the incorporated mineral $\mathrm{N}$ to higher trophic levels of the soil food web as affected by plant diversity and plant community composition in experimental temperate grassland. ${ }^{15} \mathrm{~N}$ stable isotope labeling was used for tracing $\mathrm{N}$ fluxes into different compartments of the belowground system (Crotty et al., 2012; Zieger et al., 2015). As the channeling of $\mathrm{N}$ from lower to higher trophic levels likely occurs with a time lag, we expected the ${ }^{15} \mathrm{~N}$ signal to be incorporated first into soil microorganisms, then into secondary decomposers and finally into predatory species, but not into primary decomposers (using only plant litter resources). To test these expectations, we followed the incorporation of ${ }^{15} \mathrm{~N}$ into soil microorganisms and mesofauna $2,15,30,60$, and 120 days after labeling.

In detail, we investigated the following hypotheses:

(1) Due to delayed channeling of $\mathrm{N}$ from lower to higher trophic levels, the flux of mineral $\mathrm{N}$ from soil microorganisms into higher trophic levels occurs with a time lag.

(2) Incorporation of mineral $\mathrm{N}$ into soil microorganisms and mesofauna decreases with increasing plant diversity (plant species richness and functional group richness), as high plant diversity communities more efficiently exploit nutrient resources in soil.

(3) Presence of legumes decreases the incorporation of mineral $\mathrm{N}$ into microorganisms and mesofauna, as legumes fuel the soil system with biologically fixed $\mathrm{N}$.

(4) Presence of grasses decreases the incorporation of mineral $\mathrm{N}$ into microorganisms and mesofauna, as grasses effectively compete for soil $\mathrm{N}$ with other soil organisms.

\subsection{Material and Methods}

\section{Study site}

The experiment was conducted within the framework of the Jena Experiment, a large grassland biodiversity experiment, which investigates in an integrative way the role of plant diversity for ecosystem functioning (Roscher et al., 2004). The experiment was established in 2002 on a former arable field in the floodplain of the Saale River near to the city of Jena (Thuringia, Germany, $50^{\circ} 55^{`} \mathrm{~N}$, $11^{\circ} 35^{`} \mathrm{E}, 130 \mathrm{~m}$ a.s.l.). The soil is Eutric Fluvisol, mean precipitation is $610 \mathrm{~mm}$ per year, and mean temperature is $9.9^{\circ} \mathrm{C}$ (Hoffmann et al., 2014). The plant species used in the experiment are typical for Central European mesophilic grasslands (Arrhenatherion community; Ellenberg and Leuschner, 2010). The experimental plots did not receive any fertilizer, were mown twice a year, and aboveground plant biomass was removed from the field site to imitate typical management of extensive hay 
meadows in the study region, and weeded by hand two to three times a year to maintain the target plant community composition.

The 80 plant communities were selected out of a pool of 60 plant species, and comprised a plant species richness gradient including monocultures as well as 2, 4, 8, 16, and 60 plant species combinations. The plant species were chosen from four plant functional groups, which were created according to cluster analyses based on above- and below-ground morphological traits, phenological traits and $\mathrm{N}_{2}$-fixation, resulting in 16 grasses, 12 small herbs, 20 tall herbs, and 12 legumes. Thus, the plant communities also comprised a plant functional group richness gradient $(1,2,3$, and 4 plant functional groups). The plots were grouped into four blocks with an equal number of plots per diversity level to account for changes in soil texture with increasing distance from the Saale River. For detailed information on the design of the Jena Experiment see Roscher et al. (2004).

\section{Experimental design}

In this study, a subset of 40 plots varying in plant species richness $(2,4,8$, and 16 plant species) was used, with ten replicates per plant species richness level. The number of plant functional group richness levels (1, 2, 3, and 4 plant functional groups) was balanced within each species richness level and the plots with different diversity levels were equally distributed across the four blocks. On each of the 40 experimental plots, a subplot $(56 \times 69 \mathrm{~cm})$ was established from which samples were taken in five sequential sampling campaigns. To prevent horizontal flow of the tracer solution out of the subplots and to reduce lateral migration of soil animals between labeled and unlabeled areas, PVC boards were installed as barriers along the subplot border to a height and depth of $15 \mathrm{~cm}$, respectively.

\section{Experimental procedure}

The experimental subplots were labeled with ${ }^{15} \mathrm{~N}$ at the beginning of the growing season in 2011 (18$19^{\text {th }}$ April). The ${ }^{15} \mathrm{~N}$ tracer solution ( $0.01 \mathrm{~mol}^{15} \mathrm{NH}_{4}{ }^{15} \mathrm{NO}_{3} / \mathrm{L}$ deionized water; 98 atom \%; Cambridge Isotope Laboratories, Tewksbury, MA, USA) was injected into pre-drilled holes of a depth of $7 \mathrm{~cm}$ in the soil arranged along gridlines (distance within grid lines $8.7 \mathrm{~cm}$, distance between grid lines 10 $\mathrm{cm}$, resulting in 49 holes per subplot). The tracer solution was injected using a $3 \mathrm{~mm}$ thick four-side port needle ( $2 \mathrm{~mL}$ per injection point) connected with a silicon tube to a bottle top dispenser (Socorex Isba SA, Switzerland) on a $1 \mathrm{~L}$ glass bottle. A funnel was used to prevent contamination of the vegetation with tracer solution.

For measuring the time-integrated incorporation of ${ }^{15} \mathrm{~N}$ into soil microorganisms and mesofauna, five samples were taken 2 ( 5 for mesofauna), 15, 30, 60, and 120 days after labeling. At each sampling campaign, three soil cores were taken per subplot for microbial biomass ( $\varnothing 5 \mathrm{~cm}, 0-5 \mathrm{~cm}$ depth) and 
one soil core for mesofauna ( $\varnothing 20 \mathrm{~cm}, 0-10 \mathrm{~cm}$ depth). The three samples per subplot for measuring microbial biomass were pooled, placed into plastic bags and stored at $4^{\circ} \mathrm{C}$ until further analyses. Soil cores for analyzing mesofauna were stored for a maximum of 4 days at $4^{\circ} \mathrm{C}$ to prevent soil animals from deceasing. Soil animals were extracted with a high gradient heat extractor, collected in glycerol, transferred into $70 \%$ ethanol and identified to species or genus level. For the analysis of the natural abundance of ${ }^{15} \mathrm{~N}$, reference soil cores for microorganisms and mesofauna were taken $10 \mathrm{~cm}$ adjacent to the sampling area within each plot five days before labeling as described above. Based on biomass estimates, the following mesofauna species were used for stable isotope analyses: Tectocepheus velatus sarekensis (Oribatida, primary decomposer), Lepidocyrtus cyaneus, Isotoma viridis, Parisotoma notabilis, Ceratophysella sp. and Stenaphorura denisi (all Collembola, secondary decomposers), as well as Lasioseius berlesei (Gamasina, predator). Tectocepheus velatus sarekensis (Oribatida, primary decomposer), Lepidocyrtus cyaneus, Isotoma viridis, Parisotoma notabilis, Ceratophysella sp. and Stenaphorura denisi (all Collembola, secondary decomposers), as well as Lasioseius berlesei (Gamasina, predator). In the results section, we present the analyzed animals beginning with the animal species being significantly affected by the variable time and then follow the order of variables in the statistical model with their respective interactions with time. Thus, the order of the animals follows the animal species being significantly affected by plant species richness $(S R), S R \times$ Time, plant functional group richness (FGR), FGR x Time, presence of legumes (LEG), LEG $x$ Time, presence of grasses (GR), and GR x Time.

Microbial biomass $\mathrm{N}$ was extracted from soil by chloroform fumigation-extraction (CFE) (Brookes et al., 1985). Prior to the extraction, roots were removed by hand. To remove other background N, $50 \mathrm{~g}$ fresh soil of each sample were taken, and $\mathrm{N}$ was removed via pre-extraction with $100 \mathrm{~mL} 0.05 \mathrm{M}$ $\mathrm{K}_{2} \mathrm{SO}_{4}$ with agitation for $30 \mathrm{~min}(200 \mathrm{rpm})$ and centrifugation for $10 \mathrm{~min}(200 \mathrm{U} / \mathrm{min})$ at $4000 \mathrm{~g}$. Two subsamples (10 g soil fresh weight each) were taken from each pre-extracted soil sample. One subsample was fumigated with chloroform vapor for $24 \mathrm{~h}$, the other remained unfumigated. Both subsamples were extracted with $60 \mathrm{ml} 0.05 \mathrm{M} \mathrm{K}_{2} \mathrm{SO}_{4}$ as described above, the extracts were filtered and frozen at $-18^{\circ} \mathrm{C}$ until further analysis. At each fumigation campaign, two blank samples were processed together with fumigated and unfumigated subsamples to account for contamination of the subsamples during the procedure. Before analyzing stable isotope ratios of the subsamples and blank samples, a fraction of the samples $(15 \mathrm{~mL}$ ) was freeze-dried (VaCo2, Zirbus Technology, Bad Grund, Germany) at $-30^{\circ} \mathrm{C}$ for $3 \mathrm{~d}$ and stored in plastic vessels in a desiccator. For referring results of ${ }^{15} \mathrm{~N}$ measurements to one gram dry soil, gravimetric soil water content was measured by drying $10 \mathrm{~g}$ of fresh soil subsamples of each sample at $105^{\circ} \mathrm{C}$ for $48 \mathrm{~h}$. 


\section{Stable isotope analysis}

For analyses of ${ }^{15} \mathrm{~N} /{ }^{14} \mathrm{~N}$ ratios in microbial biomass $\mathrm{N}$ and in soil mesofauna, appropriate amounts of the freeze-dried microbial $\mathrm{N}$ extract $(60-65 \mu \mathrm{g})$ and appropriate numbers of animals (10-120 individuals weighing 10-200 $\mu \mathrm{g}$ and containing 1-20 $\mu \mathrm{g} \mathrm{N}$ ) were transferred into tin capsules. In few cases individuals from the same sampling campaign but different plots with similar plant community composition were pooled. Stable isotope ratios were measured with a coupled system of an elemental analyzer (NA 1500, Carlo Erba, Milan, Italy) and a mass spectrometer (MAT 251, Finnigan, Bremen, Germany) (Reineking et al., 1993). Mesofauna samples were measured on a microelemental analyzer system (Euro-EA 300, Eurovector, Milano, Italy) allowing the analysis of small amounts of animal tissue (Langel and Dyckmans, 2014). Isotope signatures are expressed using the $\delta$ notation with $\delta^{15} \mathrm{~N}(\%)=\left(\mathrm{R}_{\text {sample }} / \mathrm{R}_{\text {standard }}-1\right) \times 1000$, where $\mathrm{R}$ is the molar ratio of heavy to the light isotope $\left({ }^{15} \mathrm{~N} /{ }^{14} \mathrm{~N}\right)$. Acetanilide $\left(\mathrm{C}_{8} \mathrm{H}_{9} \mathrm{NO}\right.$, Merck, Darmstadt, Germany) was used for internal calibration. As standard for $\delta^{15} \mathrm{~N}$, atmospheric nitrogen was used. Shifts in ${ }^{15} \mathrm{~N} /{ }^{14} \mathrm{~N}$ ratios in mesofauna species due to labeling with ${ }^{15} \mathrm{NH}_{4}{ }^{15} \mathrm{NO}_{3}$ were inspected by calculating the difference between $\delta^{15} \mathrm{~N}$ values of specimens inside and outside the subplots, i.e. $\Delta$ values.

For calculating microbial biomass $\mathrm{N}$, the amounts of $\mathrm{N}$ in the two blind samples of the different $\mathrm{CFE}$ campaigns were averaged and subtracted from the measured $\mathrm{N}$ mass of each subsample. Microbial biomass $\mathrm{N}$ was calculated as $\mathrm{N}_{\text {mic }}=\mathrm{E}_{N} / \mathrm{k}_{\mathrm{EN}}$, with $\mathrm{E}_{\mathrm{N}}$ being the difference between total $\mathrm{N}$ extracted from fumigated soil and total $\mathrm{N}$ extracted from unfumigated soil, and $\mathrm{k}_{\mathrm{EN}}$ the extractable fraction of microbial biomass $\mathrm{N}$ after fumigation (Joergensen and Mueller, 1996). Soil microbial biomass ${ }^{15} \mathrm{~N}(\mu \mathrm{g}$ ${ }^{15} \mathrm{~N} / \mathrm{g}$ dry soil) was calculated as ${ }^{15} \mathrm{~N}_{\text {mic }}\left(\mu \mathrm{g} / \mathrm{g}\right.$ dry soil) $={ }^{15} \mathrm{~N}$ ( $\mu \mathrm{g} / \mathrm{g}$ dry soil) of fumigated subsample ${ }^{15} \mathrm{~N}$ ( $\mu \mathrm{g} / \mathrm{g}$ dry soil) of unfumigated subsample (Brookes et al., 1985). Atom percent excess (APE, isotopic enrichment) of ${ }^{15} \mathrm{~N}$ in microbial biomass $\mathrm{N}$ was calculated as the difference in atom\% between labelled and natural abundance level of ${ }^{15} \mathrm{~N}$ in soil microbial biomass (Buresh et al., 1982; Dyckmans et al., 2005) as

$$
\text { APE }{ }^{15} \mathrm{~N}=\left(\left(\frac{{ }^{15} \mathrm{~N}_{\text {mic }}}{\text { total } \mathrm{N}_{\text {mic }}}\right)_{\text {labeled }}-\left(\frac{{ }^{15} \mathrm{~N}_{\text {mic }}}{\text { total } \mathrm{N}_{\text {mic }}}\right)_{\text {natural }}\right) * 100 .
$$

Microbial biomass $\mathrm{C}$ was calculated as $\mathrm{C}_{\text {mic }}=\mathrm{E}_{\mathrm{C}} / \mathrm{k}_{\mathrm{EC}}$, with $\mathrm{E}_{\mathrm{C}}$ being the difference between total $\mathrm{C}$ extracted from fumigated soil and total $\mathrm{C}$ extracted from unfumigated soil.

\section{Statistical analyses}

All statistical analyses were performed in R vers. 3.6.1 using the graphical user interface RSTUDIO vers. 1.1.383 (R Core Team, 2019). Data were inspected for normality (Shapiro-Wilk-test, Q-Q-Plot) and homoscedasticity (Levene's test). To achieve normality and homoscedasticity, we log-transformed microbial APE ${ }^{15} \mathrm{~N}$ and $\Delta^{15} \mathrm{~N}$ for the total dataset and for all animal species separately. For testing the 
effects of plant community properties on microbial APE ${ }^{15} \mathrm{~N}$ and $\Delta^{15} \mathrm{~N}$ values of mesofauna species. Plant species richness $(\mathrm{SR})$ was log-transformed to linearize the relationship between plant diversity and microbial properties (Hooper et al., 2005). Regarding the multiple linear regression model (LM) of the total data set between ${ }^{15} \mathrm{~N}$ data and the fixed factors block (factor with four levels), animal species (factor with seven levels), plant species richness (SR, log-linear term), plant functional group richness (FGR, linear term), legumes presence-absence (LEG, factor with two levels), grasses presence-absence (GR, factor with two levels) and time (days since labeling), no experimental treatment significantly influenced the response variable except of block, animal species and time (see supporting Information, Table 1). Therefore, we chose multiple linear mixed effect models (LMEs), used block as random factor, and calculated LMEs between ${ }^{15} \mathrm{~N}$ data and treatments for each animal species and microbial biomass separately. Presence-absence of grasses (GR, two factor levels) and presence-absence of legumes (LEG, two factor levels) as well as days after labeling (Time, five factor levels) were used as categorical predictors, while log-transformed plant species richness (SR) and plant functional group richness (FGR) were used as linear variables (using SR and FGR as categorical factors was not possible because the dataset was too small and unbalanced). We used the function Imer() implemented in the R package 'Ime4' vers. 1.1-21 (Bates et al., 2019, 2015) and the R package 'ImerTest' vers. 3.1-0 (Kuznetsova et al., 2019) for calculating $p$ values. We performed backward model-selection by step-wise removing the least significant variable until the final model was reached (Crawley, 2015). Additionally, we proved each model simplification step with Akaike information criterion (AIC).

\subsection{Results}

\section{Microorganisms}

Generally, the incorporation of ${ }^{15} \mathrm{~N}$ into microorganisms $\left({ }^{15} \mathrm{~N}_{\text {mic }} \mathrm{APE}\right)$ declined with time $(t=-12.78, p$ $<0.0001$, Fig. 1; supporting information Table 2), reflecting the fast incorporation of the mineral ${ }^{15} \mathrm{~N}$ into microorganisms and its following turnover. Plant species richness significantly decreased ${ }^{15} \mathrm{~N}_{\text {mic }}$ $\operatorname{APE}(t=-2.52, p=0.013$, Fig. $2 \mathrm{~A})$. Presence of legumes affected microbial ${ }^{15} \mathrm{~N}$, but this effect varied over time with microbial ${ }^{15} \mathrm{~N}$ being lower in the presence of legumes compared to plots without legumes at early sampling dates, but this effect disappeared at days 60 and $120(t=2.33, p=0.21$, Fig. $2 B$ ). ${ }^{15} \mathrm{~N}_{\text {mic }}$ ( $\mu \mathrm{g} / \mathrm{g}$ dry soil) was positively correlated with $\mathrm{N}_{\text {mic }}\left(R^{2}=0.93 ; t=43.69, p<0.0001\right)$ and $C_{\text {mic }}\left(R^{2}=0.83 ; t=26.24, p<0.0001\right)$ irrespective of the sampling date, indicating that changes in ${ }^{15} \mathrm{~N}$ incorporation paralleled changes in $\mathrm{N}_{\text {mic }}$ and $\mathrm{C}_{\text {mic }}$. 


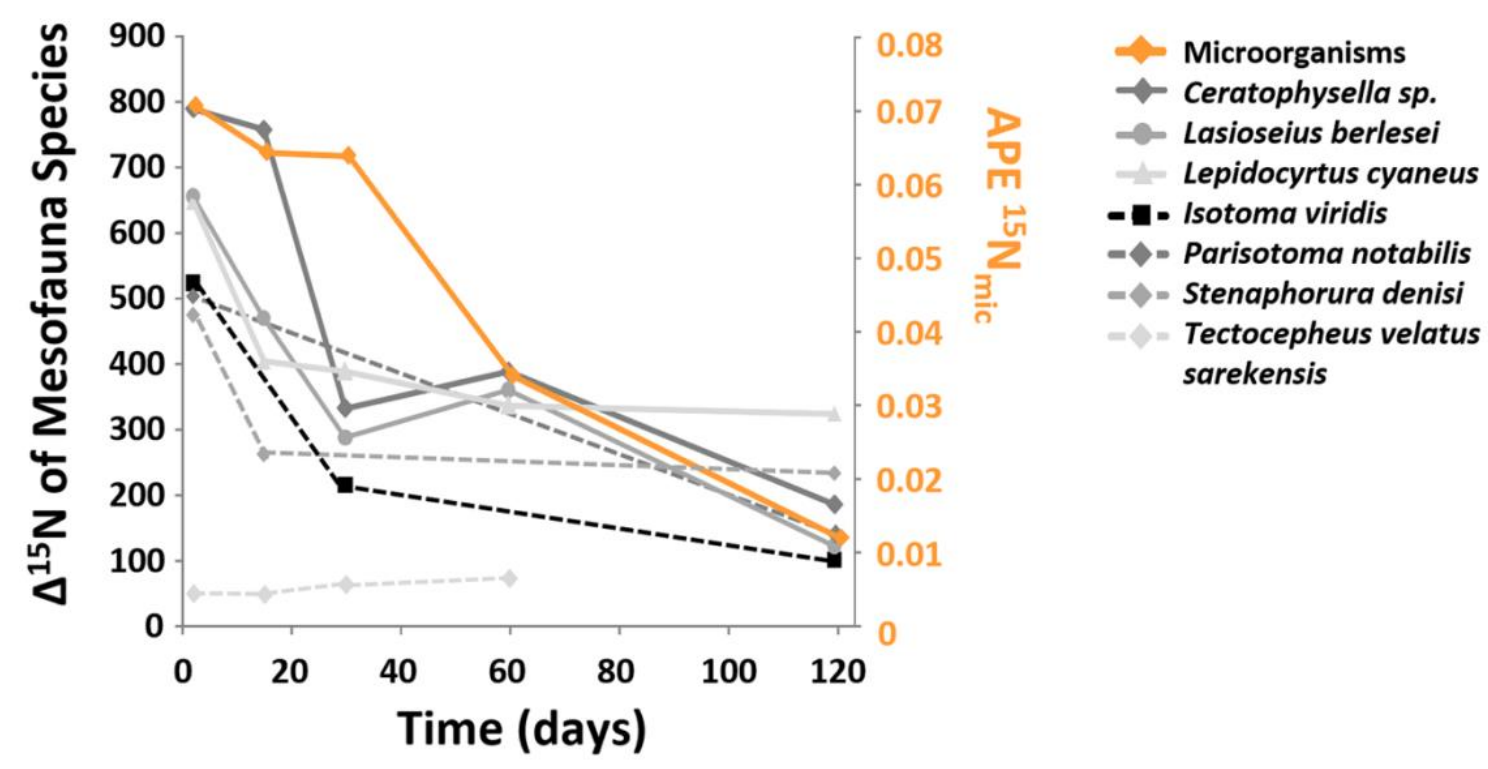

Fig. 1. Changes in the incorporation of ${ }^{15} \mathrm{~N}$ into soil mesofauna species ( $\Delta^{15} \mathrm{~N}$ values) and into soil microorganisms (APE ${ }^{15} \mathrm{~N}_{\text {mic }}$ ) over time (2-120 days for microorganisms and 5-120 days for mesofauna species).
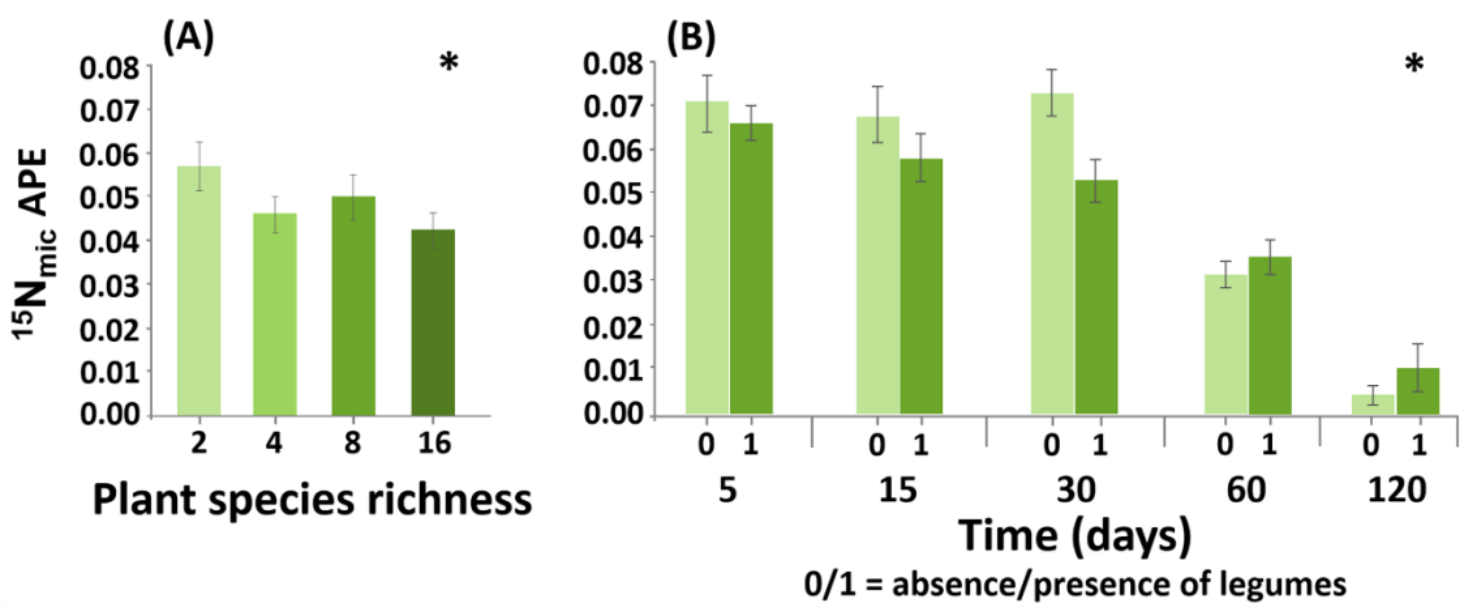

Fig. 2. Effects of (A) plant species richness, and (B) time and presence of legumes, on ${ }^{15} \mathrm{~N}$ atom percent excess in microbial biomass $\mathrm{N}\left({ }^{15} \mathrm{~N}_{\text {mic }} \mathrm{APE}\right) ; 0 / 1=$ absence/presence of legumes; means $\pm 1 \mathrm{SE}$. Asterisks indicate significant differences $\left({ }^{*} p \leq 0.05, * * p \leq 0.01, * * * p \leq 0.001\right) ;$ for details see Table 1.

\section{Mesofauna}

Generally, the incorporation of ${ }^{15} \mathrm{~N}\left(\Delta^{15} \mathrm{~N}\right.$ values) into the studied mesofauna species declined with time parallel to ${ }^{15} \mathrm{~N}_{\text {mic }}$ APE, except in T. velatus sarekensis (Fig. 1, Table 2), reflecting the dominant flux of mineral $\mathrm{N}$ into mesofauna species via microbial $\mathrm{N}$. However, the factors affecting the incorporation of ${ }^{15} \mathrm{~N}$ into mesofauna varied among the species studied (Table 2). Time affected the mineral ${ }^{15} \mathrm{~N}$ incorporation into all studied mesofauna species, either as a main factor or in combination with plant community properties. As main factor, it was only significant in L. berlesei and marginally significant in L. cyaneus with $\Delta^{15} \mathrm{~N}$ values decreasing over time (Fig. 3, Fig. 6C, Table 2). $\Delta{ }^{15} \mathrm{~N}$ values of Ceratophysella sp. significantly decreased with increasing plant species richness (Fig. 4). In T. velatus sarekensis, $\Delta^{15} \mathrm{~N}$ values also varied with plant species richness, but the effect 
depended on time. Early in the experiment, the incorporation of ${ }^{15} \mathrm{~N}$ was lower at high species richness, whereas later it was higher (Fig. 5A). Similarly, $\Delta^{15} \mathrm{~N}$ values in $P$. notabilis and S. denisi also varied significantly with plant species richness and time. In both species, $\Delta^{15} \mathrm{~N}$ values increased with plant species richness at day 5, whereas they decreased at day 120 (Fig. 5 B, C).

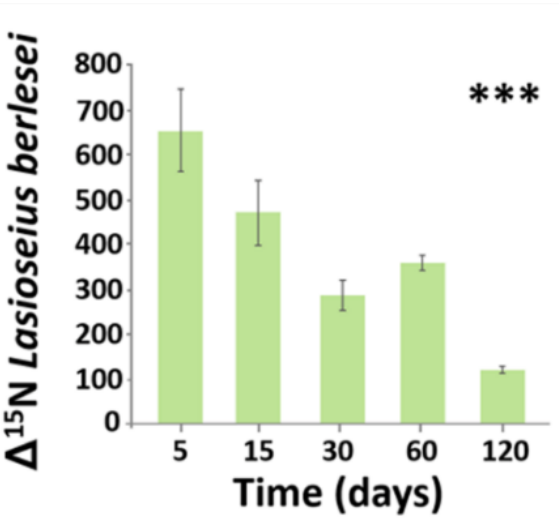

Fig. 3. Effects of time on $\Delta^{15} \mathrm{~N}$ values of Lasioseius berlesei; means $\pm 1 \mathrm{SE}$. Asterisks indicate significant differences $(* p \leq 0.05$,

$* * p \leq 0.01, * * * p \leq 0.001)$; for details see Table 2 .

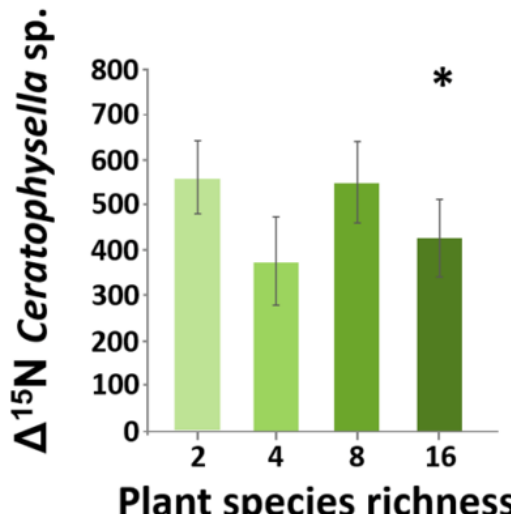

Fig. 4. Effect of plant species richness on $\Delta^{15} \mathrm{~N}$ values of Ceratophysella sp.; means $\pm 1 \mathrm{SE}$. Asterisks indicate significant differences $(* p \leq 0.05$, $\left.*^{*} \mathrm{p} \leq 0.01, * * * \mathrm{p} \leq 0.001\right)$; for details see Table 2 .
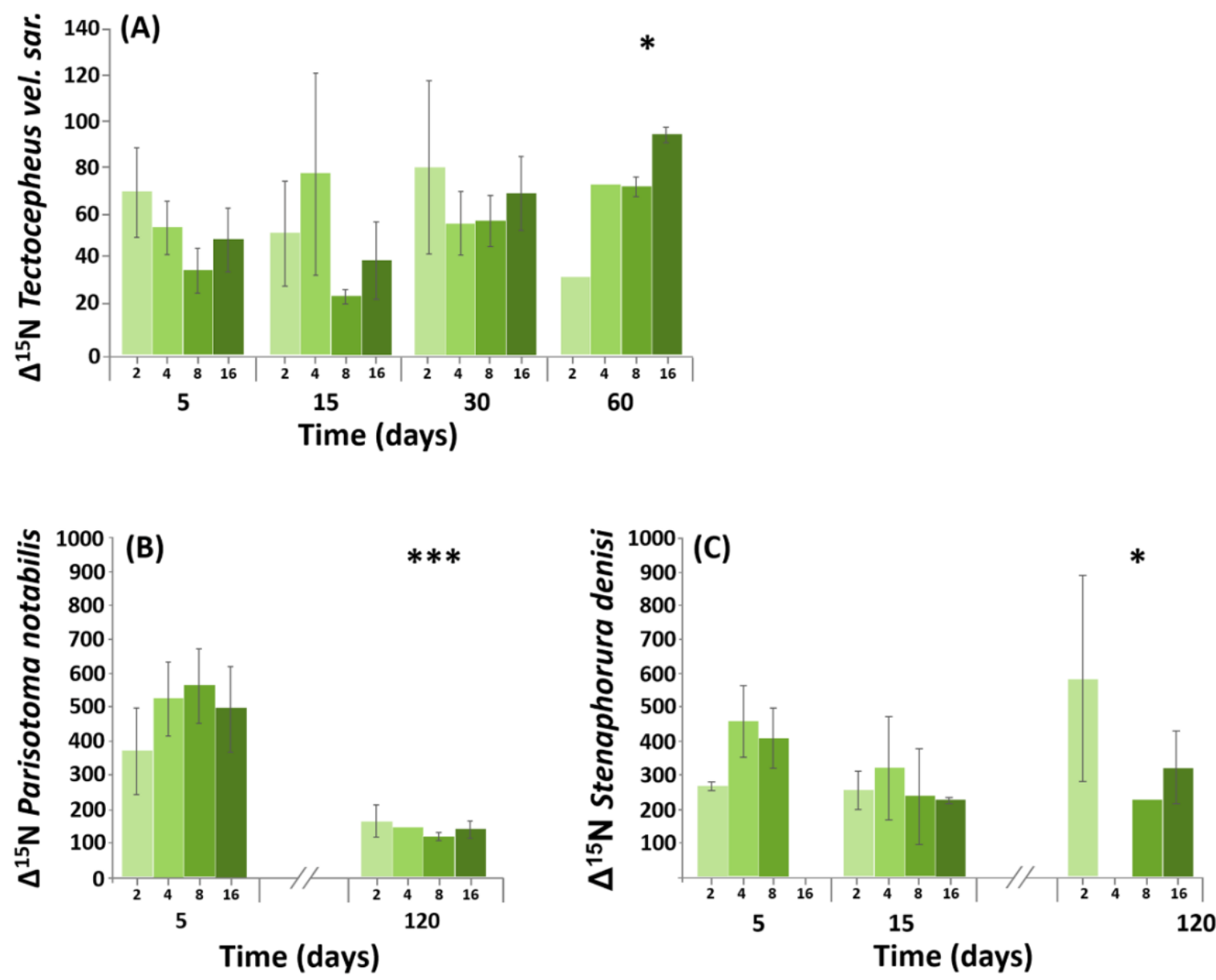

$\square, \square, \square, \square=2,4,8$ and 16 plant species per plot

Fig. 5. Interactive effects of plant species richness and time on $\Delta^{15} \mathrm{~N}$ values of (A) Tectocepheus velatus sarekensis, (B) Parisotoma notabilis, and (C) Stenaphorura denisi; means \pm 1 SE. Asterisks indicate significant effects $(* p \leq 0.05, * * p \leq 0.01$, $* * * p \leq 0.001)$; for details see Table 2. 
Functional richness as a main factor did not affect $\Delta^{15} \mathrm{~N}$ values of any studied mesofauna species. However, in combination with time, functional group richness affected $\Delta^{15} \mathrm{~N}$ values in $T$. velatus sarekensis, S. denisi, L. cyaneus, and I. viridis (Fig. 6 A-D). In T. velatus sarekensis, $\Delta^{15} \mathrm{~N}$ values decreased with increasing plant functional group richness at day 5 , but did not respond in a consistent way at the later sampling dates. In S. denisi and I. viridis, $\Delta^{15} \mathrm{~N}$ values also decreased with plant functional group richness at day 15 and 30, respectively, but not at the other sampling dates. By contrast, in L. cyaneus $\Delta^{15} \mathrm{~N}$ values decreased more consistently at days 30,60 and 120 . Presence of legumes generally did not affect $\Delta^{15} \mathrm{~N}$ values of any of the studied mesofauna species. By contrast, presence of grasses significantly affected $\Delta^{15} \mathrm{~N}$ values in Ceratophysella sp. and T. velatus sarekensis, but the effect varied with time (Fig. 7 A, B). In Ceratophysella sp., $\Delta^{15} \mathrm{~N}$ values strongly increased in presence of grasses, but only at days 5 and 15 . By contrast, in T. velatus sarekensis, $\Delta^{15} \mathrm{~N}$ values decreased in presence of grasses, with the effect being most pronounced at days 15 and 30 .
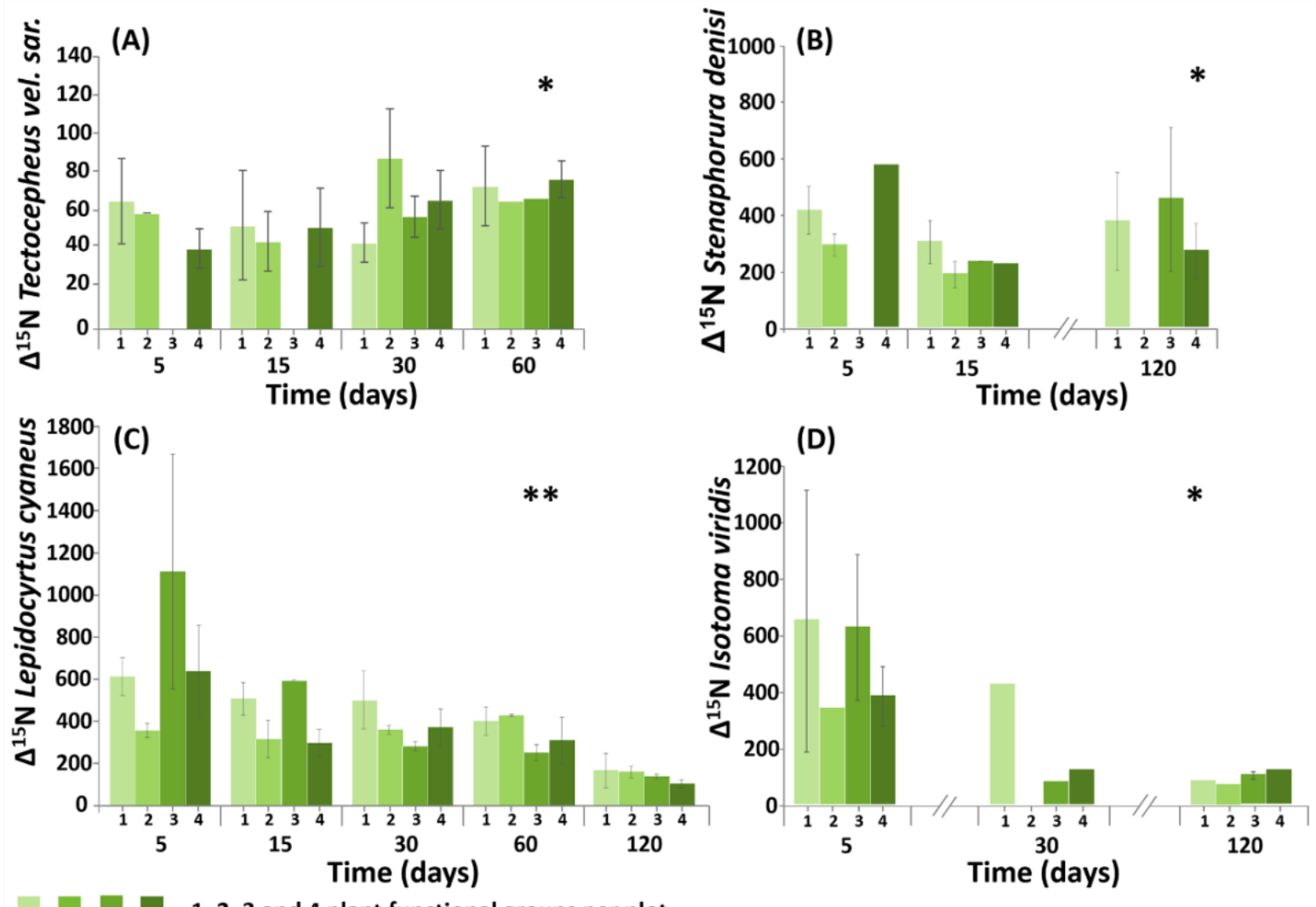

Fig. 6. Interactive effects of plant functional group richness and time on $\Delta^{15} \mathrm{~N}$ values of (A) Tectocepheus velatus sarekensis, (B) Stenaphorura denisi, (C) Lepidocyrtus cyaneus, and (D) Isotoma viridis; means $\pm 1 \mathrm{SE}$. Asterisks indicate significant differences $\left({ }^{*} p \leq 0.05,{ }^{* *} p \leq 0.01, * * * p \leq 0.001\right)$; for details see Table 2. Bars without SE represent single measurements. 

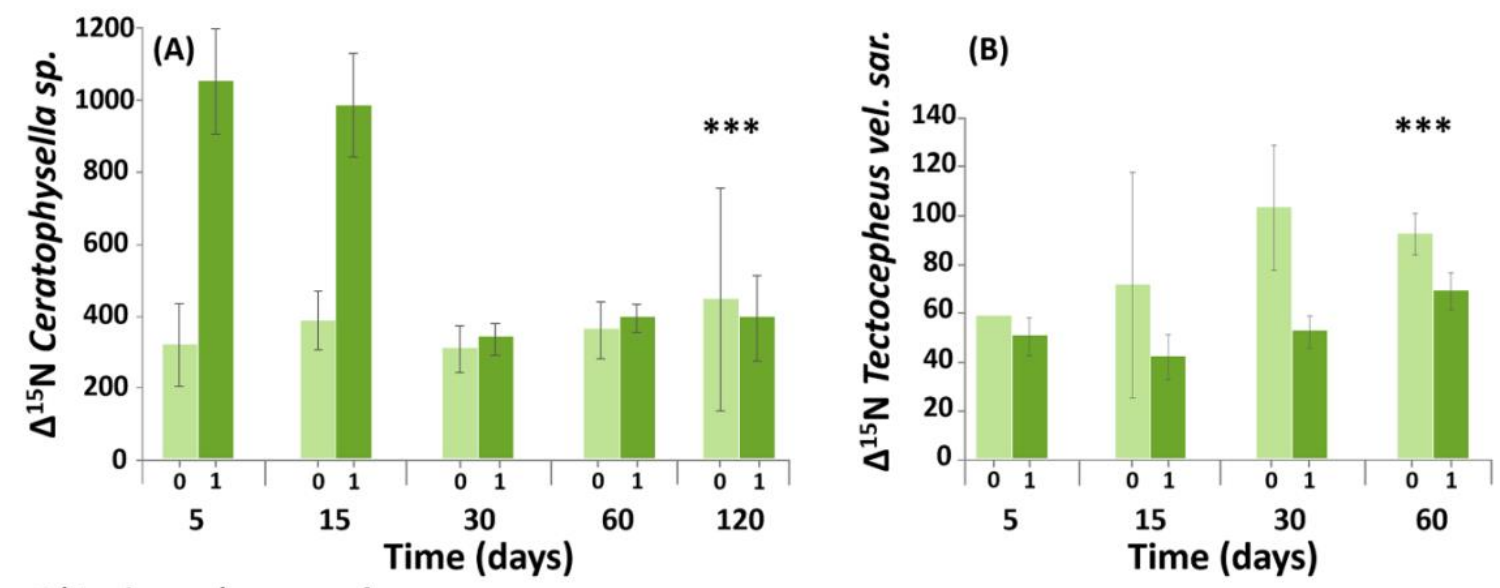

$0 / 1=$ absence $/$ presence of grasses

Fig. 7. Interactive effects of grasses and time on $\Delta 15 \mathrm{~N}$ values of (A) Tectocepheus velatus sarekensis, and (B)

Ceratophysella sp.; means \pm 1 SE. Asterisks indicate significant differences (* $\left.p \leq 0.05,{ }^{* *} p \leq 0.01, * * * p \leq 0.001\right)$; for details see Table 2. 
Table 2. Effects of plant diversity (species richness, functional group richness), plant functional group identity, and time on the incorporation of mineral-derived $\mathbf{N}$ into studied mesofauna species. LME table of $t$ - and p-values for the effects of the factors plant species richness (SR), plant functional group richness (FGR), presence of legumes (LEG), presence of grasses (GR), and time on the incorporation of mineral nitrogen into soil mesofauna species $\left(\Delta^{15} \mathrm{~N}\right.$ values). Intercept $=$ intersection point with $\mathrm{y}$-axis. $\mathrm{df}=\mathrm{estimated}$ degrees of freedom. $\downarrow / \uparrow=\mathrm{decrease} /$ increase with increase of the respective factor. Significant effects $(p \leq 0.05)$ are given in bold. Asterisks indicate levels of significance $(* p \leq 0.05, * * p \leq 0.01, * * * \leq 0.001)$. df $=$ theoretical degrees of freedom.

\begin{tabular}{|c|c|c|c|c|c|c|c|c|c|c|c|c|c|c|c|c|c|c|c|c|}
\hline & \multicolumn{4}{|c|}{ Lasioseius berlesei } & \multicolumn{4}{|c|}{ Ceratophysella sp. } & \multicolumn{4}{|c|}{ Tectocepheus velatus sarekensis } & \multicolumn{4}{|c|}{ Parisotoma notabilis } & \multicolumn{4}{|c|}{ Stenaphorura denisi } \\
\hline & Estimate & df & $t$ & p & Estimate & df & $\mathrm{t}$ & $\mathbf{p}$ & Estimate & df & $\mathrm{t}$ & p & Estimate & df & $\mathrm{t}$ & $\mathbf{p}$ & Estimate & df & $t$ & $\mathbf{p}$ \\
\hline (Intercept) & 2.711 & 75.00 & 71.27 & $<0.0001^{* * *}$ & 2.620 & 10.68 & 24.12 & $<0,0001^{* * *}$ & 1.792 & 52.00 & 20.69 & $<0,0001^{* * *}$ & 2.462 & 16.41 & 22.30 & $<0.0001^{* * *}$ & 2.449 & 22.00 & 46.25 & $<0.0001^{* * *}$ \\
\hline & & & & & -0.262 & 64.82 & -2.20 & $0.032 \downarrow *$ & -0.261 & 52.00 & -2.28 & $0.026 \downarrow *$ & 0.219 & 24.76 & 1.92 & 0.07 & & & & \\
\hline FGR & & & & & & & & & & & & & & & & & & & & \\
\hline LEG & & & & & & & & & & & & & & & & & & & & \\
\hline $\begin{array}{l}\text { GR } \\
\text { Time }\end{array}$ & & & & & 0.460 & 10.65 & 3.72 & $0.004 \uparrow * *$ & & & & & & & & & & & & \\
\hline $\begin{array}{l}\text { Time } \\
\text { SB } \times \text { Time }\end{array}$ & -0.005 & 75.00 & -8.91 & $<0.0001 \downarrow * * *$ & & & & & & & & & & & & & & & & \\
\hline $\begin{array}{l}\text { SR } \times \text { I Ime } \\
\text { FGR } \times \text { Time }\end{array}$ & & & & & & & & & $\begin{array}{l}0.007 \\
0.003\end{array}$ & 52.00 & $\begin{array}{l}2.25 \\
2.63\end{array}$ & $\begin{array}{l}0.028^{*} \\
0.011^{*}\end{array}$ & -0.005 & 24.36 & -6.67 & $<0.0001^{* * *}$ & $\begin{array}{l}-0.007 \\
0.002\end{array}$ & $\begin{array}{l}22.00 \\
22.00\end{array}$ & $\begin{array}{l}-2.55 \\
2.48\end{array}$ & $\begin{array}{l}0.0182^{*} \\
0.0214^{*}\end{array}$ \\
\hline LEG x Time & & & & & & & & & & & & & & & & & -0.005 & 22.00 & -1.99 & 0.060 \\
\hline GR x Time & & & & & -0.004 & 68.99 & -4.58 & $<0.0001^{* * *}$ & -0.010 & 52.00 & -3.80 & $0.0004^{* * *}$ & & & & & 0.003 & 22.00 & 1.42 & 0.171 \\
\hline AIC full mod. & -14.10 & & & & 35.47 & & & & 30.72 & & & & 5.15 & & & & 79.979 & & & \\
\hline AIC red. mod. & -25.38 & & & & 31.46 & & & & -1.03 & & & & -4.84 & & & & 3.35 & & & \\
\hline
\end{tabular}

\begin{tabular}{|c|c|c|c|c|c|c|c|c|}
\hline & \multicolumn{4}{|c|}{ Lepidocyrtus cyaneus } & \multicolumn{4}{|c|}{ Isotoma viridis } \\
\hline & Estimate & df & $t$ & p & Estimate & df & $t$ & p \\
\hline (Intercept) & 2.6724 & 8.72 & 61.56 & $<0.0001^{* * *}$ & 2.36 & 12 & 11.25 & $<0.0001^{* * *}$ \\
\hline SR & & & & & 0.46 & 12 & 1.772 & 0.1018 \\
\hline FGR & & & & & & & & \\
\hline LEG & & & & & -0.39 & 12 & -1.953 & 0.0746 \\
\hline GR & & & & & & & & \\
\hline $\begin{array}{l}\text { Time } \\
\text { SR }\end{array}$ & -0.002 & 63.38 & -1.80 & 0.077 & & & & \\
\hline $\begin{array}{l}\text { SR x Time } \\
\text { R }\end{array}$ & ב & & & & & & & \\
\hline FGR $x$ Time & -0.0009 & 63.51 & -2.69 & $<0.009^{* a *}$ & 0.00 & 12 & -2.915 & $0.013^{*}$ \\
\hline $\begin{array}{l}\text { LEG } \times \text { Time } \\
\text { GR } \times \text { Time }\end{array}$ & & & & & 0.01 & 12 & 2.051 & 0.0628 \\
\hline AIC full mod. & -16.48 & & & & 15.07 & & & \\
\hline AIC red. mod. & -26.57 & & & & 13.20 & & & \\
\hline
\end{tabular}




\subsection{Discussion}

Soil microorganisms are one of the main food resources of soil animals thereby channelling microbial $\mathrm{N}$ to higher trophic levels of the soil food web. Nevertheless, until today it is unclear which soil animals rely predominantly on $\mathrm{N}$ derived from microorganisms and which predominantly rely on $\mathrm{N}$ from dead organic matter. Further, it is unknown if plants modify the uptake of $\mathrm{N}$ by soil animals via these channels. Simplified ecosystems with low plant diversity may hamper ecosystem functions (Landis, 2017), including the channelling of $\mathrm{N}$ to higher trophic levels. Plant $\mathrm{N}$ uptake is driven by plant traits, such as root density and the ability to fix molecular $\mathrm{N}$, and therefore, both plant functional group identity and plant diversity needs to be considered for understanding mineral $\mathrm{N}$ uptake by microorganisms and its subsequent channelling to higher trophic levels of soil food webs. Despite the need to sustain functioning grassland ecosystems to ensure ecosystem services, detailed knowledge on the relationships between plant community properties and the channelling of $\mathrm{N}$ into higher trophic levels of the soil food web is still scarce. To address these gaps of knowledge we added mineral ${ }^{15} \mathrm{~N}$ to semi-natural grassland of different plant diversity and plant community compositions and tracked its incorporation into soil microorganisms and higher trophic levels of the soil food web.

\section{Temporal variation of mineral $\mathbf{N}$ incorporation}

Generally, the concentration of ${ }^{15} \mathrm{~N}$ in mesofauna species declined parallel to that in microorganisms with time, reflecting the dominant flux of $\mathrm{N}$ from microorganisms to higher trophic levels. The applied ${ }^{15} \mathrm{~N}$ presumably was increasingly taken up by microorganisms and plants with time. In the long-term, plants are superior to microorganisms in mineral $\mathrm{N}$ acquisition as they have longer life cycles and effectively capture $\mathrm{N}$ released by decaying microorganisms (Hodge et al., 2000; Kaye and Hart, 1997; Kuzyakov and Xu, 2013). In particular in N-limited ecosystems, such as the grassland site investigated in this study (Strecker et al., 2015), $\mathrm{N}$ is immobilized quickly by microorganisms and plants. Mowing and removal of plant aboveground biomass likely aggravates $\mathrm{N}$ limitation, even though the deposition of $\mathrm{N}$ is high and increasing on a global scale (Leimer et al., 2016, 2013; Reay et al., 2008).

In contrast to our expectations (hypothesis 1), there was no time lag in the incorporation of mineralderived $\mathrm{N}$ into species of higher trophic levels, such as the predator L. berlesei, as compared to potential prey taxa such as Collembola. Rather, $\mathrm{N}$ incorporation uniformly peaked at the first sampling date after labeling for all studied mesofauna species, except in the primary decomposer $T$. velatus sarekensis. However, the amount of mineral-derived $\mathrm{N}$ incorporated into soil animal tissue differed markedly between animal taxa reflecting different nutritional strategies. Further, the incorporation of mineral-derived $\mathrm{N}$ into soil animal species changed with time suggesting that factors 
driving the incorporation of mineral-derived $\mathrm{N}$ into soil animals, such as tissue turnover and feeding behaviour, show species-specific temporal dynamics.

At the first sampling date, incorporation of mineral-derived $\mathrm{N}$ was highest in the springtail species Ceratophysella sp., followed by the Gamasina L. berlesei and the Collembola L. cyaneus, I. viridis, P. notabilis, S. denisi, and the primary decomposer oribatid mite T. velatus sarekensis. High $\Delta^{15} \mathrm{~N}$ values in Ceratophysella sp. suggest that this species predominantly acquires its $\mathrm{N}$ by feeding on microorganisms, which were heavily labelled with ${ }^{15} \mathrm{~N}$. This is supported by other studies reporting Ceratophysella sp. and other species of Poduromorpha to predominantly feed on fungi (Chahartaghi et al., 2005; Maraun et al., 2003). However, there is evidence that Poduromorpha species also feed on plants (Sechi et al., 2014), thus, combined feeding on fungi and plant roots may have been responsible for the high $\Delta^{15} \mathrm{~N}$ values in Ceratophysella sp. Omnivory, i.e. feeding on prey from more than one trophic level, may alleviate $\mathrm{N}$ limitation by broadening the prey spectrum (Wilder and Eubanks, 2010). The Collembola L. cyaneus incorporated less ${ }^{15} \mathrm{~N}$ than Ceratophysella sp., but still incorporation was high 5 days after labeling, which also suggests that this species acquired much of its $\mathrm{N}$ from feeding on microorganisms. This is in line with other studies reporting L. cyaneus to preferentially feed on fungi and to a minor degree on bacteria (Berg et al., 2004; Ferlian et al., 2015). Unexpectedly, also the predatory Gamasina L. berlesei quickly incorporated high amounts of mineralderived $\mathrm{N}$ similar to the level in its potential prey species L. cyaneus. In addition to feeding on highly labelled Collembola prey species, the unexpected fast incorporation of mineral-derived $\mathrm{N}$ into predators may have resulted from feeding on nematodes as major grazers of soil microorganisms (Heidemann et al. 2014). In fact, L. berlesei has been shown to prey on nematodes and small arthropods such as Collembola (Christian and Karg, 2006; Walter and Ikonen, 1989), thereby quickly incorporating $\mathrm{N}$ from basal resources. Further, L. berlesei develops fast, reaching maturity after only 9-19 days (Christian and Karg, 2006), suggesting that this species incorporates mineral-derived $\mathrm{N}$ from prey species within a few days.

Intermediate levels of mineral-derived $\mathrm{N}$ incorporated into animals, such as the Collembola I. viridis, $P$. notabilis and $S$. denisi, suggest that these species only in part fed on microorganisms and that their diet includes a substantial amount of dead organic matter. However, as these species have been assumed to be predominantly microbivorous (Berg et al., 2004; Chahartaghi et al., 2005; Ngosong et al., 2011), slow tissue turnover rate may also have contributed to the lower ${ }^{15} \mathrm{~N}$ incorporation as compared to the microbivorous Ceratophysella sp. and L. cyaneus.

Low incorporation of mineral-derived ${ }^{15} \mathrm{~N}$ in $T$. velatus sarekensis suggests that this species little relies on microbial N. Notably, only in this species the incorporation of mineral-derived $\mathrm{N}$ increased slowly with time. This suggests that the predominant feeding strategy of $T$. velatus sarekensis was detritivory, potentially including microbial residues, confirming earlier studies assuming this species 
to live as primary decomposer virtually not relying on $\mathrm{N}$ from living microorganisms (Laumann et al., 2007; Maraun et al., 2011; Siepel and Ruiter-Dijkman, 1993).

\section{Variation of mineral $\mathbf{N}$ incorporation with plant diversity}

In general, plant diversity played a major role for the incorporation of mineral-derived $\mathrm{N}$ into the studied mesofauna species, and this was true for both plant species richness and plant functional group richness.

Confirming our hypothesis 2, plant species richness decreased the uptake of mineral-derived $\mathrm{N}$ by microorganisms. Competition between microorganisms and plants for mineral $\mathrm{N}$ in soil is likely to be aggravated in more diverse plant communities as they take up $\mathrm{N}$ more efficiently than communities of low diversity (Bessler et al., 2012; Jesch et al., 2018), e.g. due to different rooting depths of different plant species (Cardinale et al., 2007; Scherer-Lorenzen et al., 2003; Spehn et al., 2005). Despite stronger competition for soil $\mathrm{N}$ under high plant diversity, positive effects of plant diversity on microbial communities may surpass negative ones as soil microbial activity and biomass increases with plant diversity, probably due to increased rhizodeposition that mitigates carbon limitation of microorganisms (Cline et al. 2018; Lange et al. 2015; Strecker et al. 2016, 2015).

Also in line with hypothesis 2 , plant species richness as a main factor significantly decreased $\Delta^{15} \mathrm{~N}$ values in Ceratophysella sp., likely because Ceratophysella sp. fed on microorganisms that were also reduced in ${ }^{15} \mathrm{~N}$ due to limited $\mathrm{N}$ supply in high diverse plant communities (see above). Interestingly, plant species richness exerted time-dependent effects on $T$. velatus sarekensis, P. notabilis, and $S$. denisi. In T. velatus sarekensis, $\Delta^{15} \mathrm{~N}$ values decreased with plant species richness at the beginning of the experiment, but increased with increasing plant species richness later in the experiment.

Potentially, the increase in $\Delta^{15} \mathrm{~N}$ values in $T$. velatus sarekensis with plant species richness later in the experiment was due to increased availability of dead plant roots containing ${ }^{15} \mathrm{~N}$ from the mineral ${ }^{15} \mathrm{~N}$ added. In P. notabilis and S. denisi, $\Delta^{15} \mathrm{~N}$ values increased with increasing plant species richness early in the experiment, but this effect disappeared later. Presumably, this reflects that certain species of microorganisms associated with roots incorporated more ${ }^{15} \mathrm{~N}$ in more diverse plant communities and were heavily grazed by microbivorous microarthropods such as $P$. notabilis and $S$. denisi. In addition to plant species richness, $\Delta^{15} \mathrm{~N}$ values of microarthropods also varied significantly with plant functional group richness. In T. velatus sarekensis, S. denisi, I. viridis and L. cyaneus $\Delta^{15} \mathrm{~N}$ values decreased with increasing plant functional group richness in particular early in the experiment. Presumably, this again reflects the more effective capture of nutrients by plants in more diverse plant communities resulting in lower incorporation of ${ }^{15} \mathrm{~N}$ into microorganisms. 


\section{Variations of mineral $\mathbf{N}$ incorporation with plant functional group identity}

Conform to hypothesis 3 , the presence of legumes decreased mineral-derived $\mathrm{N}$ in soil microorganisms, with the effect being most pronounced at day 30 and declining later in the experiment. This is in line with results of Strecker et al. (2015) reporting that legumes reduce $\mathrm{N}$ limitation of soil microorganisms at the field site of the Jena Experiment, presumably via the release of $\mathrm{N}$ fixed by legumes into the soil via rhizodeposition diluting the added mineral ${ }^{15} \mathrm{~N}$ and thereby its uptake by microorganisms. However, we found no effect of legumes on the incorporation of mineralderived $\mathrm{N}$ into any of the studied mesofauna species. Obviously, the effect of legumes on soil microbial $\mathrm{N}$ did not propagate to higher trophic levels, contrasting our expectations. Potentially, the large number of other plant species in the Jena Experiment diluted the legume effect at our field site. In contrast to hypothesis 4, presence of grasses did not affect mineral-derived $\mathrm{N}$ in microorganisms. This contradicts earlier findings showing that the presence of grasses enhances the microbial C-to-Nratio, i.e. decreases the availability of $\mathrm{N}$ for soil microorganisms (Strecker et al., 2015). Although the presence of grasses did not change microbial ${ }^{15} \mathrm{~N}$ APE, they affected $\Delta{ }^{15} \mathrm{~N}$ values in Ceratophysella sp. and in $T$. velatus sarekensis. However, the effects differed between species and varied with time. In Ceratophysella sp., presence of grasses increased $\Delta^{15} \mathrm{~N}$ values with the effect being strongest at days 5 and 15. The positive effect of grasses on the $\Delta^{15} \mathrm{~N}$ values of Ceratophysella sp. support the view that the diet of this species is not restricted to microorganisms but also includes plants (Sechi et al., 2014 ) in particular roots highly labelled with ${ }^{15} \mathrm{~N}$ (Jesch et al., 2018). Conform to hypothesis 4 , grasses decreased $\Delta^{15} \mathrm{~N}$ values in $T$. velatus sarekensis, and this effect was strongest at days 30 and 60 . This suggests that $T$. velatus sarekensis mainly fed on herbs and not on grasses. This is supported by the fact that, despite effective nutrient acquisition, grasses have a higher $\mathrm{C}$-to-N ratio compared to many legume and non-legume herbs (Abbas et al., 2013; Bessler et al., 2012), resulting in low food quality.

\subsection{Conclusions}

Labeling temperate grassland soil with mineral ${ }^{15} \mathrm{~N}$ allowed tracking the incorporation of mineral $\mathrm{N}$ into soil microorganisms and its transfer into higher trophic levels of the soil food web as affected by plant diversity and community composition. Importantly, the method allowed differentiating between soil animals relying on microbial $\mathrm{N}$ and those relying on $\mathrm{N}$ from dead organic matter. All of the investigated mesofauna species at least in part incorporated microbial mineral-derived N. Our data thus underline the predominant role of microorganisms in channelling $\mathrm{N}$ to higher trophic levels of soil food webs and indicate that this resource contributes significantly to the nutrition of soil invertebrates. Notably, predatory species quickly incorporated mineral-derived N (within 5 days), suggesting that prey species with short life cycles, presumably mainly nematodes, speed up the 
channelling of microbial $\mathrm{N}$ into predators, but also secondary decomposers such as Collembola which in part also feed on nematodes.

Confirming our expectations, plant diversity (species richness as well as functional group richness) significantly modified the incorporation of mineral-derived $\mathrm{N}$ into the studied mesofauna species. The data suggest that high plant diversity reduces the incorporation of mineral-derived $\mathrm{N}$ into higher trophic levels of the soil food web due to their high competitiveness for $\mathrm{N}$ towards microorganisms. Thus, we conclude that high plant diversity may alter the competitive interactions between soil animal taxa and change the nutrient transfer across trophic levels in soil food webs via tightening the competition for N. Especially in N-limited grassland systems such as the field site of the Jena Experiment (Eisenhauer et al. 2010), this may also change the population dynamics and community composition of the soil food web as compared to those at low plant diversity. Presumably, high plant diversity may lead to soil food webs that are mainly based on fungi, as these are more efficient in exploiting soil resources as compared to bacteria. This is supported by de Vries et al. $(2007,2006)$, who found increased soil fungal biomass in grasslands with no or reduced $\mathrm{N}$ fertilizer input (hence, low mineral $\mathrm{N}$ availability). In the face of elevated $\mathrm{N}$ deposition worldwide, high plant diversity may also buffer detrimental effects of $\mathrm{N}$ deposition on soil biota (Eisenhauer et al., 2012), highlighting the importance of sustaining high plant diversity in grassland ecosystems.

\subsection{Acknowledgements}

The experiment was designed and set up by Hans de Kroon, Arthur Gessler, Liesje Mommer and Michael Scherer-Lorenzen. We are grateful to all student helpers, technicians and colleagues who helped in the labelling and sampling campaigns (especially Ahmad Sagheer for taking soil samples, further Guido Humpert and Lennart Holst). Many thanks to Gerlinde Kratzsch and the gardeners team, for maintaining the field site. In addition, many thanks to Andrea- Gräbe-Treger for help with CFE, as well as Sara Mosch and Babette Günther for help with identifying soil animals and processing samples. We further thank Reiner Georg Jörgensen for provision of lab facilities and Gabriele Dormann for advices in the lab. Special thanks to Melissa Jüds who wrote her Bachelor thesis in the framework of this study, for identifying soil animals and processing samples. We further thank Anne Ebeling for the coordination of the Jena Experiment, and Reinhard Langel as well as Lars Szwec from the Kompetenzzentrum Stabile Isotope for analyzing ${ }^{15} \mathrm{~N}$ of animals and microorganisms. This research is part of the Jena Experiment supported by the DFG (SCHE 376/36-1). Nico Eisenhauer acknowledges support by the German Centre for Integrative Biodiversity Research (iDiv) Halle-JenaLeipzig, funded by the German Research Foundation (FZT 118). 


\subsection{References}

Abbas, M., Ebeling, A., Oelmann, Y., Ptacnik, R., Roscher, C., Weigelt, A., Weisser, W.W., Wilcke, W., Hillebrand, H., 2013. Biodiversity Effects on Plant Stoichiometry. PLoS ONE 8. doi:10.1371/journal.pone.0058179

Albers, D., Schaefer, M., Scheu, S., 2006. Incorporation of plant carbon into the soil animal food web of an arable system. Ecology 87, 235-45.

Ayres, E., Dromph, K.M., Cook, R., Ostle, N., Bardgett, R.D., 2007. The influence of below-ground herbivory and defoliation of a legume on nitrogen transfer to neighbouring plants. Functional Ecology 21, 256-263. doi:10.1111/j.1365-2435.2006.01227.x

Bates, D., Mächler, M., Bolker, B.M., Walker, S.C., 2015. Fitting linear mixed-effects models using Ime4. Journal of Statistical Software 67, 1-48. doi:10.18637/jss.v067.i01

Bates, D., Maechler, M., Bolker, B., Walker, S., 2019. Ime4: Linear Mixed-Effects Models Using 'Eigen ` and S4. R package version 1.1-10, http://CRAN.R-project.org/package= Ime4.

Berg, M.P., Stoffer, M., Van Den Heuvel, H.H., 2004. Feeding guilds in Collembola based on digestive enzymes. Pedobiologia 48, 589-601. doi:10.1016/j.pedobi.2004.07.006

Bessler, H., Oelmann, Y., Roscher, C., Buchmann, N., Scherer-Lorenzen, M., Schulze, E.D., Temperton, V.M., Wilcke, W., Engels, C., 2012. Nitrogen uptake by grassland communities: Contribution of N2 fixation, facilitation, complementarity, and species dominance. Plant and Soil 358, 301-322. doi:10.1007/s11104012-1181-z

Brookes, P., Landman, A., Pruden, G., Jenkinson, D.S., 1985. Chloroform fumigation and the release of soil nitrogen: a rapid direct extraction method to measure microbial biomass nitrogen in soil. Soil Biology and Biochemistry 17, 837-842.

Buresh, R.J., Austin, E.R., Craswell, E.T., 1982. Analytical methods in 15N research. Fertilizer Research 3, 37-62. doi:10.1007/BF01063408

Buscot, F., Varma, A., 2005. Microorganisms in Soils - Roles in Genesis and Functions, 1st ed. Springer-Verlag, Berlin.

Cardinale, B.J., Duffy, J.E., Gonzalez, A., Hooper, D.U., Perrings, C., Venail, P., Narwani, A., Mace, G.M., Tilman, D., Wardle, D. a, Kinzig, A.P., Daily, G.C., Loreau, M., Grace, J.B., Larigauderie, A., Srivastava, D.S., Naeem, S., 2012. Biodiversity loss and its impact on humanity. Nature 486, 59-67. doi:10.1038/nature11148

Cardinale, B.J., Wright, J.P., Cadotte, M.W., Carroll, I.T., Hector, A., Srivastava, D.S., Loreau, M., Weis, J.J., 2007. Impacts of plant diversity on biomass production increase through time because of species complementarity. Proceedings of the National Academy of Sciences of the United States of America 104, 18123-18128. doi:10.1073/pnas.0709069104

Carrillo, Y., Ball, B.A., Bradford, M.A., Jordan, C.F., Molina, M., 2011. Soil fauna alter the effects of litter composition on nitrogen cycling in a mineral soil. Soil Biology and Biochemistry 43, 1440-1449. doi:10.1016/j.soilbio.2011.03.011

Chahartaghi, M., Langel, R., Scheu, S., Ruess, L., 2005. Feeding guilds in Collembola based on nitrogen stable isotope ratios. Soil Biology and Biochemistry 37, 1718-1725. doi:10.1016/j.soilbio.2005.02.006

Chapin, F.S., Zavaleta, E.S., Eviner, V.T., Naylor, R.L., Vitousek, P.M., Reynolds, H.L., Hooper, D.U., Lavorel, S., Sala, O.E., Hobbie, S.E., Mack, M.C., Díaz, S., 2000. Consequences of changing biodiversity. Nature 405, 23442. doi:10.1038/35012241

Chen, M., Chen, B., Marschner, P., 2008. Plant growth and soil microbial community structure of legumes and grasses grown in monoculture or mixture. Journal of Environmental Sciences 20, 1231-1237. doi:10.1016/S1001-0742(08)62401-8

Christian, A., Karg, W., 2006. The predatory mite genus Lasioseius Berlese , 1916 (Acari, Gamasina), Abhandlungen und Berichte des Naturkundemuseums Görlitz 77, 99-250.

Cline, L.C., Hobbie, S.E., Madritch, M.D., Buyarski, C.R., Tilman, D., Cavender-Bares, J.M., 2018. Resource availability underlies the plant-fungal diversity relationship in a grassland ecosystem. Ecology 99, 204-216. doi:10.1002/ecy.2075

Crotty, F. V., Adl, S.M., Blackshaw, R.P., Murray, P.J., 2012. Using stable isotopes to differentiate trophic feeding channels within soil food webs. Journal of Eukaryotic Microbiology 59, 520-526. doi:10.1111/j.15507408.2011.00608.x

Crotty, F. V, Blackshaw, R.P., Murray, P.J., 2011. Tracking the flow of bacterially derived $13 \mathrm{C}$ and $15 \mathrm{~N}$ through soil faunal feeding channels. Rapid Communications in Mass Spectrometry : RCM 25, 1503-13. doi:10.1002/rcm.4945

de Vries, F.T., Bloem, J., van Eekeren, N., Brusaard, L., Hoffland, E., 2007. Fungal biomass in pastures increases with age and reduced $\mathrm{N}$ input. Soil Biology and Biochemistry 39, 1620-1630.

doi:10.1016/j.soilbio.2007.01.013 
de Vries, F.T., Hoffland, E., van Eekeren, N., Brussaard, L., Bloem, J., 2006. Fungal/bacterial ratios in grasslands with contrasting nitrogen management. Soil Biology and Biochemistry 38, 2092-2103. doi:10.1016/j.soilbio.2006.01.008

de Witte, L.C., Stöcklin, J., 2010. Longevity of clonal plants: Why it matters and how to measure it. Annals of Botany 106, 859-870. doi:10.1093/aob/mcq191

Dyckmans, J., Scrimgeour, C.M., Schmidt, O., 2005. A simple and rapid method for labelling earthworms with15N and13C. Soil Biology and Biochemistry 37, 989-993. doi:10.1016/j.soilbio.2004.10.017

Eisenhauer, N., Bessler, H., Engels, C., Gleixner, G., Habekost, M., Milcu, A., Partsch, S., Sabais, a C.W., Scherber, C., Steinbeiss, S., Weigelt, A., Weisser, W.W., Scheu, S., 2010. Plant diversity effects on soil microorganisms support the singular hypothesis. Ecology 91, 485-96.

Eisenhauer, N., Cesarz, S., Koller, R., Worm, K., Reich, P.B., 2012. Global change belowground: impacts of elevated $\mathrm{CO}_{2}$, nitrogen, and summer drought on soil food webs and biodiversity. Global Change Biology 18, 435-447. doi:10.1111/j.1365-2486.2011.02555.x

Eisenhauer, N., Dobies, T., Cesarz, S., Hobbie, S.E., Meyer, R.J., Worm, K., Reich, P.B., 2013. Plant diversity effects on soil food webs are stronger than those of elevated $\mathrm{CO} 2$ and $\mathrm{N}$ deposition in a long-term grassland experiment. Proceedings of the National Academy of Sciences of the United States of America 110, 688994. doi:10.1073/pnas.1217382110

Eisenhauer, N., Lanoue, A., Strecker, T., Scheu, S., Steinauer, K., Thakur, M.P., Mommer, L., 2017. Root biomass and exudates link plant diversity with soil bacterial and fungal biomass. Scientific Reports 7. doi:10.1038/srep44641

Ellenberg, H., Leuschner, C., 2010. Vegetation Mitteleuropas mit den Alpen, 6th ed. Ulmer Verlag, Stuttgart.

Farrell, M., Prendergast-Miller, M., Jones, D.L., Hill, P.W., Condron, L.M., 2014. Soil microbial organic nitrogen uptake is regulated by carbon availability. Soil Biology and Biochemistry 77, 261-267. doi:10.1016/j.soilbio.2014.07.003

Ferlian, O., Klarner, B., Langeneckert, A.E., Scheu, S., 2015. Trophic niche differentiation and utilisation of food resources in collembolans based on complementary analyses of fatty acids and stable isotopes. Soil Biology and Biochemistry 82, 28-35. doi:10.1016/j.soilbio.2014.12.012

Filser, J., 2002. The role of Collembola in carbon and nitrogen cycling in soil. Pedobiologia 46, 234-245. doi:10.1078/0031-4056-00130

Heidemann, K., Hennies, A., Schakowske, J., Blumenberg, L., Ruess, L., Scheu, S., Maraun, M., 2014. Free-living nematodes as prey for higher trophic levels of forest soil food webs. Oikos 123, 1199-1211. doi:10.1111/j.1600-0706.2013.00872.x

Hodge, A., Robinson, D., Fitter, A., 2000. Are microorganisms more effective than plants at competing for nitrogen? Trends in Plant Science 5, 304-8.

Hodge, A., Robinson, D., Griffiths, B.S., Fitter, A.H., 1999. Why plants bother: Root proliferation results in increased nitrogen capture from an organic patch when two grasses compete. Plant, Cell and Environment 22, 811-820. doi:10.1046/j.1365-3040.1999.00454.x

Hoffmann, K., Bivour, W., Frueh, B., Koßmann, M., Voss, P.-H., 2014. Klimauntersuchungen in Jena fur die Anpassung an den Klimawandel und seine erwarteten Folgen: ein Ergebnisbericht, 243rd ed. Selbstverlag des Deutschen Wetterdienstes, Offenbach am Main

Hooper, D.U., Chapin, F.S., Ewel, J.J., Hector, A., Inchausti, P., Lavorel, S., Lawton, J.H., Lodge, D.M., Loreau, M., Naeem, S., Schmid, B., Setälä, H., Symstad, A.J., Vandermeer, J., Wardle, D.A., 2005. Effects Of Biodiversity On Ecosystem Functioning: A Consensus Of Current Knowledge. Ecological Monographs 75, 3-35.

Isbell, F., Calcagno, V., Hector, A., Connolly, J., Harpole, W.S., Reich, P.B., Scherer-Lorenzen, M., Schmid, B., Tilman, D., van Ruijven, J., Weigelt, A., Wilsey, B.J., Zavaleta, E.S., Loreau, M., 2011. High plant diversity is needed to maintain ecosystem services. Nature 477, 199-202. doi:10.1038/nature10282

Jesch, A., Barry, K.E., Ravenek, J.M., Bachmann, D., Strecker, T., Weigelt, A., Buchmann, N., de Kroon, H., Gessler, A., Mommer, L., Roscher, C., Scherer-Lorenzen, M., 2018. Below-ground resource partitioning alone cannot explain the biodiversity-ecosystem function relationship: A field test using multiple tracers. Journal of Ecology. doi:10.1111/1365-2745.12947

Joergensen, R.G., Mueller, T., 1996. The fumigation-extraction-method to estimate soil microbial biomass: calibration of the ken value. Soil Biology and Biochemistry 28, 33-37.

Kaye, J., Hart, S., 1997. Competition for nitrogen between plants and soil microorganisms. Trends in Ecology \& Evolution 12, 139-142.

Kuznetsova, A., Brockhoff, P.B., Christensen, R.H.B., 2019. ImerTest: Tests in Linear Mixed Effects Models. https://cran.r-project.org/web/packages/ImerTest/index.html.

Kuzyakov, Y., Xu, X., 2013. Competition between roots and microorganisms for nitrogen: Mechanisms and ecological relevance. New Phytologist 198, 656-669. doi:10.1111/nph.12235 
Landis, D.A., 2017. Designing agricultural landscapes for biodiversity-based ecosystem services. Basic and Applied Ecology 18, 1-12. doi:10.1016/j.baae.2016.07.005

Lange, M., Eisenhauer, N., Sierra, C. a, Bessler, H., Engels, C., Griffiths, R.I., Malik, A. a, Roy, J., Scheu, S., Steinbeiss, S., Mellado-va, P.G., Thomson, B.C., Trumbore, S.E., Gleixner, G., 2015. Plant diversity increases soil microbial activity and soil carbon storage. Nature Communications 6. doi:10.1038/ncomms 7707

Langel, R., Dyckmans, J., 2014. Combined $13 \mathrm{C}$ and $15 \mathrm{~N}$ isotope analysis on small samples using a nearconventional elemental analyzer/isotope ratio mass spectrometer setup. Rapid Communications in Mass Spectrometry 28, 1019-1022. doi:10.1002/rcm.6878

Laumann, M., Norton, R. a., Weigmann, G., Scheu, S., Maraun, M., Heethoff, M., 2007. Speciation in the parthenogenetic oribatid mite genus Tectocepheus (Acari, Oribatida) as indicated by molecular phylogeny. Pedobiologia 51, 111-122. doi:10.1016/j.pedobi.2007.02.001

Leimer, S., Oelmann, Y., Eisenhauer, N., Milcu, A., Roscher, C., Scheu, S., Weigelt, A., Wirth, C., Wilcke, W., 2016. Mechanisms behind plant diversity effects on inorganic and organic $\mathrm{N}$ leaching from temperate grassland. Biogeochemistry 131, 339-353. doi:10.1007/s10533-016-0283-8

Leimer, S., Wirth, C., Oelmann, Y., Wilcke, W., 2013. Biodiversity effects on nitrate concentrations in soil solution: a Bayesian model. Biogeochemistry 118, 141-157. doi:10.1007/s10533-013-9913-6

Lemanski, K., Scheu, S., 2015. The influence of fertilizer addition, cutting frequency and herbicide application on soil organisms in grassland. Biology and Fertility of Soils 51, 197-205. doi:10.1007/s00374-014-0963-2

Maraun, M., Erdmann, G., Fischer, B.M., Pollierer, M.M., Norton, R. a., Schneider, K., Scheu, S., 2011. Stable isotopes revisited: Their use and limits for oribatid mite trophic ecology. Soil Biology and Biochemistry 43, 877-882. doi:10.1016/j.soilbio.2011.01.003

Maraun, M., Martens, H., Migge, S., Theenhaus, A., Scheu, S., 2003. Adding to "the enigma of soil animal diversity": Fungal feeders and saprophagous soil invertebrates prefer similar food substrates. European Journal of Soil Biology 39, 85-95. doi:10.1016/S1164-5563(03)00006-2

Marschner, P., Crowley, D., Rengel, Z., 2011. Rhizosphere interactions between microorganisms and plants govern iron and phosphorus acquisition along the root axis - model and research methods. Soil Biology and Biochemistry 43, 883-894. doi:10.1016/j.soilbio.2011.01.005

Milcu, A., Partsch, S., Langel, R., Scheu, S., 2006. The response of decomposers (earthworms, springtails and microorganisms) to variations in species and functional group diversity of plants. Oikos 112, 513-524.

Müller, K., Kramer, S., Haslwimmer, H., Marhan, S., Scheunemann, N., Butenschön, O., Scheu, S., Kandeler, E., 2016. Carbon transfer from maize roots and litter into bacteria and fungi depends on soil depth and time. Soil Biology and Biochemistry 93, 79-89. doi:10.1016/j.soilbio.2015.10.015

Ngosong, C., Raupp, J., Richnow, H.H., Ruess, L., 2011. Tracking Collembola feeding strategies by the natural 13C signal of fatty acids in an arable soil with different fertilizer regimes. Pedobiologia 54, 225-233. doi:10.1016/j.pedobi.2011.02.004

Oelmann, Y., Buchmann, N., Gleixner, G., Habekost, M., Roscher, C., Rosenkranz, S., Schulze, E.-D., Steinbeiss, S., Temperton, V.M., Weigelt, A., Weisser, W.W., Wilcke, W., 2011. Plant diversity effects on aboveground and belowground $\mathrm{N}$ pools in temperate grassland ecosystems: Development in the first 5 years after establishment. Global Biogeochemical Cycles 25, GB2014. doi:10.1029/2010GB003869

Oelmann, Y., Kreutziger, Y., Temperton, V.M., Buchmann, N., Roscher, C., Schumacher, J., Schulze, E.-D., Weisser, W.W., Wilcke, W., 2007a. Nitrogen and phosphorus budgets in experimental grasslands of variable diversity. Journal of Environmental Quality 36, 396-407. doi:10.2134/jeq2006.0217

Oelmann, Y., Wilcke, W., Temperton, V.M., Buchmann, N., Roscher, C., Schumacher, J., Schulze, E.-D., Weisser, W.W., 2007b. Soil and Plant Nitrogen Pools as Related to Plant Diversity in an Experimental Grassland. Soil Science Society of America Journal 71, 720-729. doi:10.2136/sssaj2006.0205

Osler, G.H.R., Sommerkorn, M., 2007. Toward a complete soilC and N cycle: Incorporating the soil fauna. Ecolgy 88, 1611-1621.

Pollierer, M.M., Dyckmans, J., Scheu, S., Haubert, D., 2012. Carbon flux through fungi and bacteria into the forest soil animal food web as indicated by compound-specific $13 \mathrm{C}$ fatty acid analysis. Functional Ecology 26, 978-990. doi:10.1111/j.1365-2435.2012.02005.x

Pollierer, M.M., Langel, R., Körner, C., Maraun, M., Scheu, S., 2007. The underestimated importance of belowground carbon input for forest soil animal food webs. Ecology Letters 10, 729-736. doi:10.1111/j.1461-0248.2007.01064.x

$R$ Core Team, 2019. A language and environment for statistical computing.

Reay, D.S., Dentener, F., Smith, P., Grace, J., Feely, R.A., 2008. Global nitrogen deposition and carbon sinks. Nature Geoscience 1, 432-437.

Reineking, A., Langel, R., Schikowski, J., 1993. 15N, 13C-On-line Measurements with an Elemental Analyser (Carlo Erba, NA 1500), a Modified Trapping Box and a Gas Isotope Mass Spectrometer (Finnigan, MAT 251). 
Isotopenpraxis Isotopes in Environmental and Health Studies 29, 169-174. doi:10.1080/10256019308046151

Renker, C., Otto, P., Schneider, K., Zimdars, B., Maraun, M., Buscot, F., 2005. Oribatid Mites as Potential Vectors for Soil Microfungi: Study of Mite-Assiociated Fungal Species. Microbial Ecology 50, 518-528. doi:10.1007/s00248-005-5017-8

Roscher, C., Schumacher, J., Baade, J., 2004. The role of biodiversity for element cycling and trophic interactions: an experimental approach in a grassland community. Basic and Applied Ecology 5, 107-121.

Roscher, C., Thein, S., Schmid, B., Scherer-Lorenzen, M., 2008. Complementary nitrogen use among potentially dominant species in a biodiversity experiment varies between two years. Journal of Ecology 96, 495-504. doi:10.1111/j.1365-2745.2007.0

Schenck zu Schweinsberg-Mickan, M., Jörgensen, R.G., Müller, T., 2012. Rhizodeposition: Its contribution to microbial growth and carbon and nitrogen turnover within the rhizosphere. Journal of Plant Nutrition and Soil Science 175, 750-760. doi:10.1002/jpln.201100300

Scherber, C., Eisenhauer, N., Weisser, W.W., Schmid, B., Voigt, W., Fischer, M., Schulze, E.-D., Roscher, C., Weigelt, A., Allan, E., Bessler, H., Bonkowski, M., Buchmann, N., Buscot, F., Clement, L.W., Ebeling, A., Engels, C., Halle, S., Kertscher, I., Klein, A.-M., Koller, R., König, S., Kowalski, E., Kummer, V., Kuu, A., Lange, M., Lauterbach, D., Middelhoff, C., Migunova, V.D., Milcu, A., Müller, R., Partsch, S., Petermann, J.S., Renker, C., Rottstock, T., Sabais, A., Scheu, S., Schumacher, J., Temperton, V.M., Tscharntke, T., 2010. Bottom-up effects of plant diversity on multitrophic interactions in a biodiversity experiment. Nature 468, 553-6. doi:10.1038/nature09492

Scherer-Lorenzen, M., Palmborg, C., Prinz, A., Schulze, E.-D., 2003. The Role of Plant Diversity and Composition for Nitrate Leaching in Grasslands. Ecology 84, 1539-1552.

Scheu, S., 2002. The soil food web: Structure and perspectives. European Journal of Soil Biology 38, 11-20. doi:10.1016/S1164-5563(01)01117-7

Scheunemann, N., Pausch, J., Digel, C., Kramer, S., Scharroba, A., Kuzyakov, Y., Kandeler, E., Ruess, L., Butenschoen, O., Scheu, S., 2016. Incorporation of root $\mathrm{C}$ and fertilizer $\mathrm{N}$ into the food web of an arable field: Variations with functional group and energy channel. Food Webs 9, 39-45. doi:10.1016/j.fooweb.2016.02.006

Seastedt, T.R., 1984. The Role of Microarthropods in Decomposition and Mineralization Processes. Annual Review of Entomology 29, 25-46.

Sechi, V., D’Annibale, A., Ambus, P., Sarossy, Z., Krogh, P.H., Eriksen, J., Holmstrup, M., 2014. Collembola feeding habits and niche specialization in agricultural grasslands of different composition. Soil Biology and Biochemistry 74, 31-38. doi:10.1016/j.soilbio.2014.02.019

Siepel, H., Ruiter-Dijkman, E.M. De, 1993. Feeding guilds of oribatid mites based on their carbohydrase activities. Soil Biology and Biochemistry 25, 1491-1497. doi:10.1016/0038-0717(93)90004-U

Spehn, E.M., Hector, A., Joshil, J., Scherer-Lorenzen, M., Schmid, B., Bazeley-White, E., Beierkuhnlein, C., Caldeira, M.C., Diemer, M., Dimitrakopoulos, P.G., Finn, J.A., Freitas, H., Giller, P.S., Good, J., R., H., Hoegberg, P., Huss-Danell, K., Jumpponen, A., Koricheva, J., W., L.P., Loreau, M., Minns, A., Mulder, C.P.H., O’Donovan, G., Otway, S.J., Palmborg, C., Pereira, J.S., Pfisterer, Prinz, A., Read, D.J., Schulze, E.-D., Siamantziouras, A.-S.D., Terry, C., Troumbis, Y., Woodward, F.I., Yachi, S., Lawton, J.H., 2005. Ecosystem Effects of Biodiversity Manipulations in European Grasslands. Ecological Monographs 75, 37-63.

Spehn, E.M., Scherer-Lorenzen, M., Schmid, B., Hector, A., Caldeira, M.C., Dimitrakopoulos, P.G., Finn, J.A., Jumpponen, A., O’Donnovan, G., Pereira, J.S., Schulze, E.D., Troumbis, A.Y., Korner, C., 2002. The role of legumes as a component of biodiversity in a cross-European study of grassland biomass nitrogen. Oikos 98, 205-218. doi:10.1034/j.1600-0706.2002.980203.x

Strecker, T., Barnard, R.L., Niklaus, P. a., Scherer-Lorenzen, M., Weigelt, A., Scheu, S., Eisenhauer, N., 2015. Effects of Plant Diversity, Functional Group Composition, and Fertilization on Soil Microbial Properties in Experimental Grassland. Plos One 10, e0125678. doi:10.1371/journal.pone.0125678

Strecker, T., Mace, O.G., Scheu, S., Eisenhauer, N., 2016. Functional composition of plant communitites determines the spatial and temporal stability of soil microbial properties in a long-term plant diversity experiment. Oikos 1-12. doi:10.1111/oik.03181

Veresoglou, S.D., Chen, B., Rillig, M.C., 2012. Arbuscular mycorrhiza and soil nitrogen cycling. Soil Biology and Biochemistry 46, 53-62. doi:10.1016/j.soilbio.2011.11.018

Verhoef, H.A., Brussaard, L., 1990. Decomposition and nitrogen mineralization in natural and agro- ecosystems: the contribution of soil animals. Biogeochemistry 11, 175-211.

Vitousek, P.M., Howarth, R.W., 1991. Nitrogen limitation on land and in the sea : How can it occur ? 13, 87115. 
Walter, D.E., Ikonen, E.K., 1989. Species, guilds, and functional groups: taxonomy and behavior in nematophagous arthropods. Journal of Nematology 21, 315-27.

Wedin, D.A., Tilman, D., 1990. Species effects on nitrogen cycling : a test with perennial grasses. Oecologia 84, 433-441.

Wilder, S.M., Eubanks, M.D., 2010. Might nitrogen limitation promote omnivory among carnivorous arthropods? Comment. Ecology 91, 3114-3117. doi:10.1890/09-2080.1

Zieger, S.L., Ammerschubert, S., Polle, A., Scheu, S., 2017a. Root-derived carbon and nitrogen from beech and ash trees differentially fuel soil animal food webs of deciduous forests. PLoS ONE 12, 1-14. doi:10.1371/journal.pone.0189502

Zieger, S.L., Eissfeller, V., Maraun, M., Scheu, S., 2015. Incorporation of carbon and nitrogen from leaf litter differing in structural compounds into soil microarthropods of a deciduous forest. Pedobiologia 58, 219227. doi:10.1016/j.pedobi.2015.10.001

Zieger, S.L., Holzinger, A., Sommer, J., Rath, M., Kuzyakov, Y., Polle, A., Maraun, M., Scheu, S., 2017b. Beech trees fuel soil animal food webs via root-derived nitrogen. Basic and Applied Ecology 22, 28-35. doi:10.1016/j.baae.2017.06.006 


\subsection{Supporting Information}

Table 1. $L M$ table of $t$ - and $p$-values for the effects of species richness (SR), plant functional group richness (FGR), LEG (legumes), GR (grasses), Time, Block (1-4), mesofauna species (Isotoma viridis, Lasioseius berlesei, Lepidocyrtus cyaneus, Ceratophysella sp., Parisotoma notabilis, Stenaphorura denisi, Tectocepheus velatus sarekensis), and the respective interactions of plant community properties and time on the incorporation of mineral $N\left(\Delta{ }^{15} \mathrm{~N}\right.$ values) of the studied mesofauna species. Intercept $=$ intersection point with $y$-axis. $\downarrow / \uparrow=$ decrease $/$ increase with increase of the respective factor. Significant effects $(p \leq 0.05)$ are given in bold. Asterisks indicate levels of significance $\left({ }^{*} p \leq 0.05,{ }^{* *} p \leq 0.01\right.$, $* * * p \leq 0.001)$.

\begin{tabular}{|l|llll|}
\hline & Estimate & Std. Error & t value & $\mathbf{p}$ \\
\hline (Intercept) & 2.8070 & 0.07458 & 37.637 & $<0.0001^{* * *}$ \\
SR & -0.0351 & 0.07170 & -0.489 & 0.6252 \\
FGR & -0.0350 & 0.04000 & -0.875 & 0.3821 \\
LEG & 0.0178 & 0.08193 & 0.217 & 0.8281 \\
GR & 0.0656 & 0.07346 & 0.893 & 0.3722 \\
Time & -0.0031 & 0.00100 & -3.069 & $\mathbf{0 . 0 0 2 3} \downarrow * *$ \\
Block1 & 0.0464 & 0.08214 & 0.564 & 0.5730 \\
Block2 & -0.0715 & 0.04891 & -1.461 & 0.1448 \\
Block3 & -0.0151 & 0.04730 & -0.319 & 0.7501 \\
Block4 & 0.1309 & 0.04612 & 2.839 & $\mathbf{0 . 0 0 4 8 * *}$ \\
Isotoma viridis & -0.2912 & 0.07248 & -4.017 & $\mathbf{0 . 0 0 0 1} * * *$ \\
Lasioseius berlesei & -0.1475 & 0.04349 & -3.392 & $\mathbf{0 . 0 0 0 8} * * *$ \\
Lepidocyrtus cyaneus & -0.1593 & 0.04653 & -3.425 & $\mathbf{0 . 0 0 0 7 * * *}$ \\
Ceratophysella sp. & -0.8506 & 0.12190 & -6.979 & $<0.0001^{* * *}$ \\
Parisotoma notabilis & -0.1456 & 0.05752 & -2.531 & $\mathbf{0 . 0 1 1 8 *}$ \\
Stenaphorura denisi & -0.1785 & 0.05960 & -2.995 & $\mathbf{0 . 0 0 0 3} * *$ \\
Tectocepheus velatus sarekensis & -0.9648 & 0.04739 & -20.36 & $<0.000 \mathbf{1}^{* * *}$ \\
SR x Time & -0.0003 & 0.00124 & -0.232 & 0.8163 \\
FGR x Time & 0.0000 & 0.00059 & 0.009 & 0.9932 \\
LEG x Time & 0.0003 & 0.00117 & 0.263 & 0.7925 \\
GR x Time & -0.0002 & 0.00112 & -0.194 & 0.8465 \\
\hline
\end{tabular}

Table 2. Effects of plant diversity (species richness, functional group richness), plant functional group identity, and time on the incorporation of mineral-derived $\mathrm{N}$ into soil microbial biomass. LME table of $\mathrm{t}$ - and $\mathrm{p}$-values for the effects of the factors plant species richness (SR), plant functional group richness (FGR), presence of legumes (LEG), presence of grasses (GR) on the incorporation of mineral nitrogen $\left({ }^{15} \mathrm{~N} A P E\right)$ into soil microbial biomass. Intercept $=$ intersection point with $y$-axis. $d f=$ estimated degrees of freedom. $\downarrow / \uparrow=$ decrease / increase with increase of the respective factor. Significant effects ( $p \leq$ $0.05)$ are given in bold. Asterisks indicate levels of significance $(* p \leq 0.05, * * p \leq 0.01, * * * p \leq 0.001)$.

\begin{tabular}{|l|llll|}
\hline & \multicolumn{3}{|l}{ Microorganisms } & \\
& Estimate & df & t & p \\
\hline (Intercept) & 86.880 & 15.17 & 16.11 & $<0.0001^{* * *}$ \\
SR & -11.960 & 168.90 & -2.52 & $\mathbf{0 . 0 1 3} \downarrow^{*}$ \\
FGR & & & & \\
LEG & -9.271 & 169.60 & -1.99 & $\mathbf{0 . 0 4 8} \downarrow^{*}$ \\
GR \\
$\begin{array}{l}\text { Time } \\
\text { SR } x \text { Time } \\
\text { FGR x Time } \\
\text { LEG x Time } \\
\text { GR x Time }\end{array}$ & -0.633 & 167.20 & -12.78 & $<\mathbf{0 . 0 0 0 1} \downarrow^{* * *}$ \\
\hline $\begin{array}{l}\text { AIC full mod. } \\
\text { AIC red. mod. }\end{array}$ & -8.169 & 167.20 & 2.33 & $\mathbf{0 . 0 2 1 *}$ \\
& -860.00 & & & \\
\hline
\end{tabular}




\section{General Discussion}

The present thesis was conducted in the context of current global change and its consequences for ecosystem functioning. The experiments within this thesis were all conducted in the framework of the Jena Experiment, a large biodiversity experiment which investigates the role of plant diversity (plant species richness and functional group richness) and several environmental change factors for ecosystem functioning. We conducted three studies: in study 1 (CHAPTER 2, Stability Experiment), we investigated how plant diversity and community composition modulates spatial and temporal stability of soil microbial community properties over a time period of 12 years; study 2 (CHAPTER 3, Fertilizer Experiment) focused on how plant diversity and plant community composition interact with mineral nitrogen fertilizer (NPK) to influence soil microbial properties (basal respiration, biomass and specific respiration) in bulk soil by using an $\mathrm{O}_{2}$ micro-compensation apparatus and the chloroform-fumigation extraction method; and in study 3 (CHAPTER 4, Tracer Experiment), we examined how plant diversity and community composition modulate the incorporation of mineral nitrogen into soil microorganisms and its channeling to higher trophic levels of the soil food web (mesofauna) by labelling soil with mineral ${ }^{15} \mathrm{~N}$.

Taken together, these studies highlight the importance of both, plant diversity (plant species richness and functional group richness), as well as plant functional group identity (legumes, grasses, small herbs and tall herbs) for soil microbial properties, their stability as well as for the channeling of mineral $\mathrm{N}$ from microorganisms to higher trophic levels of the soil food web (mesofauna). In parallel, our results revealed that plant diversity as well as the identity of plant functional groups do not affect all investigated soil microbial properties (including their stability) and mesofauna species equally, but the effects are dependent on the respective microbial property, animal species identity, and rely on temporal shifts of environmental conditions, such as soil nutrient availability.

\subsection{Changes in soil microbial properties with time and plant community composition}

In study 1 and 2, soil microbial properties, i.e. basal respiration and biomass $C$, both increased with increasing plant species richness four years after the establishment of the experimental grassland until the last measurement 12 years after establishment. Our results reinforce the results of earlier studies that found plant diversity to positively affect soil microbial properties (Chung et al., 2007; Spehn et al., 2000; Zak et al., 2003). Also, the results point to the transitory period the soil system needs to react to environmental changes such as land-use change from agricultural fields to seminatural grasslands. We suggest four mechanisms to cause the positive plant diversity effect on soil microbial functions: first, higher plant species richness was associated with higher soil water content, 
implying less evaporation due to higher plant coverage under high diverse plant communities. Constant and sufficient soil moisture is an essential factor for the activity of soil organisms (Joffre et al., 2003; Lange et al., 2014; Wardle, 1992). Further, higher plant diversity implicates higher primary productivity (Hector et al., 1999; Hooper et al., 2005; Weigelt et al., 2009). Thereby, these plant communities also translocate higher amounts of resources from shoots to roots, leading us to the second and third mechanism how plant species richness fosters soil microbial functions: through higher root litter deposition, and through higher root exudation (Baudoin et al., 2003; Dennis et al., 2010; Nico Eisenhauer et al., 2017). Both, the input of dead root material as well as root exudation deliver important $\mathrm{C}$ and $\mathrm{N}$ resources for soil microbial communities (Nico Eisenhauer et al., 2017; Meyer et al., 2016; Mommer et al., 2016). Fourth, higher plant diversity implicates higher stability of favourable ecosystem properties (more constant $\mathrm{C}$ and $\mathrm{N}$ provision and soil moisture), thereby preventing a major part of the soil microbial community from switching into a dormant state and allowing for higher growth rates (Anderson and Domsch, 1985; Eisenhauer et al., 2010; Tilman and Downing, 1994):

Interestingly and against our expectation, the positive relationships did not homogeneously strengthen over time. Instead, the relationship between plant species richness and microbial basal respiration was strongest already 7 years after the establishment of the experiment, while the relationship between plant species richness and soil microbial biomass $C$ reached its steepest slope not before 11 years after the establishment of the experiment. Our results suggest that during the first 7 years of the experiment, microbial basal respiration increased with increasing plant species richness due to increasing resource inputs by plants (Marquard et al., 2009; Ravenek et al., 2014; Reich et al., 2012). This positive relationship attenuated after 7 years because the soil microbial community matured and adapted to the soil conditions in the established semi-natural grassland, leading to higher resource use efficiency of the microbial community (Wardle and Ghani, 1995). After this "optimization" period (i.e., shift in physiology and/or community structure), the soil microbial community started to increase in biomass, and this process materialized after another time lag of 4 years. With this study, for the first time we showed that the positive effects of plant species richness on soil microbial properties remain significant within a time frame of more than 10 years. As in matured grassland systems with high plant species richness plant inputs into the soil system are generally high, we assume that the positive relationship between plant species richness and soil microbial properties will continue (Weigelt et al., 2009).

Surprisingly, the results of our study 1 (Chapter 2, Stability Experiment) did not show strong evidence that plant diversity also increases the (spatial/temporal) stability of soil microbial properties, but indicated that plant diversity effects on soil microbial stability turned from being negative to neutral, and reinforced the results of study 2 (Fertilizer Experiment) that plant diversity enhances soil 
microbial properties.

Against our expectation and in contrast to other studies (Eisenhauer et al., 2013; Wardle and Ghani, 1995), microbial C use efficiency did not increase with increasing plant diversity. As indicated by the results of our long-term study (Chapter 2, Stability Experiment), both soil microbial respiration as well as biomass increased beyond the time frame of study 2 , but also showed an enhanced variance of soil microbial properties with higher plant diversity.

To mechanistically understand why the slopes of the relationships between plant species richness and soil microbial properties peaked in certain years and why the slope between plant species richness and microbial respiration peaked several years before that of microbial biomass, more studies are needed. In particular, future studies should explore the abiotic and biotic drivers of interannual differences in the slope of plant diversity-ecosystem function relationships. Drivers of these differences likely include abiotic factors such as $\mathrm{pH}$ and soil moisture/drought, and biotic factors such as rhizodeposition and shifts in microbial community structure (de Vries et al., 2012, 2007, 2006). The results of our studies 1 and 2 (Stability- and Fertilizer Experiment, Chapter 2 and 3, respectively) revealed that not only diversity of plant communities, but also their functional composition matters for soil microbial properties. Out of the four plant functional groups in the investigated plant communities (legumes, grasses, small herbs, tall herbs), especially legumes and grasses influenced the performance of soil microorganisms. Importantly, our results corroborate that different plant functional groups can exert either different or similar effects on soil microbial properties, but that the responsible mechanisms are always plant-trait-specific and differ among plant functional groups (Bardgett et al., 2014; Ebeling et al., 2014). For example, the presence of grasses increased the microbial C-to-N-ratio as well as specific respiration. Our results suggest that grasses exacerbate the limitation of nutrients and water for soil microorganisms (Kaye and Hart, 1997; Schimel et al., 1997) due to high competitiveness associated with their dense root system, high specific root length and low tissue C-to-N-ratio (Jackson et al., 1997; Weigelt et al., 2008). In contrast to grasses, legumes decreased the microbial $\mathrm{C}$-to- $\mathrm{N}$-ratio as well as the specific microbial respiration (discussed below). Further, environmental conditions such as soil nutrient availability have also to be considered, as these conditions may change the effects of plant functional groups. For example, Eisenhauer et al. (2010) found legumes to increase the soil microbial biomass, but this effect was no longer detectable in our ensuing Fertilizer Experiment (Chapter 3). We propose that legumes first facilitated soil microbial biomass by mitigating $\mathrm{N}$ limitation, but hampered further microbial growth when competition for $P$ tightened (Chaudhary et al., 2008; Oelmann et al., 2007). This suggests that interactions between specific traits of plant functional groups and environmental factors can exert temporally dynamic effects on ecosystem functions, and consequently may alter the delivery of ecosystem services for humans (Bardgett et al., 2014). 
Notably, the positive effect of legumes on soil $\mathrm{N}$ availability for microorganisms remained persistent also after their facilitating effect on microbial biomass had disappeared, as demonstrated by our result from study 2 that legumes reduced the microbial C-to-N-ratio. It is well known that legumes fuel the soil with organic $\mathrm{N}$ through $\mathrm{N}$-rich plant litter and root exudation (Fustec et al., 2010; Spehn et al., 2002). The novelty of our results is that in $\mathrm{N}$-limited soil systems, the microbial stoichiometry (C-to-N-ratio) can be used as a powerful indicator for soil microbial functioning (Hartman and Richardson, 2013). This is underpinned by the decrease in the C-to-N-ratio with decreasing microbial specific respiration in study 2. Combined with the improved $\mathrm{N}$ supply in presence of legumes (Oelmann et al., 2007), we conclude that the reduced specific respiration is the consequence of an increased soil microbial $\mathrm{C}$ use efficiency induced by legumes.

To further unravel the underlying mechanisms that act via plant functional traits on soil microbial functioning, future studies are needed that enable the tracking of plant functional trait effects on soil microbial functioning in more detail. First studies in this direction have already been performed in the framework of the Jena Experiment and revealed weak relationships between plant functional traits and soil microbial functions within the first five years of the trait-based experiment (Steinauer et al., 2017). Due to the fact that plant effects on soil microbial communities have been shown to lag for several years (Eisenhauer et al., 2010; Capter 2, Stability Experiment), especially long-term studies are needed to uncover trait-based BEF mechanisms.

Our long-term dataset from 2002-2014 highlights that positive plant diversity effects on soil microbial properties can last beyond that of many short-term studies. However, as important as the relationship between plant community properties and soil microbial properties itself, is whether plant diversity and plant functional groups influence the stability of ecosystem functions such soil microbial respiration and biomass (Haddad et al., 2011; Proulx et al., 2010; Tilman et al., 2006). Therefore, with the dataset from 2002-2014 I also analysed spatial and temporal stability of soil microbial respiration and biomass in response to plant community properties (plant diversity and functional group identity).

\subsection{Stability of soil microbial properties}

We expected plant diversity to show specific dynamic effects over the three time phases of our longterm study (each phase spanning four years) on the temporal stability of soil microbial properties. Due to the disturbance (=land-use change) at the beginning of the experiment and the following maturation of the plant communities, we expected plant diversity to exert destabilizing effects during phase 1 , neutral effects in phase 2 , and positive effects in phase 3 . These expectations were verified in part. In phase 1 , the temporal stability of soil microbial biomass indeed decreased with increasing plant diversity. Because the soil system experienced a land-use change from arable field to 
newly established semi-natural grassland with experimental plots comprising from one to 60 plant species, soil microbial communities were forced to change (adapt) according to the new conditions. Presumably, the disturbances induced by the newly establishing plant communities on soil microbial communities increased with increasing plant diversity, as the dissimilarity of organic plant inputs (amount, variety and quality) into the soil as compared to former land-use must have increased in parallel (Nico Eisenhauer et al., 2017; Lange et al., 2015; Milcu et al., 2010). Hence, the change from mineral fertilizer inputs typical for arable fields to those typical for semi-natural grassland were likely to be weakest in monocultures and low-diversity plots, and strongest in high-diversity plots, as in these more organic residues (litter and root exudates) entered the soil. The soil microbial communities in these plots therefore were confronted to greater changes (= greater disturbance) compared to those in plots of low plant diversity. Consequently, the beginning of the successional shift of the soil microbial community from disturbed (zymogenous) to more mature (autochthonous) microbial communities likely caused the observed negative relationship between plant diversity and temporal stability of microbial properties during phase 1 of the experiment.

According to our expectations, during phase 2 none of the investigated microbial properties responded to any of the plant community properties, i.e. the soil microbial communities and their temporal stability responded neutral towards plant community properties. After the soil microbial community experienced destabilization during phase 1 , the soil system now entered a phase of transition, as the positive effects of plant diversity strengthen over time (Meyer et al., 2016; Reich et al., 2012), but presumably were not yet strong enough to exert positive effects on the temporal stability of soil microbial properties. However, unexpectedly, neutral effects of plant diversity on the temporal stability of soil microbial properties persisted in phase 3. We assumed that after 8-12 years, higher amounts and stability of plant inputs of mature plant communities would stabilize soil microbial properties during the late phase of the experiment. Contrary to these expectations, the results rather suggest that the transition phase, in which soil microbial communities are still in the process of successional shift, lasts longer than the duration of our experiment (12 years). Nevertheless, the negative relationship between plant diversity and the temporal stability of soil microbial biomass progressively disappeared during phases 2 and 3 , while the means of both soil microbial biomass and respiration constantly increased with plant diversity after the establishment of the experimental field site. These results suggest that these trends are likely to continue in the future. Moreover, they point to the long time period soil microbial communities of former arable monoculture land-use need to adapt to alterations in plant community composition and associated more internal element cycling. This is in line with earlier studies (Buckley and Schmidt, 2001) which reported soil microbial communities in abandoned arable fields to resemble those in active arable field more than those of uncultivated fields even seven years after abandonment. 
In study 1 (Chapter 2, Stability Experiment), we expected a positive relationship between plant diversity and the spatial stability of soil microbial properties due to mechanisms such as higher stability of plant productivity, higher root biomass (Ravenek et al., 2014), and hence more spatially uniform organic inputs into the soil (Milcu et al., 2010). Instead, we found a neutral relationship between these two variables, which points to other mechanisms that might have outweighed the spatially stabilizing effects of plant diversity on microbial properties. A potential mechanism could be that we sampled rhizosphere soil and bulk soil, and that in these microhabitats, different soil microbial communities dominated, with energetically inefficient $r$-strategists (with low $C$ use efficiency) dominating the rhizosphere rich in labile $\mathrm{C}$ substrates, and more nutrient efficient $\mathrm{K}$ strategists dominating the bulk soil. These different soil microbial communities might have led to high respiration rates and microbial biomass in rhizosphere-patches and lower respiration rates and microbial biomass in bulk soil-patches at high plant diversity (Kuzyakov and Blagodatskaya, 2015). Further studies are needed to unravel the mechanisms that govern the spatial stability of soil microbial community properties. Also, the scales at which spatial stability really matters for microbial functioning as well as for the provisioning of ecosystem services should be considered (Weigelt et al., 2008).

We expected different plant functional groups to affect spatial and temporal stability of soil microbial properties according to their specific plant functional traits. In line with our hypothesis, legumes decreased the spatial stability of both soil microbial respiration and biomass, and decreased the temporal stability of microbial biomass at least during phase 1 . There is evidence that legumes increase the patchy distribution of $\mathrm{N}$ supply across grassland sites through deposition of organic nitrogen in their rhizosphere (Spehn et al., 2002), thereby provoking hotspots of microbial biomass and activity (Kuzyakov and Blagodatskaya, 2015). As a consequence of unevenly distributed microbial hotspots, their spatial and temporal stability were also expected to be reduced. Supporting this expectation, Chen et al. (2008) found higher soil microbial biomass when legumes were present in a greenhouse experiment and concluded this to be due to higher root exudation by legumes compared to grasses. The reason for the unexpected fading of the destabilizing legume effect on the temporal stability of soil microbial biomass after phase 1 is probably due to their inferior light acquisition and water uptake compared to grasses in mature grasslands (Haynes, 1980), resulting in reduced abundance and performance on the Jena Experiment field site (Roscher et al., 2013, 2011a). Additionally, the fading of the destabilizing legume effect on the temporal stability of soil microbial biomass fits to our finding, that legumes only during phase 1 increased soil microbial biomass (see above, Eisenhauer et al. 2010).

Similar to legumes but via another mechanism, tall herbs decreased the spatial stability of soil microbial respiration, probably due to deep rooting systems and taproots that allocate carbon to 
deeper soil layers (Roscher et al., 2011b; Sydes and Grime, 1984), thereby increasing the patchiness of $\mathrm{C}$ provisioning to soil microorganisms. Also, tall herbs reduce the small-scale spatial stability of aboveground biomass production (Weigelt et al., 2008), which could additionally have contributed to heterogeneous spatial distribution of resource allocations into the soil. In contrast to our expectation, small herbs did not increase the spatial and temporal stability of soil microbial properties. Instead, they decreased the temporal stability of soil microbial biomass. Presumably, temporal asynchrony between small herb species (Roscher et al., 2011b) accompanied by spatiotemporal changes in the rhizosphere destabilized soil microbial biomass over time. This is supported by a study reporting the soil decomposer community to vary at the scale of individual plants and with plant species identity (Bezemer et al., 2010). Contrary to legumes, grasses increased the spatial stability of soil microbial biomass, but the temporal stability of microbial respiration only during phase 1 . We assign the stabilizing effects of grasses to their dense, evenly distributed root systems that are persistent over long periods of time (de Witte and Stöcklin, 2010). However, we did not expect the stabilizing grass effect to disappear after phase 1, as grasses are strong competitors for nutrients with rather stable high coverage in the Jena Experiment (Kiær et al., 2013; Roscher et al., 2011b).

To discover the hidden mechanisms that cause either stabilization or destabilization of soil microbial properties, future studies should include the investigation of processes such as rhizodeposition including root exudation and shifts in microbial community structure (de Vries et al., 2012) , as these processes have been shown to interact with each other in affecting soil microbial properties ( $\mathrm{N}$. Eisenhauer et al., 2017; Haichar et al., 2014). and to change over time (de Vries et al., 2007). Overall, the results document that the mechanisms that cause either stabilizing or destabilizing effects of plant communities on soil microbial properties are complex. They dependent on a number of plant community properties, such as plant diversity, traits of plant functional groups (de Vries et al., 2012) and on how these plant community properties interact with environmental factors such as nutrient availability, that in turn change over time. One important environmental factor that has become prominent since the industrial revolution of agriculture and exerts strong effects on soil microbial functioning is the anthropogenic use of mineral N fertilizer (Schröder, 2014; Treseder, 2008). Mineral fertilizer use is not restricted to agricultural crop monocultures, but also applied to meadows serving as silage for animal live stock, world-wide as well as across Europe. To examine the effects of fertilization on soil microbial properties and whether fertilization interacts with plant community properties on soil microorganisms, we conducted the Fertilizer Experiment (Chapter 3). 


\subsection{Changes in soil microbial properties with fertilization}

Unexpectedly, the results of our Fertilizer Experiment (Chapter 3, study 2) revealed that fertilization did not affect soil microbial biomass. Earlier studies found contrasting effects of fertilization on microbial biomass (Chu et al., 2007; Donnison et al., 2000; Ramirez et al., 2012), indicating that fertilizer-induced increase in plant productivity does not necessarily cascade to soil microorganisms. A number of factors might have contributed to the lack of fertilization effect on soil microbial biomass. First, our two-year study may have been too short to reveal the full effects of fertilizer addition. In contrast to microbial biomass, soil microbial respiration is more flexible to react to environmental changes (Anderson and Domsch, 1985) and may decrease after $\mathrm{N}$ fertilization through fertilizer-mediated changes in rhizodeposition (Chung et al., 2007) or root exudation (Dijkstra et al., 2005). Second, fertilization was shown to reduce plant resource allocation into belowground structures, leading to reduced C resources for soil microorganisms (Bardgett et al., 1999; Phillips and Fahey, 2007; Wang et al., 2012). Third, the removal of plant aboveground biomass after mowing prevented aboveground litter from entering the soil, thereby interrupting the cascade of positive fertilizer effects from above- to below the ground.

Interestingly, the Fertilizer Experiment revealed that plant diversity and fertilization acted independently of each other on soil microorganisms. Accordingly, fertilization did not strengthen the effects of plant diversity on soil microbial respiration or biomass. We conclude that the effect of fertilization on plant productivity may have been either too weak (Weigelt et al., 2009) to cascade to the soil microorganisms, or plant diversity and fertilization act through decoupled mechanisms. As other studies found both, independent (Craven et al., 2016) as well as interactive effects of these two environmental factors (Hautier et al., 2014; Reich et al., 2004, 2001), future studies should consider longer time frames than the duration of the present Fertilizer Experiment (two years), as the soil system has been shown to react with a time-lag of several years to environmental changes such as management practice or plant diversity (Eisenhauer et al., 2010; Treseder, 2008). Also, future studies should include the investigation of shifts in soil microbial community structure in response to mineral $\mathrm{N}$ fertilizer as these are not reflected in microbial properties such as microbial respiration and biomass.

An example for interacting effects between plants and environmental factors that drive soil microbial functioning is the superimposition of the negative legume effect on specific respiration by fertilizer addition as shown in study 2 . Notably, both legumes and fertilizer decreased microbial respiration, although the underlying mechanisms are likely to be different (see above). In contrast to legumes, fertilization is known to decrease rhizosphere priming effects (Kuzyakov, 2002) by delivering inorganic $\mathrm{N}$ (Harrison et al., 2008). The effect of inorganic $\mathrm{N}$ on soil microorganisms is controversially debated and further studies are needed to distinguish between the decrease in microbial specific 
respiration due to mitigation of $\mathrm{N}$ limitation (=positive effect on $\mathrm{C}$ use efficiency; Wardle and Ghani, 1995) or due to toxicity (Ramirez et al., 2010; Treseder, 2008; Waldrop and Zak, 2004). We assume that fertilization alleviates $\mathrm{N}$ limitation of microorganisms, thus increasing their $\mathrm{C}$ use efficiency. This is supported by the result that in plots without fertilization, microbial C-to- $\mathrm{N}$ ratio was positively correlated with specific respiration, while this was not the case in fertilized plots, indicating that $\mathrm{N}$ shortage lessened under fertilization.

Although mineral $\mathrm{N}$ fertilizer neither affected soil microbial biomass nor interacted with plant diversity on soil microbial properties within the investigated time frame of two years, the interactive effect between fertilization and legumes on the soil microbial C-to-N-ratio indicates that mineral $\mathrm{N}$ was incorporated into the soil microbial biomass. To answer the questions to which extend soil microorganisms incorporate mineral $\mathrm{N}$ into their biomass, whether the microbial uptake of mineral $\mathrm{N}$ is influenced by plant community properties, and whether the mineral-derived $\mathrm{N}$ is channelled from soil microorganisms to higher trophic levels of the soil food web, we conducted the ${ }^{15} \mathrm{~N}$ Tracer Experiment (Chapter 4).

\subsection{Incorporation of mineral-derived $\mathbf{N}$ into the soil food web}

In study 3 (Chapter 4, Tracer Experiment), we used ${ }^{15} \mathrm{~N}$ to track the incorporation of mineral $\mathrm{N}$ into the soil food web. With this method we could differentiate between animals relying on microbial $\mathrm{N}$ and those relying on $\mathrm{N}$ from dead organic matter. All of the investigated mesofauna species at least in part incorporated microbial mineral-derived $\mathrm{N}$, indicating the importance of microorganisms for the channeling of mineral $\mathrm{N}$ to higher trophic levels.

Our results show that plant species richness considerably decreased the incorporation of mineralderived $\mathrm{N}$ into soil microbial biomass, demonstrating that high plant species richness aggravated the competition for N. Interestingly, as proven in studies 1 and 2 (Chapter 2 and 3, Stability- and Fertilizer Experiment), the positive effects of plant diversity on soil microbial communities via increased $C$ translocation into the soil (Lange et al., 2015) must have surpassed the effect of $\mathrm{N}$ competition, as microbial respiration and biomass increased with increasing plant diversity.

In contrast to the uniform effect on the ${ }^{15} \mathrm{~N}$-uptake into microorganisms, plant species richness displayed different effects on the incorporation of mineral-derived $\mathrm{N}$ into mesofauna species, reflecting their different nutritional strategies with species-specific dependency on microbial $\mathrm{N}$. These nutritional strategies ranged from detritivory (for the species Tectocepheus velatus sarekensis), over microbivory and omnivory (for springtail species) to predation (for the gamasid mite Lasioseius berlesei). Notably, the ${ }^{15} \mathrm{~N}$ uptake of the predator L. berlesei did not respond to plant diversity, but peaked already at the first sampling five days after labeling, and decreased with time similar to that in microorganisms, indicating an unexpectedly fast channeling of mineral-derived $\mathrm{N}$ from basal resources of the soil food web to higher trophic levels. This fast channeling of mineral-derived $\mathrm{N}$ 
presumably occurred due to combined predation on highly labelled springtails and nematodes that graze on microorganisms (Christian and Karg, 2006; Heidemann et al., 2014). Notably, for some springtail species (Parisotoma notabilis and Stenaphorura denisi), the effect of plant species richness on the incorporation of mineral-derived $\mathrm{N}$ changed over time from increasing to decreasing ${ }^{15} \mathrm{~N}$ incorporation, suggesting that these species fed on microorganisms associated with plant roots that were heavily enriched in ${ }^{15} \mathrm{~N}$ at high plant diversity shortly after labeling. This is underlined by the results of Jesch et al. (2018) proving that plant communities with high plant species richness took up more ${ }^{15} \mathrm{~N}$ than those of low plant species richness in the present study. Functional group richness decreased the incorporation of mineral-derived $\mathrm{N}$ in the majority of the investigated mesofauna species (T. velatus sarekensis, S. denisi, Isotoma viridis and Lepidocyrtus cyaneus), again reflecting high competitiveness for mineral $\mathrm{N}$ of plants in highly diverse plant communities against microorganisms.

Legumes decreased the incorporation of mineral $\mathrm{N}$ into microorganisms, probably due to rhizodeposition of organic $\mathrm{N}$ into the soil, thereby diluting the applied mineral ${ }^{15} \mathrm{~N}$ (Fustec et al., 2010). This matches with results of study 2 , where we found legumes to reduce the microbial C-to-N ratio. Unexpectedly, however, this effect was not strong enough to propagate into the investigated mesofauna species. Although grasses enhanced the soil microbial C-to-N-ratio as demonstrated in our Fertilizer Experiment (study 2), we could not show a decrease in the microbial incorporation of mineral $\mathrm{N}$ in study 3. Instead, grasses increased the incorporation of mineral-derived $\mathrm{N}$ in secondary decomposers (the springtail Ceratophysella sp.) and decreased it in primary decomposers (the oribatid mite Tectocepheus velatus sarekensis). These results reinforce the conclusion that secondary decomposers such as Ceratophysella sp. broaden their dietary spectrum from microorganisms to plant roots, and prove that primary decomposers such as T. velatus sarekensis mainly feed on herbs, probably because grasses are of lower food quality compared to herbs with higher $\mathrm{N}$ content (Abbas et al., 2013; Bessler et al., 2012).

\subsection{Conclusions and Outlook}

At first glance, it seems intuitive that plant diversity plays an important role for the functioning of intact ecosystems. Even though this is certainly true, it is a challenge to reveal the underlying ecological mechanisms, how plant diversity acts on ecosystem functioning. Especially, organisms and processes that are located below the ground are difficult to investigate. Besides, plant diversity does not affect all ecosystem functions in the same way; for some ecosystem functions plant diversity is essential, for others it is of minor importance (Allan et al., 2013). Therefore, it is indispensable to investigate the relationships between plant diversity and different ecosystem functions such as soil microbial community properties or element cycling in detail, and to also consider interrelationships 
between environmental factors that could change the effect of plant communities on the respective ecosystem function.

In the present thesis, I showed that plant diversity (plant species richness, plant functional group richness) and plant functional group composition (legumes, grasses, small herbs, tall herbs) function as important drivers of soil microbial properties (microbial respiration, biomass, C use efficiency, Cto-N-ratio) and their stability. Also, plant diversity and functional composition strongly influenced the microbial uptake and channeling of mineral-derived $\mathrm{N}$ into higher trophic levels of the soil food web. Further, functional plant traits crystallized to be important mechanisms driving the relationships between plant community composition and ecosystem functions. The results of this thesis also highlight that the transition phase in which soil microbial communities adapt from former arable monoculture land-use to semi-natural plant communities with high plant diversity and extensive management lasts more than a decade. Nevertheless, we could show that (temporal) stability of soil microbial properties increased over time, as the number of plant community properties that reduced the stability decreased constantly until the end of the experiment. Concerning the uptake of mineral-derived $\mathrm{N}$ into the soil food web, our results underline the fast and intensive incorporation of mineral $\mathbf{N}$ into soil microorganisms and its unexpectedly fast channeling to higher trophic levels. Our investigations further revealed that mineral $\mathrm{N}$ fertilization acts independently of plant diversity, but that the positive legume effect on soil microbial $C$ use efficiency was superimposed by mineral $\mathrm{N}$ fertilizer. As the application of mineral $\mathrm{N}$ has been reported to also imply negative effects on biodiversity and ecosystem functioning sustainable management practices for the long-term should be used. Therefore, the cultivation of high-diversity meadows including specific plant functional groups such as legumes seems to be superior to the application of mineral $\mathrm{N}$ fertilizer in matching both, the conservation of intact ecosystems as well as the provisioning of ecosystem services for humans, such as the production of green fodder for animal stocks.

To proceed in understanding the mechanisms that underlie effects of plant diversity, community composition and mineral $\mathrm{N}$ on soil organisms and their functioning, future long-term studies need to investigate plant functional traits such as rhizodeposition, root exudation and other plant traits known to impact the soil system. Further, investigating successional shifts in microbial- and soil fauna community structure as well as shifts in nutrient availability and abiotic soil conditions $\mathrm{pH}$, soil moisture) under fertilizer-application rates relevant for the management practice in European meadows could be promising.

Taken together, the present thesis reinforces and complements the findings of earlier BEF studies, and emphasizes the importance of maintaining grasslands with high plant diversity including all investigated plant functional groups (legumes, grasses, small and tall herbs) with their trait-specific 
effects for essential ecosystem functions and services such as decomposition, element cycling and production of food and fodder.

\subsection{References}

Abbas, M., Ebeling, A., Oelmann, Y., Ptacnik, R., Roscher, C., Weigelt, A., Weisser, W.W., Wilcke, W., Hillebrand, H., 2013. Biodiversity Effects on Plant Stoichiometry. PLoS ONE 8. doi:10.1371/journal.pone.0058179

Allan, E., Weisser, W.W., Fischer, M., Schulze, E.-D., Weigelt, A., Roscher, C., Baade, J., Barnard, R.L., Beßler, H., Buchmann, N., Ebeling, A., Eisenhauer, N., Engels, C., Fergus, A.J.F., Gleixner, G., Gubsch, M., Halle, S., Klein, A.M., Kertscher, I., Kuu, A., Lange, M., Le Roux, X., Meyer, S.T., Migunova, V.D., Milcu, A., Niklaus, P. a, Oelmann, Y., Pašalić, E., Petermann, J.S., Poly, F., Rottstock, T., Sabais, A.C.W., Scherber, C., Scherer-Lorenzen, M., Scheu, S., Steinbeiss, S., Schwichtenberg, G., Temperton, V., Tscharntke, T., Voigt, W., Wilcke, W., Wirth, C., Schmid, B., 2013. A comparison of the strength of biodiversity effects across multiple functions. Oecologia 173, 223-37. doi:10.1007/s00442-012-2589-0

Anderson, T.-H., Domsch, K.H., 1985. Determination of ecophysiological maintenance carbon requirements of soil microorganisms in a dormant state. Biology and Fertility of Soils 1, 81-89. doi:10.1007/BF00255134

Bardgett, R.D., Mawdsley, J.L., Edwards, S., Hobbs, P.J., Rodwell, J.S., Davies, W.J., 1999. Plant species and nitrogen effects on soil biological properties of temperate upland grasslands. Functional Ecology 13, 650-660. doi:10.1046/j.1365-2435.1999.00362.x

Bardgett, R.D., Mommer, L., De Vries, F.T., 2014. Going underground: Root traits as drivers of ecosystem processes. Trends in Ecology and Evolution 29, 692-699. doi:10.1016/j.tree.2014.10.006

Baudoin, E., Benizri, E., Guckert, A., 2003. Impact of artificial root exudates on the bacterial community structure in bulk soil and maize rhizosphere. Soil Biology and Biochemistry 35, 11831192. doi:10.1016/S0038-0717(03)00179-2

Bessler, H., Oelmann, Y., Roscher, C., Buchmann, N., Scherer-Lorenzen, M., Schulze, E.D., Temperton, V.M., Wilcke, W., Engels, C., 2012. Nitrogen uptake by grassland communities: Contribution of N2 fixation, facilitation, complementarity, and species dominance. Plant and Soil 358, 301-322. doi:10.1007/s11104-012-1181-z

Bezemer, T.M., Fountain, M.T., Barea, J.M., Christensen, S., Dekker, S.C., Duyts, H., Van Hal, R., Harvey, J. a., Hedlund, K., Maraun, M., Mikola, J., Mladenov, a. G., Robin, C., De Ruiter, P.C., Scheu, S., Setälä, H., Šmilauer, P., Van Der Putten, W.H., 2010. Divergent composition but similar function of soil food webs of individual plants: Plant species and community effects. Ecology 91, 3027-3036. doi:10.1890/09-2198.1

Buckley, D.H., Schmidt, T.M., 2001. The Structure of Microbial Communities in Soil and the Impact of Lasting Cultivation. Microbial Ecology 42, 11-21.

Chaudhary, M.I., Adu-Gyamfi, J.J., Saneoka, H., Nguyen, N.T., Suwa, R., Kanai, S., El-Shemy, H. a., Lightfoot, D. a., Fujita, K., 2008. The effect of phosphorus deficiency on nutrient uptake, nitrogen fixation and photosynthetic rate in mashbean, mungbean and soybean. Acta Physiologiae Plantarum 30, 537-544. doi:10.1007/s11738-008-0152-8

Chen, M., Chen, B., Marschner, P., 2008. Plant growth and soil microbial community structure of legumes and grasses grown in monoculture or mixture. Journal of Environmental Sciences 20, 1231-1237. doi:10.1016/S1001-0742(08)62401-8

Christian, A., Karg, W., 2006. The predatory mite genus Lasioseius Berlese , 1916 (Acari, Gamasina), Abhandlungen und Berichte des Naturkundemuseums Görlitz 77, 99-250.

Chu, H., Lin, X., Fujii, T., Morimoto, S., Yagi, K., Hu, J., Zhang, J., 2007. Soil microbial biomass, dehydrogenase activity, bacterial community structure in response to long-term fertilizer management. Soil Biology and Biochemistry 39, 2971-2976. doi:10.1016/j.soilbio.2007.05.031 
Chung, H., Zak, D.R., Reich, P.B., Ellsworth, D.S., 2007. Plant species richness, elevated CO2 , and atmospheric nitrogen deposition alter soil microbial community composition and function. Global Change Biology 13, 980-989. doi:10.1111/j.1365-2486.2007.01313.x

Craven, D., Isbell, F., Manning, P., Connolly, J., Bruelheide, H., Ebeling, A., Roscher, C., van Ruijven, J., Weigelt, A., Wilsey, B., Beierkuhnlein, C., de Luca, E., Griffin, J.N., Hautier, Y., Hector, A., Jentsch, A., Kreyling, J., Lanta, V., Loreau, M., Meyer, S.T., Mori, A.S., Naeem, S., Palmborg, C., Wayne Polley, H., Reich, P.B., Schmid, B., Siebenkäs, A., Seabloom, E., Thakur, M.P., Tilman, D., Vogel, A., Eisenhauer, N., 2016. Plant diversity effects on grassland productivity are robust to both nutrient enrichment and drought. Philosophical Transactions of the Royal Society B: Biological Sciences 371. doi:10.1098/rstb.2015.0277

de Vries, F.T., Bloem, J., van Eekeren, N., Brusaard, L., Hoffland, E., 2007. Fungal biomass in pastures increases with age and reduced $\mathrm{N}$ input. Soil Biology and Biochemistry 39, 1620-1630. doi:10.1016/j.soilbio.2007.01.013

de Vries, F.T., Hoffland, E., van Eekeren, N., Brussaard, L., Bloem, J., 2006. Fungal/bacterial ratios in grasslands with contrasting nitrogen management. Soil Biology and Biochemistry 38, 20922103. doi:10.1016/j.soilbio.2006.01.008

de Vries, F.T., Manning, P., Tallowin, J.R.B., Mortimer, S.R., Pilgrim, E.S., Harrison, K. a, Hobbs, P.J., Quirk, H., Shipley, B., Cornelissen, J.H.C., Kattge, J., Bardgett, R.D., Johnson, N., 2012. Abiotic drivers and plant traits explain landscape-scale patterns in soil microbial communities. Ecology Letters 15, 1230-9. doi:10.1111/j.1461-0248.2012.01844.x

de Witte, L.C., Stöcklin, J., 2010. Longevity of clonal plants: Why it matters and how to measure it. Annals of Botany 106, 859-870. doi:10.1093/aob/mcq191

Dennis, P.G., Miller, A.J., Hirsch, P.R., 2010. Are root exudates more important than other sources of rhizodeposits in structuring rhizosphere bacterial communities? FEMS Microbiology Ecology 72, 313-27. doi:10.1111/j.1574-6941.2010.00860.x

Dijkstra, F.A., Hobbie, S.E., Reich, P.B., Knops, J.M.H., 2005. Divergent effects of elevated CO2, N fertilization, and plant diversity on soil $\mathrm{C}$ and $\mathrm{N}$ dynamics in a grassland field experiment. Plant and Soil 272, 41-52. doi:10.1007/s11104-004-3848-6

Donnison, L.M., Gri, G.S., Hedger, J., Hobbs, P.J., Bardgett, D., 2000. Management influences on soil microbial communities and their function in botanically diverse haymeadows of northern England and Wales. Soil Biology and Biochemistry 32, 253-263.

Ebeling, A., Pompe, S., Baade, J., Eisenhauer, N., Hillebrand, H., Proulx, R., Roscher, C., Schmid, B., Wirth, C., Weisser, W.W., 2014. A trait-based experimental approach to understand the mechanisms underlying biodiversity-ecosystem functioning relationships. Basic and Applied Ecology 15, 229-240. doi:10.1016/j.baae.2014.02.003

Eisenhauer, N., Bessler, H., Engels, C., Gleixner, G., Habekost, M., Milcu, A., Partsch, S., Sabais, a C.W., Scherber, C., Steinbeiss, S., Weigelt, A., Weisser, W.W., Scheu, S., 2010. Plant diversity effects on soil microorganisms support the singular hypothesis. Ecology 91, 485-96.

Eisenhauer, N., Dobies, T., Cesarz, S., Hobbie, S.E., Meyer, R.J., Worm, K., Reich, P.B., 2013. Plant diversity effects on soil food webs are stronger than those of elevated $\mathrm{CO} 2$ and $\mathrm{N}$ deposition in a long-term grassland experiment. Proceedings of the National Academy of Sciences of the United States of America 110, 6889-94. doi:10.1073/pnas.1217382110

Eisenhauer, Nico, Lanoue, A., Strecker, T., Scheu, S., Steinauer, K., Thakur, M.P., Mommer, L., 2017. Root biomass and exudates link plant diversity with soil bacterial and fungal biomass. Scientific Reports 7, 1-8. doi:10.1038/srep44641

Eisenhauer, N., Lanoue, A., Strecker, T., Scheu, S., Steinauer, K., Thakur, M.P., Mommer, L., 2017. Root biomass and exudates link plant diversity with soil bacterial and fungal biomass. Scientific Reports 7. doi:10.1038/srep44641

Fustec, J., Lesuffleur, F., Mahieu, S., Cliquet, J.-B., 2010. Nitrogen rhizodeposition of legumes. A review. Agronomy for Sustainable Development 30, 57-66. doi:10.1051/agro/2009003

Haddad, N.M., Crutsinger, G.M., Gross, K., Haarstad, J., Tilman, D., 2011. Plant diversity and the stability of foodwebs. Ecology Letters 14, 42-46. doi:10.1111/j.1461-0248.2010.01548.x 
Haichar, F. el Z., Santaella, C., Heulin, T., Achouak, W., 2014. Root exudates mediated interactions belowground. Soil Biology and Biochemistry 77, 69-80. doi:10.1016/j.soilbio.2014.06.017

Harrison, K.A., Bol, R., Bardgett, R.D., 2008. Do plant species with different growth strategies vary in their ability to compete with soil microbes for chemical forms of nitrogen? Soil Biology and Biochemistry 40, 228-237. doi:10.1016/j.soilbio.2007.08.004

Hartman, W.H., Richardson, C.J., 2013. Differential nutrient limitation of soil microbial biomass and metabolic quotients (qCO2): is there a biological stoichiometry of soil microbes? PloS One 8 , e57127. doi:10.1371/journal.pone.0057127

Hautier, Y., Seabloom, E.W., Borer, E.T., Adler, P.B., Harpole, W.S., Hillebrand, H., Lind, E.M., MacDougall, A.S., Stevens, C.J., Bakker, J.D., Buckley, Y.M., Chu, C., Collins, S.L., Daleo, P., Damschen, E.I., Davies, K.F., Fay, P.A., Firn, J., Gruner, D.S., Jin, V.L., Klein, J.A., Knops, J.M.H., La Pierre, K.J., Li, W., McCulley, R.L., Melbourne, B.A., Moore, J.L., O'Halloran, L.R., Prober, S.M., Risch, A.C., Sankaran, M., Schuetz, M., Hector, A., 2014. Eutrophication weakens stabilizing effects of diversity in natural grasslands. Nature 508, 521-525. doi:10.1038/nature13014

Haynes, R.J., 1980. Competitive aspects of the grass-legume association, in: Advances in Agronomy. Academic Press, Inc., New York, New York, pp. 227-261.

Hector, A., Schmid, B., Beierkuhnlein, C., Caldeira, M.C., Diemer, M., Dimitrakopoulos, P.G., Finn, J.A., Freitas, H., Giller, P.S., Good, J., Harris, R., Högberg, P., Huss-Danell, K., Joshi, J., Jumpponen, A., Körner, C., Leadley, P.W., Loreau, M., Minns, A., Mulder, C.P.H., O`Donovan, G., Otway, S.J., Pereira, J.S., Prinz, A., Read, D.J., Scherer-Lorenzen, M., Schulze, E.-D., Siamantziouras, A.-S.D., Spehn, E.M., Terry, A.C., Troumbis, A.Y., Woodward, F.I., Yachi, S., Lawton, J.H., 1999. Plant Diversity and Productivity Experiments in European Grasslands. Science 286, 1123-1127. doi:10.1126/science.286.5442.1123

Heidemann, K., Hennies, A., Schakowske, J., Blumenberg, L., Ruess, L., Scheu, S., Maraun, M., 2014. Free-living nematodes as prey for higher trophic levels of forest soil food webs. Oikos 123, 1199-1211. doi:10.1111/j.1600-0706.2013.00872.x

Hooper, D.U., Chapin, F.S., Ewel, J.J., Hector, A., Inchausti, P., Lavorel, S., Lawton, J.H., Lodge, D.M., Loreau, M., Naeem, S., Schmid, B., Setälä, H., Symstad, A.J., Vandermeer, J., Wardle, D.A., 2005. Effects Of Biodiversity On Ecosystem Functioning: A Consensus Of Current Knowledge. Ecological Monographs 75, 3-35.

Jackson, R.B., Mooney, H.A., Schulze, E.-D., 1997. A global budget for fine root biomass, surface area and nutrient contents. Ecology 94, 7362-7366.

Jesch, A., Barry, K.E., Ravenek, J.M., Bachmann, D., Strecker, T., Weigelt, A., Buchmann, N., de Kroon, H., Gessler, A., Mommer, L., Roscher, C., Scherer-Lorenzen, M., 2018. Below-ground resource partitioning alone cannot explain the biodiversity-ecosystem function relationship: A field test using multiple tracers. Journal of Ecology. doi:10.1111/1365-2745.12947

Joffre, R., Ourcival, J.-M., Rambal, S., Rocheteau, A., 2003. The key-role of topsoil moisture on CO2 efflux from a Mediterranean Quercus ilex forest. Annals of Forest Science 60, 519-526. doi:10.1051/forest

Kaye, J., Hart, S., 1997. Competition for nitrogen between plants and soil microorganisms. Trends in Ecology \& Evolution 12, 139-142.

Kiær, L.P., Weisbach, A.N., Weiner, J., 2013. Root and shoot competition: A meta-analysis. Journal of Ecology 101, 1298-1312. doi:10.1111/1365-2745.12129

Kuzyakov, Y., 2002. Review: Factors affecting rhizosphere priming effects. Journal of Plant Nutrition and Soil Science 165, 382-396. doi:10.1002/1522-2624(200208)165:4<382::AIDJPLN382>3.0.CO;2-\#

Kuzyakov, Y., Blagodatskaya, E., 2015. Microbial hotspots and hot moments in soil: Concept \& review. Soil Biology and Biochemistry 83, 184-199. doi:10.1016/j.soilbio.2015.01.025

Lange, M., Eisenhauer, N., Sierra, C. a, Bessler, H., Engels, C., Griffiths, R.I., Malik, A. a, Roy, J., Scheu, S., Steinbeiss, S., Mellado-va, P.G., Thomson, B.C., Trumbore, S.E., Gleixner, G., 2015. Plant diversity increases soil microbial activity and soil carbon storage. Nature Communications 6. doi:10.1038/ncomms 7707 
Lange, M., Habekost, M., Eisenhauer, N., Roscher, C., Bessler, H., Engels, C., Oelmann, Y., Scheu, S., Wilcke, W., Schulze, E.-D., Gleixner, G., 2014. Biotic and abiotic properties mediating plant diversity effects on soil microbial communities in an experimental grassland. PloS One 9, e96182. doi:10.1371/journal.pone.0096182

Marquard, E., Weigelt, A., Roscher, C., Gubsch, M., Lipowsky, A., Schmid, B., 2009. Positive biodiversity-productivity relationship due to increased plant density. Journal of Ecology 97, 696704. doi:10.1111/j.1365-2745.2009.01521.x

Meyer, S.T., Ebeling, A., Eisenhauer, N., Hertzog, L., Hillebrand, H., Milcu, A., Pompe, S., Abbas, M., Bessler, H., Buchmann, N., De Luca, E., Engels, C., Fischer, M., Gleixner, G., Hudewenz, A., Klein, A.-M., De Kroon, H., Leimer, S., Loranger, H., Mommer, L., Oelmann, Y., Ravenek, J.M., Roscher, C., Rottstock, T., Scherber, C., Scherer-Lorenzen, M., Scheu, S., Schmid, B., Schulze, E.-D., Staudler, A., Strecker, T., Temperton, V., Tscharntke, T., Vogel, A., Voigt, W., Weigelt, A., Wilcke, W., Weisser, W.W., 2016. Effects of biodiversity strengthen over time as ecosystem functioning declines at low and increases at high biodiversity. Ecosphere 7. doi:10.1002/ecs2.1619

Milcu, A., Thebault, E., Scheu, S., Eisenhauer, N., 2010. Plant diversity enhances the reliability of belowground processes. Soil Biology and Biochemistry 42, 2102-2110. doi:10.1016/j.soilbio.2010.08.005

Mommer, L., Kirkegaard, J., van Ruijven, J., 2016. Root-Root Interactions: Towards A Rhizosphere Framework. Trends in Plant Science 21, 209-217. doi:10.1016/j.tplants.2016.01.009

Oelmann, Y., Kreutziger, Y., Temperton, V.M., Buchmann, N., Roscher, C., Schumacher, J., Schulze, E.D., Weisser, W.W., Wilcke, W., 2007. Nitrogen and phosphorus budgets in experimental grasslands of variable diversity. Journal of Environmental Quality 36, 396-407. doi:10.2134/jeq2006.0217

Phillips, R.P., Fahey, T.J., 2007. Fertilization effects on fineroot biomass, rhizosphere microbes and respiratory fluxes in hardwood forest soils. The New Phytologist 176, 655-64. doi:10.1111/j.1469-8137.2007.02204.x

Proulx, R., Wirth, C., Voigt, W., Weigelt, A., Roscher, C., Attinger, S., Baade, J., Barnard, R.L., Buchmann, N., Buscot, F., Eisenhauer, N., Fischer, M., Gleixner, G., Halle, S., Hildebrandt, A., Kowalski, E., Kuu, A., Lange, M., Milcu, A., Niklaus, P. a., Oelmann, Y., Rosenkranz, S., Sabais, A., Scherber, C., Scherer-Lorenzen, M., Scheu, S., Schulze, E.D., Schumacher, J., Schwichtenberg, G., Soussana, J.F., Temperton, V.M., Weisser, W.W., Wilcke, W., Schmid, B., 2010. Diversity promotes temporal stability across levels of ecosystem organization in experimental grasslands. PLOS ONE 5, 1-8. doi:10.1371/journal.pone.0013382

Ramirez, K.S., Craine, J.M., Fierer, N., 2012. Consistent effects of nitrogen amendments on soil microbial communities and processes across biomes. Global Change Biology 18, 1918-1927. doi:10.1111/j.1365-2486.2012.02639.x

Ramirez, K.S., Craine, J.M., Fierer, N., 2010. Nitrogen fertilization inhibits soil microbial respiration regardless of the form of nitrogen applied. Soil Biology and Biochemistry 42, 2336-2338. doi:10.1016/j.soilbio.2010.08.032

Ravenek, J.M., Bessler, H., Engels, C., Scherer-Lorenzen, M., Gessler, A., Gockele, A., De Luca, E., Temperton, V.M., Ebeling, A., Roscher, C., Schmid, B., Weisser, W.W., Wirth, C., de Kroon, H., Weigelt, A., Mommer, L., 2014. Long-term study of root biomass in a biodiversity experiment reveals shifts in diversity effects over time. Oikos 123, 1528-1436. doi:10.1111/oik.01502

Reich, P.B., Knops, J., Tilman, D., Craine, J., Ellsworth, D., Tjoelker, M., Lee, T., Wedin, D., Naeem, S., Bahauddin, D., Hendrey, G., Jose, S., Wrage, K., Goth, J., Bengston, W., 2001. Plant diversity enhances ecosystem responses to elevated $\mathrm{CO} 2$ and nitrogen deposition. Nature 410, 809-812. doi:10.1038/35081122

Reich, P.B., Tilman, D., Isbell, F., Mueller, K., Hobbie, S.E., Flynn, D.F.B., Eisenhauer, N., 2012. Impacts of biodiversity loss escalate through time as redundancy fades. Science (New York, N.Y.) 336, 589-92. doi:10.1126/science.1217909

Reich, P.B., Tilman, D., Naeem, S., Ellsworth, D.S., Knops, J., Craine, J., Wedin, D., Trost, J., 2004. Species and functional group diversity independently influence biomass accumulation and its 
response to $\mathrm{CO} 2$ and N. Proceedings of the National Academy of Sciences of the United States of America 101, 10101-10106. doi:10.1073/pnas.0306602101

Roscher, C., Schumacher, J., Lipowsky, A., Gubsch, M., Weigelt, A., Pompe, S., Kolle, O., Buchmann, N., Schmid, B., Schulze, E.D., 2013. A functional trait-based approach to understand community assembly and diversity-productivity relationships over 7 years in experimental grasslands. Perspectives in Plant Ecology, Evolution and Systematics 15, 139-149. doi:10.1016/j.ppees.2013.02.004

Roscher, C., Thein, S., Weigelt, A., Temperton, V.M., Buchmann, N., Schulze, E.D., 2011a. N2 fixation and performance of 12 legume species in a 6-year grassland biodiversity experiment. Plant and Soil 341, 333-348. doi:10.1007/s11104-010-0647-0

Roscher, C., Weigelt, A., Proulx, R., Marquard, E., Schumacher, J., Weisser, W.W., Schmid, B., 2011b. Identifying population- and community-level mechanisms of diversity-stability relationships in experimental grasslands. Journal of Ecology 99, 1460-1469. doi:10.1111/j.13652745.2011.01875.x

Schimel, D.S., Braswell, B.H., Parton, W.J., 1997. Equilibration of the terrestrial water, nitrogen, and carbon cycles. Proceedings of the National Academy of Sciences of the United States of America 94, 8280-3.

Schröder, J.J., 2014. The Position of Mineral Nitrogen Fertilizer in Efficient Use of Nitrogen and Land : A Review. Natural Resources 5, 936-948. doi:10.4236/nr.2014.515080

Spehn, E., Joshi, J., Schmid, B., Alphei, J., Körner, C., 2000. Plant diversity effects on soil heterotrophic activity in experimental grassland ecosystems. Plant and Soil 224, 217-230.

Spehn, E.M., Scherer-Lorenzen, M., Schmid, B., Hector, A., Caldeira, M.C., Dimitrakopoulos, P.G., Finn, J.A., Jumpponen, A., O'Donnovan, G., Pereira, J.S., Schulze, E.D., Troumbis, A.Y., Korner, C., 2002. The role of legumes as a component of biodiversity in a cross-European study of grassland biomass nitrogen. Oikos 98, 205-218. doi:10.1034/j.1600-0706.2002.980203.x

Steinauer, K., Fischer, F.M., Roscher, C., Scheu, S., Eisenhauer, N., 2017. Spatial plant resource acquisition traits explain plant community effects on soil microbial properties. Pedobiologia 65, 50-57. doi:10.1016/j.pedobi.2017.07.005

Sydes, C.L., Grime, J.P., 1984. A comparative study of root development using a simulated rock crevice. Journal of Ecology 72, 937-946.

Tilman, D., Downing, J., 1994. Biodiversity and stability in grasslands. Nature 367, 363-365.

Tilman, D., Reich, P.B., Knops, J.M.H., 2006. Biodiversity and ecosystem stability in a decade-long grassland experiment. Nature 441, 629-32. doi:10.1038/nature04742

Treseder, K.K., 2008. Nitrogen additions and microbial biomass: a meta-analysis of ecosystem studies. Ecology Letters 11, 1111-20. doi:10.1111/j.1461-0248.2008.01230.x

Waldrop, M., Zak, D., 2004. Nitrogen deposition modifies soil carbon storage through changes in microbial enzymatic activity. Ecological ... 14, 1172-1177.

Wang, C., Han, S., Zhou, Y., Yan, C., Cheng, X., Zheng, X., Li, M.-H., 2012. Responses of fine roots and soil $\mathrm{N}$ availability to short-term nitrogen fertilization in a broad-leaved Korean pine mixed forest in northeastern China. PloS One 7, e31042. doi:10.1371/journal.pone.0031042

Wardle, D., 1992. A comparative assessment of factors which influence microbial biomass carbon and nitrogen levels in soil. Biological Reviews.

Wardle, D.A., Ghani, A., 1995. A critique of the microbial metabolic quotient (qCO2) as a bioindicator of disturbance and ecosystem development. Soil Biology and Biochemistry 27, 1601-1610.

Weigelt, A., Schumacher, J., Roscher, C., Schmid, B., 2008. Does biodiversity increase spatial stability in plant community biomass? Ecology Letters 11, 338-47. doi:10.1111/j.14610248.2007.01145.x

Weigelt, A., Weisser, W.W., Buchmann, N., Scherer-Lorenzen, M., 2009. Biodiversity for multifunctional grasslands: equal productivity in high-diversity low-input and low-diversity highinput systems. Biogeosciences 6, 1695-1706. doi:10.5194/bg-6-1695-2009

Zak, D., Holmes, W., White, D., Peacock, A., Tilman, D., 2003. Plant diversity, soil microbial communities, and ecosystem function: are there any links? Ecology 84, 2042-2050. 


\section{Acknowledgement - Danksagung}

Meinem Doktorvater Stefan Scheu - dafür, dass seine Tür bei Fragen immer offenstand und er IMMER Lösungen fand.

Meinem Zweitbetreuer Nico Eisenhauer für die durchgehend hervorragende Betreuung, und dass es sich anfühlte, als würde er 2 Zimmer weiter sitzen, auch wenn mehrere hundert oder tausend Kilometer dazwischen waren.

Josephine Haase, Harald Auge - die beiden haben mich durch die gute Betreuung während meiner Diplomarbeit am UFZ geprägt und waren mir Vorbild für die Betreuung meiner Bachelor-Studentin.

Meiner Projekt-Kollegin Britta Jensen, für die vielen Gespräche, Diskussionen, die gemeinsame Zeit im Büro und im „romantischen“ Remderoda.

allen Gärtnern vom Jena-Experiment - es war immer angenehm locker und lustig mit Euch!

meinen vielen Hiwis: Tobias Lauermann, Paul Götzsch, Lennart Holst, Silvia Holzner, Sara Mosch (die eine treue Seele ist $:)$ ), Alice Böll, Babette Günther, Hatem Alkhoder, und Ahmad Sagheer (einer meiner besten Hiwis: ich danke dir, dass du immer loyal warst, auch wenn ich bei meiner ersten Alleinfahrt nach Jena eine Stunde lang auf der falschen Autobahn fuhr und du geduldig 2 Stunden auf mich gewartet hattest ohne deine gute Laune zu verlieren; dass du mir auch im Hochsommer nach einer Nachtschicht im Pflegeheim noch zuverlässig 40 Kempsonproben genommen hast, und immer für Späße zu haben warst).

Sarah Bluhm - für die Tipps in Sachen ${ }^{15} \mathrm{~N}$ und Mesofauna

Kathleen Lemanski, Odette Garcia Macé für die gute Zeit im gemeinsamen Büro

Dieter Nünchert - für die grossartige Unterstützung in Sachen „Dinge bauen“ und für seine angenehme, humorvolle Art, mit dem Leben umzugehen („Es muss immer Zeit für eine Tasse Tee sein.“) Und für den Anschub mit dem Fahrrad von der Weser hoch zurück nach Göttingen.

Susanne Böning-Klein, Andrea Gräbe-Treger, Ingrid Kleinhans, Christel Fischer, Dieter Nünchert, Guido Humpert für ihre grosse Hilfe in Sachen Labor- und Feldarbeit.

Susanne auch für die wunderschönen Khalil-Gibran-Gedichte.

Roeland Cortois und Gerlinde de Deyn für die gemeinsame gelungene Freilandarbeit.

Nicole Scheunemann, Garvin Schulz, Patrick Pachl, Diana Grubert, Kerstin Heidemann - der ganzen „Kaffeerunde“ für die vielen schönen Stunden mit und ohne Kaffeetasse.

Tobias Latzko, Torben Törbi Heckel, für die gute alte WG-Zeit und was davon noch übrig ist ();

Heiko Heilmittel Voigt, für die Milch im ostfriesischen Schwarztee.

Sondra Kleinsorge- für die vertrauten Gespräche und schönen Spaziergänge im Witzenhäusener Wald Yener Orkunoglu, für den Blick über den Tellerrand hinaus.

Astrid Mangholz, für die Unterstützung und herzlich-powervolle Art in schwierigen Zeiten.

Jelka Escher - für die enorm tolle Freundschaft die ganzen Göttinger Jahre und darüber hinaus!

Hannelore Franke, für die Freundschaft und den Spass, gemeinsam mit einer alten Dame Mitte 70 durch das Unterholz zu kriechen!

Falk Lauterbach, für die Lauterbach-Strecker-Konferenzen in der Mensa

Elisabeth Miosga und Gisela Ruhlender, dafür dass ihr so toll, lebenslustig, stark und mir so treu seid.

John Hazin, Anna Briemann, Anja Pflug, Laura Rössmann, Julia Heine, Annette Kohnen, Stefan Schäfer, Christina Grün-Wenzel - meinen langjährigen Freunden aus Darmstadt und Studiums-Zeiten.

Meinen Eltern Claudia Strecker und Helmut Vetter - dafür, dass ich als Kind ein so freies Leben zwischen Wald, Wiese, Bach und Lagerfeuer leben konnte (und das für viele heute so nicht mehr möglich ist). Ohne das Leben eines ,ourewäller Mädsches“ wäre ich wahrscheinlich nicht Ökologin geworden.

Meinem Bruder Daniel Strecker u.a. für die gemeinsamen Radtouren, durch den Darmstädter Stadtwald zu pesen.

Meinem Opa Fritz Johann Heinrich Strecker - für die besondere Heimat und Geborgenheit, die er mir gab. 
Meinem Schwiegervater Hans-Werner und seiner Lebensgefährtin Renate, dafür dass sie sich so liebevoll um Julia kümmern, und für das live-Puppentheater übers Internet während des Corona-logdowns.

Meinem Ehemann und Freund Benjamin Dann für die große Unterstützung auf verschiedensten Ebenen, dafür dass er immer am Ball bleibt, und ein so guter, liebenswerter, treuer, kritisch denkender, schlauer Mensch ist. Aaach, Bennnnn! (Und jetzt du wieder.)

Meiner bald vier-jährigen Tochter Julia, dafür dass sie da ist, mich immer wieder zum herzlichen Lachen bringt („Ich will noch einen Keks, diese Hand ist nämlich noch leer!“) und dafür, dass ich mit ihr auch Tiere-suchend im Reinhäuser Wald herumstreunen kann - das ist so ein Genuss!

Unserem kleinen „Ühmchen“, unserem vierten Familienmitglied, das wir noch nicht so gut kennen und uns aber schon sehr darauf freuen, wenn es endlich da ist, und Julia dich dann - endlich - küssen kann!

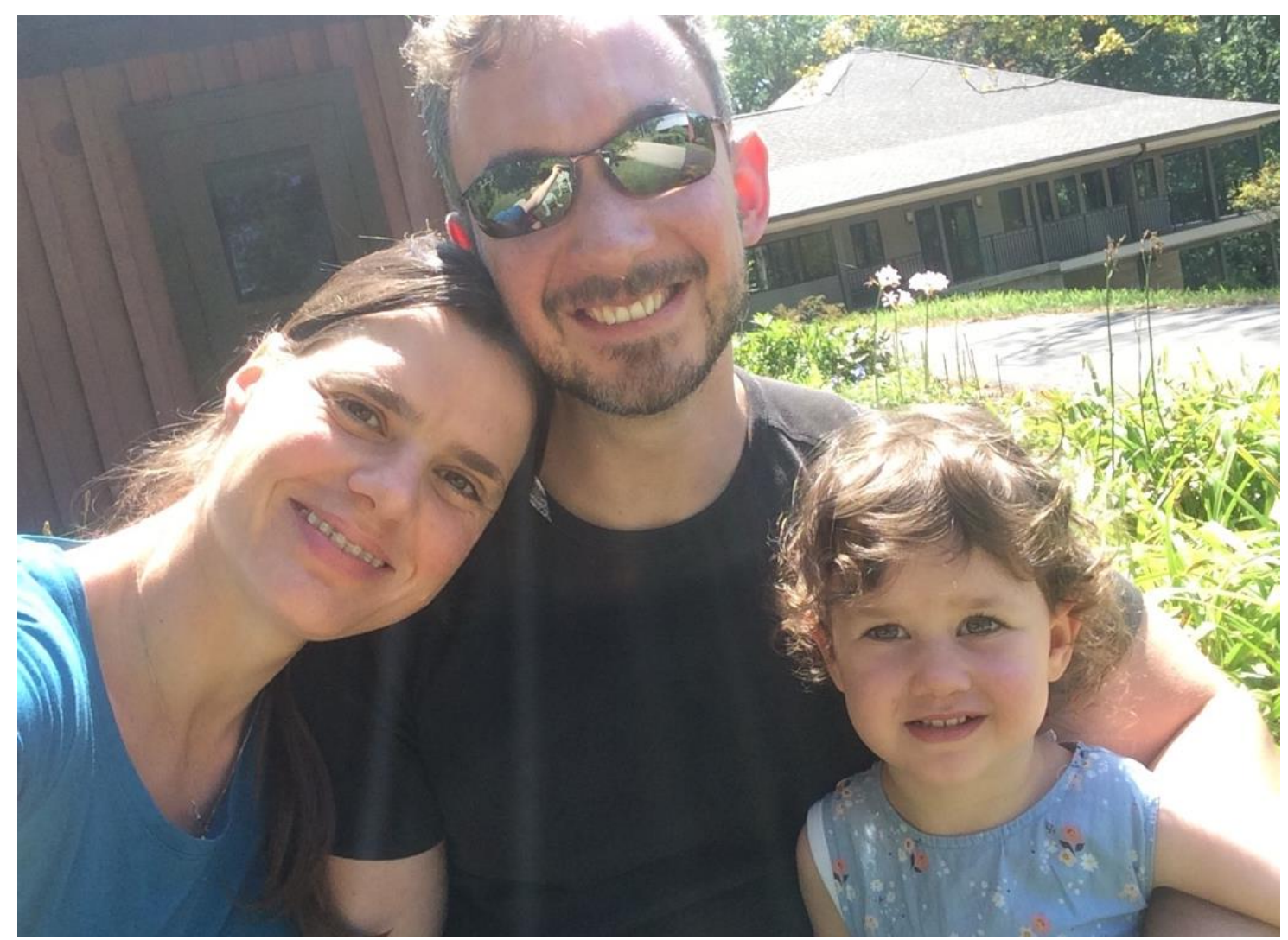

Zuletzt möchte ich noch der Jena-Wiese danken, weil sie im Sommer immer so schön geblüht hat, und dem Wind und Wetter, weil es dadurch nicht so tragisch war, wenn die Probenahme länger dauerte und ich länger als geplant in Jena blieb.

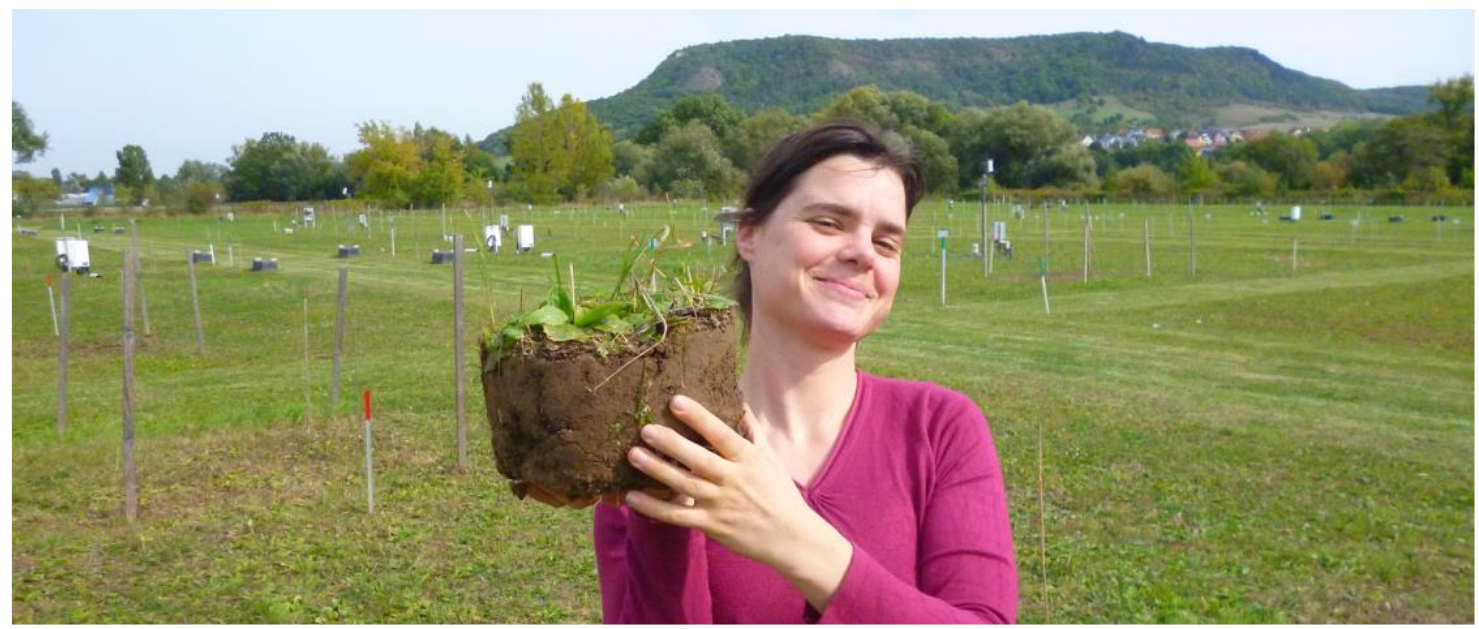




\section{List of publications}

1) (submitted to Ecology and Evolution) Strecker T, Annette Jesch A, Eisenhauer N, Bachmann D, Jüds $M$, Ravenek J, Roscher C, Weigelt A. Scheu S (2020) Incorporation of mineral nitrogen into the soil food web as affected by plant community composition.

2) Buzhdygan OY, Meyer ST, Weisser WW, Eisenhauer N, Anne Ebeling A, Stuart R. Borrett SR, Nina Buchmann N, Cortois R, De Deyn GB, de Kroon H, Gleixner G, Hertzog L, Hines J, Lange M, Mommer L, Ravenek J, Scherber C, Scherer-Lorenzen M, Scheu S, Schmid B, Steinauer K, Strecker T, Tietjen B, Anja Vogel A,Weigelt A, Petermann JS (2020) Biodiversity increases multitrophic energy use efficiency, flow, and storage in grasslands. Nature Ecology and Evolution 4: 393-405.

3) Roscher C, Karlowsky S, Milcu A, Gessler A, Bachmann D, Jesch A, Lange M, Mellado-Vázquez P, Strecker T, Landais D, Ravel O, BuchmannN, Roy J, Gleixner G (2019), Functional composition has stronger impact than species richness in carbon ain and allocation in experimental grasslands. PloS ONE 14(1): e0204715. DOI: 10.3171/journal.pone.0204715.

4) Jesch A, Barry KE, Ravenek J, Bachmann D, Strecker T, Weigelt A, Buchmann N, De Kroon H, Gessler A, Mommer L, Roscher C, Scherer-Lorenzen M (2018) Belowground resource partitioning alone cannot explain the biodiversity-ecosystem function relationship: A field test using multiple tracers. Journal of Ecology, 108, pp. 2002-2018, DOI: 10.1111/1365-2745.12947.

5) Cortois R, Veen G F, Duyts H, Abbas M, Strecker T, Kostenko O, Eisenhauer N, Scheu S, Gleixner G, De Deyn G B, van der Putten W H (2017) Possible mechanisms underlying abundance and diversity responses of nematode communities to plant diversity. Ecosphere 8(5): e01719.

6) Eisenhauer E, Lanoue A, Strecker T, Scheu S, Steinauer K, Thakur MP, Mommer L (2017) Root biomass and exudates link plant diversity with soil bacterial and fungal biomass, Scientific Reports, 7, article number 44641, DOI: 10.1038/srep44641.

7) Steinauer K, Jensen B, Strecker T, de Luca E, Scheu S, Eisenhauer N (2016) Convergence of Soil microbial properties after plant colonization of an experimental plant diversity gradient, BMC Ecology 16:19, DOI: 10.1186/s12898-016-0073-0.

8) Meyer ST, Ebeling A, Eisenhauer N, Hertzog L, Hillebrand H, Milcu A, Strecker T, et al (2016) Effects of biodiversity strengthen over time as ecosystem functioning declines at low and increases at high biodiversity. Ecosphere, 7 (12), p. e01619.

9) Strecker T, Gonzalez Mace O, Scheu S, Eisenhauer E (2016) Functional composition of plant communities determine the spatial and temporal stability of soil microbial properties in a long-term plant diversity experiment, Oikos 125: 1743-1754, DOI: 10.1111/oik.03181.

10) Thakur MP, Milcu A, Manning P, Niklaus PA, Roscher C, Power S, Reich PB, Scheu S, Tilman D, Ai F, Guo H, Ji R, Pierce S, Guerrero Ramirez N, Richter AN, Steinauer K, Strecker T, Vogel A, Eisenhauer N (2015) Plant diversity drives soil microbial biomass carbon in grasslands irrespective of global environmental change factors. Global Change Biology, 21, 4076-4085, DOI: 10.1111/gcb.13011.

11) Strecker T, Barnard RL, Niklaus PA, Scherer-Lorenzen M, Weigelt A, Scheu S, Eisenhauer N (2015) Effects of plant diversity, functional group composition, and fertilization on soil microbial properties in experimental grassland. Plos One 10(5): e0125678. doi:10.1371/journal.pone.0125678.

12) Wright AJ, Ebeling A, de Kroon $H$, Roscher $C$, Weigelt A, Buchmann N, Buchmann T, Fischer $C$, Hacker $N$, Hildebrandt A, Leimer S, Mommer L, Oelmann Y, Scheu S, Steinauer K, Strecker T, Weisser WW, Wilcke $W$, Eisenhauer $N$ (2015) Flooding disturbance increase resource availability and productivity, but reduce stability in diverse plant communities. Nature Communications 6: 6092, DOI: 10.1038/ ncomms7092.

13) Bachmann D, Gockele A, Ravenek JM, Roscher C, Strecker T, Weigelt A, Buchmann N (2015) No Evidence of Complementary Water Use along a Plant Species Richness Gradient in Temperate Experimental Grasslands. Plos One 10(1): 0116367. DOI:10.1371/journal.pone.0116367

14) Hertel D, Strecker T, Müller-Haubold H, Leuschner C (2013) Fine root biomass and dynamics in beech forests across a precipitation gradient - is optimal resource partitioning theory applicable to waterlimited mature trees? Journal of Ecology (101) 1183-1200. DOI: 10.1111/1365-2745.1212 
Short CV - kurzer Lebenslauf

- Inhalte aus Gründen des Datenschutzes entfernt. -

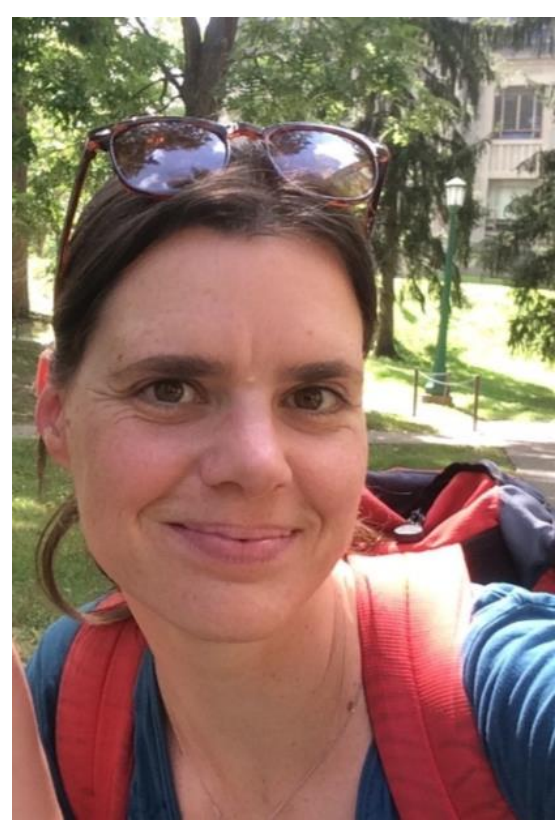

\section{Dipl.-Biol. Tanja Strecker}

Adresse:

Telefon:

E-Mail:

Geburtsdatum:

Geburtsort:

Familienstand:

\section{Ausbildung}

\section{Arbeitserfahrungen}

\section{Zusatzqualifikationen}

Fortbildungen zu folgenden Themen 


\section{Thesis declarations}

\section{Declaration of the author's own contribution to manuscripts with multiple authors}

Chapter 2 - Study 1: Stability Experiment (published in Oikos, 2016)

I am the first author of the paper, collected the data from 2010-2014, analysed the dataset (data from 2002-2014), wrote the manuscript, developed the main ideas, created tables, figures and appendices. Stefan Scheu and Nico Eisenhauer created the study design. Odette González Macé supported the data collection. All co-authors contributed to finalizing the manuscript.

Chapter 3 - Study 2: Fertilization experiment (published in PLosOne 2015)

I am the first author of the paper, analysed the dataset, wrote the manuscript, developed the main ideas, created tables, figures and appendices. Stefan Scheu, Romain L. Barnard, Pascal A. Niklaus, Michael Scherer-Lorenzen, Alexandra Weigelt and Nico Eisenhauer created the study design. Nico Eisenhauer, Romain L. Barnard, Pascal A. Niklaus, Michael Scherer-Lorenzen, Stefan Scheu and Alexandra Weigelt performed the experiment and collected the data. All co-authors contributed to finalizing the manuscript.

Chapter 4 -Study 3: Tracer Experiment (submitted to Ecology and Evolution, end of April 2020) I am the first author of the manuscript, performed the experiment and collected data, analysed the dataset, wrote the manuscript, developed main ideas, created figures, tables and appendices. Stefan Scheu and Nico Eisenhauer created the study design. Kevin Karbstein supported the data analysis. Annette Jesch, Dörte Bachmann, Melissa Jüds, Janneke Ravenek, Christiane Roscher and Alexandra Weigelt supported the establishment of the experiment and data collection. All co-authors contributed to finalizing the manuscript.

\section{Plagiarism declaration}

I declare that I have written this doctoral thesis independently. All persons contributing to the manuscripts have been named so. All sentences or passages quoted from other people's work have been specifically acknowledged by clear cross-referencing. I have not submitted this thesis in any form for another degree at any university or institution.

Tanja Strecker

Göttingen, im Mai 2020 